\title{
Psychological interventions for needle-related procedural pain and distress in children and adolescents (Review)
}

Birnie KA, Noel M, Chambers CT, Uman LS, Parker JA

Birnie KA, Noel M, Chambers CT, Uman LS, Parker JA.

Psychological interventions for needle-related procedural pain and distress in children and adolescents.

Cochrane Database of Systematic Reviews 2018, Issue 10. Art. No.: CD005179.

DOI: 10.1002/14651858.CD005179.pub4.

www.cochranelibrary.com 
TABLE OF CONTENTS

HEADER

ABSTRACT

PLAIN LANGUAGE SUMMARY .....

SUMMARY OF FINDINGS

BACKGROUND

OBJECTIVES

METHODS

RESULTS

Figure 1.

Figure 2.

Figure 3.

Figure 4.

Figure 5.

Figure 6.

Figure 7.

Figure 8.

Figure 9.

DISCUSSION

AUTHORS' CONCLUSIONS

ACKNOWLEDGEMENTS

REFERENCES

CHARACTERISTICS OF STUDIES

DATA AND ANALYSES

Analysis 1.1. Comparison 1: Distraction, Outcome 1: Self-reported pain

Analysis 1.2. Comparison 1: Distraction, Outcome 2: Self-reported distress

Analysis 1.3. Comparison 1: Distraction, Outcome 3: Observer-reported pain

Analysis 1.4. Comparison 1: Distraction, Outcome 4: Observer-reported distress

Analysis 1.5. Comparison 1: Distraction, Outcome 5: Behavioral measures- Pain

Analysis 1.6. Comparison 1: Distraction, Outcome 6: Behavioral measures- Distress

Analysis 1.7. Comparison 1: Distraction, Outcome 7: Physiological measure - heart rate

Analysis 1.8. Comparison 1: Distraction, Outcome 8: Physiological measure - oxygen saturation

Analysis 2.1. Comparison 2: CBT-combined, Outcome 1: Self-reported pain

Analysis 2.2. Comparison 2: CBT-combined, Outcome 2: Self-reported distress

Analysis 2.3. Comparison 2: CBT-combined, Outcome 3: Observer-reported pain

Analysis 2.4. Comparison 2: CBT-combined, Outcome 4: Observer-reported distress

Analysis 2.5. Comparison 2: CBT-combined, Outcome 5: Behavioral measures- Pain

Analysis 2.6. Comparison 2: CBT-combined, Outcome 6: Behavioral measures- Distress

Analysis 2.7. Comparison 2: CBT-combined, Outcome 7: Physiological measure - Cortisol

Analysis 3.1. Comparison 3: Hypnosis, Outcome 1: Self-reported pain

Analysis 3.2. Comparison 3: Hypnosis, Outcome 2: Self-reported distress

Analysis 3.3. Comparison 3: Hypnosis, Outcome 3: Behavioral measures- Pain ...

Analysis 3.4. Comparison 3: Hypnosis, Outcome 4: Behavioral measures- Distress

Analysis 4.1. Comparison 4: Preparation/Information, Outcome 1: Self-reported pain

Analysis 4.2. Comparison 4: Preparation/Information, Outcome 2: Observer-reported pain

Analysis 5.1. Comparison 5: Breathing, Outcome 1: Self-reported pain

Analysis 6.1. Comparison 6: Suggestion, Outcome 1: Self-reported pain 
[Intervention Review]

\section{Psychological interventions for needle-related procedural pain and distress in children and adolescents}

Kathryn A Birnie',2, Melanie Noel ${ }^{3}$, Christine T Chambers,5, Lindsay S Uman' ${ }^{4}$, Jennifer A Parker 5

1Lawrence S. Bloomberg Faculty of Nursing, University of Toronto, Toronto, Canada. ${ }^{2}$ Child Health Evaluative Sciences, The Hospital for Sick Children, Toronto, Canada. ${ }^{3}$ Department of Psychology, University of Calgary, Calgary, Alberta, Canada. ${ }^{4}$ Department of Pediatrics and Department of Psychology and Neuroscience, IWK Health Centre and Dalhousie University, Halifax, Canada. ${ }^{5}$ Centre for Pediatric Pain Research, IWK Health Centre, Halifax, Canada. ${ }^{6}$ Complex Pain Team, IWK Health Centre, Halifax, Canada

Contact address: Kathryn A Birnie, kbirnie@dal.ca, kathryn.birnie@sickkids.ca.

Editorial group: Cochrane Pain, Palliative and Supportive Care Group.

Publication status and date: Stable (no update expected for reasons given in 'What's new'), published in Issue 10, 2020.

Citation: Birnie KA, Noel M, Chambers CT, Uman LS, Parker JA. Psychological interventions for needle-related procedural pain and distress in children and adolescents. Cochrane Database of Systematic Reviews 2018, Issue 10. Art. No.: CD005179. DOI:

10.1002/14651858.CD005179.pub4.

Copyright () 2018 The Cochrane Collaboration. Published by John Wiley \& Sons, Ltd.

\section{A B S T R A C T}

\section{Background}

This is the second update of a Cochrane Review (Issue 4, 2006). Pain and distress from needle-related procedures are common during childhood and can be reduced through use of psychological interventions (cognitive or behavioral strategies, or both). Our first review update (Issue 10, 2013) showed efficacy of distraction and hypnosis for needle-related pain and distress in children and adolescents.

\section{Objectives}

To assess the efficacy of psychological interventions for needle-related procedural pain and distress in children and adolescents.

\section{Search methods}

We searched six electronic databases for relevant trials: Cochrane Central Register of Controlled Trials (CENTRAL); MEDLINE; PsycINFO; Embase; Web of Science (ISI Web of Knowledge); and Cumulative Index to Nursing and Allied Health Literature (CINAHL). We sent requests for additional studies to pediatric pain and child health electronic listservs. We also searched registries for relevant completed trials: clinicaltrials.gov; and World Health Organization International Clinical Trials Registry Platform (www.who.int.trialsearch). We conducted searches up to September 2017 to identify records published since the last review update in 2013.

\section{Selection criteria}

We included peer-reviewed published randomized controlled trials (RCTs) with at least five participants per study arm, comparing a psychological intervention with a control or comparison group. Trials involved children aged two to 19 years undergoing any needle-related medical procedure.

\section{Data collection and analysis}

Two review authors extracted data and assessed risks of bias using the Cochrane 'Risk of bias' tool. We examined pain and distress assessed by child self-report, observer global report, and behavioral measurement (primary outcomes). We also examined any reported physiological outcomes and adverse events (secondary outcomes). We used meta-analysis to assess the efficacy of identified psychological interventions relative to a comparator (i.e. no treatment, other active treatment, treatment as usual, or waitlist) for each outcome separately. We used Review Manager 5 software to compute standardized mean differences (SMDs) with 95\% confidence intervals (CIs), and GRADE to assess the quality of the evidence. 


\section{Main results}

We included 59 trials ( 20 new for this update) with 5550 participants. Needle procedures primarily included venipuncture, intravenous insertion, and vaccine injections. Studies included children aged two to 19 years, with few trials focused on adolescents. The most common psychological interventions were distraction $(n=32)$, combined cognitive behavioral therapy $(C B T ; n=18)$, and hypnosis $(n=8)$. Preparation/information $(n=4)$, breathing $(n=4)$, suggestion $(n=3)$, and memory alteration $(n=1)$ were also included. Control groups were often 'standard care', which varied across studies. Across all studies, 'Risk of bias' scores indicated several domains at high or unclear risk, most notably allocation concealment, blinding of participants and outcome assessment, and selective reporting. We downgraded the quality of evidence largely due to serious study limitations, inconsistency, and imprecision.

Very low- to low-quality evidence supported the efficacy of distraction for self-reported pain ( $n=30,2802$ participants; SMD -0.56, 95\% CI -0.78 to -0.33 ) and distress ( $n=4,426$ participants; SMD $-0.82,95 \% \mathrm{Cl}-1.45$ to -0.18$)$, observer-reported pain $(n=11,1512$ participants; SMD $-0.62,95 \% \mathrm{Cl}-1.00$ to -0.23 ) and distress ( $n=5,1067$ participants; SMD $-0.72,95 \% \mathrm{Cl}-1.41$ to -0.03 ), and behavioral distress ( $\mathrm{n}=7$, 500 participants; SMD $-0.44,95 \% \mathrm{Cl}-0.84$ to -0.04$)$. Distraction was not efficacious for behavioral pain $(n=4,309$ participants; $S M D-0.33$, $95 \% \mathrm{Cl}-0.69$ to 0.03$)$. Very low-quality evidence indicated hypnosis was efficacious for reducing self-reported pain ( $n=5,176$ participants; SMD $-1.40,95 \% \mathrm{Cl}-2.32$ to -0.48$)$ and distress $(n=5,176$ participants; SMD $-2.53,95 \% \mathrm{Cl}-3.93$ to -1.12$)$, and behavioral distress ( $n=6$, 193 participants; SMD $-1.15,95 \% \mathrm{Cl}-1.76$ to -0.53 ), but not behavioral pain ( $\mathrm{n}=2,69$ participants; SMD $-0.38,95 \% \mathrm{Cl}-1.57$ to 0.81 ). No studies assessed hypnosis for observer-reported pain and only one study assessed observer-reported distress. Very low- to low-quality evidence supported the efficacy of combined CBT for observer-reported pain ( $n=4,385$ participants; SMD $-0.52,95 \% \mathrm{Cl}-0.73$ to -0.30 ) and behavioral distress $(n=11,1105$ participants; SMD $-0.40,95 \% \mathrm{Cl}-0.67$ to -0.14$)$, but not self-reported pain $(n=14,1359$ participants; SMD $-0.27,95 \% \mathrm{Cl}-0.58$ to 0.03 ), self-reported distress ( $\mathrm{n}=6,234$ participants; $\mathrm{SMD}-0.26,95 \% \mathrm{Cl}-0.56$ to 0.04 ), observer-reported distress ( $\mathrm{n}=6$, 765 participants; SMD $0.08,95 \% \mathrm{Cl}-0.34$ to 0.50$)$, or behavioral pain $(n=2,95$ participants; SMD $-0.65,95 \% \mathrm{Cl}-2.36$ to 1.06$)$. Very low-quality evidence showed efficacy of breathing interventions for self-reported pain ( $n=4,298$ participants; SMD $-1.04,95 \% \mathrm{Cl}-1.86$ to -0.22 ), but there were too few studies for meta-analysis of other outcomes. Very low-quality evidence revealed no effect for preparation/information ( $n=4,313$ participants) or suggestion ( $n=3,218$ participants) for any pain or distress outcome. Given only a single trial, we could draw no conclusions about memory alteration. Adverse events of respiratory difficulties were only reported in one breathing intervention.

\section{Authors' conclusions}

We identified evidence supporting the efficacy of distraction, hypnosis, combined CBT, and breathing interventions for reducing children's needle-related pain or distress, or both. Support for the efficacy of combined CBT and breathing interventions is new from our last review update due to the availability of new evidence. The quality of trials and overall evidence remains low to very low, underscoring the need for improved methodological rigor and trial reporting. Despite low-quality evidence, the potential benefits of reduced pain or distress or both support the evidence in favor of using these interventions in clinical practice.

\section{PLAIN LANGUAGESUMMARY}

\section{Psychological strategies to reduce pain and distress for children and adolescents getting needles}

\section{Bottom line}

Psychological strategies help reduce children's pain, distress, and fear of needles. Distraction and hypnosis are helpful, although specific breathing (such as inflating a balloon), and combining multiple psychological strategies can also help.

\section{Background}

Psychological strategies affect how children think or what they do before, during, or after a needle. They can be used by children or with support from parents or medical staff, like nurses, psychologists, or child life specialists. The information applies to children aged from two to 19 years who are healthy or ill, undergoing all types of needle procedures at the hospital, in a clinic, or at school.

\section{Key results}

For this update, in September 2017, we searched for clinical trials looking at psychological strategies for reducing pain and distress of children and teens getting a needle. We found 59 trials including 5550 children and teens. Twenty of these trials were new for this update. We found six psychological strategies, four of which help reduce children's pain and distress during needles. These include distraction, hypnosis, specific breathing, and combining multiple strategies ('combined cognitive behavioral'). Ways to distract children and teens during needles include reading, watching a movie, listening to music, playing video games, or virtual reality. Hypnosis involves deep relaxation and imagery, and is usually taught to a child by a trained professional. Examples of strategies that can be combined include distraction, breathing, relaxation, positive thoughts, having the child learn or practice the steps of the needle procedure, and coaching parents about ways to support their child. Other psychological strategies have been tested but do not seem helpful on their own. For example, children do not have less pain or distress when they are only told what is going to happen before or during the needle ('providing information or preparation or both) or when someone merely suggests to the child that something is being done to help them. One other strategy is helping children to remember their previous needles more positively. There is not enough information yet to know if this is helpful. 


\section{Quality of evidence}

We rated the quality of the evidence from studies using four levels: very low, low, moderate, or high. The quality of the evidence from this review is very low to low, as results may be biased by including only small numbers of children or by children knowing what psychological intervention they received. This means that we are uncertain about the results. 


\section{SUMMARY OF FINDINGS}

\section{Summary of findings 1. Distraction compared to control for needle-related procedural pain and distress in children and adolescents}

\section{Distraction compared to control for needle-related procedural pain and distress in children and adolescents}

Patient or population: children aged 2-19 years with mixed medical (acute or chronic illness) or generally healthy undergoing venipuncture, immunization, intravenous insertion, lumbar puncture, bone marrow aspiration, routine injection, allergy testing injections, or laceration repair Setting: hospital (inpatient/outpatient/emergency department), community clinic, or school

Intervention: distraction

Comparison: control (varied across studies)

\begin{tabular}{|c|c|c|c|c|c|}
\hline \multirow[t]{2}{*}{ Outcomes } & \multicolumn{2}{|c|}{ Anticipated absolute effects ${ }^{\star}(95 \% \mathrm{Cl})$} & \multirow{2}{*}{$\begin{array}{l}\text { № of participants } \\
\text { (studies) }\end{array}$} & \multirow{2}{*}{$\begin{array}{l}\text { Certainty of the } \\
\text { evidence } \\
\text { (GRADE) }\end{array}$} & \multirow[t]{2}{*}{ Comments $^{\star \star}$} \\
\hline & Risk with control & Risk with distraction & & & \\
\hline Self-reported pain & $\begin{array}{l}\text { The mean level } \\
\text { of self-reported } \\
\text { pain in the control } \\
\text { group ranged from } \\
0.65 \text { to } 8.32 \text { (ad- } \\
\text { justed to a } 0 \text { to } 10 \\
\text { scale). }\end{array}$ & $\begin{array}{l}\text { The mean level of self-reported pain with dis- } \\
\text { traction was } \mathbf{0 . 5 6} \text { standard deviations lower } \\
\text { ( } 0.78 \text { to } 0.33 \text { lower). }\end{array}$ & $\begin{array}{l}2802 \\
\text { (30 RCTs) }\end{array}$ & $\begin{array}{l}\oplus \oplus \Theta \Theta \\
\text { LOW a,b }\end{array}$ & $\begin{array}{l}\text { This result equates to a mod- } \\
\text { erate difference in favor of } \\
\text { distraction }\end{array}$ \\
\hline $\begin{array}{l}\text { Self-reported dis- } \\
\text { tress }\end{array}$ & See comment & $\begin{array}{l}\text { The mean level of self-reported distress with } \\
\text { distraction was } \mathbf{0 . 8 2} \text { standard deviations low- } \\
\text { er } \\
\text { ( } 1.45 \text { to } 0.18 \text { lower) }\end{array}$ & $\begin{array}{l}426 \\
(4 \mathrm{RCTs})\end{array}$ & $\begin{array}{l}\oplus \ominus \odot \ominus \\
\text { VERY LOW a,b,c }\end{array}$ & $\begin{array}{l}\text { This result equates to a large } \\
\text { difference in favor of distrac- } \\
\text { tion }\end{array}$ \\
\hline $\begin{array}{l}\text { Observer-report- } \\
\text { ed pain }\end{array}$ & See comment & $\begin{array}{l}\text { The mean level of observer-reported pain with } \\
\text { distraction was } \mathbf{0 . 6 2} \text { standard deviations low- } \\
\text { er } \\
\text { ( } 1 \text { to } 0.23 \text { lower) }\end{array}$ & $\begin{array}{l}1512 \\
\text { (11 RCTs) }\end{array}$ & $\begin{array}{l}\oplus \odot \Theta \odot \\
\text { VERY LOW a,d }\end{array}$ & $\begin{array}{l}\text { This result equates to a mod- } \\
\text { erate to large difference in fa- } \\
\text { vor of distraction }\end{array}$ \\
\hline $\begin{array}{l}\text { Observer-report- } \\
\text { ed distress }\end{array}$ & See comment & $\begin{array}{l}\text { The mean level of observer-reported distress } \\
\text { with distraction was } \mathbf{0 . 7 2} \text { standard deviations } \\
\text { lower } \\
\text { (1.41 to } 0.03 \text { lower) }\end{array}$ & $\begin{array}{l}1067 \\
\text { (5 RCTs) }\end{array}$ & $\begin{array}{l}\oplus \odot \odot \ominus \\
\text { VERY LOW a,d }\end{array}$ & $\begin{array}{l}\text { This result equates to a mod- } \\
\text { erate to large difference in fa- } \\
\text { vor of distraction }\end{array}$ \\
\hline $\begin{array}{l}\text { Behavioral mea- } \\
\text { sures- pain }\end{array}$ & See comment & $\begin{array}{l}\text { The mean level of behavioral pain with distrac- } \\
\text { tion was } 0.33 \text { standard deviations lower } \\
\text { ( } 0.69 \text { lower to } 0.03 \text { higher) }\end{array}$ & $\begin{array}{l}309 \\
(4 \mathrm{RCTs})\end{array}$ & $\begin{array}{l}\oplus \oplus \ominus \ominus \\
\text { LOW a,c }\end{array}$ & $\begin{array}{l}\text { There is no evidence of an ef- } \\
\text { fect of distraction }\end{array}$ \\
\hline
\end{tabular}




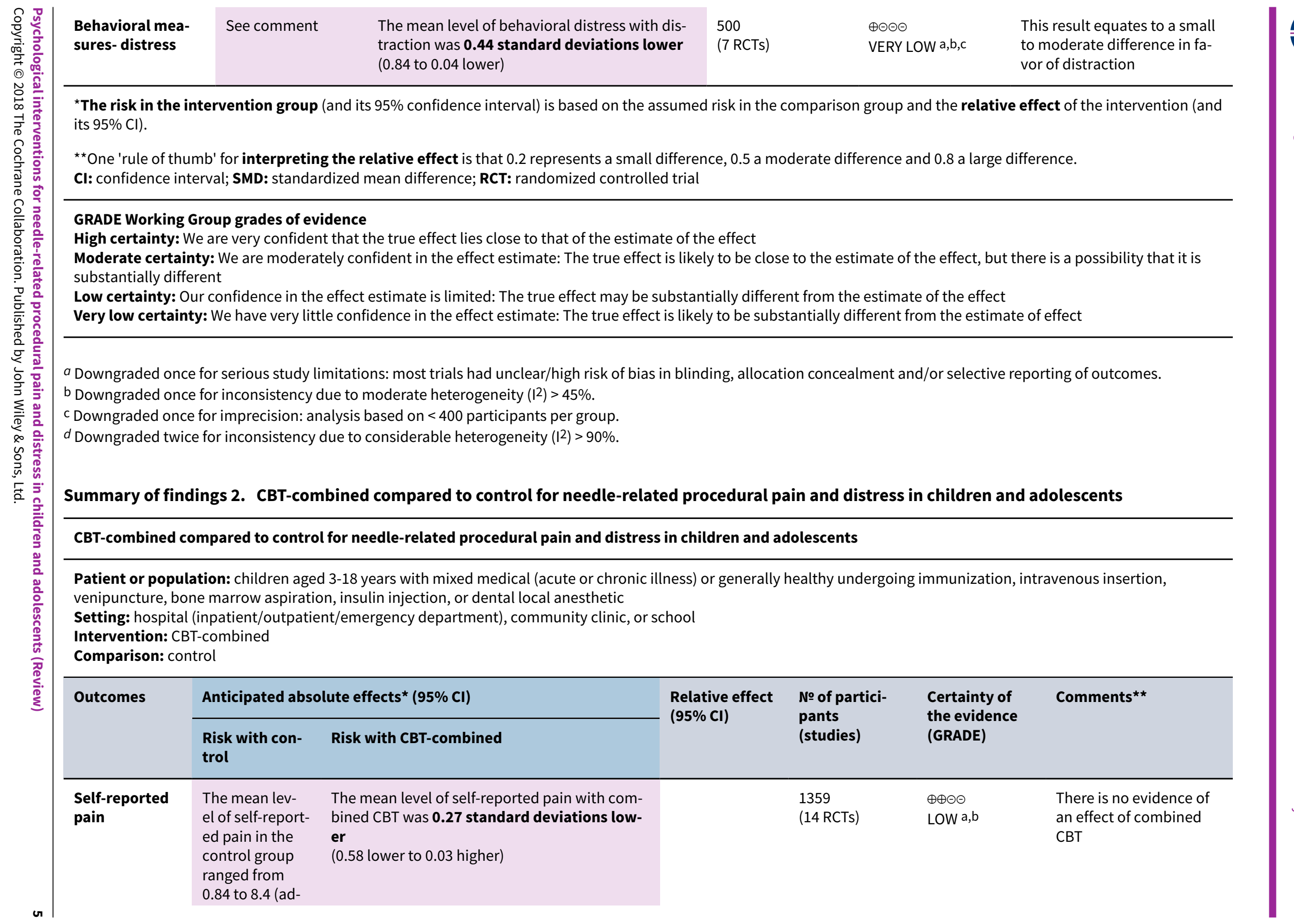




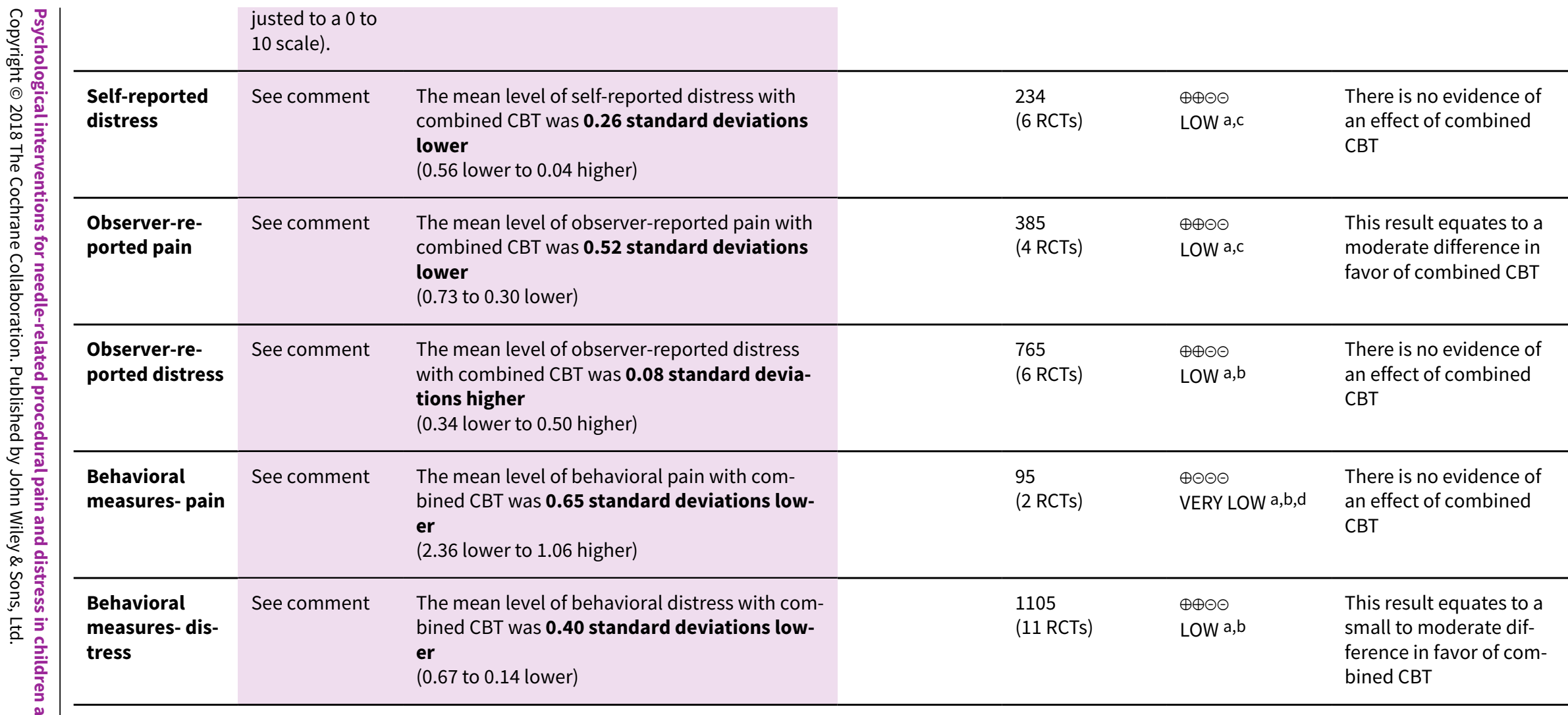

${ }^{*}$ The risk in the intervention group (and its 95\% confidence interval) is based on the assumed risk in the comparison group and the relative effect of the intervention (and its $95 \% \mathrm{Cl})$.

**One 'rule of thumb' for interpreting the relative effect is that 0.2 represents a small difference, 0.5 a moderate difference and 0.8 a large difference. Cl: Confidence interval; SMD: standardized mean difference; RCT: randomized controlled trial

\section{GRADE Working Group grades of evidence}

High certainty: We are very confident that the true effect lies close to that of the estimate of the effect

Moderate certainty: We are moderately confident in the effect estimate: The true effect is likely to be close to the estimate of the effect, but there is a possibility that it is substantially different

Low certainty: Our confidence in the effect estimate is limited: The true effect may be substantially different from the estimate of the effect

Very low certainty: We have very little confidence in the effect estimate: The true effect is likely to be substantially different from the estimate of effect

a Downgraded once for serious study limitations: most trials had unclear/high risk of bias in blinding, allocation concealment and/or selective reporting of outcomes.

b Downgraded once for inconsistency due to moderate heterogeneity $\left(I^{2}\right)>45 \%$.

c Downgraded once for imprecision: analysis based on $<400$ participants per group.

dDowngraded twice for imprecision: analysis based on $<100$ participants per group. 


\section{Summary of findings 3. Hypnosis compared to control for needle-related procedural pain and distress in children and adolescents}

\section{Hypnosis compared to control for needle-related procedural pain and distress in children and adolescents}

Patient or population: children aged 3-16 years with chronic illness (cancer) or generally healthy undergoing bone marrow aspirations, lumbar punctures, venipuncture, or local dental anesthetic

Setting: hospital (inpatient/outpatient), community clinic

Intervention: hypnosis

Comparison: control

\begin{tabular}{|c|c|c|c|c|c|}
\hline \multirow[t]{2}{*}{ Outcomes } & \multicolumn{2}{|c|}{ Anticipated absolute effects ${ }^{\star}(95 \% \mathrm{Cl})$} & \multirow{2}{*}{$\begin{array}{l}\text { № of participants } \\
\text { (studies) }\end{array}$} & \multirow{2}{*}{$\begin{array}{l}\text { Certainty of the } \\
\text { evidence } \\
\text { (GRADE) }\end{array}$} & \multirow[t]{2}{*}{ Comments ${ }^{\star \star}$} \\
\hline & Risk with control & Risk with hypnosis & & & \\
\hline Self-reported pain & $\begin{array}{l}\text { The mean level of } \\
\text { self-reported pain } \\
\text { in the control group } \\
\text { ranged from } 4.17 \text { to } \\
8.6 \text { (adjusted to a } 0 \\
\text { to } 10 \text { scale) }\end{array}$ & $\begin{array}{l}\text { The mean level of self-reported pain with } \\
\text { hypnosis was } 1.40 \text { standard deviations } \\
\text { lower } \\
\text { ( } 2.32 \text { to } 0.48 \text { lower) }\end{array}$ & $\begin{array}{l}176 \\
(5 \mathrm{RCTs})\end{array}$ & $\begin{array}{l}\oplus \ominus \ominus \ominus \\
\text { VERY LOW a,b,c,d }\end{array}$ & $\begin{array}{l}\text { This result equates to a large } \\
\text { difference in favor of hypnosis }\end{array}$ \\
\hline $\begin{array}{l}\text { Self-reported dis- } \\
\text { tress }\end{array}$ & See comment & $\begin{array}{l}\text { The mean level of self-reported distress } \\
\text { with hypnosis was } \mathbf{2 . 5 3} \text { standard devia- } \\
\text { tions lower } \\
\text { (3.93 to } 1.12 \text { lower) }\end{array}$ & $\begin{array}{l}176 \\
(5 \mathrm{RCTs})\end{array}$ & $\begin{array}{l}\oplus \ominus \ominus \ominus \\
\text { VERY LOW a,c,d,e }\end{array}$ & $\begin{array}{l}\text { This result equates to a large } \\
\text { difference in favor of hypnosis }\end{array}$ \\
\hline $\begin{array}{l}\text { Observer-report- } \\
\text { ed pain }\end{array}$ & See comment & See comment & See comment &.- & $\begin{array}{l}\text { This outcome was not assessed } \\
\text { in any study }\end{array}$ \\
\hline $\begin{array}{l}\text { Behavioral mea- } \\
\text { sures- pain }\end{array}$ & See comment & $\begin{array}{l}\text { The mean level of behavioral pain with hyp- } \\
\text { nosis was } \mathbf{0 . 3 8} \text { standard deviations lower } \\
\text { (1.57 lower to } 0.81 \text { higher) }\end{array}$ & $\begin{array}{l}69 \\
(2 \mathrm{RCTS})\end{array}$ & $\begin{array}{l}\oplus \ominus \ominus \ominus \\
\text { VERY LOW a,b,c }\end{array}$ & $\begin{array}{l}\text { There is no evidence of an ef- } \\
\text { fect of hypnosis }\end{array}$ \\
\hline $\begin{array}{l}\text { Behavioral mea- } \\
\text { sures- distress }\end{array}$ & See comment & $\begin{array}{l}\text { The mean level of behavioral distress with } \\
\text { hypnosis was } \mathbf{1 . 1 5} \text { standard deviations } \\
\text { lower } \\
\text { (1.76 to } 0.53 \text { lower) }\end{array}$ & $\begin{array}{l}193 \\
\text { (6 RCTs) }\end{array}$ & $\begin{array}{l}\oplus \ominus \ominus \ominus \\
\text { VERY LOW a,b,c,d }\end{array}$ & $\begin{array}{l}\text { This result equates to a large } \\
\text { difference in favor of hypnosis }\end{array}$ \\
\hline
\end{tabular}

${ }^{\star}$ The risk in the intervention group (and its 95\% confidence interval) is based on the assumed risk in the comparison group and the relative effect of the intervention (and its $95 \% \mathrm{Cl})$. 


\begin{tabular}{|c|c|c|c|c|c|}
\hline \multicolumn{6}{|c|}{$\begin{array}{l}\text { GRADE Working Group grades of evidence } \\
\text { High certainty: We are very confident that the true effect lies close to that of the estimate of the effect } \\
\text { Moderate certainty: We are moderately confident in the effect estimate: The true effect is likely to be close to the estimate of the effect, but there is a possibility that it is } \\
\text { substantially different } \\
\text { Low certainty: Our confidence in the effect estimate is limited: The true effect may be substantially different from the estimate of the effect } \\
\text { Very low certainty: We have very little confidence in the effect estimate: The true effect is likely to be substantially different from the estimate of effect }\end{array}$} \\
\hline \multicolumn{6}{|c|}{$\begin{array}{l}\text { a Downgraded once for serious study limitations: most trials had unclear/high risk of bias in blinding, allocation concealment and/or selective reporting of outcomes. } \\
\text { b Downgraded once for inconsistency due to moderate heterogeneity }\left(I^{2}\right)>45 \% \text {. } \\
\text { c Downgraded twice for imprecision: analysis based on }<100 \text { participants per group. } \\
\text { d Downgraded once for possibility of publication bias given that almost all trials are from one expert group. } \\
\text { e Downgraded twice for inconsistency due to considerable heterogeneity }\left(I^{2}\right)>90 \% . \\
\text { Summary of findings 4. Preparation/information compared to control for needle-related procedural pain and distress in children and adolescents }\end{array}$} \\
\hline \multicolumn{6}{|c|}{ Preparation/information compared to control for needle-related procedural pain and distress in children and adolescents } \\
\hline \multicolumn{6}{|c|}{$\begin{array}{l}\text { Patient or population: children aged 3-12 years with mixed medical (acute or chronic illness) or unclear diagnoses undergoing venipuncture or intravenous insertion } \\
\text { Setting: hospital (outpatient/emergency department) or community clinic } \\
\text { Intervention: preparation/information } \\
\text { Comparison: control }\end{array}$} \\
\hline \multirow[t]{2}{*}{ Outcomes } & \multicolumn{2}{|c|}{ Anticipated absolute effects* $(95 \% \mathrm{Cl})$} & \multirow{2}{*}{$\begin{array}{l}\text { № of participants } \\
\text { (studies) }\end{array}$} & \multirow{2}{*}{$\begin{array}{l}\text { Certainty of the } \\
\text { evidence } \\
\text { (GRADE) }\end{array}$} & \multirow[t]{2}{*}{ Comments ${ }^{\star \star}$} \\
\hline & Risk with control & Risk with preparation/information & & & \\
\hline Self-reported pain & $\begin{array}{l}\text { The mean level of self- } \\
\text { reported pain in the } \\
\text { control group ranged } \\
\text { from } 2.6 \text { to } 6.12 \text { (ad- } \\
\text { justed to a } 0 \text { to } 10 \\
\text { scale) }\end{array}$ & $\begin{array}{l}\text { The mean level of self-reported pain } \\
\text { with preparation/information was } \mathbf{0 . 1 8} \\
\text { standard deviations lower } \\
\text { (0.60 lower to } 0.23 \text { higher) }\end{array}$ & $\begin{array}{l}313 \\
(4 \mathrm{RCTs})\end{array}$ & $\begin{array}{l}\oplus \ominus \ominus \ominus \\
\text { VERY LOW a,b,c }\end{array}$ & $\begin{array}{l}\text { There is no evidence of an effect } \\
\text { of preparation/information }\end{array}$ \\
\hline $\begin{array}{l}\text { Self-reported dis- } \\
\text { tress }\end{array}$ & See comment & See comment & See comment & - & $\begin{array}{l}\text { This outcome was not assessed } \\
\text { in any study }\end{array}$ \\
\hline $\begin{array}{l}\text { Observer-report- } \\
\text { ed pain }\end{array}$ & See comment & $\begin{array}{l}\text { The mean level of observer-reported } \\
\text { pain with preparation/information was } \\
\mathbf{0 . 4 0} \text { standard deviations lower } \\
\text { (0.98 lower to } 0.18 \text { higher) }\end{array}$ & $\begin{array}{l}259 \\
(3 \mathrm{RCTs})\end{array}$ & $\begin{array}{l}\oplus \ominus \ominus \ominus \\
\text { VERY LOW a,b,c }\end{array}$ & $\begin{array}{l}\text { There is no evidence of an effect } \\
\text { of preparation/information }\end{array}$ \\
\hline
\end{tabular}




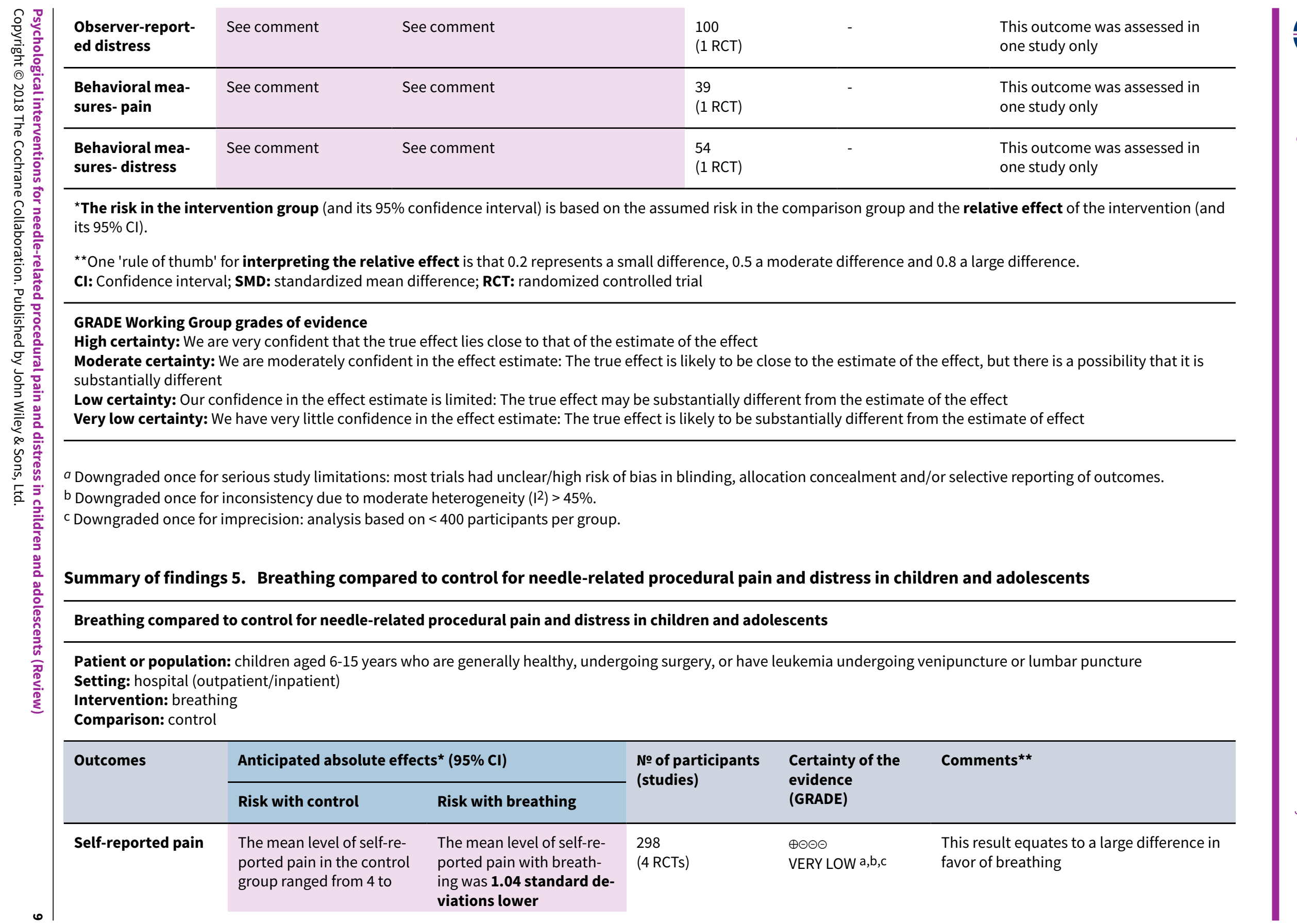




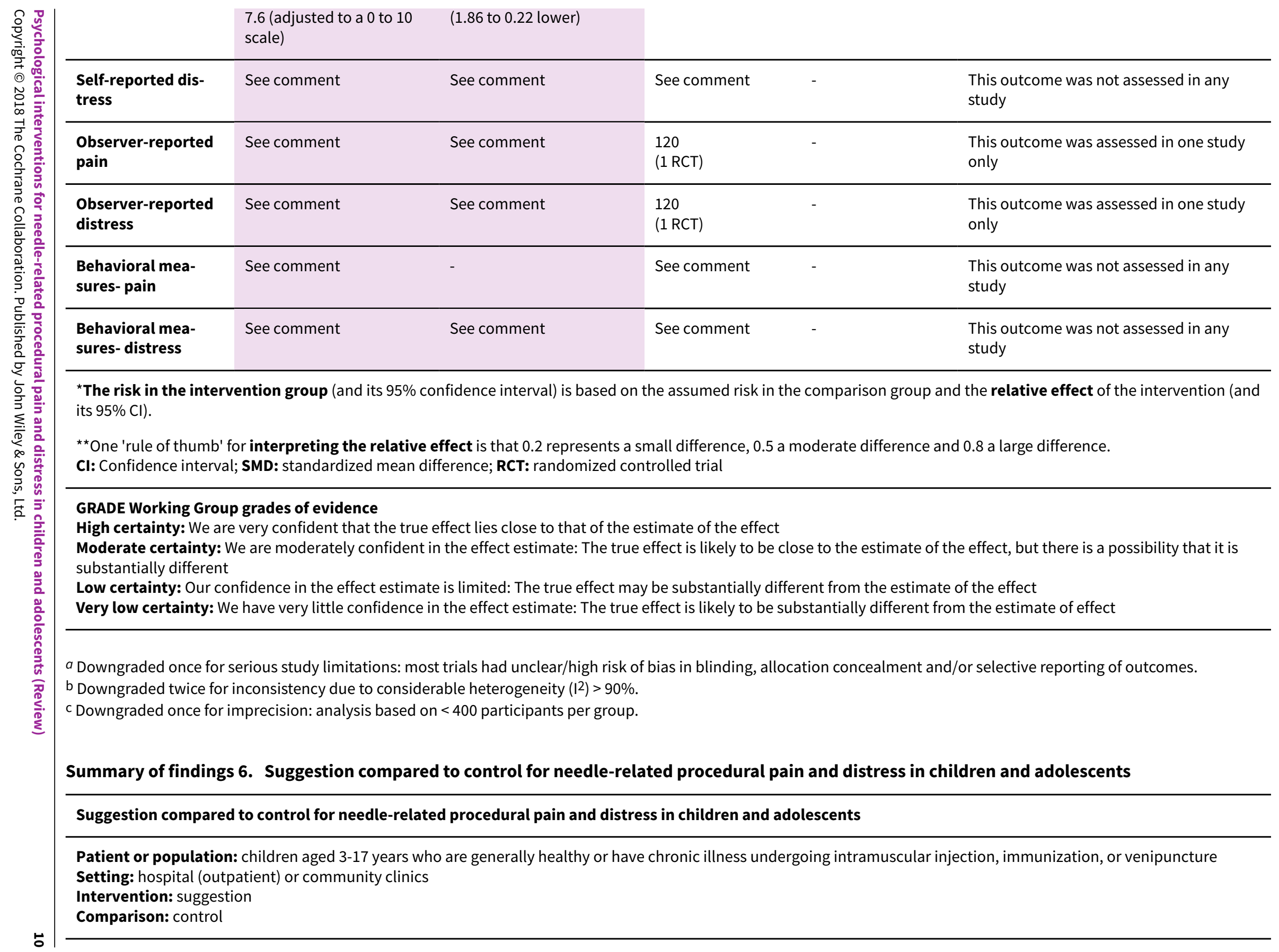




\begin{tabular}{|c|c|c|c|c|c|c|c|}
\hline \multirow{3}{*}{\multicolumn{2}{|c|}{ 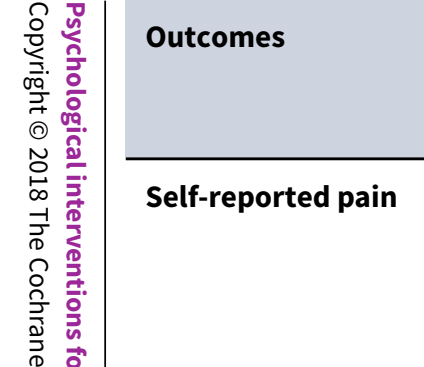 }} & \multicolumn{2}{|c|}{ Anticipated absolute effects ${ }^{\star}(95 \% \mathrm{Cl})$} & \multirow{3}{*}{$\begin{array}{l}\text { № of participants } \\
\text { (studies) } \\
218 \\
\text { (3 RCTs) }\end{array}$} & \multirow{2}{*}{$\begin{array}{l}\text { Certainty of the } \\
\text { evidence } \\
\text { (GRADE) }\end{array}$} & \multirow[t]{2}{*}{ Comments ${ }^{\star \star}$} & \\
\hline & & Risk with control & Risk with suggestion & & & & \\
\hline & & $\begin{array}{l}\text { The mean level of self-re- } \\
\text { ported pain in the control } \\
\text { group ranged from } 1.83 \text { to } \\
9.33 \text { (adjusted to a } 0 \text { to } 10 \\
\text { scale). }\end{array}$ & $\begin{array}{l}\text { The mean level of self-re- } \\
\text { ported pain with suggestion } \\
\text { was } \mathbf{0 . 1 3} \text { standard devia- } \\
\text { tions lower } \\
\text { ( } 0.40 \text { lower to } 0.15 \text { higher) }\end{array}$ & & $\begin{array}{l}\oplus \ominus \ominus \ominus \\
\text { VERY LOW a,b }\end{array}$ & $\begin{array}{l}\text { There is no evidence of an effect of } \\
\text { suggestion }\end{array}$ & ํํㄹำ \\
\hline 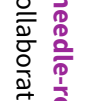 & $\begin{array}{l}\text { Self-reported dis- } \\
\text { tress }\end{array}$ & See comment & See comment & $\begin{array}{l}78 \\
(1 \mathrm{RCT})\end{array}$ & - & $\begin{array}{l}\text { This outcome was assessed in one } \\
\text { study only }\end{array}$ & 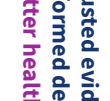 \\
\hline 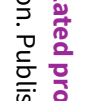 & $\begin{array}{l}\text { Observer-reported } \\
\text { pain }\end{array}$ & See comment & See comment & $\begin{array}{l}78 \\
(1 \mathrm{RCT})\end{array}$ & - & $\begin{array}{l}\text { This outcome was assessed in one } \\
\text { study only }\end{array}$ & \\
\hline 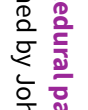 & $\begin{array}{l}\text { Observer-reported } \\
\text { distress }\end{array}$ & See comment & See comment & $\begin{array}{l}20 \\
(1 \mathrm{RCT})\end{array}$ & - & $\begin{array}{l}\text { This outcome was assessed in one } \\
\text { study only }\end{array}$ & \\
\hline 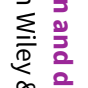 & $\begin{array}{l}\text { Behavioral mea- } \\
\text { sures- pain }\end{array}$ & See comment & See comment & See comment & - & $\begin{array}{l}\text { This outcome was not assessed in any } \\
\text { study }\end{array}$ & \\
\hline 垔 & $\begin{array}{l}\text { Behavioral mea- } \\
\text { sures- distress }\end{array}$ & See comment & See comment & See comment & - & $\begin{array}{l}\text { This outcome was not assessed in any } \\
\text { study }\end{array}$ & \\
\hline $\begin{array}{l}\overline{\overline{2}} \\
\frac{2}{10} \\
\frac{3}{2} \\
\frac{2}{2} \\
\frac{2}{0} \\
\frac{0}{0}\end{array}$ & \multicolumn{6}{|c|}{$\begin{array}{l}{ }^{*} \text { The risk in the intervention group (and its } 95 \% \text { confidence interval) is based on the assumed risk in the comparison group and the relative effect of the intervention (and } \\
\text { its } 95 \% \mathrm{Cl} \text { ). }\end{array}$} & \\
\hline 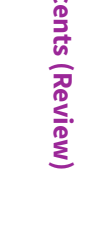 & \multicolumn{6}{|c|}{$\begin{array}{l}\text { GRADE Working Group grades of evidence } \\
\text { High certainty: We are very confident that the true effect lies close to that of the estimate of the effect } \\
\text { Moderate certainty: We are moderately confident in the effect estimate: The true effect is likely to be close to the estimate of the effect, but there is a possibility that it is } \\
\text { substantially different } \\
\text { Low certainty: Our confidence in the effect estimate is limited: The true effect may be substantially different from the estimate of the effect } \\
\text { Very low certainty: We have very little confidence in the effect estimate: The true effect is likely to be substantially different from the estimate of effect }\end{array}$} & 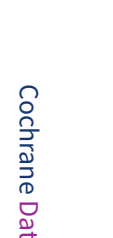 \\
\hline & $\begin{array}{l}\text { a Downgraded once fo } \\
\text { b Downgraded twice f }\end{array}$ & $\begin{array}{l}\text { erious study limitations: mo } \\
\text { imprecision: analysis based }\end{array}$ & $\begin{array}{l}\text { ials had unclear/high risk of } \mathrm{b} \\
100 \text { participants per group. }\end{array}$ & in blinding, allocat & concealment and & elective reporting of outcomes. & 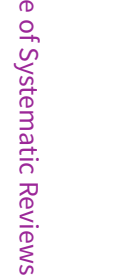 \\
\hline
\end{tabular}




\begin{tabular}{|c|c|c|c|c|c|}
\hline \multicolumn{6}{|c|}{ Memory alteration compared to control for needle-related procedural pain and distress in children and adolescents } \\
\hline \multicolumn{6}{|c|}{$\begin{array}{l}\text { Patient or population: children aged 3-18 years with chronic illness (leukemia) undergoing lumbar puncture } \\
\text { Setting: hospital (inpatient) } \\
\text { Intervention: memory alteration } \\
\text { Comparison: control }\end{array}$} \\
\hline \multirow[t]{2}{*}{ Outcomes } & \multicolumn{2}{|c|}{ Anticipated absolute effects ${ }^{\star}(95 \% \mathrm{Cl})$} & \multirow{2}{*}{$\begin{array}{l}\text { № of participants } \\
\text { (studies) }\end{array}$} & \multirow{2}{*}{$\begin{array}{l}\text { Certainty of the } \\
\text { evidence } \\
\text { (GRADE) }\end{array}$} & \multirow[t]{2}{*}{ Comments ${ }^{\star \star}$} \\
\hline & Risk with control & $\begin{array}{l}\text { Risk with memory } \\
\text { alteration }\end{array}$ & & & \\
\hline Self-reported pain & See comment & See comment & $\begin{array}{l}24 \\
(1 \mathrm{RCT})\end{array}$ & - & This outcome was assessed in one study only \\
\hline Self-reported distress & See comment & See comment & See comment & - & This outcome was not assessed in any study \\
\hline Observer-reported pain & See comment & See comment & $\begin{array}{l}42 \\
(1 \mathrm{RCT})\end{array}$ & - & This outcome was assessed in one study only \\
\hline $\begin{array}{l}\text { Observer-reported dis- } \\
\text { tress }\end{array}$ & See comment & See comment & $\begin{array}{l}50 \\
(1 \mathrm{RCT})\end{array}$ & - & This outcome was assessed in one study only \\
\hline Behavioral measures- pain & See comment & See comment & See comment & - & This outcome was not assessed in any study \\
\hline $\begin{array}{l}\text { Behavioral measures- dis- } \\
\text { tress }\end{array}$ & See comment & See comment & $\begin{array}{l}50 \\
(1 \mathrm{RCT})\end{array}$ & - & This outcome was assessed in one study only \\
\hline $\begin{array}{l}{ }^{\star} \text { The risk in the intervention } \\
\text { its } 95 \% \mathrm{Cl}) \text {. } \\
\\
\text { *^ One 'rule of thumb' for inte } \\
\text { Cl: Confidence interval; SMD: }\end{array}$ & $\begin{array}{l}\text { group (and its } 95 \% \mathrm{C} \\
\text { preting the relative } \\
\text { standardized mean d }\end{array}$ & $\begin{array}{l}\text { fidence interval) is ba } \\
\text { fect is that } 0.2 \text { repres } \\
\text { erence; } \mathbf{R C T} \text { : random }\end{array}$ & $\begin{array}{l}\text { d on the assumed risk } \\
\text { s a small difference, } \\
\text { d controlled trial }\end{array}$ & the comparison $q$ & $\begin{array}{l}p \text { and the relative effect of the intervention (and } \\
\text { e and } 0.8 \text { a large difference. }\end{array}$ \\
\hline
\end{tabular}

\section{GRADE Working Group grades of evidence}

High certainty: We are very confident that the true effect lies close to that of the estimate of the effect

Moderate certainty: We are moderately confident in the effect estimate: The true effect is likely to be close to the estimate of the effect, but there is a possibility that it is substantially different

Low certainty: Our confidence in the effect estimate is limited: The true effect may be substantially different from the estimate of the effect

Very low certainty: We have very little confidence in the effect estimate: The true effect is likely to be substantially different from the estimate of effect 


\section{B A C K G R O U N D}

This review is an update of two previous iterations published in the Cochrane Library (2006, Issue 4 and 2013, Issue 10).

\section{Description of the condition}

Pain and distress due to medical procedures are common during childhood. Needles are routinely given from the first year of life, particularly for vaccine injections. Current recommendations state that healthy children receive 20 to 30 immunizations before the age of 18 years (CDC 2018; NACI 2018; WHO 2018). Among children with acute or chronic illness, needle procedures are even more frequent for the assessment and management of their conditions (Stevens 2011; Stevens 2012), and are reported as the most distressing part of treatment (Ljungman 1999). Unfortunately, pain and distress associated with medical procedures are often poorly managed in routine care (Berberich 2012; Stevens 2011; Taddio 2009). As well as negatively impacting the child, significant child pain and distress during needle procedures are reported as highly distressing and challenging for parents and healthcare providers (Kennedy 2008).

Failure to adequately manage pain and distress during needle procedures can lead to the development of significant needle fears, which often begin in early to middle childhood and persist into adulthood (McMurtry 2015b). Moreover, fear of needles contributes to vaccine hesitancy (Taddio 2012), and medical non-adherence (Pate 1996). Thus, needle pain and distress are critical and timely to address, given the growing concern for increasing outbreaks of preventable and infectious diseases and the potential loss of herd immunity (Smith 2014).

In recent years, there has been increasing recognition of the need to adequately manage needle-related pain and distress. Evidence-based clinical practice guidelines have been developed for the management of pain and fear during vaccine injections, and include recommended pharmacological, physical, and psychological strategies (McMurtry 2016; Taddio 2015). For psychological interventions, existing guidelines recommend using a variety of cognitive and behavioral interventions that have been deemed efficacious in reducing pain during needle procedures (e.g. blowing bubbles, distraction). Moreover, guidelines recommend not using strategies that have been deemed ineffective in reducing pain (e.g. making reassuring statements like "don't worry"). Many of these strategies have been recommended by the World Health Organization's Strategic Advisory Group of Experts for the management of immunizations worldwide (WHO 2015). Additional efforts include hospital certifications (ChildKind International; www.childkindinternational.org; Schechter 2010a) and hospitalwide policies (Schechter 2008), as well as recommended standards of care for the management of medical procedures, including needles, for youth with cancer (Flowers 2015), and social media efforts targeting parents (\#itdoesnthavetohurt; www.itdoesnthavetohurt.ca).

\section{Description of the intervention}

Consistent with previous iterations of this review (Uman 2006; Uman 2013), we include only non-pharmacological psychological interventions for pain that are cognitive-behavioral in this update. We do not include non-pharmacological physical interventions such as acupuncture, heat, or cold.
Cognitive interventions include techniques that target negative or unrealistic thoughts to help replace them with more positive beliefs and attitudes. Behavioral interventions include techniques that target negative or maladaptive behaviors to help replace them with more positive and adaptive behaviors. Cognitive behavioral therapy (CBT) uses a combination or variation of strategies targeting cognitions (thoughts) or behaviors, or both (Barlow 1999). CBT for pain management aims to help individuals develop and use coping skills to manage their pain and distress, and often includes a combination of various techniques, such as distraction, relaxation training, deep breathing, hypnosis, preparing for and rehearsing the procedure in advance, using positive reinforcement for adaptive behaviors, making positive coping statements, and receiving coaching to use adaptive strategies (Chen 2000a; Christophersen 2001; Keefe 1992). Engagement and developmental appropriateness are thought to contribute to the efficacy of each intervention (Birnie 2017)

Many of the psychological interventions described in this review do not require highly specialized training and can be administered by non-psychologists, such as other healthcare providers (e.g. child life specialists, nurses) and parents. However, some trials describe brief training and education in order to maximize the effectiveness of interventions. Furthermore, psychological interventions often have natural appeal, given their tendency to draw on children's coping tendencies, potential use of minimal or widely available resources, and feasible implementation across clinical care settings.

\section{How the intervention might work}

There are several proposed mechanisms through which psychological interventions might work. Cognitive interventions target thoughts whereas behavioral interventions target individual behaviors. CBT uses a combination or variation of both cognitive or behavioral strategies, or both (Barlow 1999). Cognitive, behavioral, and combined cognitive-behavioral strategies are believed to influence pain and distress through cognitive (e.g. attention, motivation, expectations, suggestibility), learning processes, physiological, or neurobiological or both mechanisms (Accardi 2009; Birnie 2017; Jafari 2017; Noel 2018). As in our previous reviews, all of the cognitive, behavioral, and cognitive-behavioral strategies described above fall under the overarching category of 'psychological' interventions. Psychological interventions for pain management aim to help individuals to develop and use coping skills to manage their pain and distress, and can include various techniques such as distraction, relaxation training, deep breathing, hypnosis, preparing for and rehearsing the procedure in advance, using positive reinforcement for adaptive behaviors, making positive coping statements, and receiving coaching to use adaptive strategies (Chen 2000a; Christophersen 2001; Keefe 1992).

For this second review update, we revised the previous intervention categories that focused on methodological similarities to now reflect theorized or proposed mechanisms of treatment effect versus methodological similarities (e.g. virtual reality interventions are now encompassed within distraction interventions) (Accardi 2009; Birnie 2017; Jafari 2017; Noel 2018). We hoped this would lead to more meaningful conclusions and would also minimize the number of intervention categories that had small numbers of trials. 


\section{Why it is important to do this review}

Previous narrative, non-systematic reviews and book chapters on this topic have been published (Alvarez 1997; Blount 2003; Chen 2000a; Christophersen 2001; Kazak 2001; Powers 1999; Young 2005); however, more rigorous systematic reviews examining a variety of psychological interventions for needle pain and distress are essential to draw firmer conclusions about intervention efficacy and guide clinical decision-making.

Our original Cochrane Review (Uman 2006; Uman 2008) included 28 RCTs, supported the efficacy of several interventions (distraction, hypnosis, and CBT), and led to recommendations about improving the quality of trials in this area (Uman 2010). Our first review update (Uman 2013) expanded this original review, and included 39 RCTs (18 new) and coded each trial for risks of bias. We found evidence for the efficacy of distraction and hypnosis. Overall, we rated the risks of bias of trials as high or unclear, suggesting the need for improvements in methodological rigor and reporting.

In the five years since the publication of our first update, several new trials have been published, examining psychological interventions for needle-related pain and distress in children and adolescents. Advances and expansion of technology have been made (e.g. humanoid robots, smartphone apps), and peerreviewed journals have continued to raise standards for trial reporting and quality. The aim of this second review update was therefore to identify new trials, to synthesize the results of new trials with those previously reviewed, and to extend assessment of trial quality. This enables us to make firmer, more refined conclusions about the existing evidence on the efficacy of these interventions and to strengthen the evidence base for future research and clinical practice.

\section{OB JECTIVES}

To assess the efficacy of psychological interventions for needlerelated procedural pain and distress in children and adolescents.

\section{METHODS}

\section{Criteria for considering studies for this review}

\section{Types of studies}

We included published randomized controlled trials (RCTs) with at least five participants in each study arm. The original version of this review (Uman 2006) included quasi-randomized trials (e.g. alternating assignment) and unpublished trials (e.g. dissertations). We excluded these from the first review update (Uman 2013) and from this current update, to focus only on the highest-quality evidence available. We applied no language restrictions during the search, and obtained translations when necessary.

\section{Types of participants}

We included RCTs involving children and adolescents aged two to 19 years, undergoing any needle-related medical procedure. Participants included healthy children and children with chronic or transitory illnesses from both inpatient and outpatient settings. We excluded children under two years old, due to developmental differences either precluding the appropriateness of reviewed psychological interventions in infancy or the qualitatively different application of these interventions in that age group. Furthermore, the efficacy of psychological interventions for procedural pain and distress in infants is thoroughly addressed in another review (Pillai-Riddell 2011; Pillai-Riddell 2015). We selected a maximum age of 19 years to be consistent with the World Health Organization (WHO) definition of adolescence that extends to 19 years of age (http://www.searo.who.int/ en/ Section13/Section1245_4980.htm). The efficacy of psychological interventions for needle-related procedural pain in adults is reviewed elsewhere (Boerner 2015). We preferred a broad age range to minimize exclusion of any relevant studies. We excluded studies including any participants beyond two- to 19-year olds unless we could obtain data from authors for the relevant eligible subsample, while also continuing to meet the minimum criterion of five participants per group.

This review focuses on needle-related procedures performed for medical purposes, which are the most commonly occurring and feared procedures for both healthy and chronically-ill children (Broome 1990; Ljungman 1999; McMurtry 2015a). A list of common included needle-related procedures and their definitions can be found in Table 1. We excluded needle procedures performed for non-medical purposes (e.g. body piercings or tattoos).

We also excluded studies if they specifically included participants with known needle phobias (i.e. diagnosed by a qualified professional such as a psychologist and warranting specific clinical assessment, diagnoses, and targeted intervention). Other reviews address specific evidenced-based psychological interventions for high levels of needle fears/phobias that are different from those indicated for procedural pain management (e.g. exposure-based treatment) (McMurtry 2015a; McMurtry 2016).

We excluded children undergoing surgery, given the numerous factors specific to surgery or intensive care units that complicate or interfere with self-report of pain and distress (e.g. sedation, intubation, more intensive pharmacological interventions, longterm hospitalization, inability or difficulty attributing pain or distress to a specific medical procedure) (Puntillo 2004). We made an exception for studies evaluating a psychological intervention for a pre-surgical needle procedure (e.g. intravenous insertion) only when outcomes of interest were completed prior to surgery or sedation.

\section{Types of interventions}

Studies had to include at least one trial arm that assessed a primarily psychological intervention. Trials had to include at least one comparator arm (i.e. no treatment, other active treatment, treatment as usual, or waitlist). We placed no restrictions on duration, intensity, or frequency of psychological interventions. Interventions had to occur at some point prior to the needle procedure and the assessment of outcomes of interest. We excluded studies in which psychological intervention(s) were combined with a non-psychological intervention (e.g. pharmacological, physical), so that the unique effects of the psychological intervention could not be isolated and evaluated.

As specified in the review protocol and original version of this review (Uman 2005; Uman 2006), psychological interventions were broadly defined as those using cognitive, behavioral, or combined cognitive-behavioral strategies. In brief, cognitive interventions are those primarily targeting thoughts and feelings, whereas behavioral interventions are those primarily targeting overt behaviors (Barlow 1999). Combined cognitive-behavioral 
interventions are defined as those including at least one cognitive strategy combined with at least one behavioral strategy. For this update, intervention categories were generally based on key theorized mechanisms of effect or specific distinct strategies, or both (Accardi 2009; Birnie 2017; Jafari 2017; Noel 2018), with similar interventions grouped together based on conceptualizations or intervention descriptions or both, included in published papers. Emphasizing mechanisms of effect in defining intervention categories resulted in some intervention categories from previous iterations of this review being subsumed under other broader categories. We did this to allow more meaningful meta-analyses, and to avoid intervention categories with very small numbers of studies or single trials only. Specifically, we now include virtual reality interventions as one type of distraction, given their conceptualized application in this context for pain reduction (Kenney 2016). We now include the following interventions from the previous review as combined CBT, as they include at least one cognitive and one behavioral strategy as described in the original review protocol (Uman 2005): parenting coaching plus child distraction, parent positioning plus child distraction, and distraction plus suggestion. As stated in our original review protocol (Uman 2005), the division of psychological interventions into mutually exclusive categories is difficult, given a lack of consistent operational definitions. We feel our emphasis on treatment mechanisms in this second update reflects emerging empirical evidence and contemporary thinking in our understanding of psychological interventions for acute pain and distress.

Studies in this second update fall under one of the following psychological intervention categories:

- Distraction;

- Combined CBT;

- Hypnosis;

- Preparation/information;

- Breathing;

- Suggestion;

- Memory alteration.

\section{Types of outcome measures}

\section{Primary outcomes}

Primary outcomes of interest were pain intensity and distress. These are two core outcome domains recommended for clinical trials in pediatric acute pain (PedIMMPACT; McGrath 2008). Distress is broadly defined as any type of negative affect associated with the needle procedure (e.g. anxiety, fear, stress). We extracted pain and distress outcomes separately, as assessed by child self-report, observer global report (e.g. parents, nurses, researchers, etc. report using single-item scales), and/or behavioral measurement (e.g. validated rating scales assessing observed pain or distress behaviors or both, displayed by the child).

\section{Secondary outcomes}

Secondary outcomes include any physiological measurement that has been associated with pain and distress and that it is practical to quantify in a clinical setting. Examples include heart rate, respiratory rate, blood pressure, oxygen saturation, cortisol levels, transcutaneous oxygen tension (tcPO2), and transcutaneous carbon dioxide tension (tcPCO2) (Jafari 2017; Sweet 1998). We also assessed adverse events.

\section{Timing of outcome assessment}

Where possible, we extracted outcomes assessed during the needle procedure. If outcomes during the needle procedure were not evaluated, we selected the next time point occurring closest to the completion of the procedure. If outcomes were assessed both during and following the needle-related procedure, we included only outcomes assessed during the needle procedure. We did not include outcomes assessed at other times (e.g. pre-needle outcomes).

\section{Search methods for identification of studies}

We identified published studies through electronic database searches, postings to various electronic listservs, and clinical trial registries.

\section{Electronic searches}

We developed detailed search strategies through consultation with a reference librarian and assistance from the Cochrane Pain, Palliative and Supportive Care (PaPaS) Group. Definitions for included medical procedures (MedLine 2004) are described in Table 1.

We searched the following six electronic databases for relevant trials:

- Cochrane Central Register of Controlled Trials (CENTRAL), the Cochrane Library Issue 8 of 12, 2017;

- MEDLINE and MEDLINE in Process (OVID), March 2013 to 12 September 2017;

- Embase (OVID), March 2013 to 2016, week 37;

- PsycINFO (OVID), 2013 to September week 1, 2017;

- Web of Science (ISI Web of Knowledge), 2013 to 12 September 2017;

- Cumulative Index to Nursing and Allied Health Literature (CINAHL), March 2013 to September 2017.

Database search terms were consistent with previous versions of this review (Uman 2006; Uman 2013). We conducted updated searches in September 2016 and September 2017 to identify any records published since the last review update in 2013. See appendices for search strategies, keywords, and MeSH terms as appropriate for each database: MEDLINE (Appendix 1), PsycINFO (Appendix 2), CENTRAL (Appendix 3), Embase (Appendix 4), IBI Web of Knowledge (Appendix 5), and CINAHL (Appendix 6).

\section{Searching other resources}

We also solicited relevant studies through professional listservs, including:

1. Pain in Child Health (PICH);

2. Pediatric Pain;

3. American Psychological Association's Society of Pediatric Psychology Division 54;

4. American Psychological Association's Health Psychology Division 38.

For this update, we also searched clinical trial registries for any relevant completed trials, including clinicaltrials.gov and the World Health Organization International Clinical Trials Registry Platform (www.who.int.trialsearch). We also included any other relevant 
studies identified and included in the original review and the previous update.

\section{Data collection and analysis}

\section{Selection of studies}

Two review authors considered titles and abstracts retrieved from database searches for review inclusion (LU and CC for original review; KB and $\mathrm{MN}$ for first and second review updates). Two review authors checked full-text articles when relevance and eligibility for the current review were unclear from the abstract alone (LU and $\mathrm{CC}$ for original review; $\mathrm{KB}$ and $\mathrm{MN}$ for review updates). We resolved discrepancies through discussion with a third review author.

Included studies had to use true random assignment. We determined this based on the description of participant assignment available in each study's peer-reviewed publication. We retrieved and included 28 RCTs in the original review (Uman 2006), although we later excluded seven of these studies from subsequent review updates, including this one, as they were unpublished dissertations or reported quasi-randomized methods (e.g. alternating assignment). Updated database searches (conducted March 2012 and March 2013) for the last review update (Uman 2013) identified an additional 18 RCTs meeting our inclusion criteria and providing necessary data. Searches for the current (second) update (conducted September 2016 and September 2017) identified an additional 20 RCTs, for a total of 59 RCTs included in this review. We coded all included RCTs in full. References for included studies are provided below in the 'Description of studies' section.

\section{Data extraction and management}

Two review authors extracted data (LU and CC original review; $\mathrm{KB}$ and $\mathrm{MN}$ for review updates), using a data extraction form designed for the original review. A researcher outside the review team who was fluent in Farsi reviewed one non-English study in the previous review update, to confirm inclusion eligibility and conduct data extraction. Extracted data included study design, participant demographics, diagnosis (when applicable), type of needle procedure, type of intervention and control conditions, outcomes, as well as other related variables. A third review author was available to resolve coding discrepancies, if needed. If studies reported incomplete data necessary for meta-analysis, we contacted study authors. We excluded RCTs if the data necessary for data pooling were not available in the published study, could not be identified through contact with the study authors, or could not be calculated based on other data provided. A trained research assistant or another study author, or both, reviewed the extracted data for errors. We analyzed all data suitable for pooling using Review Manager 5 software (RevMan) (RevMan 2014).

\section{Assessment of risk of bias in included studies}

Two review authors ( $\mathrm{KB}$ and $\mathrm{MN}$ ) independently assessed risks of bias for all included studies, using the criteria outlined in the Cochrane Handbook (Higgins 2017), with any disagreements resolved by discussion. We completed a 'Risk of bias' table for each included study using the 'Risk of bias' tool in RevMan.

We assessed the following for each study.

- Random sequence generation (checking for possible selection bias). We assessed the method used to generate the allocation sequence as: low risk of bias (any truly random process, e.g. random-number table; computer random-number generator); unclear risk of bias (method used to generate sequence not clearly stated). We excluded studies using a non-random process (e.g. odd or even date of birth; hospital or clinic record number).

- Allocation concealment (checking for possible selection bias). The method used to conceal allocation to interventions prior to assignment determines whether intervention allocation could have been foreseen in advance of or during recruitment, or changed after assignment. We assessed the methods as: low risk of bias (e.g. telephone or central randomization; consecutivelynumbered sealed opaque envelopes); unclear risk of bias (method not clearly stated). We considered studies that did not conceal allocation (e.g. open list) to have high risk of bias.

- Blinding of participants and personnel (checking for possible performance bias). We assessed the methods used to blind study participants and personnel from knowledge of which intervention a participant received. We assessed methods as: low risk of bias (study states that it was blinded and describes the method used to achieve blinding); unclear risk of bias (study states that it was blinded but does not provide an adequate description of how this was achieved). We considered studies that were not blinded or when the nature of the psychological intervention precluded participants and personnel from being blinded (e.g. obvious intervention such as watching television or a medical clown in the room) to have high risk of bias.

- Blinding of outcome assessment (checking for possible detection bias). We assessed the methods used to blind study participants and outcome assessors from knowledge of which intervention a participant received. We assessed the methods as: low risk of bias (study has a clear statement that outcome assessors were unaware of treatment allocation, and ideally describes how this was achieved); unclear risk of bias (study states that outcome assessors were blind to treatment allocation but lacks a clear statement on how this was achieved). We considered studies where outcome assessment was not blinded or when the nature of the psychological intervention precluded outcome assessors from being blinded to have a high risk of bias.

- Incomplete outcome data (checking for possible attrition bias due to the amount, nature and handling of incomplete outcome data). We assessed the methods used to deal with incomplete data as: low risk (no missing data, reasons for missing data unlikely to be related to true outcome or balanced with similar reasons across groups); unclear risk of bias (insufficient information to permit judgment of risk); high risk of bias (reasons for missing data judged likely to be related to true outcome, with either imbalance in numbers or reasons across groups).

- Selective reporting (checking for reporting bias). We assessed whether primary and secondary outcome measures were prespecified and whether these were consistent with those reported: low risk of bias (study protocol is available, or is not available but it is clear that the report specified and reported on all expected outcomes); unclear risk of bias (insufficient information to permit judgment of risk); high risk of bias (study did not prespecify and/or report all primary outcomes, one or more outcomes is reported incompletely so that it cannot be entered in meta-analysis).

- Other bias (checking for possible biases not covered elsewhere). We assessed other bias in studies as: low risk of bias (study

Psychological interventions for needle-related procedural pain and distress in children and adolescents (Review) 
appears to be free of other sources of bias); unclear risk of bias (insufficient information to permit judgment of risk); high risk of bias (at least one important risk of bias likely to impact study findings, such as baseline group differences reported and not accounted for, using unvalidated/unreliable measurement tool, inadequate sample size/study underpowered).

\section{Measures of treatment effect}

Given the nature of the outcome measures in this review, all outcome data were continuous (e.g. rating scales). We calculated standardized mean differences (SMDs) with 95\% confidence intervals (Cls), which allowed the combination of results across different measurement scales assessing the same outcome (e.g. pain). We applied the following rule of thumb for interpreting SMDs as effect sizes, as suggested by Cochrane (Higgins 2017): 0.2 represents a small effect, 0.5 represents a medium effect, and 0.8 represents a large effect (Cohen 1988). We assessed each category of psychological intervention separately in a metaanalysis. Within each intervention category, we assessed outcomes and measurement type separately. We pooled all comparators together. We only conducted meta-analysis when data from more than a single RCT were available. Thus, for each psychological intervention we assessed possible treatment effects for the following seven outcomes:

- Pain: self-report;

- Pain: observer global report;

- Pain: behavioral measure;

- Distress: self-report;

- Distress: observer global report;

- Distress: behavioral measure;

- Physiological measures: each physiological outcome was assessed separately.

\section{Unit of analysis issues}

We included parallel two-group RCTs as well as cluster-randomized trials (i.e. groups of individuals randomized together to the same intervention). We included cross-over trials only when data were available separately for each group following the first treatment arm (i.e. prior to cross-over). We did this because once psychological interventions have been introduced, it can be difficult to prevent participants from using these strategies themselves at subsequent needle procedures (e.g. distraction). We included studies with multiple treatment groups so long as each treatment group separately met the review inclusion criteria.

\section{Dealing with missing data}

We tried to contact study authors in all situations when data necessary for data pooling were not reported in published RCTs (e.g. means, standard deviations (SDs), group sizes). If this was not possible, we used statistical methods for calculating missing data from other reported measures of variation as recommended (e.g. calculating standard deviations from standard errors, confidence intervals, $t$ values, and $P$ values) (Higgins 2017). We excluded studies or outcomes or both from this review when we could not contact the authors or they did not respond, did not have data available, or when we could not calculate data necessary for pooling from available data. We included the number of participants in each group identified in published study results sections. When not otherwise specified by the authors, we assumed there were no study dropouts and used the reported group sizes in the meta-analyses.

\section{Assessment of heterogeneity}

We assessed heterogeneity using both the $\mathrm{Chi}^{2}$ test and the $\mathrm{I}^{2}$ statistic. Given that $\mathrm{Chi}^{2}$ tests often have low statistical power, we used a Type 1 error level of 0.10 for rejecting the null hypothesis of homogeneity. While $\mathrm{Chi}^{2}$ tests are useful for identifying whether heterogeneity is present, it has been argued that there will always be some level of heterogeneity in meta-analyses, given the clinical and methodological diversity (Higgins 2017). The $\mathrm{I}^{2}$ statistic provides a measure of inconsistency across studies to assess the impact of heterogeneity on the meta-analysis (Higgins 2017). 12 is expressed as a percentage from $0 \%$ to $100 \%$, and we used the following rough interpretation guide: $0 \%$ to $40 \%$, might not be important; $30 \%$ to $60 \%$, may represent moderate heterogeneity; $50 \%$ to $90 \%$, may represent substantial heterogeneity; and $75 \%$ to $100 \%$ represents considerable heterogeneity (Higgins 2017). Ranges overlap, as the importance of 12 depends on several other factors such as the magnitude and direction of effects, as well as the strength of evidence for the heterogeneity (for example, the $P$ value for the $\mathrm{Chi}^{2}$ test or the confidence interval for the $\mathrm{I}^{2}$ statistic). In cases where we found statistically significant heterogeneity, data were still pooled but should be interpreted with caution. Given significant heterogeneity for several analyses, we analyzed results using a random-effects model.

\section{Assessment of reporting biases}

We used several strategies to overcome publication, language, and outcome reporting bias in this update and previous iterations (Uman 2006; Uman 2013). We imposed no language barriers in database searches, we searched clinical trial registries, we posted requests to listservs in pediatric health and pain regarding any published, unpublished, or in-progress studies, and tried to obtain any and all missing data from included studies through repeated email requests to study authors or co-authors. We included any studies in the meta-analysis that provided completed results (i.e. means, SDs, and cell sizes for both treatment and control groups) for at least one outcome measure of interest. Information related to reporting biases is also captured in the 'Risk of bias' tool. Fourteen of the studies included in this review had authors who responded to requests for missing data (Balan 2009; Bisignano 2006; Caprilli 2007; Cavender 2004; Crevatin 2016; Gupta 2006; Kleiber 2001; Liossi 1999; McCarthy 2010; Meiri 2016; Miguez-Navarro 2016; Nilsson 2015; Sinha 2006; Sander Wint 2002).

\section{Data synthesis}

We calculated SMDs using a random-effects model separately for all outcomes for each intervention category when necessary data were available. We considered interventions to be efficacious when the SMD and corresponding $\mathrm{Cls}$ were negative. The reported $\mathrm{P}$ values reflect the strength of the evidence against the null hypothesis.

We combined intervention groups that included variations of the same psychological intervention category (e.g. two types of distraction) to create a single pair-wise comparison, as recommended by Cochrane (Higgins 2017). When multiple control conditions were available, we selected the condition that could most clearly isolate the active ingredient of the intervention condition. For example, comparing eutectic mixture of local 
anesthetics (EMLA) + distraction (intervention group) to EMLA only (selected control group) instead of no-EMLA standard care (not-selected control group). Another example includes comparing music with headphones (intervention group) to headphones only without music (selected control group) instead of no headphones or music (not-selected control group).

Many control conditions are defined as standard or routine care groups. Some include cognitive or behavioral techniques, or both. We made an a priori decision to consider these as control groups as conceptualized by the authors themselves, and it is ethical for the conduct of clinical trials not to offer below current standard of care. Less common are studies that report the use of pharmacological strategies, such as topical anesthetics, in standard care. In such cases, we also considered these as a control condition as long as it was offered similarly to the intervention condition, in addition to psychological strategies.

We combined outcomes in cases when multiple observers rated children's pain or distress or both (e.g. nurses, parents, researchers) or when multiple behavioral measures assessed pain or distress or both (e.g. both the child-adult medical procedure inventory scale (CAMPIS) and observation scale of behavioral distress (OSBD) for distress). We pooled data using statistical formulae recommended by Cochrane for combining means and SDs: pooled mean $=\left[\left(\right.\right.$ mean $_{1}$ $\left.x N_{1}\right)+\left(\right.$ mean $\left.\left._{2} \times N_{2}\right) /\left(N_{1}+N_{2}\right)\right]$ and pooled $S D=$ square root of $\left[S_{1} 2\right.$ $\left.\left(\mathrm{N}_{1}-1\right)+\mathrm{SD}_{2} 2\left(\mathrm{~N}_{2}-1\right)\right] / \mathrm{N}_{1}+\mathrm{N}_{2}-2$.

\section{Quality of the evidence}

Two review authors ( $K B$ and $M N$ ) independently rated the quality of the outcomes. We used the GRADE system as applied to continuous outcomes (Guyatt 2013) to rate the quality of evidence separately for all intervention categories and all outcomes with data from more than one RCT. We used the GRADE profiler Guideline Development Tool software (GRADEpro GDT 2015), GRADE recommendations (Guyatt 2011) and the guidelines provided by Cochrane (Higgins 2017).

The GRADE system uses the following criteria for assigning a quality level to a body of evidence (Higgins 2017):

- High: randomized trials; or double-upgraded observational studies

- Moderate: downgraded randomized trials; or upgraded observational studies

- Low: double-downgraded randomized trials; or observational studies

- Very low: triple-downgraded randomized trials; or downgraded observational studies; or case series/case reports

Factors that may decrease the quality level of a body of evidence are:

- Limitations in the design and implementation of available studies suggesting a high likelihood of bias;

- Indirectness of evidence (indirect population, intervention, control, outcomes);

- Unexplained heterogeneity or inconsistency of results (including problems with subgroup analyses);

- Imprecision of results (wide confidence intervals);

- High probability of publication bias.
Factors that may increase the quality level of a body of evidence are:

- Large magnitude of effect;

- All plausible confounding would reduce a demonstrated effect or suggest a spurious effect when results show no effect;

- Dose-response gradient.

We decreased the GRADE rating by one $(-1)$ or two $(-2)$ if we identified:

- Serious $(-1)$ or very serious $(-2)$ limitation to study quality;

- Important inconsistency: 12 statistic moderate $>45 \%(-1)$ or 12 statistic considerable $>90 \%(-2)$;

- Some $(-1)$ or major $(-2)$ uncertainty about directness;

- Imprecise or sparse data: sample size $<400(-1)$ or sample size $<100)(-2)$;

- High probability of reporting bias $(-1)$.

For transparency, we documented all reasons for downgrading the GRADE quality of evidence rating. Decreases of 3 or more ratings dropped the GRADE quality levels to 'very low'.

GRADE quality levels are interpreted as follows:

- High: we are very confident that the true effect lies close to that of the estimate of the effect;

- Moderate: we are moderately confident in the effect estimate; the true effect is likely to be close to the estimate of effect, but there is a possibility that it is substantially different;

- Low: our confidence in the effect estimate is limited; the true effect may be substantially different from the estimate of the effect; and

- Very low: we have very little confidence in the effect estimate; the true effect is likely to be substantially different from the estimate of effect.

\section{'Summary of findings' tables}

We include seven 'Summary of findings' tables to present the main findings in a transparent and simple tabular format. In particular, we included key information about the quality of evidence, the magnitude of effect of the interventions examined, and the sum of available data on all primary outcomes:

- Pain: self-report;

- Pain: observer global report;

- Pain: behavioral measure;

- Distress: self-report;

- Distress: observer global report;

- Distress: behavioral measure

\section{Subgroup analysis and investigation of heterogeneity}

We assessed each category of psychological intervention separately (i.e. distraction, hypnosis, etc.) as consistent with previous versions of this review. For each intervention, we conducted analyses separately by type of outcome (pain and distress) and measurement (self-report, observer-report, behavioral, physiological). We assessed different physiological outcomes separately (e.g. heart rate versus blood pressure). As described above, we calculated the $\mathrm{Chi}^{2}$ test and $\mathrm{I}^{2}$ statistic for all outcomes to assess heterogeneity.

Psychological interventions for needle-related procedural pain and distress in children and adolescents (Review) 


\section{Sensitivity analysis}

We were unable to conduct all of the sensitivity analyses that we had proposed in our original review, due to insufficient data reported within and across studies, as well as the small number of studies within each intervention category. The main sensitivity analyses conducted in the original review involved comparing the study results when quasi-randomized trials were added to the analyses. However, in order to strengthen the methodological quality of the findings in subsequent updates, we have limited the included trials to only true RCTs. We have therefore not conducted additional sensitivity analyses.

\section{RESULTS}

\section{Description of studies}

See Characteristics of included studies; Characteristics of excluded studies.

\section{Results of the search}

We conducted six electronic database searches in total: one for the original review (February 2005) (Uman 2006); three for the first review update (December 2010, March 2012, March 2013) (Uman 2013); and two for the current review update (September 2016, September 2017).
Database searches conducted in September 2017 for this review update identified 714 records, and our searches of other resources (i.e. professional listservs and trials registries) identified an additional three studies that appeared to meet the inclusion criteria. After duplicate records had been removed, there remained 572 unique abstracts for review. Of these, 511 records were deemed not eligible. We reviewed 61 manuscripts in full, of which 20 met our inclusion criteria and provided the data necessary for data pooling. We included 39 trials in the previous review update (Uman 2013). This incorporated 21 studies from the original review published prior to 2005 (Uman 2006), plus 18 additional studies published between 2005 and 2013. Although the original review included 28 studies (Uman 2006), we excluded seven of these (reported in eight publications) from subsequent review updates, including this one, due to lack of adequate randomization procedures (Cohen 1997; Cohen 1999; Cohen 2002; French 1994) and being unpublished dissertation theses (Krauss 1996; Posner 1998; Zabin 1982). We found no non-English studies in the database searches for this review update. Previous review searches identified studies in Portuguese (Santos 2000), German (Hoffman 2011; Kammerbauer 2011), Italian (Bufalini 2009; Lessi 2011), and Farsi (Alavi 2005; Shahabi 2007; Vosoghi 2010) which were either translated or assessed and coded in full by a native language speaker. Thus, 59 studies meet the inclusion criteria for this review update. For a further description of our screening process, see the study PRISMA flow diagram (Figure 1). 
Figure 1. Study flow diagram.

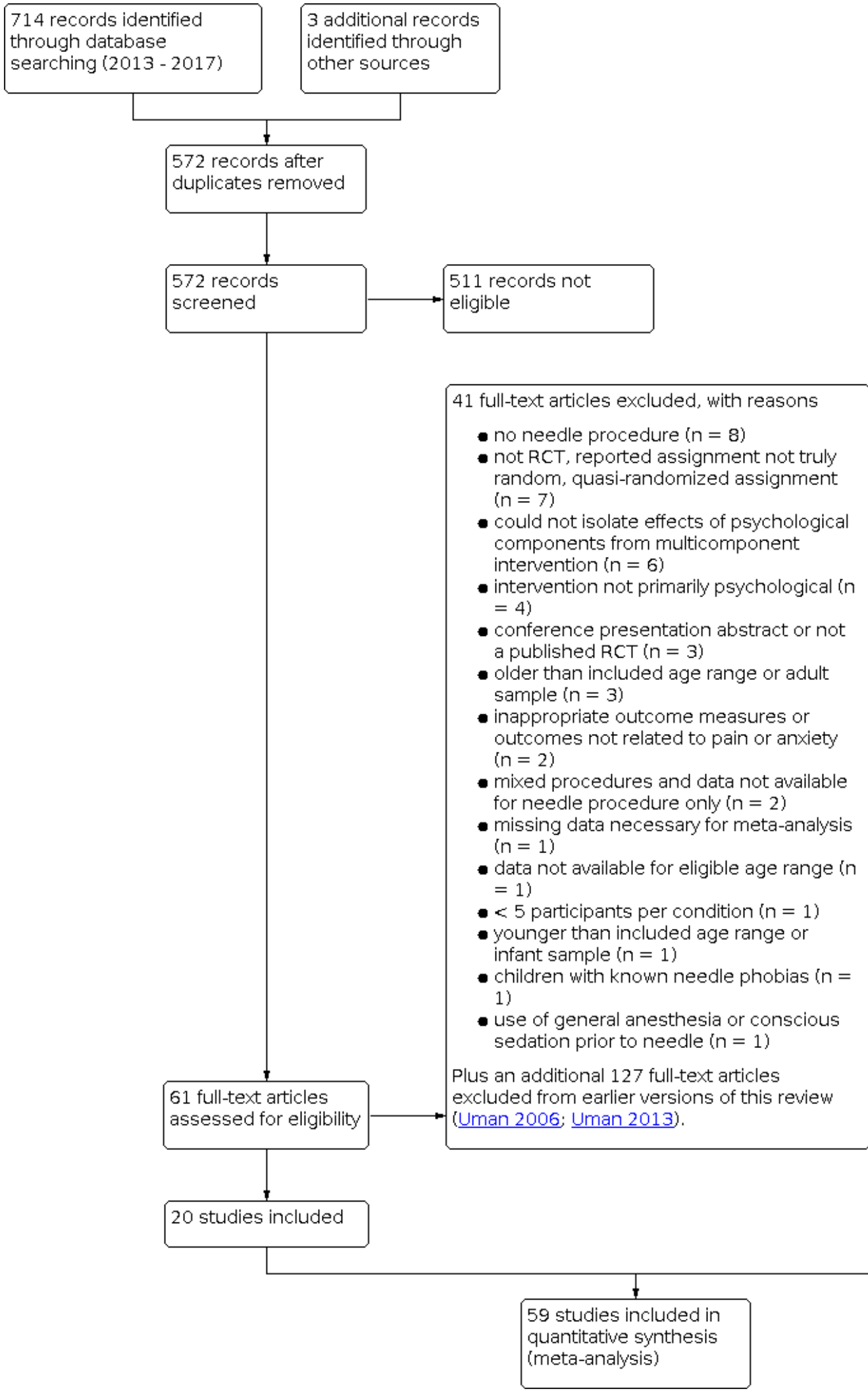

39 studies included in previous version of this review (Uman 2013) 


\section{Included studies}

This review and meta-analysis includes 59 studies ( $\mathrm{n}=5550$ participants). Of these, 21 studies were identified in the original review (Blount 1992; Cassidy 2002; Cavender 2004; Chen 1999; Eland 1981; Fanurik 2000; Fowler-Kerry 1987; Gonzalez 1993; Goodenough 1997; Harrison 1991; Katz 1987; Kleiber 2001; Kuttner 1987; Liossi 1999; Liossi 2003; Liossi 2006; Press 2003; Tak 2006; Tyc 1997; Vessey 1994; Sander Wint 2002), 18 studies from the first review update (Balan 2009; Bellieni 2006; Bisignano 2006; Caprilli 2007; Gold 2006; Gupta 2006; Huet 2011; Inal 2012; Jeffs 2007; Kristjansdottir 2010; Liossi 2009; McCarthy 2010; Nguyen 2010; Noguchi 2006; Sinha 2006; Vosoghi 2010; Wang 2008; WindichBiermeier 2007), and 20 studies from the most recent searches conducted in September 2017 (Aydin 2017; Beran 2013; Cohen 2015; Crevatin 2016; Ebrahimpour 2015; Kamath 2013; Luthy 2013; Meiri 2016; Miguez-Navarro 2016; Miller 2016; Minute 2012; Mutlu 2015a; Nilsson 2015; Oliveira 2017; Pourmovahed 2013; Ramírez-Carrasco 2017; Rimon 2016; Sahiner 2016; Yinger 2016; Zieger 2013). Included trials had two to six study arms. Two studies used cross-over designs (Nilsson 2015; Oliveira 2017), and there were no clusterRCTs.

Of the 59 included studies, nine assessed multiple psychological interventions (Cohen 2015; Fowler-Kerry 1987; Gupta 2006; Kuttner 1987; Liossi 1999; Miller 2016; Sahiner 2016; Tak 2006; Wang 2008). In one study (Mutlu 2015a), we deemed only one of two interventions eligible for inclusion in the review (i.e. balloon inflation). Four studies assessed multiple types of distraction interventions (Aydin 2017; Bellieni 2006; Miller 2016; Sahiner 2016). Assessed interventions included distraction $(n=32)$, followed by combined CBT $(n=18)$, hypnosis $(n=8)$, preparation and information $(n=4)$, breathing $(n=4)$, suggestion $(n=3)$, and memory alteration $(n=1)$.

Needle procedures varied, and included venipuncture or blood draw only $(n=20)$, immunization or injection $(n=11)$, intravenous insertion ( $n=8)$, lumbar puncture $(n=6)$, intravenous cannulation or venipuncture $(n=4)$, bone marrow aspiration $(n=3)$, local dental anesthetic injection ( $n=3)$, and intramuscular injection, laceration repair, allergy testing involving injection, and insulin injection ( $n=1$ each). Ages of participating children and adolescents ranged from two to 19 years old. Most studies $(n=34)$ focused exclusively on children in early childhood (two to five years old) or middle childhood (i.e. six to 12 years old). Only one study focused exclusively on adolescents (i.e. 13 to 15 years old). All remaining studies $(n=24)$ included children ranging from early childhood to late adolescence (up to 19 years olds). Most studies ( $n=33$ ) provided no specific health diagnoses for participating children and adolescents. The remaining studies included children with mixed chronic illness $(n=13)$, children with cancer $(n=12)$, or children with diabetes $(n=1)$. Trials were conducted in a variety of settings, including hospital inpatients, hospital outpatient clinics, emergency departments, community clinics, and schools.

See the 'Characteristics of included studies' tables for more detail by study and the seven 'Summary of findings' tables for more details by type of intervention.

\section{Excluded studies}

Overall, across all three iterations of this review, we excluded 168 studies after reviewing full-text articles. Of these 168 excluded studies, 51 were excluded from the original review (Uman 2006),
69 from the previous review update (Uman 2013), 41 from the current review update, plus an additional seven included in the original review that we excluded from subsequent review updates, due to studies lacking true randomization or being unpublished dissertation theses. Additionally, we excluded one intervention arm for an otherwise included study (Mutlu 2015b).

Primary reasons for exclusion were:

- Not a randomized controlled trial, reported assignment not truly random, quasi-randomized assignment, randomization failed ( $n=53$ ) (Agarwal 2017; Alhani 2010; Ashkenzai 2006; Atkinson 2009; Bagnasco 2012; Ben-Pazi 2017; Boivin 2008; Bowen 1999; Cline 2006; Cohen 1997; Cohen 1999; Cohen 2002; Cohen 2010; Crowley 2011; Davit 2011; Dufresne 2010; Forsner 2014; French 1994; Heckler-Medina 2006; Hedén 2009; Hoffman 2011; Howe 2011; Jimeno 2014; Kammerbauer 2011; Kearl 2015; Lawes 2008; Lessi 2011; Liossi 2007; MacLaren 2005; MacLaren 2007; Manimala 2000; Manne 1990; Manne 1994; McCarthy 1998; McCarthy 2014; McInally 2005; Nilsson 2009; Powers 1993; Ramponi 2009; Rogovik 2007; Schechter 2010b; Sikorova 2011; Singh 2016; Slifer 2011; Sparks 2001; Stefano 2005; Sury 2010; Thurgate 2005; Tüfekci 2009; Vohra 2011; Wood 2002; Yoo 2011; Zahr 1998);

- Missing data necessary for pooling, such as means, SDs, and cell sizes $(n=24)$ (Arts 1994; Bengston 2002; Carlson 2000; Chen 2000b; Dahlquist 2002; Fassler 1985; Gilbert 1982; Goymour 2000; Inal 2010; Hartling 2013; Jay 1987; Kazak 1996; Kazak 1998; Klingman 1985; Kuttner 1988; Malone 1996; Megel 1998; O'Laughlin 1995; Peretz 1999; Reeb 1997; Santos 2000; Vernon 1974; Young 1988; Zeltzer 1982);

- Older than included age range or adult sample $(n=14)$ (Agarwal 2008; Anson 2010; Drahota 2008; Hudson 2015; Jacobson 2006; Kwekkeboom 2003; McWhorter 2014; Salih 2010; Schneider 2011; Shabanloei 2010; Shimizu 2005; Slack 2009; Tokunaga 2017; Vika 2009);

- No needle procedure ( $n=11$ ) (Chow 2017; Cumino 2017; Franzoi 2016; Isong 2014; Kettwich 2007; Marechal 2017; Quan 2016; Seiden 2014; Suresh 2015; Weber 2010; Weinstein 2003);

- Intervention not primarily psychological $(n=9)$ (Anghelescu 2013; Demir 2012; Garret-Bernardin 2017; Marec-Bérard 2009; Mutlu 2015b; Park 2008; Shemesh 2017; Ujaoney 2013; Wallace 2010);

- Unpublished dissertation ( $\mathrm{n}=$ 9) (Christiano 1996; Krauss 1996; Lustman 1983; Myrvik 2009; Olsen 1991; Posner 1998; Schur 1986; Winborn 1989; Zabin 1982);

- No control or comparison group or inappropriate control group $(n=8)$ (Broome 1998; Hawkins 1998; Jay 1995; Kolk 2000; Slifer 2009; Smith 1989; Smith 1996; Wall 1989);

- Inappropriate intervention or could not isolate effects of psychological components from multi-component intervention ( $\mathrm{n}=8$ ) (Baxter 2011; Benjamin 2016; Franck 2014; Jay 1991; Lee 2013; Moadad 2016; Schreiber 2016; Stevenson 2005);

- Conference presentation abstract or not a published RCT ( $\mathrm{n}=$ 6) (Bufalini 2012; Fancourt 2016; Firoozi 2014; Inal 2010; Russell 2012; Skinner 2015);

- Inappropriate outcome measures or outcomes not related to pain or anxiety $(n=5)$ (Alderfer 2010; Bruck 1995; Chan 2013; Jay 1990; Oberoi 2016); 
- Surgical procedure ( $n=3$ ) (Hatava 2000; Klorman 1980; Melamed 1974);

- Cross-over design with data not available pre-cross-over $(n=3)$ (Alavi 2005; El-Sharkawi 2012; Shahabi 2007);

- Younger than included age range or infant sample $(n=3)$ (Cramer-Berness 2005; Hillgrove-Stuart 2013; Ozdemir 2012);

- Use of general anesthesia or conscious sedation prior to needle procedure ( $n=3$ ) (Bufalini 2009; Kain 2006; Rajan 2017);

- Variable medical procedures or causes of pain, and data not available for needle procedure only $(n=3)$ (Jibb 2017; Mohan 2015; Tyson 2014).

- Fewer than five participants per condition $(n=2)$ (Felluga 2016; Pederson 1996);

- Data not available for eligible age range $(n=1)$ (Shanmugam 2016)

\section{Figure 2. Risk of bias graph: review authors' judgements about each risk of bias item presented as percentages} across all included studies.

Random sequence generation (selection bias)

Allocation concealment (selection bias) Blinding of participants and personnel (performance bias): All outcomes Blinding of outcome assessment (detection bias): All outcomes Incomplete outcome data (attrition bias): All outcomes Selective reporting (reporting bias)

Other bias

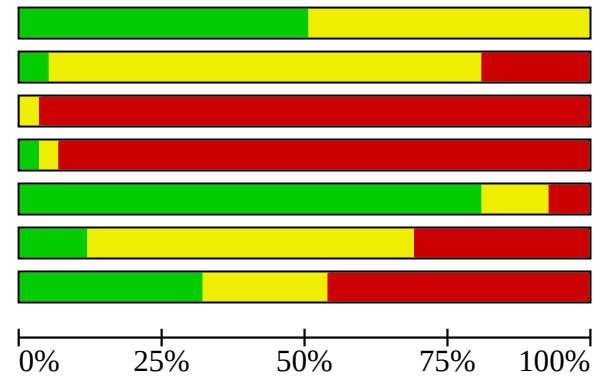

Low risk of bias
Unclear risk of bias
High risk of bias 
Figure 3. Risk of bias summary: review authors' judgements about each risk of bias item for each included study.

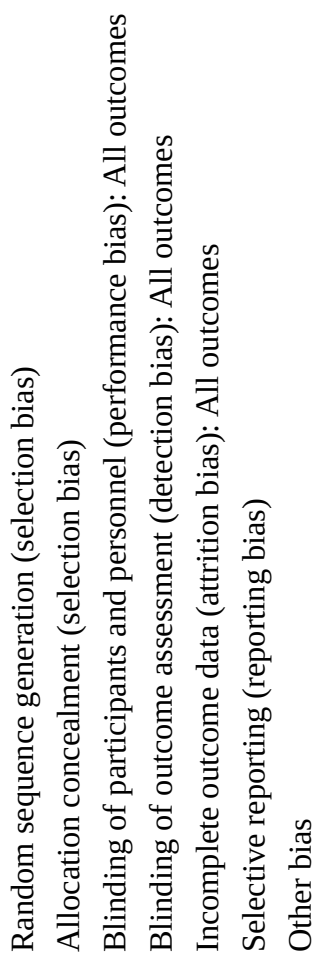

Aydin 2017

Balan 2009

Bellieni 2006

Beran 2013

Bisignano 2006

Blount 1992

Caprilli 2007

Cassidy 2002

Cavender 2004

Chen 1999

Cohen 2015

Crevatin 2016

Ebrahimpour 2015

Eland 1981

Fanurik 2000

Fowler-Kerry 1987

Gold 2006

Gonzalez 1993

Goodenough 1997

Gupta 2006

Harrison 1991

Huet 2011

Inal 2012
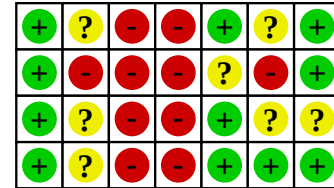

\begin{tabular}{l|l|l|l|l|l|l}
\hline$?$ & $?$ & - & - & - & $?$ \\
\hline
\end{tabular}
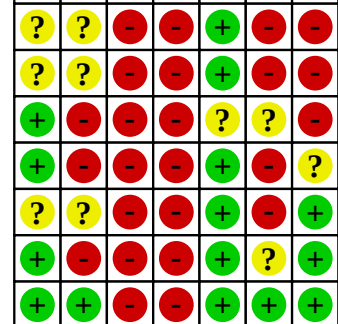

\begin{tabular}{llllll}
\hline$?$ & $?$ & - & +
\end{tabular}

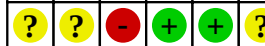

\begin{tabular}{llllllll}
\hline$?$ & $?$ & - & - & - & ?
\end{tabular}

\begin{tabular}{lllllll}
\hline$?$ & $?$ & - & - & + & $?$
\end{tabular}

\begin{tabular}{|l|l|l|l|l|l}
\hline & $?$ & - & - & - & \\
\hline
\end{tabular}

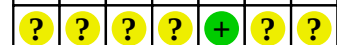

\begin{tabular}{lllllllllll}
\hline$?$ & $?$ & $?$ & $?$ & + & $?$ & + \\
\hline
\end{tabular}

\begin{tabular}{lllllllll}
\hline+ & $?$ & - & - & + & $\odot$ & $?$ \\
\hline
\end{tabular}


Figure 3. (Continued)

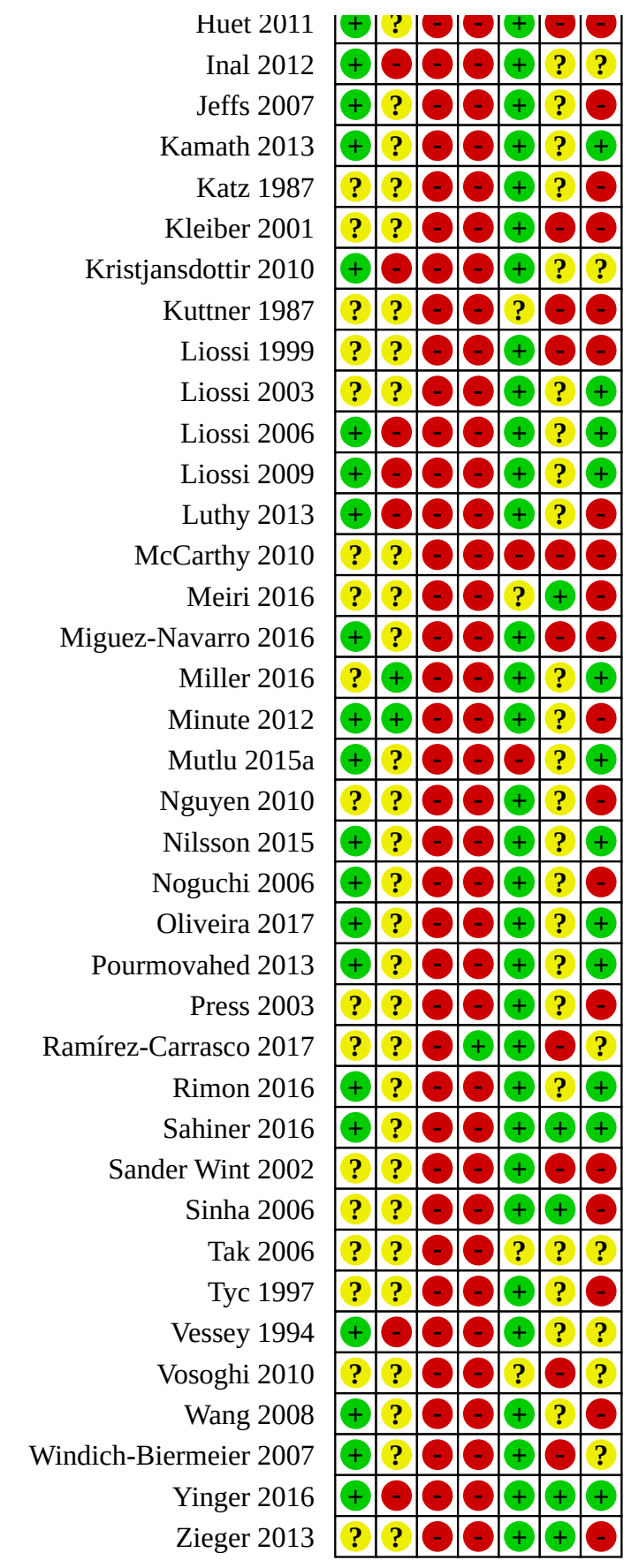

\section{Allocation}

\section{Allocation concealment}

\section{Random sequence generation}

We rated 33 studies (55.9\%) as being at unclear risk of bias, as the process for sequence generation was not clearly reported. We rated the other 26 studies $(44.1 \%)$ as being at low risk of bias, as they reported clear strategies for generating random sequences (e.g. computer-generated random-number table). We rated no studies at

We rated 46 studies (78.0\%) as being at unclear risk of bias, as they did not report any detail about allocation concealment strategies. We rated only three studies (5.1\%) as being at low risk of bias for clearly reporting use of sequentially-numbered, opaque, sealed envelopes. We rated the remaining 10 studies $(16.9 \%)$ at high risk of bias for reporting open allocation strategies. 


\section{Blinding}

We rated 57 studies (96.6\%) at high risk of bias and two (3.4\%) at unclear risk of bias for blinding of participants and personnel; we rated no studies at low risk of bias for this domain. This was largely due to the nature of psychological interventions that are often obvious to children and nurses, or they are involved in delivery of the intervention itself. We rated one study (Gonzalez 1993) at unclear risk of bias in circumstances where parents delivered the intervention, making it possible for the child or nurse administering the needle, or both, to be blind to study group, although that was unclearly reported. We rated a second study (Goodenough 1997) at unclear risk of bias, as the intervention was a minor alteration to wording (i.e. suggestion), unlikely to be detected by the child.

We rated 56 studies (94.9\%) at high risk of bias, two studies (3.4\%) at unclear risk, and one study (1.7\%) at low risk for blinding of outcome assessment. Similarly, most studies at high risk of bias were attributable to the obvious nature of psychological interventions. The few instances with unclear or low risk of bias occurred when the psychological intervention was not overtly apparent or when outcome raters were unaware of the group assignment (e.g. blinded observational assessment).

\section{Incomplete outcome data}

We rated 48 studies (81.4\%) at low risk of bias, seven studies (11.9\%) at unclear risk, and four (6.8\%) at high risk for incomplete reporting of outcome data. We gave low ratings in circumstances where all outcomes were reported in full and with sufficient detail to be included in meta-analysis, or where missing data were balanced across groups, or likely not to be related to study outcomes. We gave high risk of bias ratings when reasons for missing data were likely related to study outcomes, or an imbalance in missing data or dropouts between groups. We gave unclear ratings where insufficient information was provided.

\section{Selective reporting}

We rated 36 studies (61.0\%) at unclear risk of bias, 17 studies $(28.8 \%)$ at high risk, and six studies $(10.2 \%)$ at low risk for selective reporting of outcomes. Most studies were given unclear risk of bias ratings when primary and secondary outcomes of interest were not clearly outlined, making it difficult to determine whether study outcomes were fully reported. We gave high risk of bias ratings when one or more outcomes of interest were incompletely reported. We gave low risk of bias ratings in circumstances where primary and secondary outcomes were identified a priori and reported in full.

\section{Other potential sources of bias}

We rated 32 studies $(54.2 \%)$ at high risk of bias, 15 studies $(25.4 \%)$ at low risk, and 12 studies (20.3\%) at unclear risk for other potential sources of bias. Common areas of concern contributing to high risk of bias ratings included studies with small sample sizes or that were underpowered to detect treatment effects, contamination of intervention strategies between groups, use of unreliable or unvalidated outcome measures, or significant group differences that were not controlled for in analyses (e.g. variable number of injections, parental presence).

\section{Effects of interventions}

See: Summary of findings 1 Distraction compared to control for needle-related procedural pain and distress in children and adolescents; Summary of findings 2 CBT-combined compared to control for needle-related procedural pain and distress in children and adolescents; Summary of findings 3 Hypnosis compared to control for needle-related procedural pain and distress in children and adolescents; Summary of findings 4 Preparation/information compared to control for needle-related procedural pain and distress in children and adolescents; Summary of findings $\mathbf{5}$ Breathing compared to control for needle-related procedural pain and distress in children and adolescents; Summary of findings 6 Suggestion compared to control for needle-related procedural pain and distress in children and adolescents; Summary of findings 7 Memory alteration compared to control for needlerelated procedural pain and distress in children and adolescents

\section{Distraction}

Thirty-two studies assessed the efficacy of distraction for reducing children's needle-related pain and distress, of which four studies evaluated two types of distraction each (Aydin 2017; Bellieni 2006; Miller 2016; Sahiner 2016). Distraction interventions were varied and included watching cartoons or a movie $(n=9)$ (Bellieni 2006; Cassidy 2002; Cohen 2015; Luthy 2013; Miguez-Navarro 2016 Oliveira 2017; Sahiner 2016; Tak 2006; Wang 2008), listening to music or a spoken story $(\mathrm{n}=8$ ) (Aydin 2017; Balan 2009; Caprilli 2007; Fowler-Kerry 1987; Kristjansdottir 2010; Nguyen 2010; Noguchi 2006; Press 2003), interactive handheld computer or video games $(n=3)$ (Crevatin 2016; Miller 2016; Minute 2012), distraction cards ( $=3$ ) (Aydin 2017; Inal 2012; Sahiner 2016), virtual reality $(\mathrm{n}=2)$ (Gold 2006; Sander Wint 2002), playing with a toy $(n=2)$ (Vessey 1994; Vosoghi 2010), parent distraction $(n=2)$ (Bellieni 2006; Gonzalez 1993), medical clown $(n=1)$ (Meiri 2016), squeezing a rubber ball $(n=1)$ (Gupta 2006), or a combination or selection of various distractors such as toys, books, cartoons, games, or music $(n=5)$ (Aydin 2017; Fanurik 2000; Jeffs 2007; Kuttner 1987; Sinha 2006).

Of these 32 studies assessing distraction, needle procedures included venipuncture or blood draws only $(n=14)$ (Aydin 2017; Balan 2009; Bellieni 2006; Caprilli 2007; Crevatin 2016; Gupta 2006; Inal 2012; Miguez-Navarro 2016; Oliveira 2017; Press 2003; Sahiner 2016; Tak 2006; Vessey 1994; Wang 2008), immunization or injection ( $n=7$ ) (Cassidy 2002; Cohen 2015; Fowler-Kerry 1987; Gonzalez 1993; Luthy 2013; Kristjansdottir 2010; Noguchi 2006), intravenous insertion $(n=4)$ (Fanurik 2000; Gold 2006; Miller 2016; Vosoghi 2010), intravenous cannulation or venipuncture $(n=2)$ (Meiri 2016; Minute 2012), lumbar puncture $(n=2)$ (Nguyen 2010; Sander Wint 2002), laceration repair $(n=1)$ (Sinha 2006), allergy testing involving injection $(n=1)$ (Jeffs 2007), and bone marrow aspiration ( $n=$ 1) (Kuttner 1987). Across the 32 studies, distraction efficacy was assessed in two- to 19-year-olds. Twenty-three studies included children 12 years old or younger, of which seven studies exclusively included children aged seven or younger (Cassidy 2002; Cohen 2015; Fowler-Kerry 1987; Gonzalez 1993; Kuttner 1987; Noguchi 2006; Vosoghi 2010). Seven more studies included samples ranging from early childhood to late adolescence (up to 19 years old) (Caprilli 2007; Crevatin 2016; Fanurik 2000; Jeffs 2007; Press 2003; Sinha 2006; Sander Wint 2002). Only one study exclusively included adolescents (Kristjansdottir 2010). 
Thirty studies including 2802 participants (intervention group = 1509) revealed a moderate effect of distraction for self-reported pain: standardized mean difference (SMD) $-0.56,95 \%$ confidence interval $(\mathrm{Cl})-0.78$ to $-0.33, \mathrm{Z}=4.83, \mathrm{P}<0.001, \mathrm{I}^{2}=87 \%$ (Analysis 1.1 ; Figure 4). We found a large effect of distraction relative to control groups in meta-analysis of four studies including 426 participants (intervention group $=214$ ) for self-reported distress: SMD -0.82 , $95 \% \mathrm{Cl}-1.45$ to $-0.18, \mathrm{Z}=2.52, \mathrm{P}=0.01, \mathrm{I}^{2}=89 \%$ (Analysis 1.2 ). We also found a moderate effect of distraction in meta-analysis of 11 studies including 1512 participants (intervention group = 921) for observer-reported pain: SMD $-0.62,95 \% \mathrm{Cl}-1.00$ to $-0.23, \mathrm{Z}=$ $3.14, P=0.002,1^{2}=91 \%$ (Analysis 1.3 ), and a moderate-to-large effect in meta-analysis of five studies including 1067 participants (intervention group $=635$ ) for observer-reported distress: SMD $-0.72,95 \% \mathrm{Cl}-1.41$ to $-0.03, \mathrm{Z}=2.05, \mathrm{P}=0.04, \mathrm{I}^{2}=96 \%$ (Analysis 1.4). Analyses reported no evidence of effect for distraction relative to control groups for behavioral pain in four studies including
309 participants (intervention group $=164$ ): SMD $-0.33,95 \% \mathrm{Cl}$ -0.69 to $0.03, Z=1.80, P=0.07, I^{2}=57 \%$ (Analysis 1.5 ). Analyses revealed a moderate effect of distraction for behavioral distress in seven studies including 500 participants (intervention group $=261)$ : SMD $-0.44,95 \% \mathrm{Cl}-0.84$ to $-0.04, \mathrm{Z}=2.16, \mathrm{P}=0.03$, $\mathrm{I}^{2}=75 \%$ (Analysis 1.6), and for the physiological measure of heart rate in three studies including 252 participants (intervention group $=126)$ : SMD $-0.64,95 \% \mathrm{Cl}-0.89$ to $-0.38, \mathrm{Z}=4.93, \mathrm{P}<$ $0.001,1^{2}=0 \%$ (Analysis 1.7). Analysis of two studies including 112 participants (intervention group $=56$ ) revealed a moderate effect of lowered oxygen saturation in control groups relative to distraction: SMD $0.60,95 \% \mathrm{Cl} 0.22$ to $0.98, \mathrm{Z}=3.10, \mathrm{P}=0.002, \mathrm{I}^{2}$ $=0 \%$ (Analysis 1.8). Only one study (Nguyen 2010) assessed the efficacy of distraction for physiological outcomes (i.e. respiratory rate, systolic and diastolic blood pressure); we can therefore draw no conclusions about its efficacy for these outcomes. Sample size, means, and SDs for these outcomes are available in Table 2. No adverse events were reported.

Figure 4. Forest plot of comparison: 1 Distraction, outcome: 1.1 Self-reported pain.

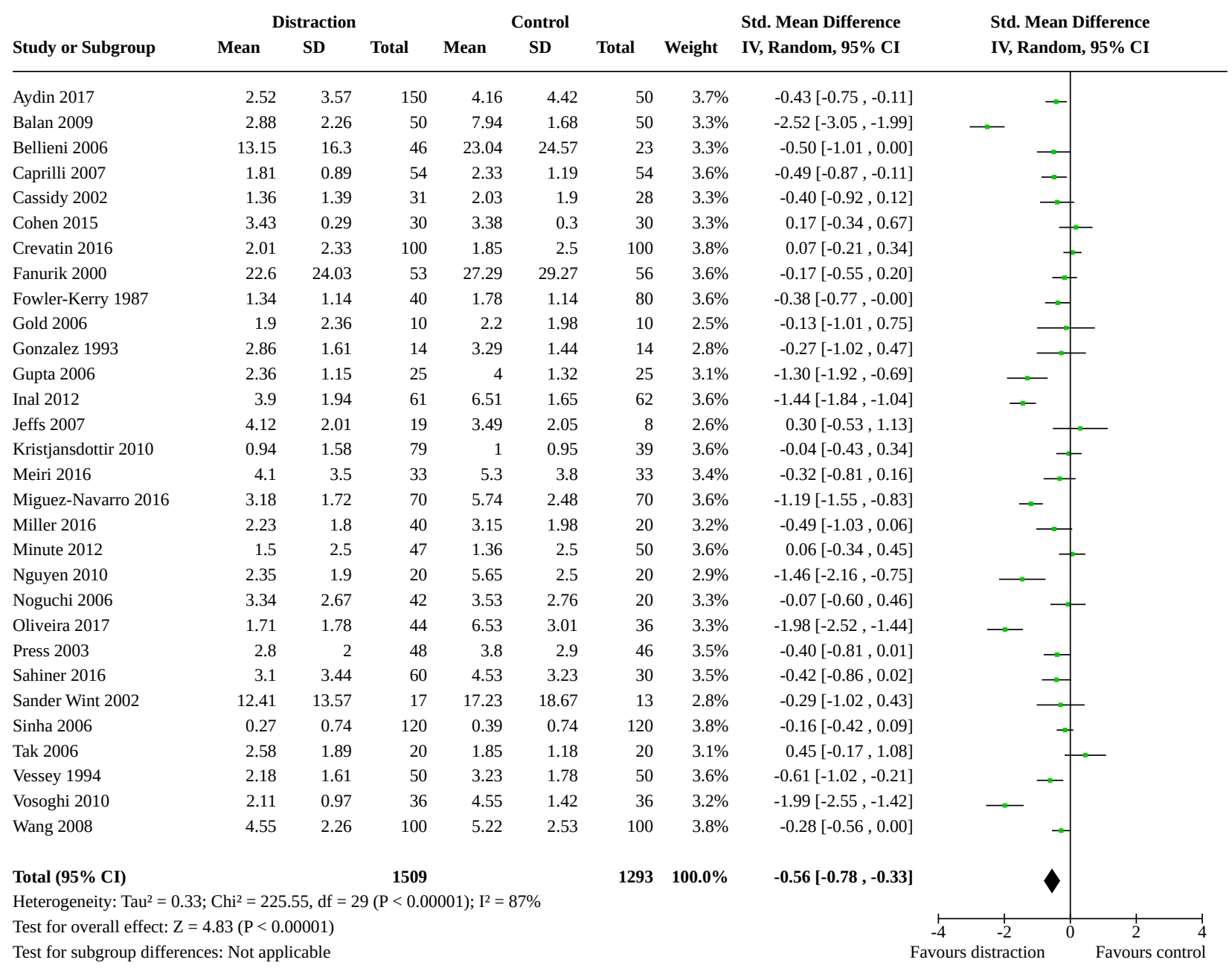

\section{Quality of Evidence}

The quality of evidence was low for self-reported pain and behavioral measures of pain; further research is therefore likely to have an important impact on our confidence in the estimate of these effects, and is likely to change the estimates for these outcomes. The quality of evidence was very low for all other outcomes, including self-reported distress, observer-reported pain and distress, and behavioral measures of distress. Given this, we 
are very uncertain of the estimates of effects for these outcomes. See Summary of findings 1. Primary reasons for downgrading the quality of the evidence were serious study limitations (most trials had unclear or high risk of bias), inconsistency (analyses demonstrated moderate to considerable heterogeneity), and imprecision of results due to small numbers of participants.

\section{Combined CBT}

Eighteen studies assessed the efficacy of combined cognitive behavioral interventions for reducing children's needle-related pain and distress. The interventions involved different combinations of two or more cognitive and behavioral strategies, including distraction, preparation/information, modeling and rehearsal, breathing, suggestion, relaxation, guided imagery, positive coping statements, cognitive restructuring, positioning, and parent coaching. Interventions were delivered to the child by a music therapist, a medical clown, humanoid robot, electronic device, parent, or healthcare provider. Needle procedures included immunization ( $n=6$ ) (Beran 2013; Blount 1992; Cohen 2015; FowlerKerry 1987; Nilsson 2015; Yinger 2016), intravenous insertion ( = 5) (Bisignano 2006; Kleiber 2001; McCarthy 2010; Miller 2016; Tyc 1997), venipuncture $(n=3)$ (Rimon 2016 Wang 2008; WindichBiermeier 2007), intravenous insertion or venipuncture $(n=1)$ (Cavender 2004), bone marrow aspiration $(n=1)$ (Liossi 1999), insulin injection ( $n=1$ ) (Ebrahimpour 2015), or local dental anesthetic injection $(n=1)$ (Kamath 2013). Across the 18 studies, combined cognitive behavioral strategies were assessed in threeto 18 -year-olds. Fourteen studies included children aged 12 or younger, of which five studies exclusively included children aged seven or younger (Blount 1992; Cohen 2015; Fowler-Kerry 1987; Kleiber 2001; Yinger 2016). Four more studies included participants ranging from early childhood to late adolescence (up to 18 years old) (Liossi 1999; Rimon 2016; Tyc 1997; Windich-Biermeier 2007).

Analysis of 14 studies examining combined cognitive-behavioral strategies with 1359 participants (intervention group $=633$ ) revealed no evidence of an effect for self-reported pain: SMD-0.27, $95 \% \mathrm{Cl}-0.58$ to $0.03, \mathrm{Z}=1.74, \mathrm{P}=0.08, \mathrm{I}^{2}=83 \%$ (Analysis 2.1; Figure 5). Six studies examining combined cognitive-behavioral strategies for self-reported distress with 234 participants (intervention group $=110$ ) also showed no evidence of an effect: SMD $-0.26,95 \% \mathrm{Cl}$ -0.56 to $0.04, Z=1.69, P=0.09,12=24 \%$ (Analysis 2.2). A moderate effect of combined cognitive-behavioral strategies compared to control groups was shown for reduced observer-reported pain across four studies including 385 participants (intervention group $=191) \mathrm{SMD}-0.52,95 \% \mathrm{Cl}-0.73$ to $-0.30, \mathrm{Z}=4.68, \mathrm{P}<0.001, \mathrm{I}^{2}=8 \%$ (Analysis 2.3), but no effect was shown across six studies including 765 participants (intervention group $=358$ ) examining observerreported distress: SMD $0.08,95 \% \mathrm{Cl}-0.34$ to $0.50, \mathrm{Z}=0.39, \mathrm{P}=$ $0.70,12=78 \%$ (Analysis 2.4). Analysis of two studies including 95 participants (intervention group $=47$ ) showed no evidence of an effect for behavioral pain: SMD $-0.65,95 \% \mathrm{Cl}-2.36$ to $1.06, \mathrm{Z}=0.74$, $P=0.46, I^{2}=94 \%$ (Analysis 2.5); however, analysis of 11 studies including 1105 participants (intervention group $=529$ ) revealed a moderate effect of combined cognitive-behavioral strategies for behavioral distress: SMD $-0.40,95 \% \mathrm{Cl}-0.67$ to $-0.14, \mathrm{Z}=3.00, \mathrm{P}$ $=0.003,1^{2}=70 \%$ (Analysis 2.6). Analysis of three studies including 310 participants examining the physiological outcome of cortisol (intervention group $=150$ ) showed no evidence of an effect: SMD $-1.16,95 \mathrm{Cl}-3.37$ to $1.06, \mathrm{Z}=1.02, \mathrm{P}=0.31, \mathrm{I}^{2}=98 \%$ (Analysis 2.7). No adverse events were reported.

Figure 5. Forest plot of comparison: 2 CBT-combined, outcome: 2.1 Self-reported pain.

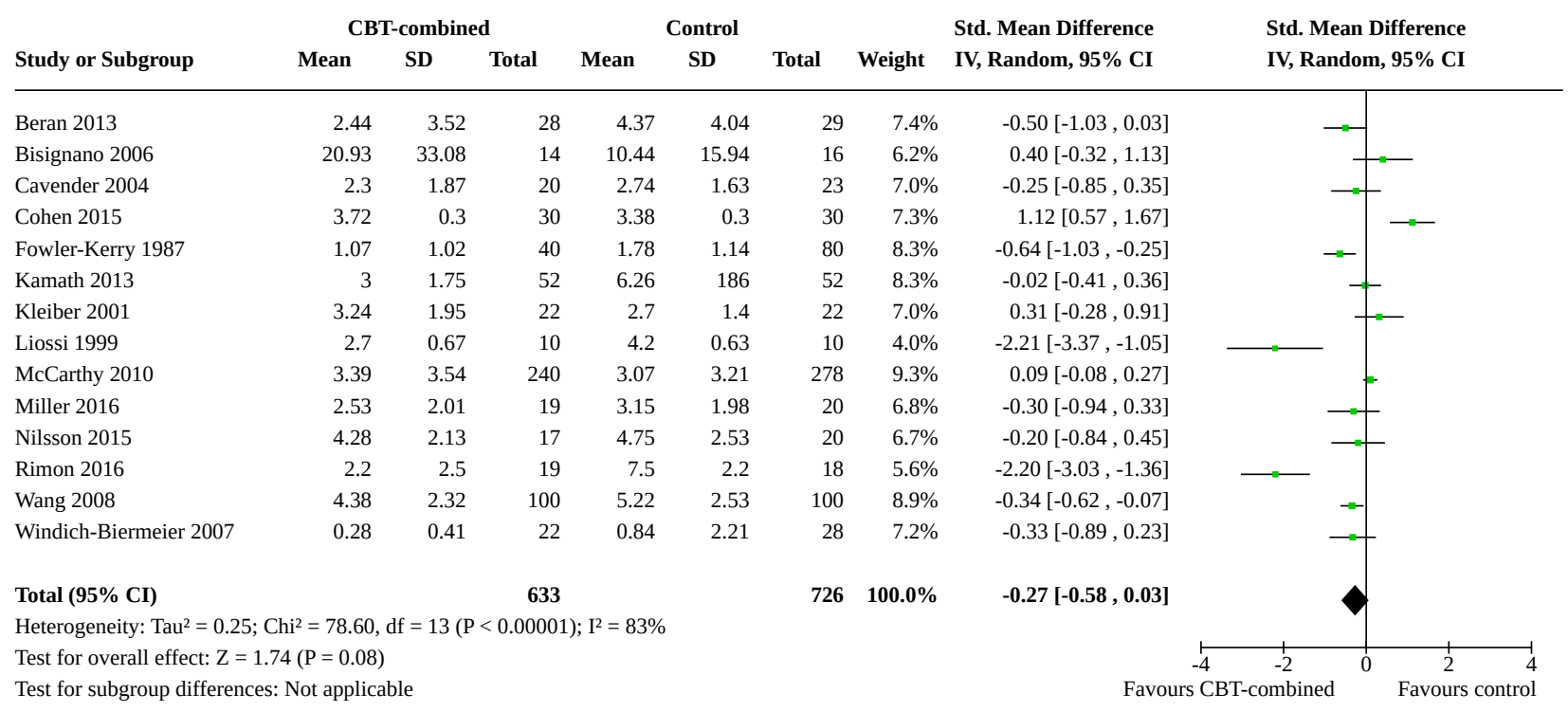

\section{Quality of Evidence}

The quality of evidence was low for outcomes of self-reported pain and distress, observer-reported pain and distress, and behavioral measures of distress. Further research is likely to have an important impact on our confidence in the estimate of these effects and is likely to change the estimates for these four outcomes. The quality of evidence was very low for behavioral measures of pain. We are therefore very uncertain of the estimate of effects for this outcome. See Summary of findings 2. Primary reasons for downgrading the quality of the evidence were serious study limitations (most trials had unclear or high risk of bias), inconsistency (analyses 
demonstrated moderate heterogeneity), and imprecision of results due to small numbers of participants.

\section{Hypnosis}

Eight studies assessed the efficacy of hypnosis interventions for reducing children's needle-related pain and distress. Interventions included both direct (i.e. analgesic) and indirect hypnotic suggestion, led by a therapist or taught to the child (i.e. selfhypnosis). Needle procedures included bone marrow aspirations ( $\mathrm{n}$ = 3) (Katz 1987; Kuttner 1987; Liossi 1999), lumbar puncture $(n=2)$ (Liossi 2003; Liossi 2006), local dental anesthetic injections $(n=2)$ (Huet 2011; Ramírez-Carrasco 2017), or venipuncture $(n=1)$ (Liossi 2009). Across studies, hypnosis was assessed in two- to 16 yearolds.

Five studies including 176 participants (intervention group $=97$ ) revealed a large effect of hypnosis for self-reported pain: SMD
$-1.40,95 \% \mathrm{Cl}-2.32$ to $-0.48, Z=2.97, P=0.003,12=85 \%$ (Analysis 3.1; Figure 6), and self-reported distress: SMD -2.53, 95\% $\mathrm{Cl}-3.93$ to $-1.12, \mathrm{Z}=3.53, \mathrm{P}<0.001, \mathrm{I}^{2}=91 \%$ (Analysis 3.2). Two studies including 69 participants (intervention group $=34$ ) were not significant for behavioral pain: SMD $-0.38,95 \% \mathrm{Cl}-1.57$ to 0.81 , Z $=0.62, \mathrm{P}=0.53, \mathrm{I}^{2}=83 \%$ (Analysis 3.3). Six studies including 193 participants (intervention group $=106$ ) revealed a large effect of hypnosis for behavioral distress: SMD $-1.15,95 \% \mathrm{Cl}-1.76$ to -0.53 , $Z=3.66, P<0.001, I^{2}=71 \%$ (Analysis 3.4 ). Single trials only reported the effects of hypnosis for observer-reported distress (Katz 1987) and physiological outcomes of skin conductance and heart rate variability (Ramírez-Carrasco 2017). Sample size, means, and SDs for these outcomes are available in Table 2. No adverse events were reported.

Figure 6. Forest plot of comparison: 3 Hypnosis, outcome: 3.1 Self-reported pain.

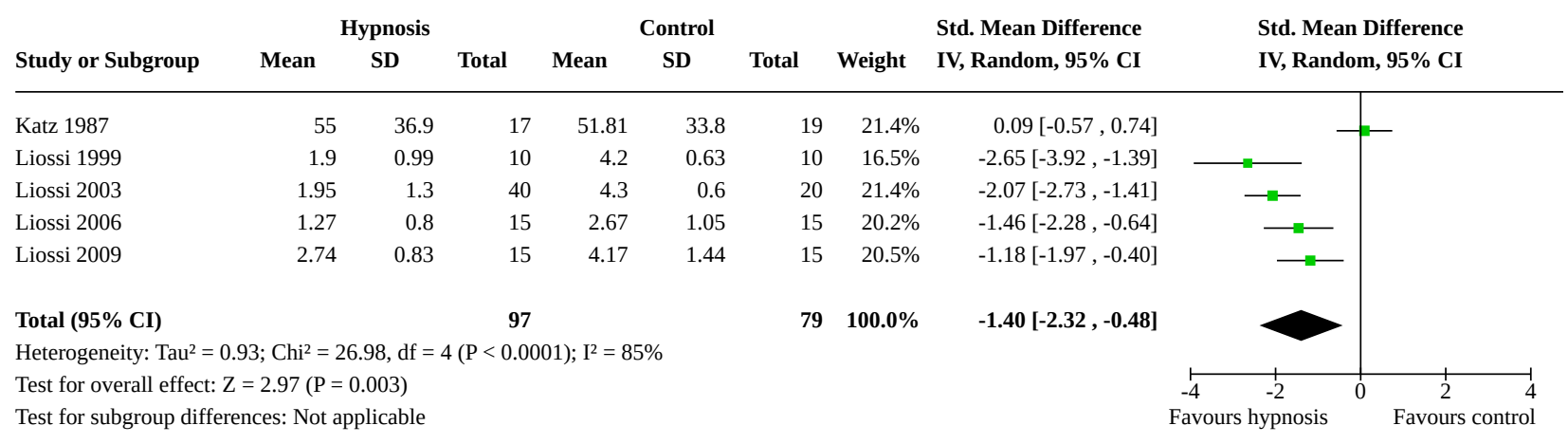

\section{Quality of Evidence}

The quality of evidence was very low for all meta-analyzed outcomes, including self-reported pain, self-reported distress, and behavioral measures of pain and distress. We are therefore very uncertain of the estimate of effects for these outcomes. See Summary of findings 3. Primary reasons for downgrading the quality of the evidence were serious study limitations (most trials had unclear or high risk of bias), inconsistency (analyses demonstrated moderate to considerable heterogeneity), imprecision of results due to small numbers of participants, and the possibility of publication bias with most studies from one expert group.

\section{Preparation and information}

Four studies assessed the efficacy of preparation/information interventions for reducing children's needle-related pain and distress. Preparatory information was provided through picture/ photo storybook before venipuncture (Harrison 1991; Tak 2006;
Zieger 2013) or through an interactive handheld electronic device before an intravenous cannulation (Miller 2016). All studies included children under 12 years old.

Analysis of four studies examining the effects of preparation/ information for self-reported pain including 313 participants (intervention group $=155$ ) showed no evidence of an effect: SMD $-0.18,95 \% \mathrm{Cl}-0.60$ to $0.23, \mathrm{Z}=0.86, \mathrm{P}=0.39, \mathrm{I}=68 \%$ (Analysis 4.1; Figure 7). Similarly, three studies examining observer-reported pain including 259 participants (intervention group $=129$ ) showed no evidence of an effect of preparation/information compared to control groups: SMD $-0.40,95 \% \mathrm{Cl}-0.98$ to $0.18, \mathrm{Z}=1.35, \mathrm{P}$ $=0.18,1^{2}=80 \%$ (Analysis 4.2). Due to the availability of single trials only, we could reach no conclusions about the efficacy of preparation/information for observer-reported distress (Harrison 1991), behavioral pain (Miller 2016), behavioral distress (Tak 2006), or physiological outcomes (pulse rate; Harrison 1991). No adverse events were reported. 
Figure 7. Forest plot of comparison: 4 Preparation/Information, outcome: 4.1 Self-reported pain.

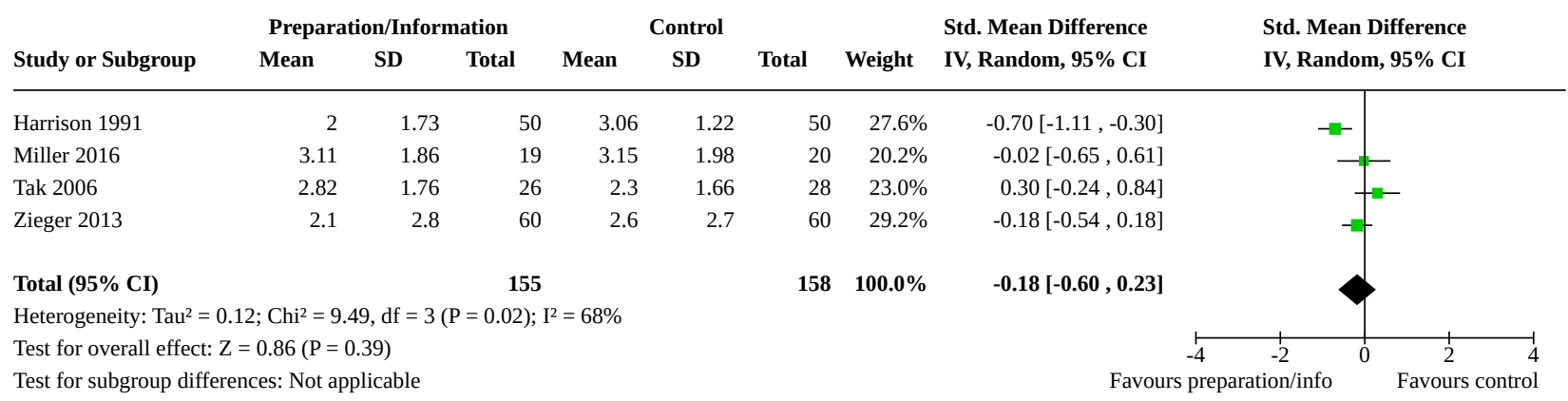

\section{Quality of Evidence}

The quality of evidence was very low for all meta-analyzed outcomes, including self-reported and observer-reported pain. We are therefore very uncertain about the estimate of effects for these outcomes. See Summary of findings 4 . Primary reasons for downgrading the quality of the evidence were serious study limitations (most trials had unclear or high risk of bias), inconsistency (analyses demonstrated moderate heterogeneity), and imprecision of results due to small numbers of participants.

\section{Breathing}

Four studies assessed the efficacy of breathing interventions for reducing children's needle-related pain and distress. Interventions included asking children to inflate a balloon during venipunctures
( $n=3$ ) (Gupta 2006; Mutlu 2015a; Sahiner 2016) and deep breathing during lumbar puncture $(n=1)$ (Pourmovahed 2013). These studies included children aged from six to 15 years.

Four studies including 298 participants (intervention group = 149) revealed a large effect of breathing interventions for self-reported pain: SMD $-1.04,95 \% \mathrm{Cl}-1.86$ to $-0.22, \mathrm{Z}=2.48, \mathrm{P}=0.01, \mathrm{I}^{2}=$ $90 \%$ (Analysis 5.1; Figure 8). Only one study assessed the effects of breathing for observer-reported pain and distress (Sahiner 2016); we could therefore draw no conclusions about treatment efficacy for these outcomes. Sample size, means, and SDs for these outcomes are available in Table 2. Adverse events were reported in one study (Pourmovahed 2013), where three children discontinued a deep-breathing intervention due to respiratory difficulties.

Figure 8. Forest plot of comparison: 5 Breathing, outcome: 5.1 Self-reported pain.

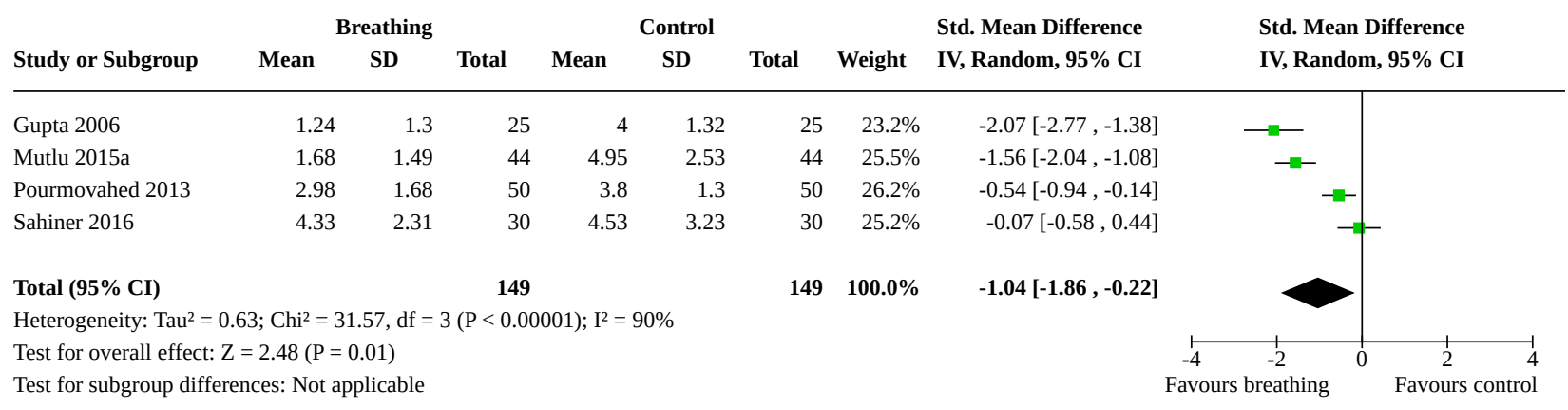

\section{Quality of Evidence}

The quality of evidence was very low for the one meta-analyzed outcome of self-reported pain. We are very uncertain of the estimate of effects for this outcome. See Summary of findings 5. Primary reasons for downgrading the quality of the evidence were serious study limitations (most trials had unclear or high risk of bias), inconsistency (analyses demonstrated considerable heterogeneity), and imprecision of results due to small numbers of participants.

\section{Suggestion}

No new studies of suggestion were identified since the previous review update (Uman 2013); there is therefore no change in results for suggestion interventions for reducing children's needlerelated pain and distress. Three studies assessed the efficacy of

suggestion. Interventions included positive suggestions to the child that something was being done to make the needle easier or less painful. Studies were conducted mostly with children aged under seven during intramuscular injection (Eland 1981) or immunization (Fowler-Kerry 1987). One study included three- to 17-year-olds undergoing venipunctures (Goodenough 1997).

Analysis of three studies showed no effect of suggestion for selfreported pain including 218 participants (intervention group $=89$ ): SMD $-0.13,95 \% \mathrm{Cl}-0.40$ to $0.15, \mathrm{Z}=0.90, \mathrm{P}=0.37, \mathrm{I}=0 \%$ (Analysis 6.1; Figure 9). Only one study assessed the effects of suggestion for observer-reported pain and self-reported distress (Goodenough 1997), and only one study for observer-reported distress (Eland 1981); we are therefore unable to draw any conclusions about treatment efficacy for these outcomes. Sample size, means, and 
SDs for these outcomes are available in Table 2. No adverse events were reported.

Figure 9. Forest plot of comparison: 6 Suggestion, outcome: 6.1 Self-reported pain.

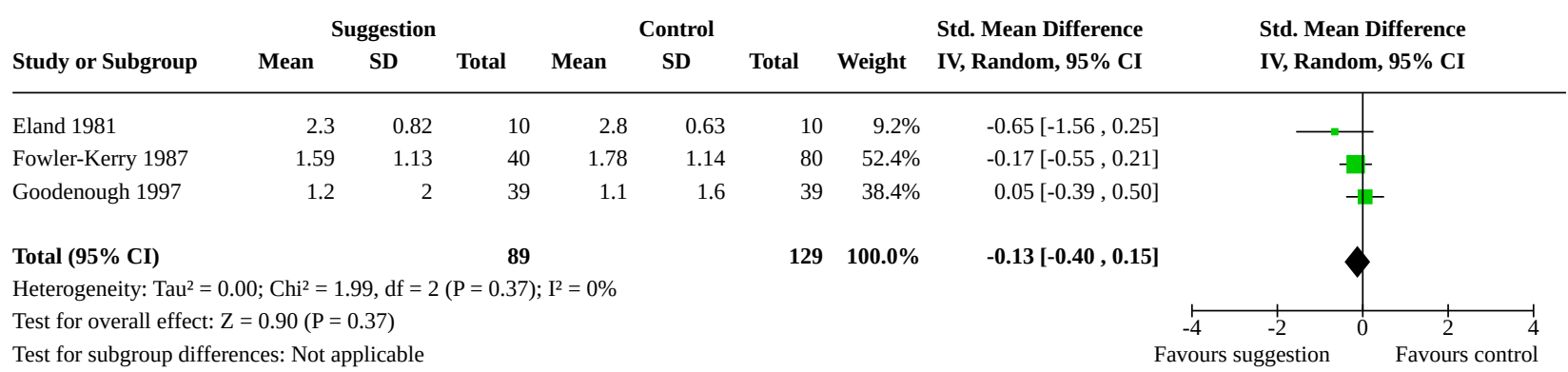

\section{Quality of Evidence}

The quality of evidence was very low for the one meta-analyzed outcome of self-reported pain. We are very uncertain of the estimate of effects for this outcome. See Summary of findings 6. Primary reasons for downgrading the quality of the evidence were serious study limitations (most trials had unclear or high risk of bias) and imprecision of results due to small numbers of participants.

\section{Memory alteration}

No new studies were identified since the previous review update (Uman 2013); there is therefore no change in results for memory alteration interventions. Only one study assessed the effects of memory alteration in children aged three to 18 , undergoing lumbar punctures (Chen 1999). This study included outcomes of selfand observer-reported pain, observer-reported and behavioral distress, and physiological measures (heart rate, cortisol, systolic and diastolic blood pressure). Given only this single study, we can draw no conclusions about treatment efficacy. Sample size, means, and SDs for these outcomes are available in Table 2. No adverse events were reported.

\section{Quality of Evidence}

Given this single study, we drew no conclusions about the quality of evidence in this area. See Summary of findings 7.

\section{DISCUSSION}

\section{Summary of main results}

This review synthesizes the results of 59 RCTs; 39 identified from previous versions of this review (Uman 2006; Uman 2013) and an additional 20 identified for this second review update. By including only truly randomized controlled trials published in peer-reviewed journals, we offer a rigorous systematic examination of the efficacy of psychological interventions for reducing needle-related pain and distress in children and adolescents. Consistent with our first update (Uman 2013), results from this update continue to demonstrate the efficacy of distraction for pain and hypnosis for pain and distress based on very low to low-quality evidence; however, very low-quality evidence now also demonstrates the efficacy of distraction for distress outcomes. Other interventions now identified as efficacious for at least one primary outcome include combined CBT for pain and distress, and breathing for pain.
No evidence was available to support the efficacy of preparation and information or suggestion interventions for reducing children's pain and distress. Furthermore, we could draw no conclusions about the efficacy of memory alteration, as only a single trial addressed this intervention. No new trials have assessed the efficacy of suggestion or memory alteration since our first review update (Uman 2013).

Trials support the use of a variety of distraction interventions for reducing self-reported pain and distress, observer-reported pain and distress, behavioral measures of distress, and heart rate. This second review update now offers evidence supporting the efficacy of distraction for all distress outcomes. The efficacy of distraction for distress outcomes was not demonstrated in our first update (Uman 2013). This change toward supportive evidence underscores the very low GRADE quality of evidence ratings for these outcomes. Very low ratings reflect very little confidence in these effect estimates, suggesting that subsequent research may contribute to different findings. As we stated in our previous update, we continue to note significant variability in the distraction methods used across the included trials. A growing number of trials included head-to-head comparisons of distraction interventions (Aydin 2017; Bellieni 2006 Miller 2016; Sahiner 2016), although it remains unclear whether the type of distraction influences its efficacy across child development, or with different needle procedures. Nevertheless, data are available to support the efficacy of distraction interventions from studies including children from two to 19 years old in a wide variety of settings and needle procedures.

Trials continue to support the use of hypnosis for the reduction of self-reported pain, as well as self-reported and behavioral measures of distress. We found only one new trial of hypnosis for inclusion since our first update (Ramírez-Carrasco 2017), enabling additional meta-analysis of behavioral measures of pain that did not find a significant effect of hypnosis for this outcome. No new trials contributed to any other primary outcomes. Comments we made about hypnosis in our previous update continue to be relevant (Uman 2013). Specifically, although hypnosis continues to demonstrate the largest effect sizes for reducing pain and distress during needle-related procedures, most of these trials are published by a single research group, predominantly in children with cancer. This raises some concern about generalizability to other contexts, populations, and healthcare providers. Furthermore, higher hypnotizability appears to be 
related to greater treatment benefit (Liossi 2003), suggesting that hypnosis may not be equally effective for all children. The only two studies assessing hypnosis for behavioral measures of pain, and not demonstrating an effect, were local dental anesthetic injections in otherwise generally healthy children. We restate the need for additional research assessing the efficacy of hypnosis administered by different providers in different pediatric settings. Rigorous assessment of hypnosis interventions delivered remotely by a smartphone applications would be particularly valuable (Sucala 2013).

Low-quality evidence supports the efficacy of combined CBT interventions for reductions in observer reports of child pain and behavioral measures of child distress. Combined CBT was identified as efficacious in our original review in this area (Uman 2006), but not in our most recent update (Uman 2013). This may have been due to our removal of less rigorously designed studies at that time. It is worth noting that no evidence was available to support the efficacy of combined CBT for children's self-reported pain and distress. This is relevant, given the inherently subjective nature of children's pain experience (IASP 2004), and the many factors contributing bias to the rating of children's pain and distress by others, such as their parents or nurses (Craig 2010). Given this, children's self-reported outcomes have previously been prioritized in the development of clinical practice guidelines for the management of immunization pain and distress (Taddio 2015).

Since our first update (Uman 2013), a number of new trials contribute very low-quality evidence for the efficacy of breathing interventions for reducing children's self-reported pain during needle procedures. We could draw no conclusions about other primary pain or distress outcomes, due to an insufficient number of trials assessing those outcomes. Notably, this was the only type of intervention in this review to report adverse events, in which three of 50 children reported respiratory difficulties when asked to engage in a specialized form of deep breathing (Pourmovahed 2013). It may therefore be prudent to weigh the potential benefits against possible harms of this type of intervention, based on the medical status of each child.

When comparing the findings from this update to those of our first update (Uman 2013), it is important to reiterate changes to the categorization of psychological interventions. As described earlier in this review (How the intervention might work), we grouped the interventions according to key theorized mechanisms of treatment effect, to reflect contemporary thinking in the field (Accardi 2009; Birnie 2017; Jafari 2017; Noel 2018). Several intervention categories that we separately identified in our first update were subsumed under broader intervention categories for this second update (e.g. virtual reality as distraction; parent coaching and child distraction as combined (BT). An additional benefit of this focus on treatment mechanisms was to allow for more meaningful meta-analyses, while reducing the number of intervention categories from which we could draw no conclusions because of too few trials. Specifically, we could draw no conclusions in our first update about parent positioning plus distraction or about distraction plus suggestion interventions, because of single RCTs (Uman 2013). These are now subsumed under combined CBT interventions, as they include both cognitive and behavioral strategies. Inclusion of these additional studies within the combined CBT category does not account for new findings supporting its efficacy for observer-reported pain and behavioral measures of distress. Only new studies published since the first update contributed findings to the meta-analysis for observer-reported pain. Furthermore, findings for behavioral measures of distress remained significant when studies from these previously separate intervention categories were removed from the meta-analysis. Findings for distraction did not change, even with the inclusion of virtual-reality interventions.

\section{Overall completeness and applicability of evidence}

The evidence presented in this review is directly relevant to the efficacy of psychological interventions for needle-related procedural pain and distress in children and adolescents. Included trials reported on a variety of psychological interventions for an array of needle procedures, settings, children's ages, and medical diagnoses. Findings from this review are therefore directly applicable to the clinical context and populations in whom they are studied.

We note that many interventions have much less or limited outcome data beyond self-report of pain. Distraction and combined CBT are the only interventions for which we could meta-analyze all six primary pain and distress outcomes; self-report of pain was the only outcome that we could meta-analyze for breathing and suggestion. Of the 59 studies in this review, only 35 (59\%) include at least one outcome of distress (self-report, observer report, or behavioral measure). As well as pain, assessment of emotional response, such as negative affect or distress, is a recommended core outcome in pediatric acute pain clinical trials (PedIMMPACT; McGrath 2008). The evidence therefore speaks most directly to experienced or observed pain intensity and, to a lesser extent, to procedure-related distress. This is notable, as needle-related distress is associated with a decreased efficacy of psychological interventions typically helpful for reducing pain, as well as increases in fear behaviors that interfere with completion of medical procedures (e.g. flailing, attempts to escape) or avoidance of medical procedures altogether (McMurtry 2015a). As we have described in our previous update, outcomes beyond child pain and distress may be relevant and may influence treatment efficacy. Examples include child preference or choice of intervention (Birnie 2014a), child pain-related fear (Birnie 2017; Verhoeven 2012), parent distress and parent behaviors (Campbell 2017; Dahlquist 2005).

This review included trials of children aged between two and 19. Most of the evidence is available for children aged 12 or younger, with 34 of 59 trials (58\%) focused exclusively on this age group. While several trials (24 of 59; $41 \%$ ) included samples crossing early childhood to late adolescence, only one trial focused exclusively on adolescents (Kristjansdottir 2010). Furthermore, this trial reported a significant effect of music distraction without headphones, but not with headphones, for adolescents' self-report of pain, compared with standard care. The direct applicability of the evidence reviewed here to adolescents is therefore more limited, compared with needle procedures in younger children. Considerations of differences in coping tendencies and preferences across normative development during childhood and adolescence may be relevant (Skinner 2007). It is worth noting that the evidence of psychological interventions for adults undergoing needle procedures is based on a small number of studies with mixed findings. Specifically, meta-analysis supports the efficacy of breathing interventions for pain in adults, but not for music or visual distraction (Boerner 2015). 
Although included trials assessed the efficacy of psychological interventions for needle procedures in a variety of hospital and community settings, there are a few settings for which there is less evidence. Only two studies were conducted within the context of school-based immunization clinics; one study assessed music distraction in 14-year-olds as already noted above (Kristjansdottir 2010), and a second study assessed a combined CBT intervention of relaxation and guided imagery in 11- to 12 -year-olds (Nilsson 2015). This environment is distinct from other settings in which children undergo needle procedures, with additional potential barriers to implementation of psychological interventions. For example, additional factors may include the absence of parents, the presence of teachers or peers or both, possible observational learning of fear (i.e. 'fear contagion'), and limited education about pain management by public health immunizers (Boerner 2014). Schoolbased immunization programs are a promising strategy promoted by the World Health Organization for offering equitable benefits of immunization to all children, thereby reducing the prevalence of infectious diseases worldwide (WHO 2017). This review identifies gaps in the availability of direct evidence to inform implementation and efficacy of psychological interventions for such programs.

Included RCTs assessed the efficacy of psychological interventions for an array of needle procedures, predominantly venipuncture or blood draws, immunizations, and intravenous insertions. These seem to reflect the most common needle procedures experienced by hospitalized children (Stevens 2011) or generally healthy children (with respect to immunizations only) (CDC 2018; NACI 2018; WHO 2018). This review also includes other needle procedures experienced less frequently in hospital, outpatient, and community settings, such as lumbar punctures, intramuscular injections, and injections for local dental anesthetic and insulin.

Over half of the included trials (32 of 59) examined the efficacy of distraction. There remains a clear need for more research examining the efficacy of other types of psychological interventions in RCTs, particularly interventions for which there is limited evidence (e.g. breathing, memory alteration). Despite this, the array of cognitive and behavioral psychological strategies reflected in the included trials is vast. While this review provides valuable knowledge supporting the use of psychological interventions, studies investigating the use of pain management strategies for needle procedures suggest that such interventions are highly underused in clinical practice (Birnie 2014b; Stevens 2011). Furthermore, most studies in this review with 'standard care' control groups did not include any psychological pain management strategies, and in many cases did not include any specific pain management strategies whatsoever. Clinical practice guidelines for the management of immunization pain and distress across the lifespan promote a multimodal approach, with recommendations to integrate pharmacological, physiological, procedural, and psychological strategies for optimal pain management (Taddio 2015). While it is recognized that current practice may vary internationally and is, in part, impacted by the cost and availability of interventions, the use of low-cost and effective psychological interventions for needle procedures in children is supported by this review.

\section{Quality of the evidence}

To our knowledge, this review represents the largest, most rigorous and up-to-date review of psychological interventions for needlerelated pain and distress in children and adolescents. We include
59 peer-reviewed published RCTs, covering 5550 children and adolescents aged two to 19 years old. This can be considered the most comprehensive and well-reported review in the field.

We assessed the quality of the evidence in this review using the GRADE system as applied to continuous outcomes (Guyatt 2013). GRADE considers the quality of evidence pertaining to limitations in the design and implementation, indirectness of evidence, unexplained heterogeneity or inconsistency of results, imprecision of results, and high probability of publication bias. To inform these quality ratings, we also considered ratings from the Cochrane 'Risk of bias' tool for each trial (Higgins 2017). Across all types of psychological interventions and all outcomes, we rated the quality of evidence as very low or low. No interventions or outcomes obtained quality ratings of 'moderate' or 'high', despite the inclusion of only the highest-quality evidence (i.e. RCTs). This suggests that overall we have very little to limited confidence in the reported effect estimates in this review, suggesting that the true effects may be substantially different.

In large part, the quality of evidence was consistently downgraded from high to low or very low due to serious limitations in study design or implementation (as evidenced by the lack of blinding of participants or study personnel or of assessment of study outcomes, poor allocation concealment, and selective reporting), serious concerns with unexplained heterogeneity, or inconsistency of results (as evidenced by moderate to considerable heterogeneity in many meta-analyses), and imprecision (as evidenced by low numbers of participants for several group comparisons). It is important to recognize that it may be difficult, if not impossible, for RCTs of psychological interventions to obtain the highest quality of evidence ratings due to the inherent challenges in blinding of study participants and personnel, and to the assessment of self-report and observer report of child pain or distress. Many psychological interventions are obvious and, by their very nature, preclude the achievement of true blinding. Despite that, the quality of evidence can be improved through better design, implementation, and reporting of trials. In particular, future trials should strive for use of appropriate sequence generation and allocation concealment, provide clear a priori identification of primary and secondary outcomes, include larger sample sizes, and make available registered clinical trial protocols. Exaggerated treatment effects have previously been shown in trials with inadequate or unclear random sequence generation, allocation concealment, or selective reporting (Savovic 2012); however, exploration of such potential bias in RCTs of distraction for needle procedures in children and adolescents has not been replicated (Birnie 2014a).

\section{Potential biases in the review process}

Strengths of this review include comprehensive and updated literature searches, focus on the highest quality of evidence, inclusion of non-English publications, and contacting authors when relevant data were missing from published reports. An identified concern in previous versions (Uman 2006; Uman 2013) was the number of studies excluded for not providing sufficient data in published reports or through correspondence to allow for data pooling in meta-analysis ( $n=24$ trials in the current review). Any associated bias in review findings appears less concerning over time, as we omitted only one study in this second update for not providing necessary data. This improvement may be due to the availability of published guidelines for the reporting of RCTs (Consolidated Standards of Reporting Trials; CONSORT; 
www.consort-statement.org), which recommend that findings for each primary and secondary outcome be reported separately for each study group. Many higher-impact peer-reviewed journals are also requiring published RCTs to follow CONSORT. Nevertheless, to minimize any potential bias, we continue to encourage authors to include all summary statistics (i.e. means, SDs, cell sizes) separately for all groups and for all assessed outcomes, regardless of study results. Specifically, authors should provide all summary statistics even when there are no significant differences between groups. It is possible that some bias is introduced through the exclusion of unpublished trials. This represents a small number of studies overall, and available information suggests their probable exclusion for other reasons. Unpublished dissertation studies were included in our original review (Uman 2006), with no new dissertations excluded in this review update. While we accept that peer review and subsequent publication are not consistent measures of quality, we have standardized the included studies based on the common factor of peer review and publication status. Furthermore, systematic identification of unpublished trials remains difficult at this time, given the general lack of registration of trial protocols. We also encourage journals to publish RCTs with non-significant findings, to minimize this potential bias.

As we identified in our previous update, we combined assessments of reported pain or distress at varying times during or following the needle procedure available in included trials. Specifically, some of the included studies assessed outcomes during the needle procedure while others assessed outcomes following the needle procedure. This may introduce bias, as the timing of assessment of pain and distress varied across trials. Individual studies and reviews have also included assessment of preprocedural anxiety and distress (Birnie 2015), although we excluded those assessments from our review due to the inconsistent timing of psychological intervention delivery. For example, while implementation of some psychological interventions began prior to the needle procedure, this was not consistent across intervention strategies. Not all pre-procedural measures of anxiety or distress would be expected to be influenced by psychological interventions delivered only during and after the needle procedure itself. We have previously recommended that, at minimum, the standard assessment of post-needle pain or distress should be conducted immediately following the procedure (i.e. as soon as the needle is removed). We acknowledge that it is possible that we have introduced potential bias by excluding such studies. Potential bias is also introduced by the pooling of studies with various sources of clinical heterogeneity, such as variability in types of distractors, child age, child diagnosis, and healthcare setting. This is a limitation of psychological interventions that are inevitably more heterogeneous than medication interventions. Previous preliminary work suggests factors such as type of distractor and child age may have some influence on treatment efficacy (Birnie 2014a), and should be considered in future work.

It is possible that bias was introduced through the exclusion of trials in which the effects of particular psychological interventions could not be isolated. Practically, this leads to the exclusion of trials using multimodal interventions or with head-to-head comparisons of differing psychological interventions without a standard-care comparison group. We excluded an increasing number of trials from this second update, as we could not isolate the effects of psychological components from a multicomponent intervention $(n=8)$. Half of these studies included interventions combining vibration with distraction (e.g. Buzzy device or vibrating wand) (Baxter 2011; Benjamin 2016; Moadad 2016; Schreiber 2016). While the intervention was described by several trial authors as distraction, we have chosen to exclude these interventions as the reported mechanisms of treatment effect are varied (likely also physical) and have not been adequately studied. Furthermore, there is clearly a physical component with a physiological mechanism proposed to impact pain processing. To address these concerns, we underscore the need for future research focused on delineating the mechanisms of treatment effect to clearly identify any additional benefit of psychological strategies (e.g. distraction) to a multimodal intervention.

\section{Agreements and disagreements with other studies or reviews}

To our knowledge, this is the most comprehensive review of this topic. However, other systematic reviews in related areas are available, which also support the efficacy of various psychological interventions for pediatric pain management. These include, and are not limited to, systematic reviews of psychological interventions for reducing pain and distress during immunizations in children and adults (Birnie 2015; Boerner 2015; Chambers 2009) and medical procedures in children with cancer (Bukola 2017; Flowers 2015), hypnosis for painful procedures in children and adolescents (Accardi 2009; Richardson 2006), memory alteration interventions for pediatric needle procedures (Noel 2018), as well as music (Klassen 2008) and virtual reality interventions (Kenney 2016) for acute and chronic pain in children and adults.

\section{AUTHORS' CONCLUSIONS}

\section{Implications for practice}

The findings of this review support the efficacy of distraction, hypnosis, combined CBT, and breathing interventions for reducing children's needle-related pain and distress. Despite very lowto low-quality evidence across psychological interventions, the potentially desirable outcomes and value of reduced pain or distress or both provide justification for their use in clinical practice (Andrews 2013a; Andrews 2013b; Higgins 2017).

Clinically, distraction interventions can be used during a variety of routine and more invasive needle procedures across a range of outpatient, inpatient, community, and emergency-care settings. Findings suggest that a variety of distractors are efficacious; thus, the type of distraction intervention (e.g. books, verbal distraction, virtual reality) does not seem to matter. The evidence supports clinicians using distraction interventions as appropriate for their setting, availability, resources, and expertise. These are particularly useful psychological interventions for even lowresourced areas and can be feasibly delivered by any healthcare provider. Although parents could potentially deliver distraction interventions, their efficacy is questionable among parents with higher levels of anxiety (Dahlquist 2005). We also assert that these interventions may not be useful for children with significant needle fears who require more intensive, exposure-based psychological interventions (McMurtry 2016).

Findings also continue to support the use of hypnosis for the management of children's pain and distress during needle procedures. Hypnosis is particularly applicable in the context of more invasive needle-related procedures for children with cancer 
(e.g. bone marrow aspirations, lumbar punctures). Practically speaking, hypnosis requires clinician training for professionals or parents or training in self-hypnosis for children, and probably greater resources (e.g. time) to implement, which may limit the feasibility of these interventions in some clinical settings.

While we found preliminary support for the use of some basic breathing interventions (e.g. balloon inflation, deep breathing), three adverse events were reported in one of these trials, with children discontinuing intervention due to respiratory difficulties (Pourmovahed 2013). Indeed, the appropriateness of each intervention may differ across settings and clinical populations.

Although we found combined CBT interventions to be efficacious in reducing observer-reported pain and behavioral distress, findings did not support the use of combined CBT for other outcomes, most notably self-report. This suggests that increased efforts (time, resources) towards combining elements of CBT in multipronged interventions may not be worthwhile or grounded in evidence. Single-strategy interventions, i.e. hypnosis, distraction, and breathing, were the only interventions found to be efficacious in reducing child self-report of pain in this setting. Providing preparatory information alone or merely suggesting something was being done to reduce pain or distress was not effective for any outcomes.

Although the findings here are drawn from studies including children from two to 19 years old, most studies focused on children aged 12 and younger. It is therefore difficult to ascertain the efficacy of interventions for children of particular ages, particularly adolescents. Overall, the implications for practice described here are most directly applicable to children aged 12 and under.

Research knowledge of the efficacy of psychological interventions to reduce needle pain and distress is of little value unless that knowledge is disseminated and taken up into clinical practice. Researchers, clinicians, policy-makers, parents, and other knowledge users are strongly encouraged to use the evidence reviewed here to inform dissemination and implementation of efficacious psychological strategies to needle procedure and pain management practice. Examples include clinical practice guidelines (Taddio 2015; McMurtry 2016), standards of care (Flowers 2015), institutional policies (ChildKind International; www.childkindinternational.org; Schechter 2008; Schechter 2010a; WHO 2015), and videos and pamphlets targeting healthcare providers and parents (Chambers 2013; www.youtube.com/watch? v=KgBwVSYqfps; Chambers 2016; www.parentscanada.com/ health/expert-advice-to-help-make-vaccinations-easier). It is critical to ensure that research evidence reaches those who need it and will use it.

\section{Implications for research}

\section{General Implications}

Examining psychological interventions to reduce needle-related pain and distress experienced by children and adolescents is a large and very active area of research. For those interventions that are shown to be efficacious, it is time to turn our research attention to ensuring that dissemination of such knowledge is timely, meaningful, and effective. We are referring to the need for empirical evaluation of factors that increase the uptake of intervention strategies into clinical practice, a field known as implementation science (Bauer 2015; Curran 2012; Wittmeier 2015).
This is a critical and worthy research endeavor. Several new studies included in this updated review continue to include standard care for needle procedures with children that exclude evidence-based pain management strategies identified in our original review (Uman 2006). This reflects a lag of more than 11 years to move research evidence into practice, and highlights the need for concerted efforts to reduce this evidence-to-practice gap (Morris 2011).

We continue to assert that future studies comparing distraction interventions to standard care are of little value, given continued support for their efficacy. To advance treatment research in this area, studies should include head-to-head comparisons of different types of distraction interventions (Birnie 2014a). This has seldom been done, with some exception (Aydin 2017; Bellieni 2006; Miller 2016; Sahiner 2016). We also note a clear lack of evidence and need for future trials of interventions that are frequently used in clinical practice, widely accessible, and potentially deliverable through e-health or m-health platforms (e.g. smartphones, tablets). More trials are needed for those interventions covered only by single trials (e.g. memory alteration) and for those where there has been little new evidence in the past several years (e.g. hypnosis). Given the integral role of parents in children's experience of needlerelated pain and fear, and their presence during these procedures, additional trials involving parents are needed.

\section{Design}

At this point in time, strong emphasis should be placed on clinical equipoise when designing clinical trials in this area. Robust evidence exists for the efficacy of particular psychological interventions (distraction, hypnosis) in reducing children's needlerelated distress and pain; there should therefore not be any new trials in which a comparison group receives less than standard care (i.e. some form of evidence-based pain relief, such as topical anesthetic). The use of placebo or no-analgesia control groups has been strongly condemned in clinical trials of analgesic treatments for procedural pain in infants, with calls for ethics committees and journals not to approve or publish such trials (Bellieni 2016). Given the evidence in this review, it is reasonable to apply the same expectations that trials stop implementing no-treatment comparison groups to children and adolescents. Although some trials have moved to including pain management interventions in their standard-care control groups (distraction, Crevatin 2016; topical anesthetics, Miller 2016), we continue to note inconsistencies in this regard across the evidence base.

Researchers should carefully follow the CONSORT guidelines (Moher 2010; www.consort-statement.org) when reporting randomized trials to ensure that details relevant to randomization, allocation, and blinding are adequately addressed. We continue to strongly encourage researchers to draw from available standards and guidelines for designing pediatric trials (StaR Child Health) informing recruitment, consent (Caldwell 2012), sample size estimation (Van der Tweel 2012), minimizing risk of bias (Hartling 2012), considering developmental stage (Williams 2012), and outcome selection, assessment, and reporting (Sinha 2012; PedIMMPACT McGrath 2008; CONSORT, Altman 2001). All trials should be registered (clinicaltrials.gov or www.who.int.trialsearch).

\section{Measurement}

Trial reporting should include all outcomes necessary for metaanalysis (e.g. means, SDs, participant cell sizes). Manuscripts should also clearly report the types and characteristics of all

Psychological interventions for needle-related procedural pain and distress in children and adolescents (Review) 
interventions used in sufficient detail to be understood and replicated by another clinician or researcher (Birnie 2014a). Findings from this second review update suggest that treatment efficacy differs across different outcomes; trials should therefore include a variety of primary outcomes beyond self-report of pain, such as emotional response (e.g. distress, anxiety, fear, unhappiness), satisfaction with treatment, physical recovery, economic factors (e.g. costs), and adverse events and symptoms (PedIMMPACT; McGrath 2008). We suggest that self-report be included among children who can provide valid and reliable selfreport (e.g. children aged four to five years and upwards; Von Baeyer 2017); however, researchers should also strive to include reports of child pain and distress by others (e.g. parents, behavioral scales). We continue to encourage researchers to take all efforts to blind outcomes wherever possible (e.g. behavioral ratings coded from video).

\section{Other}

Future research efforts should focus on examining and confirming treatment mechanisms. This includes integration with other types of experimental designs and methods (e.g. neuroimaging, Birnie 2017). This research is particularly important for interventions where the mechanism of effect is unclear or where multiple potential mechanisms are involved. This is critical, as it directly informs the determination and design of most effective treatments, which are now difficult to determine given the significant heterogeneity within intervention categories such as distraction. Further research in this area may also inform more accurate categorization of psychological interventions. For example, breathing interventions in which children are instructed to inflate a balloon may evoke a physiological mechanism, expectancy, or distraction (Gupta 2006; Sahiner 2016).

We encourage researchers to conduct studies informing how to tailor the right intervention to the right child at the right time. Interventions should ideally be matched to child, setting, and context. Individual differences will invariably influence responsiveness to psychological interventions. For example, children with high versus low fear of pain or tendencies to catastrophize about pain may benefit less from distraction (Birnie 2017; Campbell 2017; Verhoeven 2012) and more from hypnosis that involves more intensive training, attentional engagement, and suggestion. The influence of participant preference and choice on treatment efficacy should also be considered (Birnie 2014a). Particularly in the context of vaccination, there is a notable dearth of interventions delivered in the school setting. Given that schoolaged children and adolescents often receive vaccine injections in this setting, research in this unique context would be valuable (Boerner 2014).
Once again, we argue it is imperative that future trials take into account the child's age and developmental stage when developing, implementing, and evaluating interventions. There was a notable lack of trials specifically targeting adolescents, and participant samples included a wide range of children spanning several developmental periods. Age can influence treatment efficacy in these interventions (Birnie 2014a). We suggest that studies including a wide age range of children used age-based analyses and report outcomes by recommended age groups for pediatric clinical trials (Williams 2012). Previous experience with and associated memories of needle procedures also invariably influence the child's pain experience and treatment responsiveness (Noel 2012). Comparison of intervention efficacy for single (vaccine injection) versus repeated needle procedures (bone marrow aspirations for cancer treatment regimens) is warranted. Relatedly, trials examining intervention implementation and efficacy among youth with developmental disabilities are notably absent from the literature and are needed (Boerner 2014).

Finally, wide dissemination of efficacious interventions is critically important and can be threatened by real-world concerns about time, resources, and feasibility in busy clinical settings. Given that our findings suggest a variety of distraction interventions are efficacious regardless of cost and level of technology, cost effectiveness should be assessed and considered. This is highly relevant for uptake of evidence-based pain management in less resourced areas.

\section{ACKNOWLEDGEMENTS}

We wish to thank the many individuals who helped in the preparation of the second update of this review. We would like to thank all members of the Cochrane Pain, Palliative, and Supportive Care (PaPaS) team, particularly Anna Erskine and Joanne Abbott (who conducted the updated searches). Thank you to Jaimie Beveridge for her support reviewing database searches and updating tables in this review update. We also wish to acknowledge and thank Dr. Patrick McGrath and Dr. Steven Kisely for their contributions to previous iterations of this review. Please see the original review (Uman 2006) and first review update (Uman 2013) for additional acknowledgements specific to those versions.

Cochrane Review Group funding acknowledgement: this project was supported by the National Institute for Health Research, via Cochrane Infrastructure funding to the Cochrane Pain, Palliative and Supportive Care Review Group (PaPaS). The views and opinions expressed therein are those of the authors and do not necessarily reflect those of the Systematic Reviews Programme, NIHR, NHS or the Department of Health. 


\section{RE F E R E N C E S}

\section{References to studies included in this review}

Aydin 2017 \{published data only\}

Aydin D, Sahiner NC. Effects of music therapy and distraction cards on pain relief during phlebotomy in children. Applied Nursing Research 2017;33:164-8.

\section{Balan 2009 \{published data only\}}

Balan R, Bavdekar SB, Jadhav S. Can Indian classical instrumental music reduce pain felt during venepuncture? Indian Journal of Pediatrics 2009;76(5):469-73.

Bellieni 2006 \{published data only\}

Bellieni CV, Cordelli DM, Raffaelli M, Ricci B, Morgese G, Buonocore G. Analgesic effect of watching TV during venipuncture. Archives of Disease in Childhood 2006;91(12):1015-7.

\section{Beran 2013 \{published data only\}}

Beran TN, Ramirez-Serrano A, Vanderkooi OG, Kuhn S. Reducing children's pain and distress towards flu vaccinations: A novel and effective application of humanoid robotics. Vaccine 2013;31(25):2772- 7.

\section{Bisignano 2006 \{published data only\}}

Bisignano A, Bush JP. Distress in pediatric hematology-oncology patients undergoing intravenous procedures: Evaluation of a CD-ROM intervention. Children's Health Care 2006;35(1):61-74.

\section{Blount 1992 \{published data only\}}

Blount RL, Bachanas PJ, Powers SW, Cotter MC, Franklin A, Chaplin W, et al. Training children to cope and parents to coach them during routine immunizations: Effects on child, parent, and staff behaviors. Behavior Therapy 1992;23:689-705.

\section{Caprilli 2007 \{published data only\}}

Caprilli S, Anastasi F, Grotto RP, Scollo Abeti M, Messeri A. Interactive music as a treatment for pain and stress in children during venipuncture: A randomized prospective study. Journal of Developmental and Behavioral Pediatrics 2007;28(5):399-403.

Cassidy 2002 \{published data only\}

Cassidy K-R, Reid GJ, McGrath PJ, Finley GA, Smith DJ, Morley C, et al. Watch needle, watch TV: Audiovisual distraction in preschool immunization. American Academy of Pain Medicine 2002;3(2):108-18.

\section{Cavender 2004 \{published data only\}}

Cavender K, Goff MD, Hollon EC, Guzzetta CE. Parent's positioning and distracting children during venipuncture. Journal of Holistic Nursing 2004;22(1):32-56.

\section{Chen 1999 \{published data only\}}

Chen E, Zeltzer LK, Craske MG, Katz ER. Alteration of memory in the reduction of children's distress during repeated aversive medical procedures. Journal of Consulting and Clinical Psychology 1999;67(4):481-90.
Cohen 2015 \{published data only\}

Cohen LL, Rodrigues NP, Lim CS, Bearden DJ, Welkom JS, Joffe NE, et al. Automated parent-training for preschooler immunization pain relief: a randomized controlled trial. Journal of Pediatric Psychology 2015;40(5):526-34.

\section{Crevatin 2016 \{published and unpublished data\}}

Crevatin F, Cozzi G, Braido E, Bertossa G, Rizzitelli P, Lionetti D, et al. Hand-held computers can help to distract children undergoing painful venipuncture procedures. Acta Paediatrica 2016;105(8):930-4.

\section{Ebrahimpour 2015 \{published data only\}}

Ebrahimpour F, Sadeghi N, Najafi M, Iraj B, Shahrokhi A. Effect of playing interactive computer game on distress of insulin injection among type 1 diabetic children. Iranian Journal of Pediatrics 2015;25(3):e427.

Eland 1981 \{published data only\}

Eland JM. Minimizing pain associated with prekindergarten intramuscular injections. Issues in Comprehensive Pediatric Nursing 1981;5(5-6):361-72.

Fanurik 2000 \{published data only\}

Fanurik D, Koh JL, Schmitz ML. Distraction techniques combined with EMLA: Effects of IV insertion pain and distress in children. Children's Health Care 2000;29(2):87-101.

Fowler-Kerry 1987 \{published data only\}

Fowler-Kerry S, Lander JR. Management of injection pain in children. Pain 1987;30(2):169-75.

\section{Gold 2006 \{published data only\}}

Gold JI, Kim SH, Kant AJ, Joseph MH, Rizzo A. Effectiveness of virtual reality for pediatric pain distraction during IV placement. Cyberpsychology and Behavior 2006;9(2):207-12.

Gonzalez 1993 \{published data only\}

Gonzalez JC, Routh DK. Effects of maternal distraction versus reassurance on children's reactions to injections. Journal of Pediatric Psychology 1993;18(5):593-604.

\section{Goodenough 1997 \{published data only\}}

Goodenough B, Kampel L, Champion GD, Laubreaux L, Nicholas MK, Ziegler JB, et al. An investigation of the placebo effect and age-related factors in the report of needle pain from venipuncture in children. Pain 1997;72(3):383-91.

\section{Gupta 2006 \{published data only\}}

Gupta D, Agarwal A, Dhiraaj S, Tandon M, Kumar M, Singh RS, et al. An evaluation of efficacy of balloon inflation on venous cannulation pain in children: A prospective, randomized, controlled study. Anesthesia and Analgesia 2006;102(5):1372-5

Harrison 1991 \{published data only\}

Harrison A. Preparing children for venous blood sampling. Pain 1991;45(3):299-306. 
Huet 2011 \{published data only\}

Huet A, Lucas-Polomeni MM, Robert JC, Sixou JL, Wodey E. Hypnosis and dental anesthesia in children: A prospective controlled study. International Journal of Clinical and Experimental Hypnosis 2011;59(4):424-40.

Inal 2012 \{published data only\}

Inal S, Kelleci M. Distracting children during blood draw: Looking through distraction cards is effective in pain relief of children during blood draw. International Journal of Nursing Practice 2012;18(2):210-9.

\section{Jeffs 2007 \{published data only\}} Jeffs DA. A pilot study of distraction for adolescents during allergy testing. Journal for Specialists in Pediatric Nursing 2007;12(3):170-85.

\section{Kamath 2013 \{published data only\}}

Kamath PS. A novel distraction technique for pain management during local anesthesia administration in pediatric patients. Journal of Clinical Pediatric Dentistry 2013;38(1):45-8.

\section{Katz 1987 \{published data only\}}

Katz ER, Kellerman J, Ellenberg L. Hypnosis in the reduction of acute pain and distress in children with cancer. Journal of Pediatric Psychology 1987;12(3):379-94.

Kleiber 2001 \{published data only\}

Kleiber C, Craft-Rosenberg M, Harper DC. Parents as distraction coaches during IV insertion: A randomized study. Journal of Pain and Symptom Management 2001;22(4):851-61.

\section{Kristjansdottir 2010 \{published data only\}}

Kristjansdottir O, Kristjansdottir G. Randomized clinical trial of musical distraction with and without headphones for adolescents' immunization pain. Scandinavian Journal of Caring Sciences 2011;25(1):19-26.

\section{Kuttner 1987 \{published data only\}}

Kuttner L. Favorite stories: A hypnotic pain-reduction technique for children in acute pain. American Journal of Clinical Hypnosis 1988;30(4):289-95.

\section{Liossi 1999 \{published data only\}}

Liossi C, Hatira P. Clinical hypnosis versus cognitive behavioral training for pain management with pediatric cancer patients undergoing bone marrow aspirations. International Journal of Clinical and Experimental Hypnosis 1999;47(2):104-16.

\section{Liossi 2003 \{published data only\}}

Liossi C, Hatira P. Clinical hypnosis in the alleviation of procedure-related pain in pediatric oncology patients. International Journal of Clinical and Experimental Hypnosis 2003;51(1):4-28

\section{Liossi 2006 \{published data only\}}

Liossi C, White P, Hatira P. Randomized clinical trial of local anesthetic versus a combination of local anesthetic with selfhypnosis in the management of pediatric procedure-related pain. Health Psychology 2006;25(3):307-15.

\section{Liossi 2009 \{published data only\}}

Liossi C, White P, Hatira P. A randomized clinical trial of a brief hypnosis intervention to control venepuncture-related pain of paediatric cancer patients. Pain 2009;142(3):255-63.

\section{Luthy 2013 \{published data only\}}

Luthy KE, Beckstrand RL, Pulsipher A. Evaluation of methods to relieve parental perceptions of vaccine-associated pain and anxiety in children: a pilot study. Journal of Pediatric Health Care 2013;27(5):351-8.

\section{McCarthy 2010 \{published data only\}}

* McCarthy AM, Hanrahan K, Zimmerman MB, Westhus N, Allen S. Impact of parent-provided distraction on child responses to an IV insertion. Children's Health Care 2010;39(2):125-41.

McCarthy AM, Kleiber C, Hanrahan K, Zimmerman MB, Westhus N, Allen S. Factors explaining children's responses to intravenous needle insertions. Nursing Research 2010;59(6):407-16.

\section{Meiri 2016 \{published data only\}}

Meiri N, Ankri A, Hamad-Saied M, Konopnicki M, Pillar G. The effect of medical clowning on reducing pain, crying, and anxiety in children aged 2-10 years old undergoing venous blood drawing-a randomized controlled study. European Journal of Pediatrics 2016;175(3):373-9.

Miguez-Navarro 2016 \{published and unpublished data\} Miguez-Navarro C, Guerrero-Marquez G. Video-distraction system to reduce anxiety and pain in children subjected to venipuncture in pediatric emergencies. Pediatric Emergency Care and Medicine: Open Access 2016;1(1):1-8.

\section{Miller 2016 \{published data only\}}

Miller K, Tan X, Hobson AD, Khan A, Ziviani J, O'Brien E, et al. A prospective randomized controlled trial of nonpharmacological pain management during intravenous cannulation in a pediatric emergency department. Pediatric Emergency Care 2016;32(7):444-51.

\section{Minute 2012 \{published data only\}}

Minute M, Badina L, Cont G, Montico M, Ronfani L, Barbi E, et al. Videogame playing as distraction technique in course of venipuncture [Giocare con i videogiochi come distrazione attiva in corso di venipuntura]. Pediatria Medica e Chirurgica (Medical and Surgical Pediatrics) 2012;34(2):77-83.

\section{Mutlu 2015a \{published data only\}}

Mutlu B, Balcı S. Effects of balloon inflation and cough trick methods on easing pain in children during the drawing of venous blood samples: a randomized controlled trial. Journal for Specialists in Pediatric Nursing 2015;20(3):178-86.

\section{Nguyen 2010 \{published data only\}}

Nguyen TN, Nilsson S, Hellstrom A-L, Bengtson A. Music therapy to reduce pain and anxiety in children with cancer undergoing lumbar puncture: A randomized clinical trial. Journal of Pediatric Oncology Nursing 2010;27(3):146-55. 
Nilsson 2015 \{published and unpublished data\}

Nilsson S, Forsner M, Finnström B, Mörelius C. Relaxation and guided imagery do not reduce stress, pain and unpleasantness for 11- to 12 -year-old girls during vaccinations. Acta Paediatrica 2015;104(7):724-9.

\section{Noguchi 2006 \{published data only\}}

Noguchi LK. The effect of music versus nonmusic on behavioral signs of distress and self-report of pain in pediatric injection patients. Journal of Music Therapy 2006;43(1):16-38.

\section{Oliveira 2017 \{published data only\}}

Oliveira NC, Santos JL, Linhares MB. Audiovisual distraction for pain relief in paediatric inpatients: A crossover study. European Journal of Pain 2017;21(1):178-87.

\section{Pourmovahed 2013 \{published data only\}}

Pourmovahed Z, Dehghani K, Sherafat A. Effectiveness of regular breathing technique (hey-hu) on reduction of intrathecal injection pain in leukemic children: a randomized clinical trial. Iranian Journal of Pediatrics 2013;23(5):564-8.

\section{Press 2003 \{published data only\}}

Press J, Gidron Y, Maimon M, Gonen A, Goldman V, Buskila D. Effects of active distraction on pain of children undergoing venipuncture: Who benefits from it? Pain Clinic 2003;15(3):261-9.

\section{Ramírez-Carrasco 2017 \{published and unpublished data\}} Ramírez-Carrasco A, Butrón-Téllez Girón C, Sanchez-Armass O, Pierdant-Pérez M. Effectiveness of hypnosis in combination with conventional techniques of behavior management in anxiety/pain reduction during dental anesthetic infiltration. Pain Research and Management 2017;2017:1434015.

\section{Rimon 2016 \{published and unpublished data\}}

Rimon A, Shalom S, Wolyniez I, Gruber A, Schachter-Davidov A, Glatstein M. Medical clowns and cortisol levels in children undergoing venipuncture in the emergency department: A pilot study. Israel Medicine Association Journal 2016;18(11):680-3.

\section{Sahiner 2016 \{published data only\}}

Sahiner NC, Bal MD. The effects of three different distraction methods on pain and anxiety in children. Journal of Child Health Care 2016;20(3):277-85.

\section{Sander Wint 2002 \{published data only\}}

Sander Wint S, Eshelman D, Steele J, Guzzetta CE. Effects of distraction using virtual reality glasses during lumbar punctures in adolescents with cancer. ONF 2002;29(1):E8-15.

\section{Sinha 2006 \{published data only\}}

Sinha M, Christopher NC, Fenn R, Reeves L. Evaluation of nonpharmacologic methods of pain and anxiety management for laceration repair in the pediatric emergency department. Pediatrics 2006;117(4):1162-8.

\section{Tak 2006 \{published data only\}}

Tak JH, Van Bon WH. Pain- and distress-reducing interventions for venepuncture in children. Child: Care, Health, and Development 2006;32(3):257-68.

\section{Tyc 1997 \{published data only\}}

Tyc VL, Leigh L, Mulhern RK, Kumar Srivastava D, Bruce D. Evaluation of a cognitive-behavioral intervention for reducing distress in pediatric cancer patients undergoing magnetic resonance imaging procedures. International Journal of Rehabilitation and Health 1997;3(4):267-79.

Vessey 1994 \{published data only\}

Vessey JA, Carlson KL, McGill J. Use of distraction with children during an acute pain experience. Nursing Research 1994;43(6):369-72.

\section{Vosoghi 2010 \{published data only\}}

Vosoghi N, Chehrzad M, Abotalebi G, Atrkar RZ. Effects of distraction on physiologic indices and pain intensity in children aged 3-6. Journal of Hayat 2010;16(3-4):39-47.

Wang 2008 \{published data only\}

Wang ZX, Sun LH, Chen AP. The efficacy of non-pharmacological methods of pain management in school age children receiving venepuncture in a paediatric department: a randomized controlled trial of audiovisual distraction and routine psychological intervention. Swiss Medical Weekly 2008;138(39-40):579-84.

\section{Windich-Biermeier 2007 \{published data only\}}

Windich-Biermeier A, Sjoberg I, Dale JC, Eshelman D, Guzzetta CE. Effects of distraction on pain, fear, and distress during venous port access and venipuncture in children and adolescents with cancer. Journal of Pediatric Oncology Nursing 2007;24(1):8-19.

\section{Yinger 2016 \{published data only\}}

Yinger OS. Music therapy as procedural support for young children undergoing immunizations: A randomized controlled trial. Journal of Music Therapy 2016;53(4):336-63.

\section{Zieger 2013 \{published data only\}}

Zieger B, Praskova M, Busse E, Barth M. A prospective randomised control study: reduction of children's pain expectation using a picture book during blood withdrawal [Eine prospektive randomisierte Kontrollgruppenstudie: Reduktion kindlicher Schmerzerwartungen bei Blutentnahmen mithilfe eines Bilderbuches]. Klinische Padiatrie 2013;225(3):110-4.

\section{References to studies excluded from this review}

\section{Agarwal 2008 \{published data only\}}

Agarwal A, Yadav G, Gupta D, Tandon M, Singh PK, Singh U. The role of a flash of light for attenuation of venous cannulation pain: a prospective, randomized, placebo-controlled study. Anesthesia and Analgesia 2008;106(3):814-6.

\section{Agarwal 2017 \{published data only\}}

Agarwal N, Dhawan J, Kumar D, Anand A, Tangri K. Effectiveness of two topical anaesthetic agents used along with audio visual aids in paediatric dental patients. Journal of Clinical and Diagnostic Research 2017;11(1):ZC80-ZC83.

Psychological interventions for needle-related procedural pain and distress in children and adolescents (Review) 
Alavi 2005 \{published data only\}

Alavi A, Zargham A, Abdyzdan Z, Nmnbati M. The comparison of distraction and EMLA cream effects on pain intensity due to intravenous catheters in 5-12 years old thalassemic children. Journal of Shahrekord University of Medical Sciences 2005;7(3):9-15.

\section{Alderfer 2010 \{published data only\}}

Phipps S, Barrera M, Vannatta K, Xiong X, Doyle JJ, Alderfer MA. Complementary therapies for children undergoing stem cell transplantation: report of a multisite trial. Cancer 2010;116(16):3924-33.

\section{Alhani 2010 \{published data only\}}

Alhani $F$. The effect of programmed distraction on the pain caused by venipuncture among adolescents on hemodialysis. Pain Management Nursing 2010;11(2):85-91.

\section{Anghelescu 2013 \{published data only\}}

Anghelescu DL, Burgoyne LL, Faughnan LG, Hankins GM, Smeltzer MP, Pui C. Prospective randomized crossover evaluation of three anthesthetic regimens for painful procedures in children with cancer. Journal of Pediatrics 2013;162(1):137-41.

\section{Anson 2010 \{published data only\}}

Anson L, Edmundson E, Teasley S. Implications of evidencebased venipuncture practice in a pediatric health care magnet facility. Journal of Continuing Education in Nursing 2010;41(4):179-85.

\section{Arts 1994 \{published data only\}}

Arts SE, Abu-Saad HH, Champion GD, Crawford MR, Fisher RJ, Juniper $\mathrm{KH}$, et al. Age-related response to lidocaine-prilocaine (EMLA) emulsion and effect of music distraction on the pain of intravenous cannulation. Pediatrics 1994;93(5):797-801.

\section{Ashkenzai 2006 \{published data only\}}

Ashkenazi M, Blumer S, Eli I. Effectiveness of various modes of computerized delivery of local anesthesia in primary maxillary molars. Pediatric Dentistry 2006;28(1):29-39.

\section{Atkinson 2009 \{published data only\}}

Atkinson P, Chesters A, Heinz P. Pain management and sedation for children in the emergency department. $B M J$ 2009;339:b4234.

\section{Bagnasco 2012 \{published data only\}}

Bagnasco A, Pezzi E, Rosa F, Fornoni L, Sasso L. Distraction techniques in children during venipuncture: an Italian experience. Journal of Preventive Medicine and Hygiene 2012;53(1):44-8

\section{Baxter 2011 \{published data only\}}

Baxter AL, Cohen LL, McElvery HL, Lawson ML, Von Baeyer CL. An integration of vibration and cold relieves venipuncture pain in a pediatric emergency department. Pediatric Emergency Care 2011;27(12):1151-6.
Bengston 2002 \{unpublished data only\}

Bengston BS, Jacobson RM, Friedrich WM, Vierkant RA, Poland GA. Teaching self-hypnosis to alleviate vaccinationrelated distress in children: a randomized, single-blinded controlled trial. In preparation.

Benjamin 2016 \{published data only (unpublished sought but not used)\}

Benjamin AL, Hendrix TJ, Woody JL. Effects of vibration therapy in pediatric immunizations. Pediatric Nursing 2016;42(3):124-30.

\section{Ben-Pazi 2017 \{published data only\}}

Ben-Pazi H, Cohen A, Kroyzer N, Loten-Ophir R, Shvili Y, Winter $\mathrm{G}$, et al. Clown-care reduces pain in children with cerebral palsy undergoing recurrent botulinum toxin injectionsA quasi-randomized controlled crossover study. PLOS ONE 2017;12(4):e0175028.

\section{Berberich 2009 \{published data only\}}

Berberich FR, Landman Z. Reducing immunization discomfort in 4- to 6-year-old children: A randomized clinical trial. Pediatrics 2009;124(2):e203-9.

\section{Berge 2017 \{published data only\}}

Berge KG, Agdal ML, Vika M, Skeie MS. Treatment of intra-oral injection phobia: a randomized delayed intervention controlled trial among Norwegian 10- to 16-year-olds. Acta Odontologica Scandinavica 2017;75(4):294-301.

\section{Boivin 2008 \{published data only\}}

Boivin JM, Poupon-Lemarquis L, Iraqi W, Fay R, Schmitt C, Rossignol P. A multifactorial strategy of pain management is associated with less pain in scheduled vaccination of children. A study realized by family practitioners in 239 children aged 4-12 years old. Family Practice 2008;25(6):423-9.

Bowen 1999 \{published data only\}

Bowen AM, Dammeyer MM. Reducing children's immunization distress in a primary care setting. Journal of Pediatric Nursing 1999;14(5):296-303.

\section{Broome 1998 \{published data only\}}

Broome ME, Rehwaldt M, Fogg L. Relationships between cognitive behavioral techniques, temperament, observed distress, and pain reports in children and adolescents during lumbar puncture. Journal of Pediatric Nursing 1998;13(1):48-54.

\section{Bruck 1995 \{published data only\}}

Bruck M, Ceci SJ, Francoeur E, Barr R. "I hardly cried when I got my shot!" Influencing children's reports about a visit to their pediatrician. Child Development 1995;66(1):193-208.

\section{Bufalini 2009 \{published data only\}}

Bufalini A. Role of interactive music in oncological pediatric patients undergoing painful procedures [Ruolo della musica interattiva nel paziente pediatrico oncologico sottoposto a procedure dolorose]. Minerva Pediatrica 2009;61(4):379-90. 
Bufalini 2012 \{unpublished data only\}

Bufalini A. The effect of live music on oncological paediatric patients during painful procedures. European Journal of Integrative Medicine 2012.

\section{Carlson 2000 \{published data only\}}

Carlson KL, Broome M, Vessey JA. Using distraction to reduce reported pain, fear, behavioral distress in children and adolescents: A multisite study. Journal of the Society of Pediatric Nurses 2000;5(2):75-85

\section{Chan 2013 \{published data only\}}

Chan S, Pielak K, McIntyre C, Deeter B, Taddio A. Implementation of a new clinical practice guideline regarding pain management during childhood vaccine injections. Paediatric Child Health 2013;18(7):367-72.

\section{Chen 2000b \{published data only\}}

Chen E, Craske MG, Katz ER, Schwartz E, Zeltzer LK. Painsensitive temperament: Does it predict procedural distress and response to psychological treatment among children with cancer? Journal of Pediatric Psychology 2000;25(4):269-78.

\section{Chow 2017 \{published data only\}}

Chow CH, Van Lieshout RJ, Schmidt LA, Buckley N. Tablet-based intervention for reducing children's preoperative anxiety: $\mathrm{A}$ pilot study. Journal of Developmental and Behavioral Pediatrics 2017;38(6):409-16.

\section{Christiano 1996 \{unpublished data only\}}

Christiano BA. Children's coping and distress during invasive dental procedures: The effects of matching coping interventions to coping styles [Doctoral dissertation]. Case Western Reserve University, 1996.

\section{Cline 2006 \{published data only\}}

Cline RJ, Harper FW, Penner LA, Peterson AM, Taub JW, Albrecht TL. Parent communication and child pain and distress during painful pediatric cancer treatments. Social Science \& Medicine 2006;63(4):883-98.

\section{Cohen 1997 \{published data only\}}

Cohen LL, Blount RL, Panopoulos G. Nurse coaching and cartoon distraction: An effective and practical intervention to reduce child, parent, and nurse distress during immunizations. Journal of Pediatric Psychology 1997;22(3):355-70.

\section{Cohen 1999 \{published data only\}}

Cohen LL, Blount RL, Jansevics Cohen R, Ball CM, McClellan CB, Bernard RS. Children's expectations and memories of acute distress: Short- and long-term efficacy of pain management interventions. Journal of Pediatric Psychology 2001;26(6):367-74.

* Cohen LL, Blount RL, Jansevics Cohen R, Schaen ER, Zaff JF. Comparative study of distraction versus topical anesthesia for pediatric pain management during immunizations. Health Psychology 1999;18(6):591-8.

\section{Cohen 2002 \{published data only\}}

Cohen LL, Bernard RS, Greco LA, McClellan CB. A child-focused intervention for coping with procedural pain: Are parent and nurse coaches necessary? Journal of Pediatric Psychology 2002;27(8):749-57.

\section{Cohen 2010 \{published data only\}}

Cohen L. A multifaceted distraction intervention may reduce pain and discomfort in children 4-6 years of age receiving immunisation. Evidence Based Nursing 2010;13(1):15-6.

\section{Cramer-Berness 2005 \{published data only\}}

Cramer-Berness LJ, Friedman AG. Behavioral interventions for infant immunizations. Children's Health Care 2005;34(2):95-111.

\section{Crowley 2011 \{published data only\}}

Crowley MA, Storer A, Heaton K, Naccarato MK, Proehl JA, Moretz JD, et al. Emergency nursing resource: needlerelated procedural pain in pediatric patients in the emergency department. Journal of Emergency Nursing 2011;37(3):246-51.

\section{Cumino 2017 \{published data only\}}

Cumino DO, Vieira JE, Lima LC, Stievano LP, Silva RA, Mathias LA. Smartphone-based behavioural intervention alleviates children's anxiety during anaesthesia induction. European Journal of Anaesthesiology 2017;34(3):169-75.

\section{Dahlquist 2002 \{published data only\}}

Dahlquist LM, Pendley JS, Landthrip DS, Jones CL, Steuber CP. Distraction intervention for preschoolers undergoing intramuscular injections and subcutaneous port access. Health Psychology 2002;21(1):94-9.

\section{Dahlquist 2005 \{published data only\}}

Dahlquist LM, Shroff Pendley J. When distraction fails: Parental anxiety and children's responses to distraction during cancer procedures. Journal of Pediatric Psychology 2005;30(7):623-8.

Davit 2011 \{published data only\}

Davit CJ, Hundley RJ, Bacic JD, Hanson EM. A pilot study to improve venipuncture compliance in children and adolescents with autism spectrum disorders. Journal of Developmental and Behavioral Pediatrics 2011;32(7):521-5.

Demir 2012 \{published data only\}

Demir G, Cukurova Z, Eren G, Tekdos Y, Hergunsel O. The effect of "Multiphase Sedation" in the course of computed tomography and magnetic resonance imaging on children, parents and anesthesiologists. Revista Brasileira de Anestesiologia 2012;62(4):511-9.

Drahota 2008 \{published data only\}

Drahota A, Galloway E, Stores R, Ward D, Severs M, Dean T. Audiovisual distraction as an adjunct to pain and anxiety relief during minor surgery. Foot (Edinburgh) 2008;18(4):211-9.

\section{Dufresne 2010 \{published data only\}}

Dufresne A, Dugas MA, Samson Y, Barré P, Turcot L, Marc I. Do children undergoing cancer procedures under pharmacological sedation still report pain and anxiety? A preliminary study. Pain Medicine 2010;11(2):215-23. 
El-Sharkawi 2012 \{published data only\}

El-Sharkawi HF, El-Housseiny AA, Aly AM. Effectivness of new distraction technique on pain associated with injection of local anesthesia for children. Pediatric Dentistry 2012;34(2):142-5.

\section{Fancourt 2016 \{published data only\}}

Fancourt D, Lee C, Baltzer Nielsen S, Capps S, Brooks P. Relax anaesthetics: The effect of a bespoke distraction app on anxiety levels in children undergoing induction of anaesthesia. Anesthesia and Analgesia 2016;123(3S):292-3.

\section{Fassler 1985 \{published data only\}}

Fassler D. The fear of needles in children. American Journal of Orthopsychiatry 1985;55(3):371-7.

Felluga 2016 \{published data only (unpublished sought but not used)\}

Felluga M, Rabach I, Minute M, Montico M, Giorgi R, Lonciari I, et al. A quasi randomized-controlled trial to evaluate the effectiveness of clowntherapy on children's anxiety and pain levels in emergency department. European Journal of Pediatrics 2016;175(5):645-50.

\section{Firoozi 2014 \{published data only\}}

Firoozi M. Attention bias modification therapy (ABMT) as a modern technique for pain management in children with cancer. Pediatric Blood \& Cancer 2014;61(S2):S250.

\section{Forsner 2014 \{published data only\}}

Forsner M, Norstrom F, Nordyke K, Ivarsson A, Lindh V. Relaxation and guided imagery used with 12 -year-olds during venipuncture in a school-based screening study. Journal of Child Health Care 2014;18(3):241-52.

\section{Franck 2014 \{published data only\}}

Franck LS, Berberich FR, Taddio A. Parent participation in a childhood immunization pain reduction method. Clinical Pediatrics 2014;54(3):228-35.

\section{Franzoi 2016 \{published data only\}}

Franzoi MAH, Goulart CB, Lara EO, Martins G. Music listening for anxiety relief in children in the preoperative period: A randomized clinical trial. Revista Latino-Americana de Enfermagem 2016;24:e2841.

\section{French 1994 \{published data only\}}

French GM, Painter EC, Coury DL. Blowing away shot pain: A technique for pain management during immunization. Pediatrics 1994;93(3):384-8.

\section{Garret-Bernardin 2017 \{published data only\}}

Garret-Bernardin A, Cantile T, D’Antò V, Galanakis A, Fauxpoint G, Ferrazzano GF, et al. Pain experience and behavior management in pediatric dentistry: A comparison between traditional local anesthesia and the wand computerized delivery system. Pain Research \& Management 2017;2017:7941238

\section{Gilbert 1982 \{published data only\}}

Gilbert BO, Bennett Johnson S, Spillar R, McCallum M, Silverstein JH, Rosenbloom A. The effect of a peer-modelling film on children learning to self-inject insulin. Behavior Therapy 1982;13(2):186-93.

Goymour 2000 \{published data only\}

Goymour K, Stephenson C, Goodenough B, Boulton C. Evaluating the role of play therapy in the pediatric emergency department. Advanced Emergency Nursing Journal 2000;3(2):10-2.

Hartling 2013 \{published data only (unpublished sought but not used)\}

Hartling L, Newton AS, Liang Y, Jou H, Hewson K, Klassen TP, et al. Music to reduce pain and distress in the pediatric emergency department: a randomized clinical trial. JAMA Pediatrics 2013;167(9):826-35.

Hatava 2000 \{published data only\}

Hatava P, Olsson GL, Lagerkranser M. Preoperative psychological preparation for children undergoing ENT operations: a comparison of two methods. Paediatric Anaesthesia 2000;10(5):477-86.

Hawkins 1998 \{published data only\}

Hawkins PJ. Hypnosis in the alleviation of procedure related pain and distress in paediatric oncology patients. Contemporary Hypnosis 1998;15(4):199-207.

\section{Heckler-Medina 2006 \{published data only\}}

Heckler-Medina GA. The importance of child life and pain management during vascular access procedures in pediatrics. Journal of the Association for Vascular Access 2006;11(3):144-51.

Hedén 2009 \{published data only\}

Hedén L, Von Essen L, Ljungman G. Randomized interventions for needle procedures in children with cancer. European Journal of Cancer Care 2009;18(4):358-63.

\section{Hillgrove-Stuart 2013 \{published data only\}}

Hillgrove-Stuart J, Pillai Riddell R, Horton R, Greenberg S. Toy-mediated distraction: Clarifying the role of distraction agent and preneedle distress in toddlers. Pain Research \& Management 2013;18(4):197-202.

Hoffman 2011 \{published data only\}

Hoffmann F, Deanovic D. Prehospital pain management in children and adolescents [Präklinische Schmerztherapie bei Kindern und Jugendlichen]. Notfall and Rettungsmedizin 2011;14(7):549-53.

\section{Howe 2011 \{published data only\}}

Howe CJ, Ratcliffe SJ, Tuttle A, Dougherty S, Lipman TH. Needle anxiety in children with type 1 diabetes and their mothers. MCN. American Journal of Maternal Child Nursing 2011;36(1):25-31.

\section{Hudson 2015 \{published data only\}}

Hudson BF, Ogden J, Whiteley MS. Randomized controlled trial to compare the effect of simple distraction interventions on pain and anxiety experienced during conscious surgery. European Journal of Pain 2015;19(10):1447-55.

Psychological interventions for needle-related procedural pain and distress in children and adolescents (Review) 
Inal 2010 \{published data only\}

Inal S, Kelleci M. External thermomechanical stimulation and distraction are effective on pain relief of children during blood draw. In: 14th International Nursing Research Conference, Burgos. 2010.

\section{Isong 2014 \{published data only\}}

Isong IA, Rao SR, Holifield C, Iannuzzi D, Hanson E, Ware J, et al. Addressing dental fear in children with Autism Spectrum Disorders: A randomized controlled pilot study using electronic screen media. Clinical Pediatrics 2014;53(3):230-7.

\section{Jacobson 2006 \{published data only\}}

Jacobson AF. Cognitive-behavioral interventions for IV insertion pain. AORN Journal 2006;84(6):1031-48.

\section{Jay 1987 \{published data only\}}

Jay SM, Elliott CH, Katz E, Siegel SE. Cognitive-behavioral and pharmacologic interventions for children's distress during painful medical procedures. Journal of Consulting and Clinical Psychology 1987;55(6):860-5.

\section{Jay 1990 \{published data only\}}

Jay SM, Elliott $\mathrm{CH}$. A stress inoculation program for parents whose children are undergoing painful medical procedures. Journal of Consulting and Clinical Psychology 1990;58(6):799-804.

\section{Jay 1991 \{published data only\}}

Jay SM, Elliott CH, Woody PD. An investigation of cognitivebehavior therapy combined with oral Valium for children undergoing painful medical procedures. Health Psychology 1991;10(5):317-22.

\section{Jay 1995 \{published data only\}}

Jay S, Elliott CH, Fitzgibbons I, Woody P, Siegel S. A comparative study of cognitive behavior therapy versus general anesthesia for painful medical procedures in children. Pain 1995;62(1):3-9.

\section{Jibb 2017 \{published data only\}}

Jibb L, Stevens BJ, Nathan PC, Seto E, Cafazzo JA, Johnston DL, et al. Implementation and preliminary effectiveness of a realtime pain management smartphone app for adolescents with cancer: A multicenter pilot clinical study. Pediatric Blood \& Cancer 2017;64(10):1-9.

\section{Jimeno 2014 \{published data only\}}

Jimeno FG, Mercade Bellido M, Cuadros Fernandez C, Lorente Rodriguez AI, Llopis Perez J, Boj Quesada JR. Effect of audiovisual distraction on children's behaviour, anxiety and pain in the dental setting. European Journal of Paediatric Dentistry 2014;15(3):297-302.

\section{Kain 2006 \{published data only\}}

Kain ZN, Caldwell-Andrews AA, Mayes LC, Weinberg ME, Wang SM, MacLaren JE, et al. Family-centered preparation for surgery improves perioperative outcomes in children: a randomized controlled trial. Anesthesiology 2007;106(1):65-74.

\section{Kammerbauer 2011 \{published data only\}}

Kammerbauer N, Becke K. Acute pain management in pediatric and geriatric medicine - pain measurement: What pain scale in which patients? [Akutschmerztherapie in pädiatrie und geriatrie - akutschmerztherapie im kindesalter]. Anästhesiologie, Intensivmedizin, Notfallmedizin, Schmerztherapie - AINS 2011;46:344-53.

\section{Kazak 1996 \{published data only\}}

Kazak AE, Penati B, Boyer BA, Himelstein B, Brophy P, Waibel $\mathrm{MK}$, et al. A randomized controlled perspective outcome study of a psychological and pharmacological intervention protocol for procedural distress in pediatric leukemia. Journal of Pediatric Psychology 1996;21(5):615-31.

\section{Kazak 1998 \{published data only\}}

Kazak AE, Penati B, Brophy P, Himelstein B. Pharmacologic and psychologic interventions for procedural pain. Pediatrics 1998;102(1):59-66

\section{Kearl 2015 \{published data only\}}

Kearl YL, Yanger S, Montero S, Morelos-Howard E, Claudius I. Does combined use of the J-tip and Buzzy device decrease the pain of venipuncture in a pediatric population? Journal of Pediatric Nursing 2015;30(6):829-33.

\section{Kettwich 2007 \{published data only\}}

Kettwich SC, Sibbitt WL Jr, Brandt JR, Johnson CR, Wong CS, Bankhurst AD. Needle phobia and stress-reducing medical devices in pediatric and adult chemotherapy patients. Journal of Pediatric Oncology Nursing 2007;24(1):20-8.

\section{Klingman 1985 \{published data only\}}

Klingman A. Mass inoculation in a community: the effect of primary prevention of stress reactions. American Journal of Community Psychology 1985;13(3):323-32.

\section{Klorman 1980 \{published data only\}}

Klorman F, Hilpert PL, Michael R, LaGana C, Sveen OB. Effects of coping and mastery modelling on experienced and inexperienced pedodontic patients' disruptiveness. Behavior Therapy 1980;11(2):156-68.

\section{Kolk 2000 \{published data only\}}

Kolk AM, Van Hoof R, Fiedeldij Dop MJC. Preparing children for venepuncture. The effect of an integrated intervention on distress before and during venipuncture. Child: Care, Health and Development 2000;26(3):251-60.

\section{Krauss 1996 \{unpublished data only\}}

Krauss WJ. Videotape modelling and parent participation: Effects on reducing distress behavior in children undergoing immunization procedures [Doctoral dissertation]. California School of Professional Psychology, 1996.

\section{Kuttner 1988 \{published data only\}}

Kuttner L, Bowman M, Teasdale M. Psychological treatment of distress, pain, and anxiety for young children with cancer. Developmental and Behavioral Pediatrics 1988;9(6):374-81. 
Kwekkeboom 2003 \{unpublished data only\}

Kwekkeboom KL. Music versus distraction for procedural pain and anxiety in patients with cancer. Oncology Nursing Forum 2003;30(3):433-40.

\section{Lawes 2008 \{published data only\}}

Lawes C, Sawyer L, Amos S, Kandiah M, Pearce L, Symons J. Impact of an education programme for staff working with children undergoing painful procedures. Paediatric Nursing 2008;20(2):33-7.

\section{Lee 2013 \{published data only\}}

Lee J-H, Jung H-K, Lee G-G, Kim H-Y, Park S-G, Woo S-C. Effect of behavioral intervention using smartphone application for preoperative anxiety in pediatric patients. Korean Journal of Anesthesiology 2013;65(6):508-18.

\section{Lessi 2011 \{published data only\}}

Lessi E, Biasutto M, Ferrazzo M. The pain from venipuncture in children: The benefit of visual distraction [II dolore da venipuntura nel bambino: Il beneficio della distrazione con audiovisivi]. Gli Infermieri dei Bambini GISIP 2011;3(2):43-8.

\section{Liossi 2007 \{published data only\}}

Liossi C, White P, Franck L, Hatira P. Parental pain expectancy as a mediator between child expected and experienced procedure-related pain intensity during painful medical procedures. Clinical Journal of Pain 2007;23(5):392-9.

\section{Lustman 1983 \{published data only\}}

Lustman NM. The effectiveness of two different components of stress inoculation, preparatory information and the teaching of coping devices aimed at mothers whose children are undergoing minor surgery [Doctoral dissertation]. Yale University, 1983.

\section{MacLaren 2005 \{published data only\}}

MacLaren JE, Cohen LL. A comparison of distraction strategies for venipuncture distress in children. Journal of Pediatric Psychology 2005;30(5):387-96.

\section{MacLaren 2007 \{published data only\}}

MacLaren JE, Cohen LL. Interventions for paediatric procedurerelated pain in primary care. Paediatrics \& Child Health 2007;12(2):111-6.

\section{Malone 1996 \{published data only\}}

Malone AB. The effects of live music on the distress of pediatric patients receiving intravenous starts, venipunctures, injections, and heel sticks. Journal of Music Therapy 1996;33(1):19-33.

\section{Manimala 2000 \{published data only\}}

Manimala R, Blount RL, Cohen LL. The effects of parental reassurance versus distraction on child distress and coping during immunizations. Child Health Care 2000;29(3):161-77.

\section{Manne 1990 \{published data only\}}

Manne SL, Redd WH, Jacobsen PB, Gorfinkle K, Schorr O. Behavioral intervention to reduce child and parent distress during venipuncture. Journal of Consulting and Clinical Psychology 1990;58(5):565-72.

\section{Manne 1994 \{published data only\}}

Manne SL, Bakerman R, Jacobsen PB, Gorfinkle K, Redd WH. An analysis of a behavioral intervention for children undergoing venipuncture. Health Psychology 1994;13(6):556-66.

\section{Marec-Bérard 2009 \{published data only\}}

Marec-Bérard P, Bissery A, Kebaïli K, Schell M, Aubert F, Gaillard $S$, et al. A positioning pillow to improve lumbar puncture success rate in paediatric haematology-oncology patients: a randomized controlled trial. BMC Cancer 2009;9(21):1-8.

\section{Marechal 2017 \{published data only\}}

Marechal C, Berthiller J, Tosetti S, Cogniat B, Desombres H, Bouvet $\mathrm{L}$, et al. Children and parental anxiolysis in paediatric ambulatory surgery: a randomized controlled study comparing $0.3 \mathrm{mg} \mathrm{kg}-1$ midazolam to tablet computer based interactive distraction. British Journal of Anaesthesia 2017;118(2):247-53.

\section{McCarthy 1998 \{published data only\}}

McCarthy AM, Cool VA, Hanrahan K. Cognitive behavioral interventions for children during painful procedures: research challenges and program development. Journal of Pediatric Nursing 1998;13(1):55-63.

\section{McCarthy 2014 \{published data only\}}

McCarthy AM, Kleiber C, Hanrahan K, Zimmerman MB, Ersig A, Westhus $\mathrm{N}$, et al. Matching doses of distraction with child risk for distress during a medical procedure: A randomized clinical trial. Nursing Research 2014;63(6):397-407.

\section{McInally 2005 \{published data only\}}

Mclnally W. Whose line is it anyway? Management of central venous catheters in children. Paediatric Nursing 2005;17(5):14-8.

\section{McWhorter 2014 \{published data only\}}

McWhorter LG, Gil-Rivas V. The effect of brief functional relaxation on college students' needle anxiety during injected vaccinations. Journal of American College Health 2014;62(3):166-172.

\section{Megel 1998 \{published data only\}}

Megel ME, Houser CW, Gleaves LS. Children's responses to immunizations: Lullabies as a distraction. Issues in Comprehensive Pediatric Nursing 1998;21(3):129-45.

\section{Melamed 1974 \{published data only\}}

Melamed BG, Hawes RR, Heiby E, Glick J. Use of filmed modelling to reduce uncooperative behavior of children during dental treatment. Journal of Dental Research 1974;54(4):797-801.

\section{Moadad 2016 \{published data only\}}

Moadad N, Kozman K, Shahine R, Ohanian S, Badr LK. Distraction using the BUZZY for children during an IV insertion. Journal of Pediatric Nursing 2016;31(1):64-72.

\section{Mohan 2015 \{published data only\}}

Mohan S, Nayak R, Thomas RJ, Ravindran V. The effect of Entonox, play therapy and a combination on pain relief in

Psychological interventions for needle-related procedural pain and distress in children and adolescents (Review) 
children: a randomized controlled trial. Pain Management Nursing 2015;16(6):938-43.

\section{Mutlu 2015b \{published data only\}}

Mutlu B, Balcı S. Effects of balloon inflation and cough trick methods on easing pain in children during the drawing of venous blood samples: a randomized controlled trial. Journal for Specialists in Pediatric Nursing 2015;20(3):178-86.

\section{Myrvik 2009 \{unpublished data only\}}

Myrvik MP. A behavioral intervention targeting a reduction in child distress during a routine immunization [Dissertation]. University of North Dakota, 2008.

\section{Nilsson 2009 \{published data only\}}

Nilsson S, Finnström B, Kokinsky E, Enskär K. The use of Virtual Reality for needle-related procedural pain and distress in children and adolescents in a paediatric oncology unit. European Journal of Oncology Nursing 2009;13(2):102-9.

\section{O'Laughlin 1995 \{published data only\}}

O'Laughlin E, Ridley-Johnson R. Maternal presence during children's routine immunizations: The effect of mother as observer in reducing child distress. Children's Health Care 1995;24(3):175-91.

\section{Oberoi 2016 \{published data only\}}

Oberoi J, Panda A, Garg I. Effect of hypnosis during administration of local anesthesia in six- to 16-year-old children. Pediatric Dentistry 2016;38(2):112-5.

\section{Olsen 1991 \{published data only\}}

Olsen BR. Brief interventions for routine use with children in a phlebotomy laboratory [Doctoral dissertation]. West Virginia University, 1991.

\section{Ozdemir 2012 \{published data only\}}

Ozdemir FK, Tufekci FG. The effect of using musical mobiles on reducing pain in infants during vaccination. Journal of Research in Medical Sciences 2012;17(7):662-7.

\section{Park 2008 \{published data only\}}

Park SH, Bang SM, Nam E, Cho EK, Shin DB, Lee JH, et al. A randomized double-blind placebo-controlled study of low-dose intravenous Lorazepam to reduce procedural pain during bone marrow aspiration and biopsy. Pain Medicine 2008;9(2):249-52.

\section{Pederson 1996 \{published data only\}}

Pederson C. Promoting parental use of nonpharmacologic techniques with children during lumbar punctures. Journal of Pediatric Oncology Nursing 1996;13(1):21-30.

\section{Peretz 1999 \{published data only\}}

Peretz B, Gluck GM. Assessing an active distracting technique for local anesthetic injection in pediatric dental patients: repeated deep breathing and blowing out air. Journal of Clinical Pediatric Dentistry 1999;24(1):5-8.

\section{Posner 1998 \{unpublished data only\}}

Posner K. A pharmacobehavioral intervention to reduce child cancer distress [Doctoral dissertation]. Ferkauf Graduate School of Psychology, Yeshiva University, 1998.

\section{Powers 1993 \{published data only\}}

Powers SW, Blount RL, Bachanas PJ, Cotter MW, Swan SC. Helping preschool leukemia patients and their parents cope during injections. Journal of Pediatric Psychology 1993;18(6):681-95

\section{Quan 2016 \{published data only\}}

Quan X, Joseph A, Nanda U, Moyano-Smith O, Kanakri S, Ancheta $C$, et al. Improving pediatric radiography patient stress, mood, and parental satisfaction through positive environmental distractions: a randomized control trial. Journal of Pediatric Nursing 2016;31(1):e11-e22.

Rajan 2017 \{published data only\}

Rajan D, Lakshman G, Gupta SK, Sivasubramanian R, Saxena A, Juneja R. Effect of recorded maternal voice on child's cooperation during cardiac catheterization - A randomized controlled trial. Indian Pediatrics 2017;54(3):204-7.

\section{Ramponi 2009 \{published data only\}}

Ramponi D. Reducing pain in pediatric procedures in the emergency department. Journal of Emergency Nursing 2009;35(4):379-82

\section{Reeb 1997 \{published data only\}}

Reeb RN, Busch JP. Preprocedural psychological preparation in pediatric oncology: A process-oriented intervention study. Children's Health Care 1997;25(4):265-79.

\section{Rogovik 2007 \{published data only\}}

Rogovik AL, Goldman RD. Hypnosis for treatment of pain in children. Canadian Family Physician 2007;53(5):823-5.

\section{Russell 2012 \{unpublished data only\}}

Russell K, Nicholson R, Legge L, Leauanae E, Olsen A, Marsh S, et al. Reducing the pain of Bicillin injections in the rheumatic fever population of CMDHB. In: Journal of Paediatrics. Vol. 48. 2012:7.

\section{Salih 2010 \{published data only\}}

Salih N, Bäumler PI, Simang M, Irnich D. Deqi sensations without cutaneous sensory input: results of an RCT. BMC Complementary and Alternative Medicine 2010;10:81.

\section{Santos 2000 \{published data only\}}

Santos LM, Borba RI, Sabates AL. The importance of the preschool in the preparation for intramuscular injection using the play [La importancia del preparo de ninos en edad prescolar para la injeccion intramuscular con el uso del juguete]. Acta Paulista de Enfermagem 2000;13(2):52-8.

\section{Schechter 2010b \{published data only\}}

Schechter NL, Bernstein BA, Zempsky WT, Bright NS, Willard AK. Educational outreach to reduce immunization pain in office settings. Pediatrics 2010;126(6):1514-21. 
Schneider 2011 \{published data only\}

Schneider SM, Kisby CK, Flint EP. Effect of virtual reality on time perception in patients receiving chemotherapy. Support Care in Cancer 2011;19(4):555-64.

Schreiber 2016 \{published and unpublished data\} Schreiber S, Cozzi G, Rutigliano R, Assandro P, Tubaro M, Wiel LC, et al. Analgesia by cooling vibration during venipuncture in children with cognitive impairment. Acta Paediatrica 2016;105(1):e12-e16.

\section{Schur 1986 \{unpublished data only\}}

Schur JM. Alleviating behavioral distress with music or lamaze pant-blow breathing in children undergoing bone marrow aspirations and lumbar punctures [Doctoral dissertation]. The University of Texas Health Science Center at Dallas, 1986.

\section{Seiden 2014 \{published data only\}}

Seiden SC, McMullan S, Sequera-Ramos L, De Oliveira GS Jr, Roth A, Rosenblatt A, et al. Tablet-based interaction distraction (TBID) vs oral midazolam to minimize preoperative anxiety in pediatric patients: a noninferiority randomized trial. Pediatric Anesthesia 2014;24(12):1217-23.

\section{Shabanloei 2010 \{published data only\}}

Shabanloei R, Golchin M, Esfahani A, Dolatkhah R, Rasoulian M. Effects of music therapy on pain and anxiety in patients undergoing bone marrow biopsy and aspiration. AORN Journal 2010;91(6):746-51.

\section{Shahabi 2007 \{published data only\}}

Shahabi M, Kalani-Tehrani D, Eghbal M, Alavi-Majd H, Abed Saidi J. Comparing the effects of EMLA ointment with a diversionary activity (music) on vein puncture pain at schoolage children. Journal of Nursing and Midwifery 2007;17:56.

Shanmugam 2016 \{published data only (unpublished sought but not used)\}

Shanmugam RS, Subramani G. Effectiveness of distraction techniques upon pain among children receiving immunization. International Journal of Scientific Research 2016;5(2):517-20.

\section{Shemesh 2017 \{published data only\}}

Shemesh E, D'Urso C, Knight C, Rubes M, Picerno KM, Posillico AM, et al. Food-allergic adolescents at risk for anaphylaxis: A randomized controlled study of supervised injection to improve comfort with epinephrine self-injection. Journal of Allergy and Clinical Immunolology: In Practice 2017;5(2):391-7.

\section{Shimizu 2005 \{published data only\}}

Shimizu T, Inomata S, Kihara S, Toyooka H, Brimacombe JR. Rapid injection reduces pain on injection with propofol. European Journal of Anaesthesiology 2005;22(5):394-6.

\section{Sikorova 2011 \{published data only\}}

Sikorova L, Hrazdilova P. The effect of psychological intervention on perceived pain in children undergoing venipuncture. BioBiomedical Papers of the Medical Faculty of the University Palacky, Olomouc, Czechoslovakia 2011;155(2):149-54.
Singh 2016 \{published data only\}

Singh P. Effect of selected distraction techniques in behavior responses to pain among toddlers receiving invasive immunization. International Journal of Nursing and Medical Science 2016;5(1):504-12.

\section{Skinner 2015 \{published data only\}}

Skinner SR, Davies C, Cooper S, Stoney T, Marshall H, Jones J, et al. Randomised controlled trial of a complex intervention to improve school-based HPV vaccination for adolescents: The HPV. EDU study. Sexually Transmitted Infections 2015;91:A77.

Slack 2009 \{published data only\}

Slack D, Nelson L, Patterson D, Burns S, Hakimi K, Robinson L. The feasibility of hypnotic analgesia in ameliorating pain and anxiety among adults undergoing needle electromyography. American Journal of Physical Medicine \& Rehabilitation 2009;88(1):21-9.

\section{Slifer 2009 \{published data only\}}

Slifer KJ, Demore M, Vona-Messersmith N, PulbrookVetter V, Beck M, Dalhquist L, et al. Comparison of two brief parent-training interventions for child distress during parent-administered needle procedures. Child Health Care 2009;38(1):23-48

\section{Slifer 2011 \{published data only\}}

Slifer KJ, Hankinson JC, Zettler MA, Frutchey RA, Hendricks MC, Ward CM, et al. Distraction, exposure therapy, counterconditioning, and topical anesthetic for acute pain management during needle sticks in children with intellectual and developmental disabilities. Clinical Pediatrics 2011;50(8):688-97.

\section{Smith 1989 \{published data only\}}

Smith KE, Ackerson JD, Blotcky AD. Reducing distress during invasive medical procedures: Relating behavioral interventions to preferred coping style in pediatric cancer patients. Journal of Pediatric Psychology 1989;14(3):405-19.

\section{Smith 1996 \{published data only\}}

Smith JT, Barabasz A, Barabasz M. Comparison of hypnosis and distraction in severely ill children undergoing painful medical procedures. Journal of Counseling Psychology 1996;43(2):187-95

\section{Sparks 2001 \{published data only\}}

Sparks L. Taking the "ouch" out of injections for children: Using distraction to decrease pain. American Journal of Maternal/Child Nursing 2001;26(2):72-8.

\section{Stefano 2005 \{unpublished data only\}}

Stefano C, Giancarlo I, Corrado V. The experience of control related to the procedure of non-pharmacologic pain management in paediatric oncology and heamatology. Poster abstract - no source identified. 2005

\section{Stevenson 2005 \{published data only\}}

Stevenson MD, Bivins CM, O'Brien K, Gonzalez del Rey JA. Child life intervention during angiocatheter insertion in the 
pediatric emergency department. Pediatric Emergency Care 2005;21(11):712-8.

\section{Suresh 2015 \{published data only\}}

Suresh BS, De Oliveira GS Jr, Suresh S. The effect of audio therapy to treat postoperative pain in children undergoing major surgery: A randomized controlled trial. Pediatric Surgery International 2015;31(2):197-201.

\section{Sury 2010 \{published data only\}}

Sury M, Bullock I, Rabar S, DeMott K. Sedation for diagnostic and therapeutic procedures in children and young people: summary of NICE guidance. BMJ 2010;341:c6819.

\section{Thurgate 2005 \{published data only\}}

Thurgate C, Heppell S. Needle phobia--changing venepuncture practice in ambulatory care. Paediatric Nursing 2005;17(9):15-8.

\section{Tokunaga 2017 \{published data only\}}

Tokunaga N, Fukai K. Psychosomatic effects of blanketing in nursing care. Japan Journal of Nursing Science 2017;14(2):89102.

\section{Tüfekci 2009 \{published data only\}}

Tüfekci FG, Celebioğlu A, Küçükoğlu S. Turkish children loved distraction: using kaleidoscope to reduce perceived pain during venipuncture. Journal of Clinical Nursing 2009;18(15):2180-6.

Tyson 2014 \{published data only (unpublished sought but not used)\}

Tyson ME, Bohl DD, Blickman JG. A randomized controlled trial: child life services in pediatric imaging. Pediatric Radiology 2014;44(11):1426-32.

Ujaoney 2013 \{published data only (unpublished sought but not used)\}

Ujaoney S, Mamtani M, Thakre T, Tote J, Hazarey V, Hazarey P, et al. Efficacy trial of Camouflage Syringe to reduce dental fear and anxiety. European Journal of Pediatric Dentistry 2013;14(4):273-8.

\section{Vernon 1974 \{published data only\}}

Vernon DT. Modeling and birth order in responses to painful stimuli. Journal of Personality and Social Psychology 1974;29(6):794-9.

\section{Vika 2009 \{published data only\}}

Vika M, Skaret E, Raadal M, Ost LG, Kvale G. One-vs. five-session treatment of intra-oral injection phobia: a randomized clinical study. European Journal of Oral Sciences 2009;117(3):279-85

\section{Vohra 2011 \{published data only\}}

Vohra S, Nilsson S. Does music therapy reduce pain and anxiety in children with cancer undergoing lumbar puncture? Focus on Alternative and Complementary Therapies 2011;16(1):66-7.

\section{Wall 1989 \{published data only\}}

Wall VJ, Womack W. Hypnotic versus active cognitive strategies for alleviation of procedural distress in pediatric oncology patients. American Journal of Clinical Hypnosis 1989;31(3):181-91.

Wallace 2010 \{published data only\}

Wallace DP, Allen KD, Lacroix AE, Pitner SL. The "cough trick:" a brief strategy to manage pediatric pain from immunization injections. Pediatrics 2010;125(2):e367-73.

Weber 2010 \{published data only\}

Weber FS. The influence of playful activities on children's anxiety during the preoperative period at the outpatient surgical center. Jornal de Pediatria 2010;86(3):209-14.

Weinstein 2003 \{published data only\}

Weinstein P, Raadal M, Naidu S, Yoshida T, Kvale G, Milgrom P. $A$ videotaped intervention to enhance child control and reduce anxiety of the pain of dental injections. European Journal of Paediatric Dentistry 2003;4(4):181-5.

Winborn 1989 \{published data only\}

Winborn MD. Associative and dissociative preparatory strategies for children undergoing dental treatment [Doctoral dissertation]. Memphis State University, 1989.

Wood 2002 \{published data only\}

Wood C. Introducing a protocol for procedural pain. Paediatric Nursing 2002;14(8):30-3

Yoo 2011 \{published data only\}

Yoo H, Kim S, Hur HK, Kim HS. The effects of an animation distraction intervention on pain response of preschool children during venipuncture. Applied Nursing Research 2011;24(2):94-100.

Young 1988 \{published data only\} Young MR, Fu VR. Influence of play and temperament on the young child's response to pain. Children's Health Care 1988;16(3):209-15.

\section{Zabin 1982 \{unpublished data only\}}

Zabin MA. The modification of children's behavior during blood work procedures [Doctoral dissertation]. West Virginia University, 1982.

Zahr 1998 \{published data only\}

Zahr KL. Therapeutic play for hospitalized preschoolers in Lebanon. Pediatric Nursing 1998;24(5):449-54.

Zeltzer 1982 \{published data only\}

Zeltzer L, LeBaron S. Hypnosis and nonhypnotic techniques for reduction of pain and anxiety during painful procedures in children and adolescents with cancer. Pediatrics 1982;101(6):1032-5.

\section{Additional references}

\section{Accardi 2009}

Accardi MC, Milling LS. The effectiveness of hypnosis for reducing procedure-related pain in children and adolescents: 
A comprehensive methodological review. Journal of Behavior Medicine 2009;32:328-39.

\section{Altman 2001}

Altman DG, Schulz KF, Moher D, Egger M, Davidoff F, Elbourne D, et al, CONSORT GROUP (Consolidated Standards of Reporting Trials). The revised CONSORT statement for reporting randomized trials: Explanation and elaboration. Annals of Internal Medicine 2001;134:663-94.

\section{Alvarez 1997}

Alvarez CB, Marcos AF. Psychological treatment of evoked pain and anxiety by invasive medical procedures in paediatric oncology. Psychology in Spain 1997;1(1):17-36.

\section{Andrews 2013a}

Andrews J, Guyatt G, Oxman AD, Alderson P, Dahm P, FalckYtter Y, et al. GRADE guidelines: 14 . Going from evidence to recommendations: the significance and presentation of recommendations. Journal of Clinical Epidemiology 2013;66:719-25.

\section{Andrews 2013b}

Andrews J, Schunemann HJ, Oxman AD, Pottie K, Meerpohl J, Coello PA, et al. GRADE guidelines: 15. Going from evidence to recommendationddeterminants of a recommendation's direction and strength. Journal of Clinical Epidemiology 2013;66:726-35.

\section{Barlow 1999}

Barlow DH, Durand VM. Abnormal Psychology: An Integrative Approach. California: Brooks/Cole Publishing Company, 1999.

\section{Bauer 2015}

Bauer MS, Damschroder L, Hagedorn H, Smith J, Kilbourne AM. An introduction to implementation science for the nonspecialist. BMC Psychology 2015;3:1-12.

\section{Bellieni 2016}

Bellieni CV, Johnston CC. Analgesia, nil or placebo to babies, in trials that test new analgesic treatments for procedural pain. Acta Paediatrica 2016;105:129-36.

\section{Berberich 2012}

Berberich FR, Schechter NL. Pediatric office pain: crying for attention. Pediatrics 2012;129:e1057-59.

\section{Birnie 2014a}

Birnie KA, Noel M, Parker JA, Chambers CT, Uman LS, Kisely SR, et al. Systematic review and meta-analysis of distraction and hypnosis for needle-related pain and distress in children and adolescents. Journal of Pediatric Psychology 2014;39(8):783808.

\section{Birnie 2014b}

Birnie KA, Chambers CT, Fernandez CV, Forgeron PA, Latimer MA, McGrath PJ, et al. Hospitalized children continue to report undertreated and preventable pain. Pain Research and Management 2014;19:198-204.

\section{Birnie 2015}

Birnie KA, Chambers CT, Taddio A, McMurtry CM, Noel M, Pillai Riddell R, et al HELPinKids\&Adults Team. Psychological interventions for vaccine injections in children and adolescents: Systematic review of randomized and quasi-randomized controlled trials. Clinical Journal of Pain 2015;31:S72-S89.

\section{Birnie 2017}

Birnie KA, Chambers CT, Spellman CM. Mechanisms of distraction in acute pain perception and modulation. Pain 2017;158:1012-1013.

\section{Blount 2003}

Blount RL, Piira T, Cohen LL. Management of pediatric pain and distress due to medical procedures. In: MC Roberts, editors(s). Handbook of Pediatric Psychology. 3rd edition. New York: The Guilford Press, 2003.

\section{Boerner 2014}

Boerner KE, Gillespie JM, McLaughlin EN, Kuttner L, Chambers CT. Implementation of evidence-based psychological interventions for pediatric needle pain. Clinical Practice in Pediatric Psychology 2014;2:224-35.

\section{Boerner 2015}

Boerner KE, Birnie KA, Chambers CT, Taddio A, McMurtry CM, Noel M, et al HELPinKids\&Adults Team. Simple psychological interventions for reducing pain from common needle procedures in adults: Systematic review of randomized and quasi-randomized controlled trials. Clinical Journal of Pain 2015;31:S90-8.

\section{Broome 1990}

Broome ME, Bates TA, Lillis PP, McGahee TW. Children's medical fears, coping behaviors, and pain perceptions during a lumbar puncture. Oncology Nursing Forum 1990;17(3):361-7.

\section{Bukola 2017}

Bukola IM, Paula D. The effectiveness of distraction as procedural pain management technique in paediatric oncology patients: A meta-analysis and systematic review. Journal of Pain and Symptom Management 2017; Epub ahead of print:Epub ahead of print.

\section{Caldwell 2012}

Caldwell PH, Dans L, De Vries MC, Newman J, Sammon H, Spriggs M, et al. Standard 1: Consent and recruitment. Pediatrics 2012;129:S118-23.

\section{Campbell 2017}

Campbell L, DiLorenzo M, Atkinson N, Pillai Riddell R. Systematic review: A systematic review of the interrelationships among children's coping responses, children's coping outcomes, and parent cognitive-affective, behavioral, and contextual variables in the needle-related procedures context. Journal of Pediatric Psychology 2017;42:611-21.

\section{CDC 2018}

Centers for Disease Control and Prevention. Recommended Immunization Schedule for Children and Adolescents Aged 18 Years or Younger, United States, 2018. https://www.cdc.gov/ 
vaccines/schedules/hcp/imz/child-adolescent-compliant.htm (accessed August 30, 2018).

\section{Chambers 2009}

Chambers C, Taddio A, Uman L, McMurtry C. Psychological interventions for reducing pain and distress during routine childhood immunizations: a systematic review. Clinical Therapeutics 2009;31:S77-103.

\section{Chambers 2013}

Chambers CT, Taddio A, Stinson J, Campbell-Yeo M, Halperin S, Parker JA. It doesn't have to hurt: Strategies for helping children with shots and needles - A YouTube video for parents [Video file]. www.youtube.com/watch? $v=K g B w V S Y q f p s$ (accessed 4 November 2013).

\section{Chambers 2016}

Chambers CT, McMurtry CM, MacDonald N, Barwick M, Taddio A, Birnie K, et al. Needles Don't Have To Hurt. Parents Canada Advertorial all 2016.

\section{Chen 2000a}

Chen E, Joseph MH, Zeltzer LK. Acute pain in children: Behavioral and cognitive interventions in the treatment of pain in children. Pediatric Clinics of North America 2000;47(3):1-13.

\section{Christophersen 2001}

Christophersen ER, Mortweet SL. Assessment and management of pain. In: Treatments that Work with Children: Empirically Supported Strategies for Managing Childhood Problems. Washington: American Psychological Association, 2001.

\section{Cohen 1988}

Cohen J. Statistical Power Analysis in the Behavioral Sciences. 2nd edition. Hillsdale (NJ): Lawrence Erlbaum Associates, Inc., 1988.

\section{Craig 2010}

Craig KD, Versloot J, Goubert L, Vervoort T, Crombez G. Perceiving pain in others: Automatic and controlled mechanisms. Journal of Pain 2010;11:101-108.

\section{Curran 2012}

Curran GM, Bauer M, Mittman B, Pyne JM, Stetler C. Effectiveness-implementation hybrid designs: Combining elements of clinical effectiveness and implementation research to enhance public health impact. Medical Care 2012;50:217-26.

\section{Flowers 2015}

Flowers SR, Birnie KA. Procedural preparation and support as a standard of care in pediatric oncology. Pediatric Blood and Cancer 2015;62:S668-73.

\section{GRADEpro GDT 2015 [Computer program]}

McMaster University (developed by Evidence Prime, Inc.) GRADEpro GDT. Version Accessed 27 August 2018. Hamilton, ON: McMaster University (developed by Evidence Prime, Inc.), 2015. Available from gradepro.org.

\section{Guyatt 2011}

Guyatt G, Oxman AD, Akl EA, Kunz R, Vist G, Brozek J, et al. GRADE guidelines: 1 . Introduction-GRADE evidence profiles and summary of findings tables. Journal of Clinical Epidemiology 2011;64:383-94.

\section{Guyatt 2013}

Guyatt GH, Thorlund K, Oxman AD, Walter SD, Patrick D, Furukawa TA, et al. GRADE guidelines: 13 . Preparing summary of findings tables and evidence profiles-continuous outcomes. Journal of Clinical Epidemiology 2013;66:173-183.

\section{Hartling 2012}

Hartling L, Hamm M, Klassen T, Chen A-W, Meremikwu M, Moyer V, et al. Standard 2: Containing risk of bias. Pediatrics 2012;129:S124-31.

\section{Higgins 2017}

Higgins JPT, Churchill R, Chandler J, Cumpston MS (editors). Cochrane Handbook for Systematic Reviews of Interventions version 5.2.0 (updated June 2017), Cochrane, 2017. Available from www.training.cochrane.org/handbook.

\section{IASP 2004}

IASP Task Force on Taxonomy. Classification of Chronic Pain. 2nd edition. Seattle: IASP Press, 2004.

\section{Jadad 1996}

Jadad A, Moore RA, Carroll D, Jenkinson C, Reynolds DJ, Gavaghan DJ, et al. Assessing the quality of reports of randomized clinical trials: Is blinding necessary? Controlled Clinical Trials 1996;17:1-12.

\section{Jafari 2017}

Jafari H Courtois I, Van den Bergh O, Vlaeyen JWS, Van Diest I. Pain and respiration: A systematic review. Pain 2017;158:995-1006.

\section{Kazak 2001}

Kazak AE, Kunin-Batson A. Psychological and integrative interventions in pediatric procedure pain. In: GA Finley, PJ McGrath, editors(s). Acute and Procedure Pain in Infants and Children. Seattle: IASP Press, 2001:77-100.

\section{Keefe 1992}

Keefe FJ, Dunsmore J, Burnett R. Behavioral and cognitivebehavioral approaches to chronic pain: Recent advances and future directions. Special issue: Behavioral medicine: An update for the 1990s. Journal of Consulting and Clinical Psychology 1992;60(4):528-36.

\section{Kennedy 2008}

Kenney RM, Luhmann J, Zempsky WT. Clinical implications of unmanaged needle-insertion pain and distress in children. Pediatrics 2008;122:S130-3.

\section{Kenney 2016}

Kenney MP, Milling LS. The effectiveness of virtual reality distraction for reducing pain: A meta-analysis. Psychology of Consciousness: Theory, Research, and Practice 2016;3:199-210. 


\section{Klassen 2008}

Klassen J, Liang Y, Tjosvold L, Klassen T, Hartling L. Music for pain and anxiety in children undergoing medical procedures: $\mathrm{A}$ systematic review of randomized controlled trials. Acute Pain 2008;10(2):106.

\section{Ljungman 1999}

Ljungman G, Gordh T, Sorenson S, Kreuger A. Pain in paediatric oncology: interviews with children, adolescents and their parents. Acta Paediatrica 1999;88:623-30.

\section{McGrath 2008}

McGrath PJ, Walco GA, Turk DC, Dworkin RH, Brown MT, Davidson $\mathrm{K}$, et al. Core outcome domains and measures for pediatric acute and chronic/recurrent pain clinical trials: PedIMMPACT recommendations. Journal of Pain 9;9:771-83.

\section{McMurtry 2015a}

McMurtry CM, Noel M, Taddio A, Antony MM, Asmundson GJ, Pillai Riddell R, et al HELPinKids\&Adults Team. Interventions for individuals with high levels of needle fear: Systematic review of randomized controlled trials and quasi-randomized controlled trials. Clinical Journal of Pain 2015;31:S109-23.

\section{McMurtry 2015b}

McMurtry CM, Pillai Riddell R, Taddio A, Racine N, Asmundson GJ, Noel M, et al, HELPinKids\&Adults Team. Far from "just a poke": Common painful needle procedures and the development of needle fear. Clinical Journal of Pain 2015;31:S3-11.

\section{McMurtry 2016}

McMurtry CM, Taddio A, Noel M, Antony MM, Chambers CT, Asmundson GJ, et al. Exposure-based interventions for the management of individuals with high levels of needle fear across the lifespan: A clinical practice guideline and call for further research. Cognitive Behaviour Therapy 2016;45(3):217-35.

\section{MedLine 2004}

MedlinePlus Medical Encyclopedia. www.nIm.nih.gov/ medlineplus/mplusdictionary.html (accessed 4 February 2004).

\section{Moher 2010}

Moher D, Hopewell S, Schulz KF, Montori V, Gøtzsche PC, Devereaux PJ, et al. CONSORT 2010 explanation and elaboration: updated guidelines for reporting parallel group randomised trials. British Medical Journal 2010;340:c869. [DOI: 10.1136/bmj.c869]

\section{Morris 2011}

Morris ZS, Wooding S, Grant J. The answer is 17 years, what is the question: understanding time lags in translational research. Journal of the Royal Society of Medicine 2011;104:510-20.

\section{NACl 2018}

National Advisory Committee on Immunization. Canada's Provincial and Territorial Routine (and Catch-up) Vaccination Routine Schedule Programs for Infants and Children, 2018. https://www.canada.ca/en/public-health/services/provincialterritorial-immunization-information/provincial-territorial- routine-vaccination-programs-infants-children.html (accessed August 30, 2018).

\section{Noel 2012}

Noel M, Chambers CT, Petter M, McGrath PJ, Klein RM, Stewart SH. "Pain is not over when the needle ends": A review and preliminary model of acute pain memory development in childhood. Pain Management 2012;2:487-97.

\section{Noel 2018}

Noel M, McMurtry CM, Pavlova M, Taddio A. Brief Clinical Report: A systematic review and meta-analysis of pain memoryreframining interventions for children's needle procedures. Pain Practice 2018;18(1):123-9.

\section{Pate 1996}

Pate JT, Blount RL, Cohen LL, Smith AJ. Childhood medical experience and temperament as predictors of adult functioning in medical situations. Children's Health Care 1996;25:281-98.

\section{Pillai-Riddell 2011}

Pillai Riddell R, Racine N, Turcotte K, Uman LS, Horton R, Din Osmun L, et al. Nonpharmacological management of procedural pain in infants and young children: An abridged Cochrane review. Pain Research and Management 2011;16(5):321-30.

\section{Pillai-Riddell 2015}

Pillai Riddell RR, Racine NM, Gennis HG, Turcotte K, Uman LS, Horton RE, et al. Non-pharmacological management of infant and young child procedural pain. Cochrane Database of Systematic Reviews 2015, Issue 12. Art. No: CD006275. [DOI: 10.1002/14651858.CD006275.pub3]

\section{Powers 1999}

Powers SW. Empirically supported treatments in pediatric psychology: Procedure-related pain. Journal of Pediatric Psychology 1999;24(2):131-45.

\section{Puntillo 2004}

Puntillo KA, Morris AB, Thompson CL, Stanik-Hutt J, White CA, Wild LR. Pain behaviors observed during six common procedures: Results from Thunder Project II. Critical Care Medicine 2004;32(2):421-7.

\section{RevMan 2014 [Computer program]}

The Nordic Cochrane Centre, The Cochrane Collaboration Review Manager (RevMan). Version 5.3. Copenhagen: The Nordic Cochrane Centre, The Cochrane Collaboration, 2014.

\section{Richardson 2006}

Richardson J, Smith JE, McCall G, Pilkington K. Hypnosis for procedure-related pain and dis- tress in pediatric cancer patients: A systematic review of effectiveness and methodology related to hypnosis interventions. Journal of Pain and Symptom Management 2006;31:70-84.

\section{Savovic 2012}

Savovic J, Jones HE, Altman DG, Harris RJ, Jüni P, Pildal J, et al. Influence of reported study design characteristics on 
intervention effect estimates from randomized, controlled trials. Annals of Internal Medicine 2012;157:429-38.

\section{Schechter 2008}

Schechter NL. From the ouchless place to comfort central: The evolution of a concept. Pediatrics 2008;122:S154-60.

\section{Schechter 2010a}

Schechter NL, Finley GA, Bright NS, Laycock M, Forgeron P. ChildKind: A global initiative to reduce pain in children. Pediatric Pain Letter 2010;12:26-30.

\section{Sinha 2012}

Sinha IP, Altman DG, Beresford MW, Boers M, Clarke M, Craig J, et al. Standard 5: Selection, measurements, and reporting of outcomes in clinical trials in children. Pediatrics 2012;129:S146-52.

\section{Skinner 2007}

Skinner EA, Zimmer-Gembeck MJ. The development of coping. Annual Review of Psychology 2007;58:119-44.

\section{Smith 2014}

Smith KF, Goldberg M, Rosenthal S, Carlson L, Chen J, Chen C, et al. Global rise in human infectious disease outbreaks. Jouranl of the Royal Society Interfance 2014;11:1-6.

\section{Stevens 2011}

Stevens B, Abbott L, Yamada J, Harrison D, Stinson J, Finley A, et al. Epidemiology and management of painful procedures in children in Canadian hospitals. Canadian Medical Association Journal 2011;183(7):E403-10.

\section{Stevens 2012}

Stevens BJ, Harrison D, Rashotte J, Yamada J, Abbott LK, Coburn G, et al. Pain assessment and intensity in hospitalized children in Canada. Journal of Pain 2012;13(9):857-65.

\section{Sucala 2013}

Sucala M, Schnur JB, Glazier K, Miller SJ, Green JP, Montgomery GH. Hypnosis - There's an app for that: A systematic review of hypnosis apps. International Journal of Clinical and Experimental Hypnosis 2013;61:463-74.

\section{Sweet 1998}

Sweet SD, McGrath PJ. Physiological measures of pain. In: GA Finley, PJ McGrath, editors(s). Measurement of Pain in Infants and Children. Seattle: IASP Press, 1998:59-81.

\section{Taddio 2009}

Taddio A, Chambers CT, Halperin SA, Ipp M, Lockett D, Rieder, $M J$, et al. Inadequate pain management during routine childhood immunizations: The nerve of it. Clinical Therapeutics 2009;31 Suppl 2:S152-67.

\section{Taddio 2012}

Taddio A, Ipp M, Thivakaran S, Jamal A, Parikh C, Smart S, et al. Survey of the prevalence of immunization non-compliance due to needle fears in children and adults. Vaccine 2012;30:4807-12.

\section{Taddio 2015}

Taddio A, McMurtry CM, Shah V, Pillai Riddell R, Chambers CT, Noel $M$, et al HELPinKids\&Adults. Reducing pain during vaccine injections: Clinical practice guideline. Canadian Medical Association Journal 2015;187:975-82.

\section{Uman 2008}

Uman LS, Chambers CT, McGrath PJ, Kisely S. A systematic review of randomized controlled trials examining psychological interventions for needle-related procedural pain and distress in children and adolescents: An abbreviated Cochrane Review. Journal of Pediatric Psychology 2008;33:842-54.

\section{Uman 2010}

Uman LS, Chambers CT, McGrath PJ, Kisely S, Matthews D, Hayton K. Assessing the quality of randomized controlled trials examining psychological interventions for pediatric procedural pain: Recommendations for quality improvement. Journal of Pediatric Psychology 2010;35:693-703.

\section{Van der Tweel 2012}

Van der Tweel I, Askie L, Vandermeer B, Ellenberg S, Fernandes RM, Saloojee H, et al. Standard 4: Determining adequate sample size. Pediatrics 2012;129:S138-45.

\section{Verhoeven 2012}

Verhoeven K, Goubert L, Jaaniste T, Van Ryckeghem DM, Crombez $\mathrm{G}$. Pain catastrophizing influences the use and the effectiveness of distraction in schoolchildren. European Journal of Pain 2012;16:256-67.

\section{Von Baeyer 2017}

Von Baeyer CL, Jaaniste T, Vo HL, Brunsdon G, Lao H-C, Champion GD. Systematic review of self-report measures of pain intensity in 3- and 4-year-old children: Bridging a period of rapid cognitive development. Journal of Pain 2017;18:1017-26.

\section{WHO 2015}

World Health Organization. Meeting of the Strategic Advisory Group of Experts on immunization, April 2015: conclusions and recommendations. Weekly Epidemiological Record 29 May 2015;22:261-80.

\section{WHO 2017}

World Health Organization. School-based Immunization. www.who.int/immunization/programmes_systems/policies_ strategies/school_based_immunization/en/ (accessed 23 March 2017).

\section{WHO 2018}

World Health Organization. Table 1: Summary of WHO Position Papers - Recommendations for Routine Immunization, 2018. http://www.who.int/immunization/policy/Immunization_ routine_table1.pdf (accessed August 30, 2018).

\section{Williams 2012}

Williams K, Thomson D, Seto I, Contopoulos-Ioannidis DG, loannidis JP, Curtis S, et al. Standard 6: Age groups for pediatric trials. Pediatrics 2012;129:S153-60. 


\section{Wittmeier 2015}

Wittmeier KD, Klassen TP, Sibley KM. Implementation science in pediatric health care: Advances and opportunities. JAMA Pediatrics 2015;169:307-9.

\section{Young 2005}

Young KD. Pediatric procedural pain. Annals of Emergency Medicine 2005;45(2):160-71.

\section{References to other published versions of this review Uman 2005 \\ Uman LS, Chambers CT, McGrath PJ, Kisely S. Psychological interventions for needle-related procedural pain and distress in children and adolescents. Cochrane Database of Systematic Reviews 2005, Issue 1. Art. No: CD005179. [DOI: 10.1002/14651858.CD005179]}

\section{CHARACTERISTICS OF STUDIES}

Characteristics of included studies [ordered by study ID]

\section{Uman 2006}

Uman LS, Chambers CT, McGrath PJ, Kisely S. Psychological interventions for needle-related procedural pain and distress in children and adolescents (Review). Cochrane Database of Systematic Reviews 2006, Issue 4. Art. No: CD005179. [DOI: 10.1002/14651858.CD005179.pub2]

\section{Uman 2013}

Uman LS, Birnie KA, Noel M, Parker JA, Chambers CT, McGrath PJ, Kisely SR. Psychological interventions for needle-related procedural pain and distress in children and adolescents. Cochrane Database of Systematic Reviews 2013, Issue 10. Art. No: CD005179. [DOI: 10.1002/14651858.CD005179.pub3]

* Indicates the major publication for the study

Aydin 2017

\section{Study characteristics}

Methods RCT. 4 arms.

Participants

Number of children: 50 control, 150 treatment (50 per treatment group)

Sex of children: $116 \mathrm{M}, 84 \mathrm{~F}$

Age range of children: 7 - 12 years

Mean age of children: $9.01 \pm 2.35$ years

Needle procedure: blood draw

Diagnosis of child: none stated

Inclusion criteria: children aged 7 - 12 years and requiring blood tests

Exclusion criteria: neuro-developmentally delayed, had verbal difficulties, hearing or visual impairments, used analgesics within the last 6 hours, or a history of syncope due to blood sampling

Setting: phlebotomy station of the Bandirma State Hospital, Turkey

1. Distraction cards: Children were shown Flippits distraction cards (MMJ Labs, Atlanta, Georgia, USA). Children were given the opportunity to examine the cards, and then the researcher asked the children about what they could see on the cards. Distraction with the cards began immediately prior to phlebotomy and continued until the procedure had been complete.

2. Music: During phlebotomy process, the children and were asked to choose one of 20 Turkish pop fast songs stored in a tablet $\mathrm{pc}$, which was then played throughout the phlebotomy process.

3. Distraction cards plus music: Distraction cards + music were applied together during phlebotomy.

4. Control: Children in this group were allowed to keep their family nearby. The routine blood-taking procedure was conducted.

Outcomes Pain measure:

- Child self-report: Wong Baker FACES Scale 
Aydin 2017 (Continued)

- Parent report: Wong Baker FACES Scale

- Nurse report: Wong Baker FACES Scale

Distress measure:

- Parent-report: Children's Fear Scale (CFS)

- Nurse-report: Children's Fear Scale (CFS)

Adverse events: none mentioned

\begin{tabular}{ll}
\hline Notes & Study dates: July 1 to September 20, 2015 \\
& Funding source: none stated \\
Conflicts of interest: none declared \\
\hline
\end{tabular}

\section{Risk of bias}

\section{Bias}

Authors' judgement Support for judgement

Random sequence genera- Low risk tion (selection bias)

Quote: "...randomly distributed...using a computer program" (p.165)

\begin{tabular}{|c|c|c|}
\hline $\begin{array}{l}\text { Allocation concealment } \\
\text { (selection bias) }\end{array}$ & Unclear risk & Insufficient information to permit judgment of 'low' or 'high' risk. \\
\hline $\begin{array}{l}\text { Blinding of participants } \\
\text { and personnel (perfor- } \\
\text { mance bias) } \\
\text { All outcomes }\end{array}$ & High risk & Study participants and personnel were not blinded \\
\hline $\begin{array}{l}\text { Blinding of outcome as- } \\
\text { sessment (detection bias) } \\
\text { All outcomes }\end{array}$ & High risk & No blinding of outcome assessment \\
\hline $\begin{array}{l}\text { Incomplete outcome data } \\
\text { (attrition bias) } \\
\text { All outcomes }\end{array}$ & Low risk & No missing data \\
\hline $\begin{array}{l}\text { Selective reporting (re- } \\
\text { porting bias) }\end{array}$ & Unclear risk & Insufficient information to permit judgment of 'low' or 'high' risk \\
\hline Other bias & Low risk & Appears to be free of other bias that would affect outcomes \\
\hline
\end{tabular}

Balan 2009

\section{Study characteristics}

\begin{tabular}{ll}
\hline Methods & RCT. 3 arms. \\
\hline Participants & Number of children: 50 control, 50 treatment \\
& Sex of children: $55 \mathrm{M}, 45 \mathrm{~F}$ \\
& Age range of children: $5-12$ years \\
& Mean age of children: $7.96 \pm 2.18$ years
\end{tabular}


Balan 2009 (Continued)

Needle procedure: venepuncture for blood collection

Diagnosis of child: heterogeneous (see exclusion criteria).

Inclusion criteria: 5 - 12 years old, requiring venepuncture for blood collection

Exclusion criteria: history of hypersensitivity to local anesthetics of the amide type or to 1 or more of the constituents of EMLA, history of congenital or idiopathic methaemoglobinaemia, glucose-6-phosphatase deficiency or sever hepatic disease, children with altered sensorium, children whose clinical condition warranted the urgent administration of drugs

Setting: inpatient department at a hospital in Mumbai, India

Interventions Music therapy: Indian classical instrumental music using headphones
2. No intervention control: placebo cream and headphones with no music
3. EMLA cream

\begin{tabular}{ll}
\hline Outcomes & Pain measures (all ratings at minute 0 ): \\
- Child self-report: 0 - 10 VAS \\
- Caregiver/parent report of child pain: 0 - 10 VAS \\
- Nurse/health professional report of child pain: 0 - 10 VAS \\
Adverse events: none mentioned \\
We used a total $N$ of 100 for this study (instead of 150 ) because we only assessed 2 of 3 interventions \\
(music therapy versus no intervention control group). \\
Study dates: study dates not reported \\
Funding source: none stated \\
Conflicts of interest: none declared
\end{tabular}

\section{Risk of bias}

\begin{tabular}{lll}
\hline Bias & Authors' judgement & Support for judgement \\
\hline $\begin{array}{l}\text { Random sequence genera- } \\
\text { tion (selection bias) }\end{array}$ & Low risk & Quote: "randomized...using random number table" p.470 Par 1 \\
\hline $\begin{array}{l}\text { Allocation concealment } \\
\text { (selection bias) }\end{array}$ & High risk & Use of an open random allocation schedule (e.g. random-number table) \\
\hline $\begin{array}{l}\text { Blinding of participants } \\
\text { and personnel (perfor- } \\
\text { mance bias) }\end{array}$ & High risk & Participants and personnel were not blinded \\
$\begin{array}{l}\text { All outcomes } \\
\begin{array}{l}\text { Blinding of outcome as- } \\
\text { sessment (detection bias) } \\
\text { All outcomes }\end{array}\end{array}$ & High risk & $\begin{array}{l}\text { No blinding of self-report outcome assessment and researcher provided inter- } \\
\text { vention and outcome assessment }\end{array}$ \\
\hline $\begin{array}{l}\text { Incomplete outcome data } \\
\text { (attrition bias) } \\
\text { All outcomes }\end{array}$ & Unclear risk & $\begin{array}{l}\text { Quote: "Whenever possible this child was also told to indicate his or her score } \\
\text { on the VAS." p. 470 Par 2 }\end{array}$ \\
\hline
\end{tabular}


Balan 2009 (Continued)

Selective reporting (re- High risk One or more outcomes reported incompletely for inclusion in meta-analysis
porting bias)

Other bias Low risk Appears to be free of other bias that would affect outcomes

Bellieni 2006

\section{Study characteristics}

\begin{tabular}{|c|c|}
\hline Methods & RCT. 3 arms. \\
\hline \multirow[t]{9}{*}{ Participants } & Number of children: 23 control, 46 treatment \\
\hline & Sex of children: $33 \mathrm{M}, 36 \mathrm{~F}$ \\
\hline & Age range of children: 7 - 12 years \\
\hline & Mean age of children: not reported (Median = 9 years for intervention; 8 years for control) \\
\hline & Needle procedure: venepuncture \\
\hline & Diagnosis of child: "outpatients" \\
\hline & Inclusion criteria: 7 - 12 years old, last meal 3 hours before venepuncture \\
\hline & Exclusion criteria: neurodevelopmental delay, frequent venepunctures (> 1/year) \\
\hline & Setting: Italy, no other details provided \\
\hline \multirow[t]{3}{*}{ Interventions } & 1. Cartoon TV distraction: Cartoon played on a TV, started 120 seconds before venepuncture \\
\hline & $\begin{array}{l}\text { 2. Mother-directed distraction: Active distraction by mothers during the venepuncture by speaking, ca- } \\
\text { ressing, and soothing }\end{array}$ \\
\hline & 3. No distraction control: Mothers present and asked not to distract children \\
\hline \multirow[t]{4}{*}{ Outcomes } & Pain measures: \\
\hline & - Child self-report: Oucher Pain Rating Scale \\
\hline & - Parent report of child pain: Oucher Pain Rating Scale \\
\hline & Adverse events: none mentioned \\
\hline \multirow[t]{3}{*}{ Notes } & Study dates: study dates not reported \\
\hline & Funding source: none stated \\
\hline & Conflicts of interest: none declared \\
\hline
\end{tabular}

\section{Risk of bias}

\begin{tabular}{lll}
\hline Bias & Authors' judgement & Support for judgement \\
\hline $\begin{array}{l}\text { Random sequence genera- } \\
\text { tion (selection bias) }\end{array}$ & Low risk & $\begin{array}{l}\text { Quote: "using a random numbers from a computer generated sequence" } \\
\text { p.1015 Par 2 }\end{array}$ \\
\hline $\begin{array}{l}\text { Allocation concealment } \\
\text { (selection bias) }\end{array}$ & Unclear risk & Insufficient information to permit judgment of 'low' or 'high' risk \\
\hline
\end{tabular}


Bellieni 2006 (Continued)

Blinding of participants and personnel (perfor-

High risk Study participants and personnel were not blinded

All outcomes

\begin{tabular}{lll}
\hline $\begin{array}{l}\text { Blinding of outcome as- } \\
\text { sessment (detection bias) } \\
\text { All outcomes }\end{array}$ & High risk & No blinding of outcome assessment \\
\hline $\begin{array}{l}\text { Incomplete outcome data } \\
\text { (attrition bias) } \\
\text { All outcomes }\end{array}$ & Low risk & No missing data \\
\hline $\begin{array}{l}\text { Selective reporting (re- } \\
\text { porting bias) }\end{array}$ & Unclear risk & Insufficient information to permit judgment of 'low' or 'high' risk \\
\hline $\begin{array}{l}\text { Other bias } \\
\text { Unclear risk }\end{array}$ & $\begin{array}{l}\text { Insufficient information to assess whether an important risk of bias exists (e.g. } \\
\text { parenting pain rating..."ignoring the score given by the child" p.1015) }\end{array}$
\end{tabular}

Beran 2013

\section{Study characteristics}

\begin{tabular}{|c|c|}
\hline Methods & RCT. 2 arms. \\
\hline \multirow[t]{9}{*}{ Participants } & Number of children: 29 control, 28 treatment \\
\hline & Sex of children: $30 \mathrm{M}, 27 \mathrm{~F}$ \\
\hline & Age range of children: 4 - 9 years \\
\hline & Mean age of children: $6.87 \pm 1.34$ years \\
\hline & Needle procedure: flu vaccination \\
\hline & Diagnoses of child: $40.4 \%$ had a chronic medical condition (e.g. asthma, cystic fibrosis) \\
\hline & $\begin{array}{l}\text { Inclusion criteria: } 4 \text { - } 9 \text { years, referred for flu vaccination by their physicians or signed up for the vacci- } \\
\text { nation through posters }\end{array}$ \\
\hline & Exclusion criteria: none given \\
\hline & Setting: infectious disease outpatient clinic at tertiary care children's hospital in Canada \\
\hline \multirow[t]{2}{*}{ Interventions } & $\begin{array}{l}\text { 1. Robot: Children sat in front of a robot that was pre-programmed for distraction before, during, and } \\
\text { after the procedure. During the injection, the robot asked the child to blow on a dusty toy. The nurses } \\
\text { and parents were given no specific instructions about how to act. }\end{array}$ \\
\hline & $\begin{array}{l}\text { 2. Comparison: Children were seated beside a table with several toy objects. The nurse administered } \\
\text { the vaccine using current immunization guidelines. This included minimal distraction. The nurses and } \\
\text { parents were given no specific instructions about how to act. }\end{array}$ \\
\hline \multirow[t]{5}{*}{ Outcomes } & Pain measures: \\
\hline & - Child self-report: FPS-R \\
\hline & - Parent report of child pain: FPS-R \\
\hline & - Nurse report of child pain: FPS-R \\
\hline & - Researcher report of child pain: FPS-R \\
\hline
\end{tabular}

Psychological interventions for needle-related procedural pain and distress in children and adolescents (Review) 
Distress measures:

- Behavioral approach - avoidance and distress scale

Adverse events: none mentioned

Notes

Cinical Trial Registration: NCT01529021

Study dates: October 2011

Funding source: none stated

Conflicts of interest: none declared

\section{Risk of bias}

\begin{tabular}{|c|c|c|}
\hline Bias & Authors' judgement & Support for judgement \\
\hline $\begin{array}{l}\text { Random sequence genera- } \\
\text { tion (selection bias) }\end{array}$ & Low risk & Quote: "computer generated random number sequence" p.2773 \\
\hline $\begin{array}{l}\text { Allocation concealment } \\
\text { (selection bias) }\end{array}$ & Unclear risk & Insufficient information to permit judgment of 'low' or 'high' risk. \\
\hline $\begin{array}{l}\text { Blinding of participants } \\
\text { and personnel (perfor- } \\
\text { mance bias) } \\
\text { All outcomes }\end{array}$ & High risk & Study participants and personnel were not blinded \\
\hline $\begin{array}{l}\text { Blinding of outcome as- } \\
\text { sessment (detection bias) } \\
\text { All outcomes }\end{array}$ & High risk & No blinding of outcome assessment. \\
\hline $\begin{array}{l}\text { Incomplete outcome data } \\
\text { (attrition bias) } \\
\text { All outcomes }\end{array}$ & Low risk & No missing data \\
\hline $\begin{array}{l}\text { Selective reporting (re- } \\
\text { porting bias) }\end{array}$ & Low risk & Objectives clearly stated and reported fully. \\
\hline Other bias & Low risk & Appears to be free of other bias that would affect outcomes. \\
\hline
\end{tabular}

Bisignano 2006

\section{Study characteristics}

\begin{tabular}{ll}
\hline Methods & RCT. 2 arms. \\
\hline Participants & Number of children: 16 control, 14 treatment \\
& Sex of children: $15 \mathrm{M}, 15 \mathrm{~F}$ \\
& Age range of children: $6-18$ years \\
& Mean age range of children: 11.4 years \\
& Needle procedure: IV procedures
\end{tabular}


Diagnosis of child: cancer (acute lymphoblastic leukemia, sickle cell anemia, lymphoma, acute myeloid leukemia, osteosarcoma, Hodgkin's disease, Glanzmann's thrombasthemia, aplastic anemia, chronic myelomonocystic leukemia)

Inclusion criteria: English-speaking, 7 - 18 years, scheduled for IV procedures, history of at least 2 previous IVs

Exclusion: none given

Setting: Hematology/Oncology clinic at large urban medical center (Harbor-University of California Los Angeles Medical Center) in the United States

Interventions

1. CD-ROM: Children had approximately 20 minutes to interact with $2 \mathrm{CD}-\mathrm{ROMs} 1$ to 2 hours prior to the procedure. The first CD helped children learn about the procedure using education/information, preprocedural preparation (video modeling), breathing exercises, and distracting imagery. The CD allowed children to ask questions (e.g. what is an IV?), educated children on IV procedural terms, and taught children simple breathing exercises and an imagery technique. Children were also given a choice of viewing 2 videos on the IV procedure. The second CD focused on particular IV procedures used with some of the children (i.e. Hickman, Broviac, Port-a-cath).

2. Standard medical care: Children received the routine hospital preparation for the procedure. This preparation included an explanation of the IV procedure and application of a topical anesthetic cream approximately 1 hour prior to the procedure. Children in both groups received this preparation.

Pain measures:
- Child self-report: Children's Pain Self-Report (Pain-SR)
Distress measures:
- Child self-report of fear: Children's Fear Self-Report (Fear-SR) post-procedure
- Experimenter report of anxiety: VAS (1 - 5)
- Procedural Behavioral Rating Scale (PBRS) during procedure

Adverse events: none mentioned

Study dates: study dates not reported
Funding: none stated
Conflicts of interest: none declared

\section{Risk of bias}

\begin{tabular}{lll}
\hline Bias & Authors' judgement & Support for judgement \\
\hline $\begin{array}{l}\text { Random sequence genera- } \\
\text { tion (selection bias) }\end{array}$ & Unclear risk & $\begin{array}{l}\text { Stratified randomization process was used. Insufficient information to permit } \\
\text { judgment of 'low' or 'high' risk }\end{array}$ \\
\hline $\begin{array}{l}\text { Allocation concealment } \\
\text { (selection bias) }\end{array}$ & Unclear risk & Insufficient information to permit judgment of 'low' or 'high' risk \\
\hline $\begin{array}{l}\text { Blinding of participants } \\
\text { and personnel (perfor- } \\
\text { mance bias) } \\
\text { All outcomes }\end{array}$ & High risk & Participants were not blinded \\
\hline $\begin{array}{l}\text { Blinding of outcome as- } \\
\text { sessment (detection bias) } \\
\begin{array}{l}\text { All outcomes } \\
\hline\end{array}\end{array}$ & High risk & No blinding of self-report outcome assessment \\
\hline
\end{tabular}


Bisignano 2006 (Continued)

Incomplete outcome data High risk No reason provided for missing data and imbalance in missing data across (attrition bias) groups

All outcomes

Selective reporting (re- Unclear risk Insufficient information to permit judgment of 'low' or 'high' risk
porting bias)

Other bias High risk Multiple potential sources of bias related to study design and other problems

Blount 1992

\section{Study characteristics}

\begin{tabular}{ll}
\hline Methods & RCT. 2 arms. \\
\hline Participants & Number of children: 30 control, 30 treatment \\
Sex of children: $32 \mathrm{M}, 28 \mathrm{~F}$ \\
Age range of children: $3-7$ years \\
Mean age range of children: 5 years \pm 10 months \\
Needle procedure: routine immunization \\
Diagnosis of child: none \\
Inclusion criteria: children attending a local county health department \\
Exclusion criteria: none given \\
Setting: local county health department in Georgia, United States
\end{tabular}

Interventions

1. Distraction + coping skills training: Parent instruction on how to coach their child to blow a party blower immediately prior to and during the injections, using modeling and role play with a pretend needle, followed by feedback and praise (10 - 12 minutes)

2. Standard care control: waited until called for their immunization

Pain measure:
- Child self-report: 5-faces scale
- Parent report of child pain: $10 \mathrm{~cm}$ VAS
Distress measure:
- Observational scale of behavioral distress
- Behavioral approach-avoidance and distress scale
- Child self-report of fear: 5 -faces scale
- Parent report of child distress: $10 \mathrm{~cm}$ VAS
- Parent report of child fear: $10 \mathrm{~cm}$ VAS
- Nurse report of child distress: $10 \mathrm{~cm}$ VAS
Adverse events: none mentioned
Study dates: study dates not reported
Funding: NIMH grant R29 MH44301 and support from The Institute for Behavioral Research at The Uni-
versity of Georgia

Psychological interventions for needle-related procedural pain and distress in children and adolescents (Review) 
Blount 1992 (Continued)

Conflicts of interest: none declared

\section{Risk of bias}

\begin{tabular}{|c|c|c|}
\hline Bias & Authors' judgement & Support for judgement \\
\hline $\begin{array}{l}\text { Random sequence genera- } \\
\text { tion (selection bias) }\end{array}$ & Unclear risk & $\begin{array}{l}\text { Randomized - no further details. Insufficient information to permit judgment } \\
\text { of 'low' or 'high' risk }\end{array}$ \\
\hline $\begin{array}{l}\text { Allocation concealment } \\
\text { (selection bias) }\end{array}$ & Unclear risk & Insufficient information to permit judgment of 'low' or 'high' risk \\
\hline $\begin{array}{l}\text { Blinding of participants } \\
\text { and personnel (perfor- } \\
\text { mance bias) } \\
\text { All outcomes }\end{array}$ & High risk & Study participants and personnel were not blinded \\
\hline $\begin{array}{l}\text { Blinding of outcome as- } \\
\text { sessment (detection bias) } \\
\text { All outcomes }\end{array}$ & High risk & No blinding of outcome assessment \\
\hline $\begin{array}{l}\text { Incomplete outcome data } \\
\text { (attrition bias) } \\
\text { All outcomes }\end{array}$ & Low risk & No missing data \\
\hline $\begin{array}{l}\text { Selective reporting (re- } \\
\text { porting bias) }\end{array}$ & High risk & One or more outcomes of interest are reported incompletely \\
\hline Other bias & High risk & $\begin{array}{l}\text { Potential source of bias related to validity of measurement tool with partici- } \\
\text { pant young age }\end{array}$ \\
\hline
\end{tabular}

Caprilli 2007

\section{Study characteristics}

\begin{tabular}{ll}
\hline Methods & RCT. 2 arms. \\
\hline Participants & Number of children: 54 control, 54 treatment \\
Sex of children: $52 \mathrm{M}, 56 \mathrm{~F}$ & Age range of children: 4 - 13 years \\
& Mean age range of children: $6.67 \pm 3.19$ (intervention); $7.07 \pm 3.47$ (control) \\
& Needle procedure: venepuncture \\
& Diagnosis of child: none given \\
& Inclusion criteria: native-born, Italian-speaking children \\
& Exclusion criteria: significant hearing or visual impairments, cognitive disorders, previous experience of \\
hospitalization & Setting: Anna Meyer Pediatric Hospital, Florence, Italy \\
1. Music distraction: Live musicians played and sang music before, during, and after blood sampling. \\
Parents were present and the child was invited to join in the music. Approximately 20 minutes.
\end{tabular}


Caprilli 2007 (Continued)

2. Standard medical care control: Children in this group received standard medical care. The doctor and nurse who performed the procedure were the same for the control and the music groups, and they were instructed to maintain their normal modes of consolation and/or distraction.

\begin{tabular}{ll}
\hline Outcomes & Pain measure: \\
& C Child self-report: Wong Baker Faces Scale \\
& Distress measure: \\
& A Amended form of Observational Scale of Behavioral Distress (OSBD-A) (Phase 2 used in analyses) \\
& Adverse events: none mentioned \\
\hline Notes & Study dates: November 2003 to February 2004 \\
& Funding: Anna Meyer Foundation \\
Conflicts of interest: none declared
\end{tabular}

\section{Risk of bias}

\begin{tabular}{|c|c|c|}
\hline Bias & Authors' judgement & Support for judgement \\
\hline $\begin{array}{l}\text { Random sequence genera- } \\
\text { tion (selection bias) }\end{array}$ & Unclear risk & $\begin{array}{l}\text { Quote: "children were randomly assigned to one of two groups". Insufficient in- } \\
\text { formation to permit judgment of 'low' or 'high' risk }\end{array}$ \\
\hline $\begin{array}{l}\text { Allocation concealment } \\
\text { (selection bias) }\end{array}$ & Unclear risk & Insufficient information to permit judgment of 'low' or 'high' risk \\
\hline $\begin{array}{l}\text { Blinding of participants } \\
\text { and personnel (perfor- } \\
\text { mance bias) } \\
\text { All outcomes }\end{array}$ & High risk & Study participants and personnel were not blinded \\
\hline $\begin{array}{l}\text { Blinding of outcome as- } \\
\text { sessment (detection bias) } \\
\text { All outcomes }\end{array}$ & High risk & No blinding of outcome assessment \\
\hline $\begin{array}{l}\text { Incomplete outcome data } \\
\text { (attrition bias) } \\
\text { All outcomes }\end{array}$ & Low risk & No missing data \\
\hline $\begin{array}{l}\text { Selective reporting (re- } \\
\text { porting bias) }\end{array}$ & High risk & One or more outcomes of interest are reported incompletely \\
\hline Other bias & High risk & $\begin{array}{l}\text { Had a potential source of bias related to the specific study design (e.g. timing } \\
\text { of parent ratings) }\end{array}$ \\
\hline
\end{tabular}

Cassidy 2002

\section{Study characteristics}

\begin{tabular}{ll}
\hline Methods & RCT. 2 arms. \\
\hline Participants & Number of children: 33 control, 29 treatment \\
& Sex of children: $28 \mathrm{M}, 34 \mathrm{~F}$
\end{tabular}


Age range of children: 5 years

Mean age range of children: not reported

Needle procedure: DPTP immunization

Diagnosis of child: none

Inclusion criteria: 5 years old, due to receive standard DPTP preschool immunization, in good health, developmentally normal, parent/guardian agreement to participate after initial recruitment contact

Exclusion criteria: previously immunized with DPTP vaccine, previously hospitalized, the presence of any acute or chronic medical condition

Setting: 2 urban pediatric practices in Halifax, Nova Scotia, Canada

Interventions $\quad \begin{aligned} & \text { 1. Audio-visual distraction: Age-appropriate TV musical cartoon } \\ & \text { 2. Blank screen standard care control: TV was present but off }\end{aligned}$

$\begin{array}{ll}\text { Putcomes } & \text { Pain measure: } \\ \text { - } & \text { Child self-report: Faces Pain Scale (FPS) } \\ \text { - Experimenter rating of child pain: Children's Hospital of Eastern Ontario Pain Scale (CHEOPS), from } \\ \text { videotaped procedures } \\ \text { - Experimenter rating of child pain: Child Facial Coding System (CFCS) } \\ \text { Distress measure: } \\ \text { - Parent rating of child anxiety: } 10 \mathrm{~cm} \text { VAS } \\ \text { Adverse events: none mentioned } \\ \text { Study dates: study dates not reported } \\ \text { Funding: Dalhousie Medical School Research Foundation } \\ \text { Conflicts of interest: none declared }\end{array}$

Risk of bias

\begin{tabular}{lll}
\hline Bias & Authors' judgement & Support for judgement \\
\hline $\begin{array}{l}\text { Random sequence genera- } \\
\text { tion (selection bias) }\end{array}$ & Low risk & $\begin{array}{l}\text { Quote: "subjects were randomly assigned...using a standard randomization } \\
\text { table" p.110 Par 2 }\end{array}$ \\
\hline $\begin{array}{l}\text { Allocation concealment } \\
\text { (selection bias) }\end{array}$ & High risk & Use of an open random allocation schedule (e.g. random-number table) \\
\hline $\begin{array}{l}\text { Blinding of participants } \\
\text { and personnel (perfor- } \\
\text { mance bias) }\end{array}$ & High risk & Study participants and personnel were not blinded \\
$\begin{array}{l}\text { All outcomes } \\
\text { Blinding of outcome as- } \\
\text { sessment (detection bias) } \\
\begin{array}{l}\text { All outcomes } \\
\text { Incomplete outcome data }\end{array}\end{array}$ & High risk & No blinding of self-report outcome assessment \\
$\begin{array}{l}\text { (attrition bias) } \\
\text { All outcomes }\end{array}$ & & $\begin{array}{l}\text { No reasons for missing data provided and unclear of potential impact on out- } \\
\text { comes }\end{array}$ \\
\hline
\end{tabular}


Cassidy 2002 (Continued)

Selective reporting (re- Unclear risk Insufficient information to permit judgment of 'low' or 'high' risk porting bias)

Other bias

High risk

Multiple potential sources of bias related to study design and other problems

(e.g. non-neutral control stimulus)

Cavender 2004

\section{Study characteristics}

\begin{tabular}{|c|c|}
\hline Methods & RCT. 2 arms. \\
\hline \multirow[t]{9}{*}{ Participants } & Number of children: 23 control, 20 treatment \\
\hline & Sex of children: $19 \mathrm{M}, 24 \mathrm{~F}$ \\
\hline & Age range of children: 4 - 11years \\
\hline & Mean age of children: $7.88 \pm 1.74$ years \\
\hline & Needle procedure: venepuncture or IV insertion \\
\hline & Diagnosis of child: surgical $(n=11)$, trauma $(n=7)$, vomiting $(n=9)$, other $(n=16)$ \\
\hline & Inclusion criteria: 4 - 11 years old, English-speaking, has medical order for venepuncture or IV insertion \\
\hline & Exclusion criteria: children with chronic illness, children presenting with possible child abuse \\
\hline & Setting: emergency department of private 322-bed, pediatric medical center in the Southwestern USA \\
\hline \multirow[t]{2}{*}{ Interventions } & $\begin{array}{l}\text { 1. Distraction + parental positioning: Standard care with the addition of instructions from child life spe- } \\
\text { cialists on positioning and distraction. Parents engaged their child with the distraction by asking ques- } \\
\text { tions and reminding them to concentrate }\end{array}$ \\
\hline & 2. Standard care control \\
\hline \multirow[t]{7}{*}{ Outcomes } & Pain measure: \\
\hline & - Child self-report during procedure: Wong Baker FACES Pain Rating \\
\hline & Distress measure: \\
\hline & - Child self-report during procedure: Glasses Fear Scale \\
\hline & $\begin{array}{l}\text { - Parent and Child Life Specialist report of child fear (during procedure, post-procedure): Glasses Fear } \\
\text { Scale }\end{array}$ \\
\hline & - Child Life Specialist report of child distress: Procedural Behavior Checklist (PBCL) \\
\hline & Adverse events: none mentioned \\
\hline \multirow[t]{3}{*}{ Notes } & Study dates: study dates not reported \\
\hline & Funding: Les Femmes du Monde of Dallas, Texas \\
\hline & Conflicts of interest: none declared \\
\hline
\end{tabular}

\section{Risk of bias}


Cavender 2004 (Continued)

Random sequence genera- Low risk Quote: "randomly assigned...by a table of random numbers" p.36 Par 2 tion (selection bias)

Allocation concealment High risk Use of an open random allocation schedule (e.g. random-number table)
(selection bias)

(selection bias)

Blinding of participants High risk Study participants and personnel were not blinded

and personnel (perfor-

mance bias)

All outcomes

\begin{tabular}{lll}
$\begin{array}{l}\text { Blinding of outcome as- } \\
\text { sessment (detection bias) } \\
\text { All outcomes }\end{array}$ & High risk & No blinding of outcome assessment \\
\hline $\begin{array}{l}\text { Incomplete outcome data } \\
\text { (attrition bias) } \\
\text { All outcomes }\end{array}$ & Low risk & No missing data \\
\hline $\begin{array}{l}\text { Selective reporting (re- } \\
\text { porting bias) }\end{array}$ & High risk & One or more outcomes of interest are reported incompletely \\
\hline Other bias & Unclear risk & $\begin{array}{l}\text { Insufficient information to assess whether an important risk of bias exists (e.g. } \\
\text { reliability of fear scale) }\end{array}$
\end{tabular}

Chen 1999

\section{Study characteristics}

\begin{tabular}{|c|c|}
\hline Methods & RCT. 2 arms. \\
\hline \multirow[t]{9}{*}{ Participants } & Number of children: 25 control, 25 treatment \\
\hline & Sex of children: $67 \% \mathrm{M}, 33 \% \mathrm{~F}$ \\
\hline & Age range of children: 3 - 18 years \\
\hline & Mean age range of children: $7.3 \pm 3.7$ years \\
\hline & Needle procedure: 3 lumbar punctures (LPs; baseline, post-intervention, follow-up) \\
\hline & Diagnosis of child: acute lymphoblastic leukemia \\
\hline & $\begin{array}{l}\text { Inclusion criteria: diagnosis of acute lymphoblastic leukemia, } 3 \text { to18 years, English- or Spanish-speak- } \\
\text { ing }\end{array}$ \\
\hline & Exclusion criteria: none given \\
\hline & $\begin{array}{l}\text { Setting: Outpatient Children's Center for Cancer and Blood Diseases at the Children's Hospital Los An- } \\
\text { geles, USA }\end{array}$ \\
\hline Interventions & $\begin{array}{l}\text { 1.Brief alteration of memory: Treatment was conducted at } 2 \text { time points: after the first LP and before } \\
\text { the second LP. The therapist conducted a memory interview with the child and encouraged the child to } \\
\text { re-evaluate their reactions to the LP through enhancing their beliefs about the efficacy of their coping } \\
\text { strategies, realistically appraise their responses to the LP, and increase the accuracy of their subjective } \\
\text { memory. The therapist and child discussed differences between the child's memories and observed } \\
\text { behaviors/self-reports. Children were encouraged to remember successful coping attempts. Children }\end{array}$ \\
\hline
\end{tabular}


Chen 1999 (Continued)

wrote down memories discussed on a fluorescent card with a cartoon child thinking about his or her LP experience. Children took the card to the second LP.

2. Attentional control: Children spent the same amount of time with the therapist as the treatment group, but were engaged in non-procedure-related activities (e.g. drawing). Children in both groups received support, encouragement, and preparation from staff, including information and demonstration with dolls.

Pain measure:
- Child self-report: VAS $(10 \mathrm{~cm})$ post-procedure
- Parent rating of child pain: VAS $(10 \mathrm{~cm})$ post-procedure
Distress measure:
- Child self-report of anxiety: VAS $(10 \mathrm{~cm})$ post-procedure
- Parent rating of child anxiety: VAS $(10 \mathrm{~cm})$ post-procedure
- Physician assistant rating of child's procedural distress: VAS $(10 \mathrm{~cm})$
- Procedure Behavior Check List $(\mathrm{PBCL})$
Physiological measures:
- Systolic and diastolic blood pressure ratings post-procedure
- Heart rate post-procedure
- Salivary cortisol post-procedure
Adverse events: none mentioned

Notes

Study dates: study dates not reported

Funding: Grant F31MH11365 from the National Institute of Mental Health and by Grant 3796 from the American Cancer Society, California Division.

Conflicts of interest: none declared

\section{Risk of bias}

\begin{tabular}{lll}
\hline Bias & Authors' judgement & Support for judgement \\
\hline $\begin{array}{l}\text { Random sequence genera- } \\
\text { tion (selection bias) }\end{array}$ & Unclear risk & $\begin{array}{l}\text { Randomized - no further details. Insufficient information to permit judgment } \\
\text { of 'low' or 'high' risk }\end{array}$ \\
\hline $\begin{array}{l}\text { Allocation concealment } \\
\text { (selection bias) }\end{array}$ & Unclear risk & Insufficient information to permit judgment of 'low' or 'high' risk \\
\hline $\begin{array}{l}\text { Blinding of participants } \\
\text { and personnel (perfor- } \\
\text { mance bias) } \\
\text { All outcomes }\end{array}$ & High risk & Study participants and personnel were not blinded \\
\hline
\end{tabular}

\begin{tabular}{|c|c|c|}
\hline $\begin{array}{l}\text { Blinding of outcome as- } \\
\text { sessment (detection bias) } \\
\text { All outcomes }\end{array}$ & High risk & No blinding of outcome assessment \\
\hline $\begin{array}{l}\text { Incomplete outcome data } \\
\text { (attrition bias) } \\
\text { All outcomes }\end{array}$ & Low risk & Reasons for missing data unlikely to be related to true outcome \\
\hline $\begin{array}{l}\text { Selective reporting (re- } \\
\text { porting bias) }\end{array}$ & High risk & $\begin{array}{l}\text { One or more outcomes of interest are reported incompletely (i.e. number of } \\
\text { participants per group) }\end{array}$ \\
\hline
\end{tabular}

Psychological interventions for needle-related procedural pain and distress in children and adolescents (Review) 
Chen 1999 (Continued)

Other bias Low risk Appears to be free of other bias that would affect outcomes.

Cohen 2015

\section{Study characteristics}

\begin{tabular}{|c|c|}
\hline Methods & RCT. 3 arms. \\
\hline \multirow[t]{9}{*}{ Participants } & Number of children: 30 control, 30 parenting training plus distraction, 30 distraction \\
\hline & Sex of children: $44 \mathrm{M}, 46 \mathrm{~F}$ \\
\hline & Age range of children: $4-6 \frac{1}{2}$ years \\
\hline & Mean age range of children: 4.8 years \pm 9.7 months \\
\hline & Needle procedure: routine vaccinations \\
\hline & Diagnosis of child: none reported \\
\hline & Inclusion criteria: 4 - 6 years, presenting for preschool immunizations \\
\hline & $\begin{array}{l}\text { Exclusion criteria: non-English speakers unable to complete measures, child having significant medical } \\
\text { or developmental issues }\end{array}$ \\
\hline & Setting: outpatient pediatric practice in the United States \\
\hline \multirow[t]{3}{*}{ Interventions } & $\begin{array}{l}\text { 1. Bear Essentials parent training plus distraction: Parents received a laptop loaded with the "Bear } \\
\text { Essentials" program to complete while in the waiting room. This is an interactive computer program } \\
\text { with a narrator that explains parent behaviors that positively or negatively impact child distress during } \\
\text { an immunization. In the treatment room, the nurse provided a portable DVD player and a selection of } \\
\text { movies to the family to use during the procedure. }\end{array}$ \\
\hline & $\begin{array}{l}\text { 2. Distraction only: Parents were provided with a laptop installed with parent-led computer games to } \\
\text { use while in the waiting room. In the treatment room, the nurse made available a portable DVD play- } \\
\text { er and a selection of movies to watch during the procedure. No direct training about optimal behavior } \\
\text { was provided to the parents. }\end{array}$ \\
\hline & $\begin{array}{l}\text { 3. Standard care control: Parents were provided treatment as usual. No training, movies, or other sys- } \\
\text { tematic distractions were provided. }\end{array}$ \\
\hline \multirow[t]{7}{*}{ Outcomes } & Pain measure: \\
\hline & - Child self-report: Faces Pain Scale-Revised (FPS-R) \\
\hline & - Parent report of child pain: VAS (100 mm) \\
\hline & - Nurse report of child pain: VAS (100 mm) \\
\hline & Distress measure: \\
\hline & - Child procedural behaviors of crying, screaming, and negative emoting \\
\hline & Adverse events: none mentioned \\
\hline \multirow[t]{3}{*}{ Notes } & Study dates: Study dates not reported \\
\hline & $\begin{array}{l}\text { Funding: grant from the National Institute of Child Health and Human Development at the National In- } \\
\text { stitutes of Health (1R21HD047263-01) }\end{array}$ \\
\hline & Conflicts of interest: none declared \\
\hline
\end{tabular}

Psychological interventions for needle-related procedural pain and distress in children and adolescents (Review) 
Cohen 2015 (Continued)

Risk of bias

\begin{tabular}{|c|c|c|}
\hline Bias & Authors' judgement & Support for judgement \\
\hline $\begin{array}{l}\text { Random sequence genera- } \\
\text { tion (selection bias) }\end{array}$ & Low risk & Quote: "computer generated random number table" p.3 \\
\hline $\begin{array}{l}\text { Allocation concealment } \\
\text { (selection bias) }\end{array}$ & High risk & Quote: "condition assignment remained concealed in a binder" \\
\hline $\begin{array}{l}\text { Blinding of participants } \\
\text { and personnel (perfor- } \\
\text { mance bias) } \\
\text { All outcomes }\end{array}$ & High risk & Study participants and personnel were not blinded \\
\hline $\begin{array}{l}\text { Blinding of outcome as- } \\
\text { sessment (detection bias) } \\
\text { All outcomes }\end{array}$ & High risk & No blinding of outcome assessment. \\
\hline $\begin{array}{l}\text { Incomplete outcome data } \\
\text { (attrition bias) } \\
\text { All outcomes }\end{array}$ & Low risk & No missing data \\
\hline $\begin{array}{l}\text { Selective reporting (re- } \\
\text { porting bias) }\end{array}$ & Unclear risk & Insufficient information to permit judgment of 'low' or 'high' risk \\
\hline Other bias & Low risk & Appears to be free of other bias that would affect outcomes. \\
\hline
\end{tabular}

\section{Crevatin 2016}

\section{Study characteristics}

\begin{tabular}{ll}
\hline Methods & RCT. 2 arms. \\
\hline Participants & Number of children: 100 control, 100 treatment \\
Sex of children: $98 \mathrm{M}, 102 \mathrm{~F}$ \\
Age range of children: 4 - 13 years \\
Mean age range of children: 8.6 years (treatment); 8.9 years (control) \\
Needle procedure: venipuncture \\
Diagnosis of child: $12 \%$ (treatment) and 19\% (control) with mixed chronic disease \\
Inclusion criteria: 4 - 13 years, at blood drawing center to have blood sample collected by venipuncture \\
Exclusion criteria: patient history of epilepsy, use of topical, enteral or parenteral analgesics up to 8 \\
hours before blood drawing, inability to have venipuncture performed on their hand or arm, presence \\
of cognitive impairment or inability to report pain verbally \\
Setting: blood-drawing center of tertiary-level children's hospital in Italy
\end{tabular}

Interventions

1. Hand-held computer distraction: Children played Angry Birds, a game in which they had to shoot birds into the pig's fortresses, on a hand-held computer. Children started to play the game 3 minutes before the procedure and then continued for a maximum of 3 minutes after the procedure. 
2. Nurse-led low-tech distraction ('Standard care'): Children received various kinds of conventional distractions from a nurse (nurse singing a song, reading a book, blowing bubbles, performing a puppet show) starting 3 minutes before the procedure. The technique that most engaged the child was continued during the procedure.

\begin{tabular}{|c|c|c|}
\hline Outcomes & \multicolumn{2}{|c|}{$\begin{array}{l}\text { Pain measures: } \\
\text { - Child self-report ( } 4-7 \text { year-olds): FPS-R } \\
\text { - Child self-report ( } 8 \text { - } 13 \text { year-olds): Numerical rating scale }(0-10) \\
\text { Adverse events: none mentioned }\end{array}$} \\
\hline Notes & \multicolumn{2}{|c|}{$\begin{array}{l}\text { Study dates: March to June } 2013 \\
\text { Funding: none stated } \\
\text { Conflicts of interest: none declared }\end{array}$} \\
\hline \multicolumn{3}{|l|}{ Risk of bias } \\
\hline Bias & Authors' judgement & Support for judgement \\
\hline $\begin{array}{l}\text { Random sequence genera- } \\
\text { tion (selection bias) }\end{array}$ & Low risk & Quote: "generated using a computer-based method" p.931 \\
\hline $\begin{array}{l}\text { Allocation concealment } \\
\text { (selection bias) }\end{array}$ & Low risk & $\begin{array}{l}\text { Quote: "guaranteed using sealed consecutively numbered opaque envelopes" } \\
\text { p.931 }\end{array}$ \\
\hline $\begin{array}{l}\text { Blinding of participants } \\
\text { and personnel (perfor- } \\
\text { mance bias) } \\
\text { All outcomes }\end{array}$ & High risk & Study participants and personnel were not blinded \\
\hline $\begin{array}{l}\text { Blinding of outcome as- } \\
\text { sessment (detection bias) } \\
\text { All outcomes }\end{array}$ & High risk & No blinding of outcome assessment \\
\hline $\begin{array}{l}\text { Incomplete outcome data } \\
\text { (attrition bias) } \\
\text { All outcomes }\end{array}$ & Low risk & No missing data \\
\hline $\begin{array}{l}\text { Selective reporting (re- } \\
\text { porting bias) }\end{array}$ & Low risk & Primary and secondary outcomes clearly stated and reported \\
\hline Other bias & Low risk & Appears to be free of other bias that would affect outcomes \\
\hline
\end{tabular}

Ebrahimpour 2015

\section{Study characteristics}

\begin{tabular}{ll}
\hline Methods & RCT. 2 arms. \\
\hline Participants & Number of children: 15 control, 15 treatment \\
Sex of children: $15 \mathrm{M}, 15 \mathrm{~F}$ \\
Age range of children: 3 - 12 years
\end{tabular}


Ebrahimpour 2015 (Continued)

Mean age range of children: $7 \pm 1.7$ years (treatment), $7.5 \pm 2.7$ years (control)

Needle procedure: injection of insulin by syringe or insulin pen

Diagnosis of child: type I diabetes

Inclusion criteria: 3 - 12 years, have type 1 diabetes, mother administering insulin by syringe or insulin pen, observed/mother's report of child's behavioral distress during insulin injection, willing to participate in the study, home availability of computer

Exclusion criteria: morbidity of specific mental and physical disorders, uncooperative mothers or children in follow-up, acute recent problems (acute illnesses, hospitalization, death of close family members)

Setting: Isfahan Endocrine and Metabolism Research Center, Iran

Interventions

1. Interactive computer game: Children received an interactive computer game designed to teach them about diabetes and insulin injections. Children were asked to play the game at home at least once a week.

2. Control: No intervention

\begin{tabular}{ll}
\hline Outcomes & Distress measure: \\
& Observational Scale of Behavioral Distress-Revised (OSBD-R) \\
& Adverse events: none mentioned \\
\hline Notes & Study dates: 2013 \\
& Funding: Isfahan Endocrine and Metabolism Research Center and deputy of research in Isfahan Medical \\
& Sciences University \\
& Conflicts of interest: none declared
\end{tabular}

\section{Risk of bias}

\begin{tabular}{lll}
\hline Bias & Authors' judgement & Support for judgement \\
\hline $\begin{array}{l}\text { Random sequence genera- } \\
\text { tion (selection bias) }\end{array}$ & Unclear risk & $\begin{array}{l}\text { Quote: "allocated randomly". Insufficient information to permit judgment of } \\
\text { 'low' or 'high' risk }\end{array}$ \\
\hline $\begin{array}{l}\text { Allocation concealment } \\
\text { (selection bias) }\end{array}$ & Unclear risk & Insufficient information to permit judgment of 'low' or 'high' risk \\
\hline $\begin{array}{l}\text { Blinding of participants } \\
\begin{array}{l}\text { and personnel (perfor- } \\
\text { mance bias) }\end{array}\end{array}$ & High risk & Study participants and personnel were not blinded \\
All outcomes & \\
\hline
\end{tabular}

Blinding of outcome as-
sessment (detection bias) $\quad$ High risk No blinding of outcome assessment.

All outcomes

\begin{tabular}{ll}
\hline Incomplete outcome data Low risk No missing data \\
(attrition bias)
\end{tabular}

All outcomes

Selective reporting (re- Unclear risk Insufficient information to permit judgment of 'low' or 'high' risk
porting bias)


Ebrahimpour 2015 (Continued)

Other bias High risk Had potential source of bias likely to influence outcome (i.e. parents coded OSBD-R)

\section{Eland 1981}

\section{Study characteristics}

\begin{tabular}{ll}
\hline Methods & RCT. 4 arms. \\
\hline Participants & Number of children: 40 (10 in each group) \\
Sex of children: $20 \mathrm{M}, 20 \mathrm{~F}$ \\
Age range of children: $4.9-5.9$ years \\
Mean age range of children: not reported \\
Needle procedure: intramuscular injection \\
Diagnosis of child: none given \\
Inclusion criteria: scheduled for pre-kindergarten physical examinations \\
Exclusion criteria: none given \\
Setting: private pediatrician's office in a Midwestern city in the United States with a population of \\
60,000
\end{tabular}

Interventions

1. Frigiderm coolant with cognitive information: Children were told by the nurse that they would have something sprayed on their leg that would not hurt, would make their leg feel cool, and would make the shot hurt less than other shots they have had. Children had a skin coolant sprayed on the injection site immediately prior to the injection.

2. Frigiderm coolant with no cognitive information: Children were told by the nurse that they would have something sprayed on their leg. Children had a skin coolant sprayed on the injection site immediately prior to the injection.

3. Control aerosol spray with cognitive information: Children were told by the nurse that they would have something sprayed on their leg that would not hurt, would make their leg feel cool, and would make the shot hurt less than other shots they have had. Children had aerosol air sprayed on their leg immediately prior to the injection.

4. Control aerosol spray with no cognitive information: Children were told by the nurse that they would have something sprayed on their leg. Children had aerosol air sprayed on their leg immediately prior to the injection.

Outcomes Pain measures:

- Child self-report: color scale comprising $8 \times 1 \frac{1}{2}$ inch color squares placed across the bottom of a white felt board representing different events related to varying levels of pain $(0-3)$ post-procedure

Distress measures:

- Parent verbal report: not anxious, somewhat anxious, very anxious

- Nurse verbal report: not anxious, somewhat anxious, very anxious

Adverse events: none mentioned 
Eland 1981 (Continued)

Study dates: study dates not reported

Funding: United States Public Health Service, Predoctoral Fellow, 3 F 31-NU-05153-01

Conflicts of interest: none declared

\section{Risk of bias}

\begin{tabular}{|c|c|c|}
\hline Bias & Authors' judgement & Support for judgement \\
\hline $\begin{array}{l}\text { Random sequence genera- } \\
\text { tion (selection bias) }\end{array}$ & Unclear risk & $\begin{array}{l}\text { Randomized - no further details. Insufficient information to permit judgment } \\
\text { of 'low' or 'high' risk }\end{array}$ \\
\hline $\begin{array}{l}\text { Allocation concealment } \\
\text { (selection bias) }\end{array}$ & Unclear risk & Insufficient information to permit judgment of 'low' or 'high' risk \\
\hline $\begin{array}{l}\text { Blinding of participants } \\
\text { and personnel (perfor- } \\
\text { mance bias) } \\
\text { All outcomes }\end{array}$ & High risk & Personnel were not blinded \\
\hline $\begin{array}{l}\text { Blinding of outcome as- } \\
\text { sessment (detection bias) } \\
\text { All outcomes }\end{array}$ & Low risk & $\begin{array}{l}\text { Unclear if participant blinding, but judged not likely to influence outcome } \\
\text { measurement }\end{array}$ \\
\hline $\begin{array}{l}\text { Incomplete outcome data } \\
\text { (attrition bias) } \\
\text { All outcomes }\end{array}$ & Low risk & No missing data \\
\hline $\begin{array}{l}\text { Selective reporting (re- } \\
\text { porting bias) }\end{array}$ & Unclear risk & Insufficient information to permit judgment of 'low' or 'high' risk \\
\hline Other bias & High risk & $\begin{array}{l}\text { Potential source of bias related to outcome measurement (e.g. modified mea- } \\
\text { sure with "limited reliability" p.370 Par 4) }\end{array}$ \\
\hline
\end{tabular}

\section{Fanurik 2000}

\section{Study characteristics}

Methods RCT. 2 arms.

\section{Participants}

Number of children: 80 control, 80 treatment

Sex of children: not reported

Age range of children: 2 - 16 years (mean age not reported)

Needle procedure: IV insertion

Diagnosis of child: none (undergoing elective outpatient gastrointestinal endoscopy)

Inclusion criteria: 2 - 16 years old, generally healthy, would have EMLA applied for at least 60 min prior to their IV insertion

Exclusion criteria: children with chart-documented, parent-reported, or suspected developmental delay or cognitive impairment

Setting: pediatric outpatients in the Gastroenterology Division of the Arkansas Children's Hospital, USA 
Fanurik 2000 (Continued)

Interventions

1. Age-appropriate distraction: Depending on child age different distracters were offered by nurse (e.g. bubbles, books, music)

2. Typical intervention control: Parents and children were asked to use whatever coping strategies they would typically do (age-appropriate book was available in the room with no instruction)

$\begin{array}{ll}\text { Outcomes } & \text { Pain measures: } \\ \text { - Child self-report: } 100 \mathrm{~mm} \text { VAS } \\ \text { Distress measures: } \\ \text { - Behavioral distress (post-procedure): 6-point numerical scale } \\ \text { - Child self-report of anticipatory anxiety: } 100 \mathrm{~mm} \text { VAS } \\ \text { - Parental prediction of child anxiety: } 100 \mathrm{~mm} \text { VAS } \\ \text { Adverse events: none mentioned } \\ \text { Study dates: study dates not reported } \\ \text { Fotes } \\ \text { Cunding: none stated } \\ \text { Conflicts of interest: none declared }\end{array}$

\section{Risk of bias}

Bias Authors' judgement Support for judgement

Random sequence genera- Unclear risk tion (selection bias)
Children were assigned to one of four stratified age groups (2- 4 years, 5-8 years, 9-12 years, 13-16 years) and then randomized to the treatment or control group - no further details. Insufficient information to permit judgment of 'low' or 'high' risk

Allocation concealment Unclear risk Insufficient information to permit judgment of 'low' or 'high' risk
(selection bias)

Blinding of participants High risk Study participants and personnel were not blinded
and personnel (performance bias)

All outcomes

$\begin{array}{ll}\text { Blinding of outcome as- } & \text { High risk }\end{array}$ No blinding of outcome assessment

All outcomes

Incomplete outcome data High risk Imbalance in numbers for missing data across intervention groups
(attrition bias)

All outcomes

Selective reporting (re- High risk One or more outcomes of interest are reported incompletely porting bias)

Other bias Unclear risk Insufficient information to assess whether an important risk of bias exists

\section{Study characteristics}

Psychological interventions for needle-related procedural pain and distress in children and adolescents (Review) 
Fowler-Kerry 1987 (Continued)

\begin{tabular}{|c|c|}
\hline Methods & RCT. 5 arms. \\
\hline Participants & $\begin{array}{l}\text { Number of children: } 80 \text { control, } 120 \text { treatment } \\
\text { Sex of children: } 100 \mathrm{M}, 100 \mathrm{~F} \\
\text { Age range of children: } 4.5 \text { - } 6.5 \text { years } \\
\text { Mean age of children: } 5.5 \text { years } \\
\text { Needle procedure: immunization } \\
\text { Diagnosis of child: none } \\
\text { Inclusion criteria: } 4.5 \text { - } 7 \text { years old, healthy children } \\
\text { Exclusion criteria: none given } \\
\text { Setting: patients attending } 1 \text { of } 3 \text { community health clinics located near a large metropolitan area in } \\
\text { Canada }\end{array}$ \\
\hline
\end{tabular}

Interventions

1.Music distraction through headphones: Age-appropriate music using headphones, played immediately prior to and during the injection.

2. Suggestion: Children were told that the experimenter was going to help them when they had their injection. They wore headphones but no music was played.

3. Music distraction and suggestion: Children were told that the experimenter was going to help them when they had their injection. They wore headphones and music was played.

4. Control condition with headphones: Children did not receive distraction or suggestion, but did wear headphones.

5. Control condition without headphones: Children did not receive distraction or suggestion, and did not wear headphones.

\begin{tabular}{|c|c|}
\hline Outcomes & $\begin{array}{l}\text { Pain measure: } \\
\text { - Child self-report: 4-point VAS } \\
\text { Adverse events: none mentioned }\end{array}$ \\
\hline \multirow[t]{4}{*}{ Notes } & $\begin{array}{l}\text { We used a total } \mathrm{N} \text { of } 160 \text { for this study (instead of 200), because we only included } 4 \text { of } 5 \text { interventions } \\
\text { (Distraction versus Combined } 2 \text { Control Conditions and Suggestion versus Combined } 2 \text { Control Condi- } \\
\text { tions). }\end{array}$ \\
\hline & Study dates: study dates not reported \\
\hline & Funding: grant from the Alberta Association of Registered Nurses \\
\hline & Conflicts of interest: none declared \\
\hline
\end{tabular}

\section{Risk of bias}

\begin{tabular}{lll}
\hline Bias & Authors' judgement & Support for judgement \\
\hline $\begin{array}{l}\text { Random sequence genera- } \\
\text { tion (selection bias) }\end{array}$ & Unclear risk & $\begin{array}{l}\text { Randomized - randomly assigned with the restriction that there be equal num- } \\
\text { bers of boys and girls in each group - no further details. Insufficient informa- } \\
\text { tion to permit judgment of 'low' or 'high' risk }\end{array}$ \\
\hline $\begin{array}{l}\text { Allocation concealment } \\
\text { (selection bias) }\end{array}$ & Unclear risk & Insufficient information to permit judgment of 'low' or 'high' risk \\
\hline
\end{tabular}


Fowler-Kerry 1987 (Continued)

$\begin{array}{lll}\begin{array}{l}\text { Blinding of participants } \\ \text { and personnel (perfor- }\end{array} & \text { High risk } & \begin{array}{l}\text { Although authors report blinding of participants and personnel, the nature of } \\ \text { psychological intervention precludes this }\end{array}\end{array}$
psychological intervention precludes this mance bias)

All outcomes

\begin{tabular}{lll}
$\begin{array}{l}\text { Blinding of outcome as- } \\
\text { sessment (detection bias) } \\
\text { All outcomes }\end{array}$ & High risk & No blinding of s \\
\hline $\begin{array}{l}\text { Incomplete outcome data } \\
\text { (attrition bias) }\end{array}$ & Low risk & No missing data \\
All outcomes &
\end{tabular}

\begin{tabular}{lll}
\hline $\begin{array}{l}\text { Selective reporting (re- } \\
\text { porting bias) }\end{array}$ & Unclear risk & Insufficient information to permit judgment of 'low' or 'high' risk \\
\hline Other bias & Unclear risk & $\begin{array}{l}\text { Insufficient information to assess whether an important risk of bias exists (e.g., } \\
\text { "failure of suggestion may be attributed to an ineffective suggestion state- } \\
\text { ment" p.174 Par 2) }\end{array}$ \\
\hline
\end{tabular}

\section{Gold 2006}

\section{Study characteristics}

\begin{tabular}{|c|c|}
\hline Methods & RCT. 2 arms. \\
\hline \multirow[t]{9}{*}{ Participants } & Number of children: 10 control, 10 treatment \\
\hline & Sex of children: $12 \mathrm{M}, 8 \mathrm{~F}$ \\
\hline & Age range of children: 8 - 12 years \\
\hline & Mean age of children: 10.2 years \\
\hline & Needle procedure: IV \\
\hline & Diagnosis of child: heterogeneous, $12 / 20$ had "medical conditions" \\
\hline & Inclusion criteria: awaiting MRI or CT scans, required IV placement \\
\hline & $\begin{array}{l}\text { Exclusion criteria: children with known or reported cognitive disabilities, taking pain medication, did } \\
\text { not pass the cognitive and physical screening }\end{array}$ \\
\hline & Setting: Department of Radiology at Childrens Hospital Los Angeles, United States \\
\hline \multirow[t]{2}{*}{ Interventions } & $\begin{array}{l}\text { 1. Virtual reality distraction: Standard care and VR game presented through a head-mounted display, } \\
\text { which began } 5 \text { minutes before IV placement and continued for } 5 \text { minutes afterwards }\end{array}$ \\
\hline & 2. Standard care control: Topical anesthesia spray prior to IV placement \\
\hline \multirow[t]{3}{*}{ Outcomes } & Pain measure: \\
\hline & - Child-self report: FPS-R, Wong Baker FACES Pain Rating Scale, VAS (IV pain intensity) \\
\hline & Adverse events: none mentioned \\
\hline \multirow[t]{2}{*}{ Notes } & Study dates: study dates not reported \\
\hline & Funding: donation \\
\hline
\end{tabular}


Gold 2006 (Continued)

Conflicts of interest: none declared

\section{Risk of bias}

Bias Authors' judgement Support for judgement

Random sequence genera- Unclear risk tion (selection bias)

Stratified according to age (7-9, 10-12), then randomized to condition - no further details. Insufficient information to permit judgment of 'low' or 'high' risk

Allocation concealment Unclear risk Insufficient information to permit judgment of 'low' or 'high' risk (selection bias)

Blinding of participants High risk Participants and personnel were not blinded

and personnel (perfor-

mance bias)

All outcomes

\begin{tabular}{lll}
\hline $\begin{array}{l}\text { Blinding of outcome as- } \\
\text { sessment (detection bias) } \\
\text { All outcomes }\end{array}$ & High risk & No blinding of self-report outcome assessment \\
\hline $\begin{array}{l}\text { Incomplete outcome data } \\
\text { (attrition bias) } \\
\text { All outcomes }\end{array}$ & Low risk & No missing data \\
\hline $\begin{array}{l}\text { Selective reporting (re- } \\
\text { porting bias) }\end{array}$ & High risk & $\begin{array}{l}\text { One or more outcomes of interest are reported incompletely (i.e. nurse and } \\
\text { parent report) }\end{array}$ \\
\hline Other bias & High risk & Small sample size potential source of bias affecting outcomes \\
\hline
\end{tabular}

Gonzalez 1993

\section{Study characteristics}

Methods RCT. 3 arms.

Participants Number of children: 14 control, 14 treatment

Sex of children: $21 \mathrm{M}, 21 \mathrm{~F}$

Age range of children: 3 - 7 years

Mean age of children: $4.9 \pm 1.2$ years (intervention); $4.6 \pm .8$ years (control)

Needle procedure: Immunization

Diagnosis of child: none

Inclusion criteria: none given

Exclusion criteria: none given

Setting: primary care clinic at a large, urban public hospital in the United States

Interventions

1. Distraction: Prior to the procedure, mothers were instructed how to verbally distract their child during the medical procedure with modeling (through recording) and practice of example distractions. During the procedure, a large sign with distraction examples and a research assistant were available to cue parents. 
2. No treatment control: Mothers listened to a short lecture and discussed transportation to the hospital.

3. Reassurance: Mothers taught and practised reassuring their child verbally during the medical procedure.

Pain measure:
- Child self-report: Oucher Pain Rating Scale
Distress measure:
- OSBD-R
- Modified Frankl Behavior Rating Scale
Adverse events: None mentioned
We used a total N of 28 for this study (instead of 42) because we only included 2 of 3 intervention (Dis-
traction versus Control). This is because there is already considerable existing research to suggest that
reassurance is a distress-promoting strategy, and was therefore not included as one of the interven-
tions assessed in this review.
Study dates: study dates not reported
Funding: none stated
Conflicts of interest: none declared

\section{Risk of bias}

\begin{tabular}{|c|c|c|}
\hline Bias & Authors' judgement & Support for judgement \\
\hline $\begin{array}{l}\text { Random sequence genera- } \\
\text { tion (selection bias) }\end{array}$ & Unclear risk & $\begin{array}{l}\text { Randomized - using a block randomization procedure that took age into ac- } \\
\text { count - no further details. Insufficient information to permit judgment of 'low' } \\
\text { or 'high' risk }\end{array}$ \\
\hline $\begin{array}{l}\text { Allocation concealment } \\
\text { (selection bias) }\end{array}$ & Unclear risk & Insufficient information to permit judgment of 'low' or 'high' risk \\
\hline $\begin{array}{l}\text { Blinding of participants } \\
\text { and personnel (perfor- } \\
\text { mance bias) } \\
\text { All outcomes }\end{array}$ & Unclear risk & Insufficient information to permit judgment of 'low' or 'high' risk \\
\hline $\begin{array}{l}\text { Blinding of outcome as- } \\
\text { sessment (detection bias) } \\
\text { All outcomes }\end{array}$ & Unclear risk & $\begin{array}{l}\text { Insufficient information to permit judgment of 'low' or 'high' risk (e.g. research } \\
\text { assistant ratings) }\end{array}$ \\
\hline $\begin{array}{l}\text { Incomplete outcome data } \\
\text { (attrition bias) } \\
\text { All outcomes }\end{array}$ & Low risk & No missing data \\
\hline $\begin{array}{l}\text { Selective reporting (re- } \\
\text { porting bias) }\end{array}$ & Unclear risk & Insufficient information to permit judgment of 'low' or 'high' risk \\
\hline Other bias & Unclear risk & Insufficient information to assess whether an important risk of bias exists \\
\hline
\end{tabular}


Goodenough 1997

\section{Study characteristics}

\begin{tabular}{ll}
\hline Methods & RCT. 3 arms. \\
\hline Participants & Number of children: 117 (39 in each group) \\
Sex of children: $73 \mathrm{M}, 44 \mathrm{~F}$ \\
Age range of children: $3.5-17.7$ years \\
Mean age range of children: not reported \\
Needle procedure: venipuncture \\
Diagnosis of child: none given (19.7\% receiving investigation for chronic illness, 30.8\% receiving rou- \\
tine investigation prior to hospital admission, 9.4\% undergoing assessment of blood medication levels, \\
40\% being treated for a variety of complaints) \\
Inclusion criteria: 3 - 17 years, consecutively scheduled to undergo venipuncture \\
Exclusion: a major mental handicap \\
Setting: Sydney Children's Hospital, Australia
\end{tabular}

Interventions

1. Placebo cream plus suggestion: Children were given a placebo cream from a brightly-wrapped container as the nurse said: "We are trying out a new special cream. I am going to put some cream on your arm that might make the needle hurt less."

2. Placebo cream alone: Children were given a placebo cream from a plain white wrapped container as the nurse said: "I am going to put some cream on your arm."

3. No cream control: No cream was applied and the nurse did not say anything beyond standard procedural instruction

\begin{tabular}{|c|c|c|}
\hline Outcomes & \multicolumn{2}{|c|}{$\begin{array}{l}\text { Pain measures: } \\
\text { - Child self-report: FPS post-procedure } \\
\text { - Behavioral: Observer rating of child behavioral reaction to pain during procedure } \\
\text { Distress measures: } \\
\text { - Child self-report: Children's Anxiety and Pain Scale (CAPS) } \\
\text { Adverse events: none mentioned }\end{array}$} \\
\hline Notes & $\begin{array}{l}\text { We used a total } \mathrm{N} \text { of } 7 \varepsilon \\
\text { (placebo cream }+ \text { Sug\& } \\
\text { Study dates: study dat } \\
\text { Funding: Big Brother } \\
\text { was kindly supplied b) } \\
\text { Conflicts of interest: } \mathrm{n}\end{array}$ & $\begin{array}{l}\text { for this study (instead of } 117 \text { ) because we only included } 2 \text { of } 3 \text { interventions } \\
\text { stion versus placebo cream alone). } \\
\text { s not reported } \\
\text { ovement, Brambles, Boots Co. (Australia), and private donations. Placebo cream } \\
\text { the Pharmacy Department, Prince of Wales Hospital, Australia } \\
\text { ne declared }\end{array}$ \\
\hline \multicolumn{3}{|l|}{ Risk of bias } \\
\hline Bias & Authors' judgement & Support for judgement \\
\hline $\begin{array}{l}\text { Random sequence genera- } \\
\text { tion (selection bias) }\end{array}$ & Unclear risk & $\begin{array}{l}\text { Randomized - stratified by age - no further details. Insufficient information to } \\
\text { permit judgment of 'low' or 'high' risk }\end{array}$ \\
\hline
\end{tabular}


Goodenough 1997 (Continued)

$\begin{aligned} & \text { Allocation concealment } \\ & \text { (selection bias) }\end{aligned}$ Unclear risk Insufficient information to permit judgment of 'low' or 'high' risk

Blinding of participants Unclear risk Insufficient information to permit judgment of 'low' or 'high' risk
and personnel (performance bias)

All outcomes

Blinding of outcome as-
sessment (detection bias) $\quad$ Unclear risk Insufficient information to permit judgment of 'low' or 'high' risk
(detection bias)

All outcomes

Incomplete outcome data Low risk Reasons for missing data unlikely to be related to true outcome
(attrition bias)

All outcomes

Selective reporting (re- Unclear risk Insufficient information to permit judgment of 'low' or 'high' risk
porting bias)

porting bias)

\begin{tabular}{ll}
\hline Other bias $\quad$ Low risk $\quad$ Appears to be free of other bias that would affect outcomes \\
\hline
\end{tabular}

\section{Gupta 2006}

\section{Study characteristics}

\begin{tabular}{|c|c|}
\hline Methods & RCT. 3 arms. \\
\hline \multirow[t]{9}{*}{ Participants } & Number of children: 75 (25 in each group) \\
\hline & Sex of children: $44 \mathrm{M}, 31 \mathrm{~F}$ \\
\hline & Age range of children: 6 - 12 years \\
\hline & $\begin{array}{l}\text { Mean age of children: } 8.9 \pm 2.1 \text { years (distraction); } 8.6 \pm 2.4 \text { years (balloon inflation); } 8.8 \pm 2.1 \text { years (con- } \\
\text { trol) }\end{array}$ \\
\hline & Needle procedure: venepuncture \\
\hline & Diagnosis of child: ASA physical status I - II, undergoing elective surgery \\
\hline & Inclusion criteria: ASA physical status I - II, undergoing elective surgery \\
\hline & $\begin{array}{l}\text { Exclusion criteria: children with delayed milestones, cardiac or neurological impairment, or failure to } \\
\text { cannulate on the first attempt }\end{array}$ \\
\hline & Setting: Not specified, India \\
\hline \multirow[t]{3}{*}{ Interventions } & $\begin{array}{l}\text { 1. Distraction group: Children compressed and released a rubber ball in the palm of their hand which } \\
\text { was not to be cannulated. }\end{array}$ \\
\hline & $\begin{array}{l}\text { 2. Balloon group: Children were asked to inflate a balloon at least for } 20 \text { seconds before initiation of the } \\
\text { venipuncture. The cannula insertion was performed during the act of forceful expiration. }\end{array}$ \\
\hline & 3. Control group: No rubber ball or balloon inflation \\
\hline Outcomes & $\begin{array}{l}\text { Pain measure: } \\
\text { - Child self-report: VAS } 10 \mathrm{~cm}\end{array}$ \\
\hline
\end{tabular}


Gupta 2006 (Continued)

Adverse events: none mentioned

\begin{tabular}{|c|c|}
\hline \multirow[t]{3}{*}{ Notes } & Study dates: January 1, 2005 to July 31, 2005 \\
\hline & Funding: none stated \\
\hline & Conflicts of interest: none declared \\
\hline
\end{tabular}

Risk of bias

\begin{tabular}{|c|c|c|}
\hline Bias & Authors' judgement & Support for judgement \\
\hline $\begin{array}{l}\text { Random sequence genera- } \\
\text { tion (selection bias) }\end{array}$ & Low risk & $\begin{array}{l}\text { Quote: "consecutive pediatric patients were randomized with a computer gen- } \\
\text { erated table of random numbers" p.1372 Par } 3\end{array}$ \\
\hline $\begin{array}{l}\text { Allocation concealment } \\
\text { (selection bias) }\end{array}$ & Unclear risk & Insufficient information to permit judgment of 'low' or 'high' risk \\
\hline $\begin{array}{l}\text { Blinding of participants } \\
\text { and personnel (perfor- } \\
\text { mance bias) } \\
\text { All outcomes }\end{array}$ & High risk & Participants and personnel were not blinded \\
\hline
\end{tabular}

Blinding of outcome as- High risk No blinding of self-report outcome assessment

sessment (detection bias)

All outcomes

Incomplete outcome data Low risk No missing data
(attrition bias)

All outcomes

Selective reporting (re- High risk $\quad$ One or more outcomes reported incompletely for inclusion in meta-analysis
porting bias)
porting bias)

\begin{tabular}{ll}
\hline Other bias $\quad$ Unclear risk $\quad$ Insufficient information to assess whether an important risk of bias exists \\
\hline
\end{tabular}

Harrison 1991

\section{Study characteristics}

\begin{tabular}{ll}
\hline Methods & RCT. 2 arms. \\
\hline Participants & Number of children: 50 control, 50 treatment \\
& Sex of children: $51 \mathrm{M}, 49 \mathrm{~F}$ \\
& Age range of children: 6 - 12 years \\
& Mean age range of children: 8.4 years \\
& Needle Procedure: venous blood sampling \\
& Diagnosis of child: none given \\
& Inclusion criteria: 6 - 12 years \\
& Exclusion criteria: none given
\end{tabular}


Harrison 1991 (Continued)

Setting: 4 hospital laboratories in Kuwait
1. Preparation: Children were read a picture book just prior to the procedure that described the venous blood sampling procedure, why it is carried out, and what happens to the blood after it has been collected. The story stressed that pain is noticeable during the procedure but not unbearable, and that the procedure is less painful if you relax your arm and cooperate with the technician. Children were encouraged to ask questions.

2. No preparation control: No specific description was mentioned in the study. However, it was noted that initial observations revealed that laboratory technicians generally made no attempt to prepare children or to talk to them through the procedure. If children protested and struggled, their strategy was to physically restrain the child and complete the procedure. Often, parents were recruited to help.

\begin{tabular}{ll}
\hline Outcomes & Pain measures: \\
- Child self-report: VAS $(0-5)$ \\
Distress measures: \\
- Parent observer-report of child pain: VAS $(0-5)$ \\
Physiological measures: \\
- Radial pulse rate post-procedure \\
Adverse events: none mentioned \\
Study dates: study dates not reported \\
Funding: Kuwait University Project MU 072 \\
Conflicts of interest: none declared
\end{tabular}

\section{Risk of bias}

\begin{tabular}{lll}
\hline Bias & Authors' judgement & Support for judgement \\
\hline $\begin{array}{l}\text { Random sequence genera- } \\
\text { tion (selection bias) }\end{array}$ & Unclear risk & $\begin{array}{l}\text { Randomized - no further details. Insufficient information to permit judgment } \\
\text { of 'low' or 'high' risk }\end{array}$ \\
\hline $\begin{array}{l}\text { Allocation concealment } \\
\text { (selection bias) }\end{array}$ & Unclear risk & Insufficient information to permit judgment of 'low' or 'high' risk \\
\hline $\begin{array}{l}\text { Blinding of participants } \\
\text { and personnel (perfor- } \\
\text { mance bias) }\end{array}$ & High risk & Study participants were not blinded \\
All outcomes & & \\
\hline
\end{tabular}

Blinding of outcome as- High risk No blinding of outcome assessment

sessment (detection bias)

All outcomes

$\begin{array}{ll}\begin{array}{l}\text { Incomplete outcome data } \\ \text { (attrition bias) }\end{array} & \text { Unclear risk }\end{array}$

Unclear risk

Insufficient information to permit judgment of 'low' or 'high' risk

porting bias) 
Harrison 1991 (Continued)
Other bias
High risk
Had a potential source of bias related to the specific study design (e.g. poten-
tial impact of group setting)

Huet 2011

\section{Study characteristics}

\begin{tabular}{ll}
\hline Methods & RCT. 2 arms. \\
\hline Participants & Number of children: 15 control, 14 treatment \\
Sex of children: $16 \mathrm{M}, 13 \mathrm{~F}$ \\
Age range of children: $5-12$ years \\
Mean age of children: not reported (median = 8 years and 9 years) \\
Needle procedure: local dental anesthetic \\
Diagnosis of child: none \\
Inclusion criteria: not reported \\
Exclusion criteria: not reported \\
Setting: Department of Pediatric Dentistry at Rennes University Hospital, France
\end{tabular}

Interventions

1. Hypnosis: Hypnosis followed the 3-step Ericksonian procedure and was directed by a trained hypnotherapist. Hypnotic induction began in the dentist's chair and focused on images, suggestions, and stories of interest to the child identified during an initial interview. The hypnotherapist spoke throughout the dental anesthesia and treatment, incorporating aspects of the intervention.

2. Standard care control: Children underwent the same procedures without hypnosis. The initial interview included reassuring explanations about the usual protocol.

\begin{tabular}{ll}
\hline Outcomes & Pain measure: \\
& - Child self-report: VAS 0 - 10 \\
& Dodified Objective Pain Score (MOPS) $(0-10)$ \\
& - Modified Yale preoperative anxiety scale (mYAPS) at time of dental anesthesia \\
& Adverse events: none mentioned \\
\hline Notes & Study dates: over a 3-month period with year not reported \\
& Funding: none stated \\
& Conflicts of interest: none declared \\
\hline Risk of bias & Authors' judgement Support for judgement \\
\hline Bias & Low risk \\
\hline Random sequence genera- & \\
\hline tion (selection bias) & Quote: "randomly assigned by lottery" (p.426) \\
\hline
\end{tabular}


Huet 2011 (Continued)

$\begin{aligned} & \text { Allocation concealment } \\ & \text { (selection bias) }\end{aligned} \quad$ Unclear risk Insufficient information to permit judgment of 'low' or 'high' risk

Blinding of participants

High risk

Study participants and personnel were not blinded

and personnel (perfor-

mance bias)

All outcomes

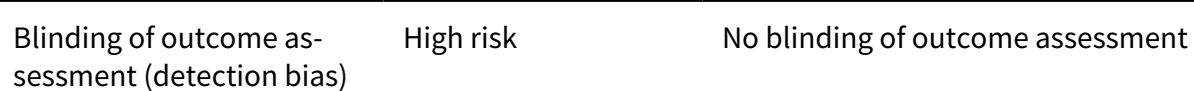

(detion bias)

All outcomes

Incomplete outcome data Low risk Missing data minimal and unlikely to be related to true outcome
(attrition bias)

All outcomes

Selective reporting (re- High risk One or more outcomes of interest are reported incompletely
porting bias)

porting bias)

Other bias

High risk

Multiple potential sources of bias related to study design and other problems

Inal 2012

\section{Study characteristics}

\begin{tabular}{|c|c|}
\hline Methods & RCT. 2 arms. \\
\hline \multirow[t]{9}{*}{ Participants } & Number of children: 62 control, 61 treatment \\
\hline & Sex of children: $62 \mathrm{M}, 61 \mathrm{~F}$ \\
\hline & Age range of children: 6 - 12 years \\
\hline & Mean age of children: $9.36 \pm 1.96$ years \\
\hline & Needle procedure: venepuncture \\
\hline & Diagnosis of child: heterogeneous \\
\hline & Inclusion criteria: 6 - 12 years old, required blood tests \\
\hline & $\begin{array}{l}\text { Exclusion criteria: neurodevelopmentally delayed, verbal difficulties, hearing or vision impairments, } \\
\text { had taken an analgesic within last } 6 \text { hours, had a history of syncope due to blood draws. }\end{array}$ \\
\hline & Setting: Pediatric Clinic of Cerrahpasa Medical Faculty, Istanbul University \\
\hline \multirow[t]{2}{*}{ Interventions } & $\begin{array}{l}\text { 1. Distraction: Children looked at "Flippits }{ }^{\circledR "} \text { distraction cards while a nurse asked the child questions } \\
\text { about the cards. }\end{array}$ \\
\hline & 2. Standard care control: Children received no intervention. \\
\hline \multirow[t]{5}{*}{ Outcomes } & Pain measure: \\
\hline & - Child self-report: FPS-R \\
\hline & - Caregiver/Parent report: FPS-R \\
\hline & - Nurse report: FPS-R \\
\hline & Distress measure: \\
\hline
\end{tabular}

Psychological interventions for needle-related procedural pain and distress in children and adolescents (Review) 
Inal 2012 (Continued)

- Caregiver/Parent report: Anxiety set of CAPS

- Scales (CAPS)

- Nurse report: CAPS

Adverse events: none mentioned

Notes

Study dates: January 14 to February 20, 2010

Funding: none stated

Conflicts of interest: none declared

\section{Risk of bias}

\begin{tabular}{|c|c|c|}
\hline Bias & Authors' judgement & Support for judgement \\
\hline $\begin{array}{l}\text { Random sequence genera- } \\
\text { tion (selection bias) }\end{array}$ & Low risk & $\begin{array}{l}\text { Quote: "randomized with a computer-generated table of random numbers" (p. } \\
212 \text { Par 6) }\end{array}$ \\
\hline $\begin{array}{l}\text { Allocation concealment } \\
\text { (selection bias) }\end{array}$ & High risk & Use of an open random allocation schedule (e.g. random-number table) \\
\hline $\begin{array}{l}\text { Blinding of participants } \\
\text { and personnel (perfor- } \\
\text { mance bias) } \\
\text { All outcomes }\end{array}$ & High risk & Study participants and personnel were not blinded \\
\hline $\begin{array}{l}\text { Blinding of outcome as- } \\
\text { sessment (detection bias) } \\
\text { All outcomes }\end{array}$ & High risk & No blinding of outcome assessment \\
\hline $\begin{array}{l}\text { Incomplete outcome data } \\
\text { (attrition bias) } \\
\text { All outcomes }\end{array}$ & Low risk & No missing data \\
\hline $\begin{array}{l}\text { Selective reporting (re- } \\
\text { porting bias) }\end{array}$ & Unclear risk & Insufficient information to permit judgment of 'low' or 'high' risk \\
\hline Other bias & Unclear risk & Insufficient information to assess whether an important risk of bias exists \\
\hline
\end{tabular}

Jeffs 2007

\section{Study characteristics}

\begin{tabular}{ll}
\hline Methods & RCT. 3 arms. \\
\hline Participants & Number of children: 8 control, 19 distraction $(10=$ investigator-selected and $9=$ self-selected) \\
& Sex of children: $17 \mathrm{M}, 15 \mathrm{~F}$ \\
& Age range of children: $11-17$ years \\
& Mean age of children: $14.06 \pm 2.31$ years \\
& Needle procedure: phase II of allergy testing involving injection \\
& Diagnosis of child: none reported
\end{tabular}


Jeffs 2007 (Continued)

Inclusion criteria: 11 - 17 years old, required environmental or food allergen testing, parental presence, ability to read and write in English

Exclusion criteria: bee venom allergy testing, cognitive and developmental disability

Setting: outpatient allergy testing clinic within large medical centre located in a moderate-size metropolitan area of the northeastern United States

1. Distraction (investigator-selected): Children watched a nursing recruitment video targeting an ado-
lescent audience prior to and during allergy testing.
2.Distraction (self-selected): Children selected 1 distracter from collection of music, audio books, or
videos.
3.Usual care control: Received no intervention and consisted of typical communication between chil-
dren and the nurse

\begin{tabular}{ll}
\hline Outcomes & Pain measure: \\
& - Child self-report: Adolescent Pediatric Pain Tool (APPT) \\
& - Child self-report: Wong Baker FACES scale $(0-10)$
\end{tabular}

Adverse events: none mentioned

\section{Notes}

Phase I allergy testing was used to determine the presence of non-reactive allergens. Distraction was resumed during Phase 2 testing, so only Phase II testing was used in the analyses for this review. Phase 1 involved an $\mathrm{N}$ of 32, while Phase 2 involved and $\mathrm{N}$ of 27 ; therefore, the total $\mathrm{N}$ reported for this study is 27.

Study dates: study dates not reported

Funding: grant funding was provided by the Foundation of the New York State Nurses Association and the Delta Pi chapter of Sigma Theta Tau International

Conflicts of interest: none declared

\section{Risk of bias}

\begin{tabular}{lll}
\hline Bias & Authors' judgement & Support for judgement \\
\hline $\begin{array}{l}\text { Random sequence genera- } \\
\text { tion (selection bias) }\end{array}$ & Low risk & $\begin{array}{l}\text { Participants randomly assigned "using a computer-generated random num- } \\
\text { bers table" (p. 175 Par 2) }\end{array}$ \\
\hline $\begin{array}{l}\text { Allocation concealment } \\
\text { (selection bias) }\end{array}$ & Unclear risk & $\begin{array}{l}\text { Unclear if all appropriate safeguards taken with assignment envelopes (i.e. se- } \\
\text { quentially numbered or opaque) }\end{array}$ \\
\hline $\begin{array}{l}\text { Blinding of participants } \\
\text { and personnel (perfor- } \\
\text { mance bias) }\end{array}$ & High risk & Quote: "unblinded experimental design" (p. 172 Par 7) \\
$\begin{array}{l}\text { All outcomes } \\
\begin{array}{l}\text { Blinding of outcome as- } \\
\text { sessment (detection bias) } \\
\text { All outcomes }\end{array}\end{array}$ & High risk & $\begin{array}{l}\text { Quote: "unblinded experimental design" and no blinding of self-report of out- } \\
\text { come assessment (p. 172 Par } 7 \text { ) }\end{array}$ \\
\hline $\begin{array}{l}\text { Incomplete outcome data } \\
\text { (attrition bias) } \\
\begin{array}{l}\text { All outcomes } \\
\hline\end{array}\end{array}$ & Low risk & No missing data for phase included in current review \\
\hline
\end{tabular}


Jeffs 2007 (Continued)

Selective reporting (re- Unclear risk Insufficient information to permit judgment of 'low' or 'high' risk porting bias)

Other bias

High risk

Multiple potential sources of bias related to study design and other problems

(e.g. low statistical power)

Kamath 2013

\section{Study characteristics}

\begin{tabular}{|c|c|}
\hline Methods & RCT. 2 arms. \\
\hline \multirow[t]{9}{*}{ Participants } & Number of children: 80 control, 80 treatment \\
\hline & Sex of children: $85 \mathrm{M}, 75 \mathrm{~F}$ \\
\hline & Age range of children: 4 - 10 years \\
\hline & $\begin{array}{l}\text { Mean age range of children: } 7.6 \pm 3.5 \text { years (treatment girls), } 7.8 \pm 3.2 \text { years (treatment boys), } 7.2 \pm 3.0 \\
\text { years (control girls), } 7.6 \pm 3.4 \text { years (control boys) }\end{array}$ \\
\hline & Needle procedure: local anesthetic dental injection \\
\hline & Diagnosis of child: none specified \\
\hline & $\begin{array}{l}\text { Inclusion criteria: } 4 \text { - } 10 \text { years, undergoing dental treatment, requiring the administration of nerve } \\
\text { blocks, had experienced the administration of local anesthesia previously and, based on a pre-oper- } \\
\text { ative behavioral assessment using the Frankl scale, demonstrated negative behavior during pretreat- } \\
\text { ment evaluation }\end{array}$ \\
\hline & Exclusion criteria: none given \\
\hline & Setting: dental clinics in India \\
\hline \multirow[t]{2}{*}{ Interventions } & $\begin{array}{l}\text { 1. Write In The Air Using Leg Intervention: Children had a topical anesthetic gel applied to the injec- } \\
\text { tion site and were made to relax and breathe deeply to a count of } 10 \text {. Children were then told to raise } \\
\text { their right leg and write their name in the air continuously and slowly throughout the procedure. The } \\
\text { technique was also demonstrated to them. The children were told that writing slowly and neatly would } \\
\text { help decrease any discomfort anticipated during the procedure. Reframing techniques (euphemistic } \\
\text { phrases) were used to describe the injection. }\end{array}$ \\
\hline & $\begin{array}{l}\text { 2. Control: Children had a topical anesthetic gel applied to the injection site and were made to relax } \\
\text { and breathe deeply to a count of } 10 \text {. Children were told to continue with deep breathing. Reframing } \\
\text { techniques (euphemistic phrases) were used to describe the injection. }\end{array}$ \\
\hline \multirow[t]{4}{*}{ Outcomes } & Pain measure: \\
\hline & - Child self-report (6 - 10 year-olds): FPS-R \\
\hline & - Behavioural (4 - 5 year-olds): Modified Toddler-Preschooler Postoperative Pain Scale (TPPPS) \\
\hline & Adverse events: none mentioned \\
\hline \multirow[t]{3}{*}{ Notes } & Study dates: study dates not reported \\
\hline & Funding: none stated \\
\hline & Conflicts of interest: none declared \\
\hline
\end{tabular}

\section{Risk of bias}

Psychological interventions for needle-related procedural pain and distress in children and adolescents (Review) 
Kamath 2013 (Continued)

\begin{tabular}{lll} 
Bias & Authors' judgement & Support for judgement \\
\hline $\begin{array}{l}\text { Random sequence genera- } \\
\text { tion (selection bias) }\end{array}$ & Low risk & Quote: "flipping a coin" (p. 45) \\
\hline $\begin{array}{l}\text { Allocation concealment } \\
\text { (selection bias) }\end{array}$ & Unclear risk & Insufficient information to permit judgment of 'low' or 'high' risk. \\
\hline
\end{tabular}

(selection bias)

Blinding of participants High risk Study participants and personnel were not blinded
and personnel (perfor-
mance bias)
All outcomes

\begin{tabular}{|c|c|c|}
\hline $\begin{array}{l}\text { Blinding of outcome as- } \\
\text { sessment (detection bias) } \\
\text { All outcomes }\end{array}$ & High risk & No blinding of outcome assessment. \\
\hline $\begin{array}{l}\text { Incomplete outcome data } \\
\text { (attrition bias) } \\
\text { All outcomes }\end{array}$ & Low risk & No missing data \\
\hline $\begin{array}{l}\text { Selective reporting (re- } \\
\text { porting bias) }\end{array}$ & Unclear risk & Insufficient information to permit judgment of 'low' or 'high' risk \\
\hline Other bias & Low risk & Appears to be free of other bias that would affect outcomes. \\
\hline
\end{tabular}

Katz 1987

\section{Study characteristics}

\begin{tabular}{|c|c|}
\hline Methods & RCT. 2 arms \\
\hline \multirow[t]{9}{*}{ Participants } & Number of children: 18 control, 18 treatment \\
\hline & Sex of children: $24 \mathrm{M}, 12 \mathrm{~F}$ \\
\hline & Age range of children: 6 - 11 years \\
\hline & Mean age of children: $8.3 \pm 1.68$ years \\
\hline & Needle procedure: BMA \\
\hline & Diagnosis of child: acute lymphoblastic leukemia (ALL) \\
\hline & $\begin{array}{l}\text { Inclusion criteria: baseline self-reported pain score }>50(0-100) \text {, baseline self-reported fear score }>4(1 \\
-7), \text { PBRS-R }>4(0-33) \text {, nurse rating of child anxiety }>3(1-5)\end{array}$ \\
\hline & Exclusion criteria: none reported. \\
\hline & Setting: Hematology-Oncology clinic at Children's Hospital of Los Angeles, USA \\
\hline Interventions & $\begin{array}{l}\text { 1.Hypnosis: Children received training in hypnosis and self-hypnosis from trained psychologist prior to } \\
\text { needle procedure. Hypnotic induction used eye fixation with or without eye closure, active imagery tai- } \\
\text { lored to child's interests, deep muscle relaxation, and suggestions. Children were cued to use hypnosis } \\
\text { during actual procedure. }\end{array}$ \\
\hline
\end{tabular}


Katz 1987 (Continued)

2. Non-directed play control: Children engaged in play sessions designed to match the amount of time and attention from a psychologist prior to the needle procedure. No discussions about the child's illness or treatment were initiated.

\begin{tabular}{ll}
\hline Outcomes & Pain measure: \\
- Child self-report: 0 - 100 thermometer \\
Distress measure: \\
- Child self-report: fear self-report \\
- Nurse report of child anxiety: 1 - 5 Likert Scale \\
- Behavioural child anxiety: PBRS-R \\
Adverse events: none mentioned
\end{tabular}

Notes

We only used data from the first BMA procedure (i.e. post-treatment 1 )

Study dates: September 1979 to July 1982

Funding: grant \#R01-6292 from the National Cancer Institute

Conflicts of interest: none declared

\section{Risk of bias}

\begin{tabular}{|c|c|c|}
\hline Bias & Authors' judgement & Support for judgement \\
\hline $\begin{array}{l}\text { Random sequence genera- } \\
\text { tion (selection bias) }\end{array}$ & Unclear risk & $\begin{array}{l}\text { Randomized - stratified by sex - no further details. Insufficient information to } \\
\text { permit judgment of 'low' or 'high' risk }\end{array}$ \\
\hline $\begin{array}{l}\text { Allocation concealment } \\
\text { (selection bias) }\end{array}$ & Unclear risk & Insufficient information to permit judgment of 'low' or 'high' risk \\
\hline $\begin{array}{l}\text { Blinding of participants } \\
\text { and personnel (perfor- } \\
\text { mance bias) } \\
\text { All outcomes }\end{array}$ & High risk & Study participants were not blinded \\
\hline $\begin{array}{l}\text { Blinding of outcome as- } \\
\text { sessment (detection bias) } \\
\text { All outcomes }\end{array}$ & High risk & No blinding of self-reported outcome assessment \\
\hline $\begin{array}{l}\text { Incomplete outcome data } \\
\text { (attrition bias) } \\
\text { All outcomes }\end{array}$ & Low risk & No missing data \\
\hline $\begin{array}{l}\text { Selective reporting (re- } \\
\text { porting bias) }\end{array}$ & Unclear risk & Insufficient information to permit judgment of 'low' or 'high' risk \\
\hline Other bias & High risk & $\begin{array}{l}\text { Potential source of bias related to timing of outcome measurement (e.g. some- } \\
\text { times after multiple procedures) }\end{array}$ \\
\hline
\end{tabular}

\section{Kleiber 2001}

\section{Study characteristics}


Kleiber 2001 (Continued)

$\begin{array}{ll}\text { Methods } & \text { RCT. } 2 \text { arms. }\end{array}$

Pumber of children: 22 control, 22 treatment
Sex of children: $11 \mathrm{M}, 33 \mathrm{~F}$
Age range of children: 4 - 7 years
Mean age of children: $62.8 \pm 16.7$ months (intervention); $59.4 \pm 11.7$ months (control)
Needle procedure: IV Insertion
Diagnosis of child: being treated or evaluated for non-life-threatening conditions such as chronic uri-
nary tract infections, urinary incontinence, chronic constipation, growth failure, reactive airway disease
Inclusion criteria: no neurological or sensory impairment at IV site, child able to distinguish between
biggest and smallest in order to complete Oucher Pain scale, parent with legal custody agreed to be
with child during procedure, parent able to speak and read English
Exclusion criteria: none reported
Setting: large Midwestern tertiary care hospital in the United States
1. Parent coaching and distraction: Parents viewed an educational video on distraction that provid-
ed rationale, suggestions, and modeling of effective distraction with children. Children remained with
their parents during the video and were involved in selecting a distracter with their parents.
2. Standard care control: Individual practitioners determined use of EMLA and parents were allowed to
accompany their child during the procedure.

Pain measure:
- Child self-report: Oucher Pain Rating Scale
Distress measure:
- Parent report: Perception of Procedures Questionnaire-Revised (PPQ-R)
- Behavioral: OSBD-R
Adverse events: none mentioned

Notes Although not stated in the paper, personal communication with the author confirmed randomization was achieved via a random table of numbers.

Study dates: study dates not reported

Funding: NIH-NINR predoctoral award \#F31 NR07107-01, and National Research Service Award \#T32NR07082-02

Conflicts of interest: none declared

\section{Risk of bias}

\begin{tabular}{lll}
\hline Bias & Authors' judgement & Support for judgement \\
\hline $\begin{array}{l}\text { Random sequence genera- } \\
\text { tion (selection bias) }\end{array}$ & Unclear risk & $\begin{array}{l}\text { Randomized - permutated block randomization used to assure that a bal- } \\
\text { anced number of children with histories of high distress were randomized to } \\
\text { the control and experimental groups. Insufficient information to permit judg- } \\
\text { ment of 'low' or 'high' risk }\end{array}$ \\
\hline $\begin{array}{l}\text { Allocation concealment } \\
\text { (selection bias) }\end{array}$ & Unclear risk & Insufficient information to permit judgment of 'low' or 'high' risk \\
\hline \hline
\end{tabular}


Kleiber 2001 (Continued)
Blinding of participants
High risk
Study participants were not blinded and personnel (perfor- mance bias)
All outcomes

\section{Blinding of outcome as- sessment (detection bias) \\ All outcomes}

Kristjansdottir 2010

\section{Study characteristics}

\begin{tabular}{|c|c|}
\hline Methods & RCT. 3 arms. \\
\hline \multirow[t]{9}{*}{ Participants } & Number of children: 39 control, 79 treatment \\
\hline & Sex of children: 63 M, $55 \mathrm{~F}$ \\
\hline & Age range of children: 13 - 15 years \\
\hline & Mean age of children: $14 \pm 0.18$ years \\
\hline & Needle procedure: polio immunization \\
\hline & Diagnosis of child: none (community sample) \\
\hline & Inclusion criteria: Icelandic-speaking adolescents for a ninth grade immunization \\
\hline & Exclusion criteria: none reported \\
\hline & Setting: school in Iceland \\
\hline \multirow[t]{3}{*}{ Interventions } & 1. Music distraction (with headphones):Adolescents listened to music using headphones. \\
\hline & 2. Music distraction (without headphones): Adolescents listened to music from loudspeakers. \\
\hline & $\begin{array}{l}\text { 3. Standard care control: Nurses maintained their normal modes of caring, which were to comfort and } \\
\text { guide the adolescents verbally. }\end{array}$ \\
\hline \multirow[t]{3}{*}{ Outcomes } & Pain measure: \\
\hline & - Child self-report: 0 - 10 VAS \\
\hline & Adverse events: none mentioned \\
\hline \multirow[t]{2}{*}{ Notes } & Study dates: study dates not reported \\
\hline & Funding: none stated \\
\hline
\end{tabular}


Kristjansdottir 2010 (Continued)

Conflicts of interest: none declared

\section{Risk of bias}

\begin{tabular}{|c|c|c|}
\hline Bias & Authors' judgement & Support for judgement \\
\hline $\begin{array}{l}\text { Random sequence genera- } \\
\text { tion (selection bias) }\end{array}$ & Low risk & $\begin{array}{l}\text { Quote: "table of random numbers was used to randomize into groups" (p. } 20 \\
\text { Par 11) }\end{array}$ \\
\hline $\begin{array}{l}\text { Allocation concealment } \\
\text { (selection bias) }\end{array}$ & High risk & Use of an open random allocation schedule (e.g. random-number table) \\
\hline $\begin{array}{l}\text { Blinding of participants } \\
\text { and personnel (perfor- } \\
\text { mance bias) } \\
\text { All outcomes }\end{array}$ & High risk & Study participants and personnel were not blinded \\
\hline $\begin{array}{l}\text { Blinding of outcome as- } \\
\text { sessment (detection bias) } \\
\text { All outcomes }\end{array}$ & High risk & No blinding of outcome assessment \\
\hline $\begin{array}{l}\text { Incomplete outcome data } \\
\text { (attrition bias) } \\
\text { All outcomes }\end{array}$ & Low risk & No missing data \\
\hline $\begin{array}{l}\text { Selective reporting (re- } \\
\text { porting bias) }\end{array}$ & Unclear risk & Insufficient information to permit judgment of 'low' or 'high' risk \\
\hline Other bias & Unclear risk & Insufficient information to assess whether an important risk of bias exists \\
\hline
\end{tabular}

Kuttner 1987

\section{Study characteristics}

\begin{tabular}{ll}
\hline Methods & RCT. 3 arms. \\
\hline Participants & Sumber of children: 8 control, 17 treatment \\
Sex of children: not reported \\
Mean age of children: not reported \\
Needle procedure: BMA \\
Diagnosis of child: leukemia \\
Inclusion criteria: leukemia patients who had expressed difficulty in coping with recurrent BMAs and \\
LPs that constituted an essential part of their treatment for cancer \\
Exclusion criteria: none reported \\
Setting: treatment/surgery room at children's hospital in Canada \\
$\begin{array}{l}\text { 1. Hypnosis: Hypnotic techniques included using the child's favorite story for hypnotic suggestion and } \\
\text { reframing of the experience. Children practised the therapist-led technique prior to the procedure. Pro- } \\
\text { cedural and sensory information was interwoven into the storyline. }\end{array}$
\end{tabular}

Psychological interventions for needle-related procedural pain and distress in children and adolescents (Review) 
Kuttner 1987 (Continued)

2. Distraction: Distracters included books, bubbles, and toys.

3. Standard care control: Standard medical practice included information, reassurance, and support.

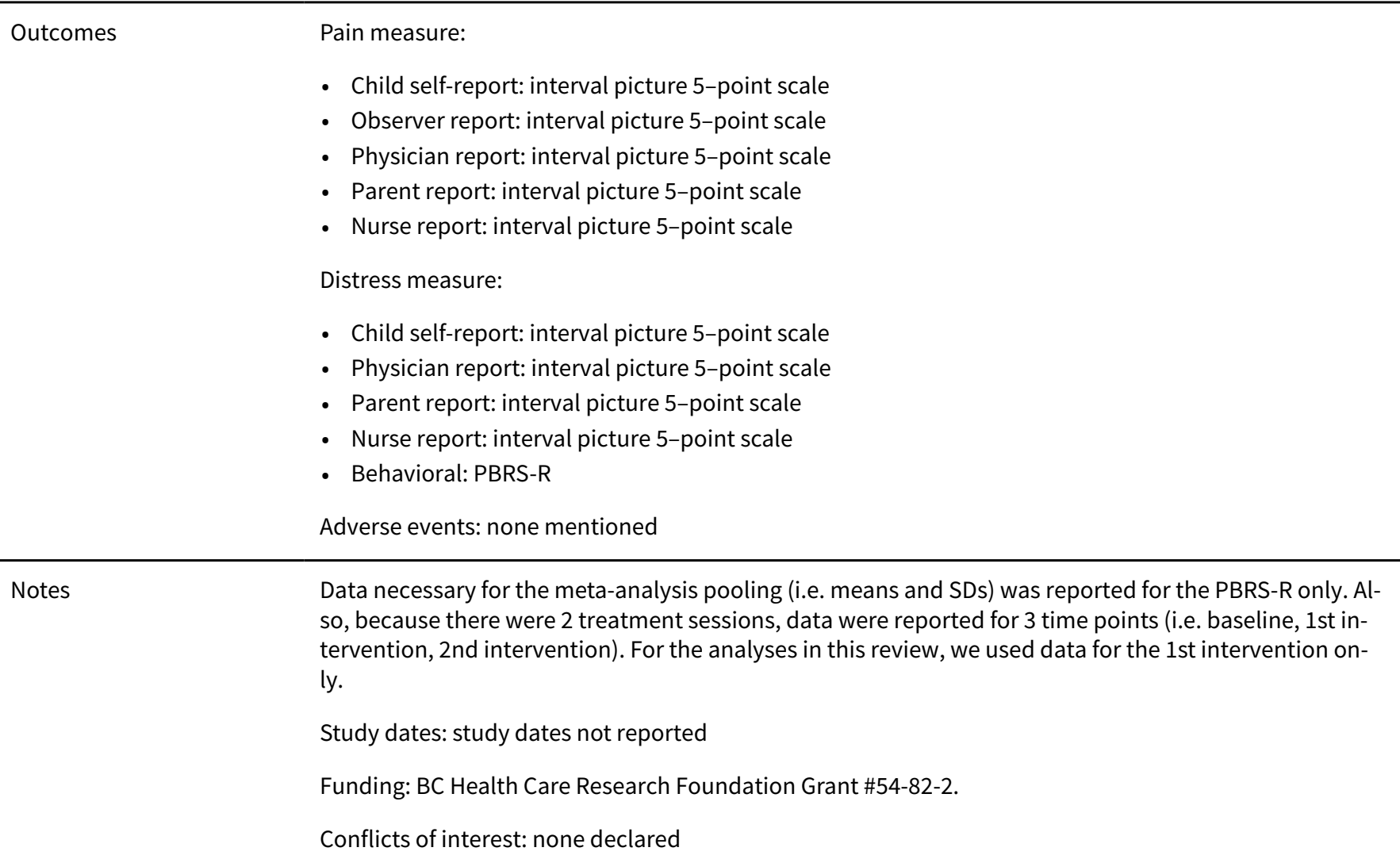

\section{Risk of bias}

Bias Authors' judgement Support for judgement

Random sequence genera- Unclear risk Randomized - no further details. Insufficient information to permit judgment tion (selection bias) of 'low' or 'high' risk

Allocation concealment Unclear risk Insufficient information to permit judgment of 'low' or 'high' risk
(selection bias)

Blinding of participants High risk Study participants and personnel were not blinded
and personnel (perfor-
mance bias)
All outcomes

\begin{tabular}{lll}
\hline $\begin{array}{l}\text { Blinding of outcome as- } \\
\text { sessment (detection bias) } \\
\text { All outcomes }\end{array}$ & High risk & No blinding of outcome assessment \\
\hline $\begin{array}{l}\text { Incomplete outcome data } \\
\text { (attrition bias) }\end{array}$ & Unclear risk & $\begin{array}{l}\text { Insufficient reporting of exclusions to permit judgment of 'low' or 'high' risk. } \\
\text { All outcomes }\end{array}$ \\
\hline
\end{tabular}

Selective reporting (re- High risk $\quad$ One or more outcomes of interest are reported incompletely.
porting bias)


Kuttner 1987 (Continued)
Other bias
High risk Multiple potential sources of bias related to study design (e.g. small sample
size)

\section{Study characteristics}

\begin{tabular}{|c|c|}
\hline Methods & RCT. 3 arms. \\
\hline \multirow[t]{9}{*}{ Participants } & Number of children: 10 control, 20 treatment (10 = hypnosis) \\
\hline & Sex of children: $17 \mathrm{M}, 13 \mathrm{~F}$ \\
\hline & Age range of children: 5 - 15 years \\
\hline & Mean age of children: $8 \pm 2.5$ years \\
\hline & Needle procedure: BMA \\
\hline & Diagnosis of child: leukemia \\
\hline & $\begin{array}{l}\text { Inclusion criteria: } 5 \text { - } 15 \text { years old, leukemia diagnosis whose medical protocol required at least } 2 \text { BMAs } \\
\text { within } 2 \frac{1}{2} \text { months }\end{array}$ \\
\hline & $\begin{array}{l}\text { Exclusion criteria: previous therapy with hypnosis or cognitive behavioral (CB) coping, or both, concur- } \\
\text { rent treatment during the project with analgesic or psychotropic medication, a major affective disorder } \\
\text { or other psychiatric diagnosis }\end{array}$ \\
\hline & Setting: treatment room of hospital clinic in Greece \\
\hline \multirow[t]{3}{*}{ Interventions } & $\begin{array}{l}\text { 1. Cognitive behavioral (CB) Intervention: This condition involved relaxation training, breathing exercis- } \\
\text { es, and cognitive restructuring. }\end{array}$ \\
\hline & $\begin{array}{l}\text { 2. Hypnosis: Hypnosis was induced by visual imagery (favorite place, activity, or television program) } \\
\text { and analgesic suggestion was given after several minutes (numbness, topical/local/glove anesthesia). } \\
\text { Relaxation techniques were also taught in sessions. As in standard care, children also received a lido- } \\
\text { caine injection. }\end{array}$ \\
\hline & 3. Standard care control: Children received a standard lidocaine injection. \\
\hline \multirow[t]{6}{*}{ Outcomes } & Pain measure: \\
\hline & - Child self-report: Wong Baker FACES Scale \\
\hline & Distress (anxiety) measure: \\
\hline & - Child self-report: Wong Baker FACES Scale \\
\hline & - $\mathrm{PBCL}$ \\
\hline & Adverse events: none mentioned \\
\hline \multirow[t]{4}{*}{ Notes } & $\begin{array}{l}\text { Although it is not stated in the paper, personal communication with author confirmed that randomiza- } \\
\text { tion was achieved by a random table of numbers. }\end{array}$ \\
\hline & Study dates: study dates not reported \\
\hline & Funding: none stated \\
\hline & Conflicts of interest: none declared \\
\hline
\end{tabular}


Liossi 1999 (Continued)

Risk of bias

\begin{tabular}{|c|c|c|}
\hline Bias & Authors' judgement & Support for judgement \\
\hline $\begin{array}{l}\text { Random sequence genera- } \\
\text { tion (selection bias) }\end{array}$ & Unclear risk & $\begin{array}{l}\text { Randomized - no further details. Insufficient information to permit judgment } \\
\text { of 'low' or 'high' risk }\end{array}$ \\
\hline $\begin{array}{l}\text { Allocation concealment } \\
\text { (selection bias) }\end{array}$ & Unclear risk & Insufficient information to permit judgment of 'low' or 'high' risk \\
\hline $\begin{array}{l}\text { Blinding of participants } \\
\text { and personnel (perfor- } \\
\text { mance bias) } \\
\text { All outcomes }\end{array}$ & High risk & Study participants were not blinded \\
\hline $\begin{array}{l}\text { Blinding of outcome as- } \\
\text { sessment (detection bias) } \\
\text { All outcomes }\end{array}$ & High risk & No blinding of self-report outcome assessment \\
\hline $\begin{array}{l}\text { Incomplete outcome data } \\
\text { (attrition bias) } \\
\text { All outcomes }\end{array}$ & Low risk & No missing data \\
\hline $\begin{array}{l}\text { Selective reporting (re- } \\
\text { porting bias) }\end{array}$ & High risk & One or more outcomes of interest are reported incompletely \\
\hline Other bias & High risk & $\begin{array}{l}\text { Quote: "the small number of subjects in this study seriously compromise pow- } \\
\text { er and may yield spuriously high correlations" (p. } 112 \text { Par } 3 \text { ) }\end{array}$ \\
\hline
\end{tabular}

Liossi 2003

\section{Study characteristics}

\begin{tabular}{ll}
\hline Methods & RCT. 4 arms. \\
\hline Participants & Number of children: 20 control, 40 treatment \\
Sex of children: Not reported \\
Age range of children: 6 - 16 years \\
Mean age of children: $8.73 \pm 2.86$ years \\
Needle procedure: LP \\
Diagnosis of child: leukemia or non-Hodgkin's lymphoma \\
Inclusion criteria: 6 - 16 years old, with leukemia or non-Hodgkin's lymphoma, undergoing regular LPs \\
over a 4-year period \\
$\begin{array}{l}\text { Exclusion criteria: previous hypnosis treatment, concurrent treatment during the project with analgesic } \\
\text { or psychotropic medication, major affective disorder or other psychiatric diagnosis } \\
\text { Setting: Hematology/Oncology Department of the Children's Hospital Aglaia Kyriakou, Athens, Greece }\end{array}$ \\
$\begin{array}{l}\text { 1. Hypnosis (direct): Prior to the procedure, children practised analgesic hypnotic suggestions (request } \\
\text { for numbness, topical/local/glove anesthesia, and switchbox). This was repeated during the procedure } \\
\text { with the help of the therapist. }\end{array}$ \\
\hline Interventions
\end{tabular}


2. Hypnosis (indirect): Prior to the procedure, children practised hypnotic suggestion to experience immediate relaxation and adaptation to discomfort. This was repeated during the procedure with the help of the therapist.

3. Standard care with attention control: Included elements such as development of rapport, non-medical play, and non-medical verbal interactions (e.g. discussing school, activities, sports, etc). New coping skills were not introduced.

4. Standard care control: Children received no therapist contact or treatment intervention, but, like all patients, received standard interventions provided by the hospital staff for pain control during LPs (i.e. medical and nursing staff offered information, support, and reassurance).

\begin{tabular}{ll}
\hline Outcomes & Pain measure: \\
- Child self-report: Wong Baker FACES Scale & Distress measure: \\
- Child self-report: Wong Baker FACES Scale \\
- Behavioral: PBCL \\
Adverse events: none mentioned
\end{tabular}

We used a total $\mathrm{N}$ of 60 for this study (instead of 80 ) because we only included 3 of 4 conditions (Direct + indirect hypnosis versus attentional control with standard medical treatment). Outcomes were assessed at various time points; however, for this review we only used the 'intervention' time point.

Study dates: over a 4-year period (study years not reported)

Funding: none stated

Conflicts of interest: none declared

\section{Risk of bias}

\begin{tabular}{|c|c|c|}
\hline Bias & Authors' judgement & Support for judgement \\
\hline $\begin{array}{l}\text { Random sequence genera- } \\
\text { tion (selection bias) }\end{array}$ & Unclear risk & $\begin{array}{l}\text { Randomized - no further details. Insufficient information to permit judgment } \\
\text { of 'low' or 'high' risk }\end{array}$ \\
\hline $\begin{array}{l}\text { Allocation concealment } \\
\text { (selection bias) }\end{array}$ & Unclear risk & Insufficient information to permit judgment of 'low' or 'high' risk \\
\hline $\begin{array}{l}\text { Blinding of participants } \\
\text { and personnel (perfor- } \\
\text { mance bias) } \\
\text { All outcomes }\end{array}$ & High risk & Study participants and personnel were not blinded \\
\hline $\begin{array}{l}\text { Blinding of outcome as- } \\
\text { sessment (detection bias) } \\
\text { All outcomes }\end{array}$ & High risk & No blinding of outcome assessment \\
\hline $\begin{array}{l}\text { Incomplete outcome data } \\
\text { (attrition bias) } \\
\text { All outcomes }\end{array}$ & Low risk & No missing data \\
\hline $\begin{array}{l}\text { Selective reporting (re- } \\
\text { porting bias) }\end{array}$ & Unclear risk & Insufficient information to permit judgment of 'low' or 'high' risk \\
\hline Other bias & Low risk & Appears to be free of other bias that would affect outcomes \\
\hline
\end{tabular}




\section{Study characteristics}

\begin{tabular}{|c|c|}
\hline Methods & RCT. 3 arms. \\
\hline \multirow[t]{9}{*}{ Participants } & Number of children: 30 control (15 = with attention), 15 treatment \\
\hline & Sex of children: 23 M, $22 \mathrm{~F}$ \\
\hline & Age range of children: $6-16$ years \\
\hline & Mean age of children: $8.84 \pm 2.86$ years \\
\hline & Needle procedure: LP \\
\hline & Diagnosis of child: leukemia or non-Hodgkin's lymphoma \\
\hline & Inclusion criteria: 6 - 16 years old, Greek-speaking patients with leukemia or non-Hodgkin's lymphoma \\
\hline & $\begin{array}{l}\text { Exclusion criteria: Previous therapy with hypnosis, concurrent treatment during the project with anal- } \\
\text { gesia or psychotropic medication, major affective disorder or other psychiatric diagnosis }\end{array}$ \\
\hline & Setting: Hematology/Oncology Department of the Children's Hospital Algaia Kriakou, Athens, Greece \\
\hline \multirow[t]{3}{*}{ Interventions } & $\begin{array}{l}\text { 1. Hypnosis (and EMLA):Prior to the procedure, hypnosis was practiced and involved visual imagery (fa- } \\
\text { vorite place, activity, or television program) and analgesic suggestion was given after several minutes } \\
\text { (numbness, topical/local/glove anesthesia, and switchbox). EMLA was applied } 60 \text { minutes prior to the } \\
\text { procedure and children were cued by a therapist to use the hypnosis during the procedure. }\end{array}$ \\
\hline & $\begin{array}{l}\text { 2. Attention control (and EMLA): Prior to the procedure, children met with a therapist and engaged in } \\
\text { non-medical play and non-medical verbal interactions. Children also had EMLA applied } 60 \text { minutes pri- } \\
\text { or to the procedure. }\end{array}$ \\
\hline & $\begin{array}{l}\text { 3. EMLA only: : All patients received standard interventions provided by the hospital staff for pain con- } \\
\text { trol during LPs (i.e., medical and nursing staff offered information, support, and reassurance, and EMLA } \\
\text { cream was applied approximately } 60 \mathrm{~min} \text { before the procedure). }\end{array}$ \\
\hline \multirow[t]{6}{*}{ Outcomes } & Pain measure: \\
\hline & - Child self-report: Wong Baker FACES Scale \\
\hline & Distress measure: \\
\hline & - Child self-report: Wong Baker FACES Scale \\
\hline & - Behavioral: Procedure Behavior Checklist (PBCL) \\
\hline & Adverse events: none mentioned \\
\hline \multirow[t]{4}{*}{ Notes } & $\begin{array}{l}\text { We used a total } \mathrm{N} \text { of } 30 \text { for this study (instead of } 45 \text { ) because we only included } 2 \text { of } 3 \text { conditions (EMLA } \\
+ \text { Hypnosis versus EMLA + Attention). Outcomes were assessed at various time points; however, for this } \\
\text { review we only used the outcomes assessed closest to the procedure (i.e., during the procedure or after } \\
\text { the procedure if a during procedure outcome was not available). }\end{array}$ \\
\hline & Study dates: study dates not reported \\
\hline & Funding: none stated \\
\hline & Conflicts of interest: none declared \\
\hline
\end{tabular}

\section{Risk of bias}


Liossi 2006 (Continued)

Bias Authors' judgement Support for judgement

Random sequence genera- Low risk "randomly allocated...with the use of a table of random numbers" p.308 Par 9
tion (selection bias)

\begin{tabular}{lll}
\hline $\begin{array}{l}\text { Allocation concealment } \\
\text { (selection bias) }\end{array}$ & High risk & \\
\hline $\begin{array}{l}\text { Blinding of participants } \\
\text { and personnel (perfor- }\end{array}$ & High risk & Study participants were not blinded \\
mance bias) & & \\
All outcomes &
\end{tabular}

Blinding of outcome as- High risk $\quad$ No blinding of self-report outcome assessment
sessment (detection bias)

sessment (detection bias)

All outcomes

\begin{tabular}{lll}
\hline $\begin{array}{l}\text { Incomplete outcome data } \\
\text { (attrition bias) } \\
\text { All outcomes }\end{array}$ & No missing data \\
\hline $\begin{array}{l}\text { Selective reporting (re- } \\
\text { porting bias) }\end{array}$ & Unclear risk & Insufficient information to permit judgment of 'low' or 'high' risk \\
\hline Other bias & Low risk & Appears to be free of other bias that would affect outcomes \\
\hline
\end{tabular}

Liossi 2009

\section{Study characteristics}

\begin{tabular}{|c|c|}
\hline Methods & RCT. 3 arms. \\
\hline \multirow[t]{9}{*}{ Participants } & Number of children: 15 control, 15 treatment \\
\hline & Sex of children: $14 \mathrm{M}, 16 \mathrm{~F}$ \\
\hline & Age range of children: 6 - 16 years \\
\hline & Mean age of children: $8.5 \pm 2.21$ years \\
\hline & Needle procedure: venepuncture \\
\hline & Diagnosis: pediatric outpatients \\
\hline & $\begin{array}{l}\text { Inclusion criteria: } 7 \text { - } 16 \text { years old, Greek-speaking patients with cancer, off active treatment and under- } \\
\text { going regular venepuncture as part of disease status monitoring, had } 1 \text { parent in attendance }\end{array}$ \\
\hline & $\begin{array}{l}\text { Exclusion criteria: major affective psychiatric disorders within last } 5 \text { years, concurrent treatment during } \\
\text { project with analgesic or psychotropic medication, no clearly visible veins as judged by nurse perform- } \\
\text { ing procedure, diagnosis of anxiety or mood disorder or other psychiatric diagnosis in past } 5 \text { years }\end{array}$ \\
\hline & Setting: Hematology/Oncology Department, Athens, Greece \\
\hline Interventions & $\begin{array}{l}\text { 1. Hypnosis (and EMLA):Prior to the procedure, hypnosis was practised and involved visual imagery (fa- } \\
\text { vorite place, activity, or television program) and analgesic suggestion was given after several minutes } \\
\text { (numbness, topical/local/glove anesthesia, and switchbox). Children were then taught self-hypnosis } \\
\text { following an abbreviated version of Gardner's model. EMLA was applied } 60 \text { minutes prior to the proce- } \\
\text { dure and children were cued by their parent to use the hypnosis during the procedure. }\end{array}$ \\
\hline
\end{tabular}


Liossi 2009 (Continued)

2. Attention control (and EMLA): Prior to the procedure, children met with a therapist and engaged in non-medical play and non-medical verbal interactions. Children also had EMLA applied 60 minutes prior to the procedure

3. EMLA only: Treated only with EMLA cream applied to the intact skin for approximately 60 minutes before the procedure. The other 2 groups also received the same EMLA application.

$\begin{array}{ll}\text { Outcomes } & \text { Pain measure: } \\ \text { - Child self-report: } 100 \mathrm{~mm} \text { VAS } \\ \text { Distress measure: } \\ \text { - Child self-report: } 100 \mathrm{~mm} \text { VAS (procedure-related) } \\ \text { - Behavioral measure: PBCL } \\ \text { Adverse events: none mentioned }\end{array}$

Notes The study involved 3 time points (Time 1, Time 2, and Time 3) but we only included Time 1 which occurred during the venepuncture and closest to the intervention. Times 2 and 3 were 3 and 6 months after the initial session and did not involve therapist-led intervention; therefore, we did not include them in this review. Also, we used a total $\mathrm{N}$ of 30 for this study (instead of 45 ) because we only included 2 of 3 conditions (EMLA + hypnosis versus EMLA + attention).

Study dates: study dates not reported

Funding: none stated

Conflicts of interest: none declared

\section{Risk of bias}

\begin{tabular}{lll}
\hline Bias & Authors' judgement & Support for judgement \\
\hline $\begin{array}{l}\text { Random sequence genera- } \\
\text { tion (selection bias) }\end{array}$ & Low risk & $\begin{array}{l}\text { Randomly allocated using computer-generated random positive integers (p. } \\
256 \text { Par 4) }\end{array}$ \\
\hline $\begin{array}{l}\text { Allocation concealment } \\
\text { (selection bias) }\end{array}$ & High risk & Used an open random allocation schedule (p. 256 par 11) \\
\hline $\begin{array}{l}\text { Blinding of participants } \\
\text { and personnel (perfor- } \\
\text { mance bias) } \\
\text { All outcomes }\end{array}$ & High risk & Participants were not blinded \\
\hline
\end{tabular}

Blinding of outcome as- High risk No blinding of self-report outcome assessment

sessment (detection bias)

All outcomes

Incomplete outcome data Low risk No missing data
(attrition bias)
All outcomes

Selective reporting (re- Unclear risk $\quad$ Insufficient information to permit judgment of 'low' or 'high' risk
porting bias)

\begin{tabular}{ll}
\hline Other bias $\quad$ Low risk $\quad$ Appears to be free of other bias that would affect outcomes \\
\hline
\end{tabular}


Luthy 2013

\section{Study characteristics}

\begin{tabular}{|c|c|}
\hline Methods & RCT. 3 arms. \\
\hline \multirow[t]{9}{*}{ Participants } & Number of children: 27 control, 27 treatment (distraction) \\
\hline & Sex of children: 32 M, $36 \mathrm{~F}$ (across all 3 arms) \\
\hline & Age range of children: 2 - 12.5 years \\
\hline & Mean age range of children: $5.2 \pm 3.4$ years (across all 3 arms) \\
\hline & Needle procedure: vaccinations \\
\hline & Diagnosis of child: none reported \\
\hline & $\begin{array}{l}\text { Inclusion criteria: } 2-12 \text { years, child in need of routine vaccinations, parent must have been present for } \\
\text { at least } 1 \text { of the child's previous vaccinations }\end{array}$ \\
\hline & $\begin{array}{l}\text { Exclusion criteria: children who were diabetic, had poor extremity circulation, had previous allergic re- } \\
\text { action to any topical anesthetic, parents with more than } 1 \text { child in need of vaccinations }\end{array}$ \\
\hline & Setting: pediatric office located in the second largest county in Utah, United States \\
\hline \multirow[t]{3}{*}{ Interventions } & $\begin{array}{l}\text { 1.DVD Distraction: Children watched a movie on a small portable DVD player before, during, and after } \\
\text { the vaccination. }\end{array}$ \\
\hline & $\begin{array}{l}\text { 2.Vapocoolant Spray: A vapocoolant spray was administered to the child for } 3 \text { to } 7 \text { seconds immediate- } \\
\text { ly before the vaccination. }\end{array}$ \\
\hline & 3.Control: Children received no intervention but were given the vaccination as usual. \\
\hline \multirow[t]{5}{*}{ Outcomes } & Pain measure: \\
\hline & - Parent report of child pain: Wong Baker FACES Pain Scale \\
\hline & Distress measure: \\
\hline & - Parent report of child anxiety: single-item scale $(0-5)$ \\
\hline & Adverse events: none mentioned \\
\hline
\end{tabular}

Notes

We did not include the vapocoolant spray condition in this review.

Study dates: study dates not reported

Funding: Brigham Young University College of Nursing Research and Scholarship Council

Conflicts of interest: none declared

\section{Risk of bias}

\begin{tabular}{lll}
\hline Bias & Authors' judgement & Support for judgement \\
\hline $\begin{array}{l}\text { Random sequence genera- } \\
\text { tion (selection bias) }\end{array}$ & Low risk & Quote: "computer randomized" (p. 353) \\
\hline $\begin{array}{l}\text { Allocation concealment } \\
\text { (selection bias) }\end{array}$ & High risk & Use of envelopes without appropriate safeguards stated \\
\hline
\end{tabular}


Luthy 2013 (Continued)
Blinding of participants
High risk
Study participants and personnel were not blinded and personnel (performance bias)

All outcomes

\begin{tabular}{lll}
\hline $\begin{array}{l}\text { Blinding of outcome as- } \\
\text { sessment (detection bias) } \\
\text { All outcomes }\end{array}$ & High risk & No blinding of outcome assessment \\
\hline $\begin{array}{l}\text { Incomplete outcome data } \\
\text { (attrition bias) } \\
\text { All outcomes }\end{array}$ & Low risk & No missing data \\
\hline $\begin{array}{l}\text { Selective reporting (re- } \\
\text { porting bias) }\end{array}$ & Unclear risk & Insufficient information to permit judgment of 'low' or 'high' risk \\
\hline $\begin{array}{l}\text { Other bias } \\
\text { High risk }\end{array}$ & $\begin{array}{l}\text { Multiple potential sources of bias related to study design (e.g. underpow- } \\
\text { ered, unclear if other interventions delivered by parents beforehand, use of re- } \\
\text { straint) }\end{array}$ \\
\hline
\end{tabular}

McCarthy 2010

\section{Study characteristics}

\begin{tabular}{ll}
\hline Methods & RCT. 2 arms. \\
\hline Participants & Number of children: 293 control, 249 treatment \\
Sex of children: 280 M, $262 \mathrm{~F}$ \\
Age range of children: 4 - 10 years \\
Mean age of children: $6.95 \pm 1.90$ years \\
Needle procedure: IV needle insertion \\
Diagnosis of child: gastroenterology clinic (45\%), nephrology (17\%), endocrinology (12\%), pulmonary \\
(8\%), cardiology (3\%), other clinics (15\%, primarily radiology) \\
Inclusion criteria: 4 - 10 years old, undergoing a scheduled IV needle insertion for a diagnostic medical \\
procedure \\
Exclusion criteria: developmental disabilities, limited English language skills to answer study ques- \\
tions, children with cancer \\
Setting: 3 Midwestern children's hospitals in the United States
\end{tabular}

Interventions

1. Parent distraction coaching training: Parent received information using educational materials, video, and discussion with research assistant on providing distraction to their child. The parent and child then selected distracters such as books, toys, and video games.

2. Routine care control: Parents were told to interact normally with their child.

Distraction items were available in the treatment room with no direction to use them.

$\begin{array}{ll}\text { Outcomes } & \text { Pain measure: } \\ & \text { - Child self-report: Oucher Pain Rating Scale }\end{array}$


Distress measures:

- Parent report: single item ("How stressed was your child today during the IV procedure?")

- Behavioral: OSBD-R

Physiological measure:

- Salivary cortisol, "measured by \% change in cortisol levels between the matched clinic and baseline cortisol levels"

Adverse events: none mentioned

Notes Study dates: study dates not reported

Funding: R01 Grant No. NR05269-01A2 from the National Institute for Nursing Research

Conflicts of interest: none declared

\begin{tabular}{|c|c|c|}
\hline \multicolumn{3}{|l|}{ Risk of bias } \\
\hline Bias & Authors' judgement & Support for judgement \\
\hline $\begin{array}{l}\text { Random sequence genera- } \\
\text { tion (selection bias) }\end{array}$ & Unclear risk & $\begin{array}{l}\text { Quote: "randomly assigned" - no further details. Insufficient information to } \\
\text { permit judgment of 'low' or 'high' risk }\end{array}$ \\
\hline $\begin{array}{l}\text { Allocation concealment } \\
\text { (selection bias) }\end{array}$ & Unclear risk & Insufficient information to permit judgment of 'low' or 'high' risk \\
\hline $\begin{array}{l}\text { Blinding of participants } \\
\text { and personnel (perfor- } \\
\text { mance bias) } \\
\text { All outcomes }\end{array}$ & High risk & $\begin{array}{l}\text { Although authors report blinding of personnel, parents aware of group assign- } \\
\text { ment }\end{array}$ \\
\hline $\begin{array}{l}\text { Blinding of outcome as- } \\
\text { sessment (detection bias) } \\
\text { All outcomes }\end{array}$ & High risk & No blinding of parent-reported outcome assessment \\
\hline $\begin{array}{l}\text { Incomplete outcome data } \\
\text { (attrition bias) } \\
\text { All outcomes }\end{array}$ & High risk & $\begin{array}{l}\text { Considerable variation in numbers of missing data across outcomes; reasons } \\
\text { not provided }\end{array}$ \\
\hline $\begin{array}{l}\text { Selective reporting (re- } \\
\text { porting bias) }\end{array}$ & High risk & One or more outcomes of interest are reported incompletely \\
\hline Other bias & High risk & $\begin{array}{l}\text { Had a potential source of bias likely to influence outcome (e.g. "control group } \\
\text { contamination" p. 137) }\end{array}$ \\
\hline
\end{tabular}

Meiri 2016

\section{Study characteristics}

\begin{tabular}{ll}
\hline Methods & RCT. 3 arms. \\
\hline Participants & Number of children: 20 control, 40 treatment (medical clown) \\
& Sex of children: $53 \mathrm{M}, 47 \mathrm{~F}$ (across all 3 arms) \\
& Age range of children: 2 - 10 years \\
\hline
\end{tabular}


Meiri 2016 (Continued)

Mean age range of children: $5.3 \pm 2.5$ years (across all 3 arms)

Needle procedure: IV cannulation or blood draw

Diagnosis of child: none reported

Inclusion criteria: 2 - 10 years, required blood sampling/line insertion for clinical reasons

Exclusion criteria: acutely ill and unstable, or potentially acutely ill and unstable

Setting: emergency department and inpatient ward at pediatric hospital in Israel

Interventions

1. Medical clown: A trained medical clown entertained and distracted the child with funny actions (inflating a comical balloon, humorous noises of animals, playing an accordion, singing funny songs) starting 10 minutes before the procedure and ending when the child left the room after the procedure.

2. Local anesthesia by EMLA (active control group): Local anesthesia was applied on the skin surface of the injection site. After 50 minutes, the procedure was performed in the routine way.

3. Standard clinical method (control group): Standard procedure was practised. The child lay on the bed while the parent was holding and talking to the child. A nurse held the hand of the child as the physician took the blood sample.

\begin{tabular}{ll}
\hline Outcomes & Pain measures: \\
- Child self-report: scale of 10 faces $(0-10)$ \\
- Parent report of child pain: VAS $(10 \mathrm{~cm})$ \\
- Pediatrician report of child pain: VAS $(10 \mathrm{~cm})$ \\
Distress measures: \\
- Parent report of child anxiety: VAS $(10 \mathrm{~cm})$ \\
- Pediatric report of child anxiety: VAS $(10 \mathrm{~cm})$ \\
- Duration of child crying (minutes) \\
Adverse events: none mentioned
\end{tabular}

Notes

We did not include the EMLA-only group in this review.

Study dates: study dates not reported

Funding: non-restrictive grant from MAGI foundation.

Conflicts of interest: none declared

\section{Risk of bias}

\begin{tabular}{lll}
\hline Bias & Authors' judgement & Support for judgement \\
\hline $\begin{array}{l}\text { Random sequence genera- } \\
\text { tion (selection bias) }\end{array}$ & Unclear risk & $\begin{array}{l}\text { Quote: "by order of arrival". Insufficient information to permit judgment of } \\
\text { 'low' or 'high' risk }\end{array}$ \\
\hline $\begin{array}{l}\text { Allocation concealment } \\
\text { (selection bias) }\end{array}$ & Unclear risk & Insufficient information to permit judgment of 'low' or 'high' risk \\
\hline $\begin{array}{l}\text { Blinding of participants } \\
\text { and personnel (perfor- } \\
\begin{array}{l}\text { mance bias) } \\
\text { All outcomes }\end{array}\end{array}$ & High risk & Study participants and personnel were not blinded \\
\hline
\end{tabular}

Blinding of outcome as-
sessment (detection bias) $\quad$ High risk No blinding of outcome assessment

Psychological interventions for needle-related procedural pain and distress in children and adolescents (Review) 
Meiri 2016 (Continued)

All outcomes

Incomplete outcome data Unclear risk Unclear as number of participants per group not clearly reported
(attrition bias)

(attrition bias)

All outcomes

\begin{tabular}{lll}
\hline $\begin{array}{l}\text { Selective reporting (re- } \\
\text { porting bias) }\end{array}$ & Low risk & Primary and secondary outcomes clearly stated and reported \\
\hline Other bias & High risk & Potential source of bias related to measurement of outcomes \\
\hline
\end{tabular}

Miguez-Navarro 2016

\section{Study characteristics}

\begin{tabular}{|c|c|}
\hline Methods & RCT. 2 arms. \\
\hline \multirow[t]{9}{*}{ Participants } & Number of children: 70 control, 70 treatment \\
\hline & Sex of children: 81 M, $59 \mathrm{~F}$ \\
\hline & Age range of children: 3 - 11 years \\
\hline & Mean age range of children: 6.82 years \\
\hline & Needle procedure: venipuncture \\
\hline & Diagnosis of child: none reported \\
\hline & Inclusion criteria: 3 - 11 years, required venipuncture \\
\hline & $\begin{array}{l}\text { Exclusion criteria: psychomotor retardation, chronic pathologies, any consciousness disorder, classi- } \\
\text { fied as Priority } 1 \text { or } 2 \text { (in a system of } 5 \text { levels of triage), parents or guardians did not sign the informed } \\
\text { consent }\end{array}$ \\
\hline & Setting: emergency department in Madrid, Spain \\
\hline \multirow[t]{2}{*}{ Interventions } & $\begin{array}{l}\text { 1.Video distraction: From the beginning of the procedure, children were shown short videos of cartoons } \\
\text { frequently watched by Spanish children using a portable DVD player. The videos were chosen by each } \\
\text { child. Parents were not allowed in the procedure room. }\end{array}$ \\
\hline & 2. Control: Standard venipuncture procedures were followed. \\
\hline \multirow[t]{8}{*}{ Outcomes } & Pain measures: \\
\hline & - Child self-report (3 - 7 year olds): Wong Baker FACES scale \\
\hline & - Child self-report (8-11 year olds): Numerical rating scale (0 - 10) \\
\hline & Distress measure: \\
\hline & - Child self-report: Groninger Distress Scale \\
\hline & Physiological measure: \\
\hline & - Heart rate: beats per minute \\
\hline & Adverse events: none mentioned \\
\hline
\end{tabular}

Notes

Study dates: July to December 2011. 
Miguez-Navarro 2016 (Continued)

\author{
Funding: none stated \\ Conflicts of interest: none declared
}

\title{
Risk of bias
}

\begin{tabular}{lll}
\hline Bias & Authors' judgement & Support for judgement \\
\hline $\begin{array}{l}\text { Random sequence genera- } \\
\text { tion (selection bias) }\end{array}$ & Low risk & Quote: "generated by Research Randomizer" (p. 2) \\
\hline
\end{tabular}

tion (selection bias)

$\begin{aligned} & \text { Allocation concealment } \\ & \text { (selection bias) }\end{aligned}$
Unclear risk Insufficient information to permit judgment of 'low' or 'high' risk.

Blinding of participants High risk Study participants and personnel were not blinded
and personnel (perfor-
mance bias)
All outcomes

\begin{tabular}{lll}
\hline $\begin{array}{l}\text { Blinding of outcome as- } \\
\text { sessment (detection bias) } \\
\text { All outcomes }\end{array}$ & High risk & No blinding of outcome assessment \\
\hline $\begin{array}{l}\text { Incomplete outcome data } \\
\text { (attrition bias) } \\
\text { All outcomes }\end{array}$ & Low risk & No missing data \\
\hline $\begin{array}{l}\text { Selective reporting (re- } \\
\text { porting bias) }\end{array}$ & High risk & One or more outcomes of interest are reported incompletely (i.e. heart rate) \\
\hline $\begin{array}{l}\text { Other bias } \\
\text { High risk }\end{array}$ & $\begin{array}{l}\text { Multiple potential sources of bias related to study design (e.g. parents not al- } \\
\text { lowed in intervention group only) }\end{array}$
\end{tabular}

Miller 2016

\section{Study characteristics}

\begin{tabular}{ll}
\hline Methods & RCT. 5 arms. \\
\hline Participants & Number of children: 20 control, 19 or 20 per treatment arm \\
Sex of children: $48 \mathrm{M}, 50 \mathrm{~F}$ \\
Age range of children: 3 - 12 years \\
Mean age range of children: $6.73 \pm 2.71$ years \\
Needle procedure: IV cannulation \\
Diagnosis of child: mixed (34\% trauma, 27\% gastrointestinal, 39\% generic medical conditions) \\
Inclusion criteria: 3 - 12 years, required an IV cannulation procedure \\
Exclusion criteria: unconscious or required high-level medical care, had cognitive difficulties impacting \\
use of self-reported outcome measures, had uncorrected visual impairment impacting the effective use \\
of interventions, were non-English-speaking \\
Setting: emergency department at the Royal Children's Hospital, Brisbane, Australia
\end{tabular}


Miller 2016 (Continued)

Interventions
1. Ditto distraction: Children had access to interactive games and stories on a Ditto device during the procedure. The distraction stories and games use multisensory stimuli including animated visual content, sound, and vibration to divert a child's attention away from painful and distressing medical procedures.

2. Ditto procedural preparation: Children had access to an interactive procedural preparation story on a Ditto device before the procedure. The story informs the child about the steps in the upcoming procedure and what the child can do to help staff during the procedure.

3. Ditto combined procedural preparation and distraction: Children had access to a Ditto device for both the procedural preparation story before the procedure and interactive stories and games as distraction during the procedure.

4. PlayStation portable: Children had access to a Sony handheld PlayStation Portable and interactive games during the procedure.

5. Standard distraction ('Usual Care'): Children had access to toys, nursing, and caregiver interaction as in standard protocol.

Pain measures:
- Child self-report: Wong Baker FACES scale (during procedure)
- Caregiver/parent report of child pain: VAS (during procedure)
- Faces, Legs, Activity, Crying, Consolability (FLACC): (during procedure)

Adverse events: none mentioned

Study dates: March 2011 to July 2012
Funding: none stated
Conflicts of interest: none declared

\section{Risk of bias}

\begin{tabular}{|c|c|c|}
\hline Bias & Authors' judgement & Support for judgement \\
\hline $\begin{array}{l}\text { Random sequence genera- } \\
\text { tion (selection bias) }\end{array}$ & Unclear risk & $\begin{array}{l}\text { Quote: "block randomization". Insufficient information to permit judgment of } \\
\text { 'low' or 'high' risk. }\end{array}$ \\
\hline $\begin{array}{l}\text { Allocation concealment } \\
\text { (selection bias) }\end{array}$ & Low risk & Quote: "use of consecutively-numbered sealed opaque envelopes" (p. 446) \\
\hline $\begin{array}{l}\text { Blinding of participants } \\
\text { and personnel (perfor- } \\
\text { mance bias) } \\
\text { All outcomes }\end{array}$ & High risk & Study participants and personnel were not blinded \\
\hline $\begin{array}{l}\text { Blinding of outcome as- } \\
\text { sessment (detection bias) } \\
\text { All outcomes }\end{array}$ & High risk & No blinding of outcome assessment \\
\hline $\begin{array}{l}\text { Incomplete outcome data } \\
\text { (attrition bias) } \\
\text { All outcomes }\end{array}$ & Low risk & No missing data \\
\hline $\begin{array}{l}\text { Selective reporting (re- } \\
\text { porting bias) }\end{array}$ & Unclear risk & Insufficient information to permit judgment of 'low' or 'high' risk \\
\hline
\end{tabular}


Miller 2016 (Continued)

Other bias Low risk Appears to be free of other bias that would affect outcomes

Minute 2012

\section{Study characteristics}

\begin{tabular}{|c|c|}
\hline Methods & RCT. 2 arms. \\
\hline \multirow[t]{9}{*}{ Participants } & Number of children: 50 control, 47 treatment \\
\hline & Sex of children: 49 M, $48 \mathrm{~F}$ \\
\hline & Age range of children: 4 - 10 years \\
\hline & Mean age range of children: 7 years (median) \\
\hline & Needle procedure: IV cannulation and venipuncture \\
\hline & Diagnosis of child: none reported \\
\hline & Inclusion criteria: 4 - 10 years, needed to undergo IV cannulation and venipuncture \\
\hline & $\begin{array}{l}\text { Exclusion criteria: positive history for epilepsy, known hypersensitivity to amide anesthetics, impossi- } \\
\text { bility for the personnel to execute the procedure on the hand or elbow, impossibility for the child to co- } \\
\text { operate and play with the video game }\end{array}$ \\
\hline & Setting: pediatric clinic, gastroenterology service, and day hospital of pediatric hospital in Trieste, Italy \\
\hline \multirow[t]{2}{*}{ Interventions } & $\begin{array}{l}\text { 1. Active distraction: Children had EMLA cream applied to the injection site at least } 60 \text { minutes before } \\
\text { the procedure. The procedure was explained step by step to the child and parent, with the child rou- } \\
\text { tinely sitting on the parent's legs. During the procedure, children were shown a simple interactive video } \\
\text { game in which they had to aim at different targets using a single-handed remote as a pointer. Children } \\
\text { were instructed to aim at the target and try to concentrate on the video. }\end{array}$ \\
\hline & $\begin{array}{l}\text { 2. Conventional care: Standard protocol was followed. Children had EMLA cream applied to the injec- } \\
\text { tion site at least } 60 \text { minutes before the procedure. The procedure was explained step by step to the } \\
\text { child and parent, with the child routinely sitting on the parent's legs. }\end{array}$ \\
\hline \multirow[t]{4}{*}{ Outcomes } & Pain measure: \\
\hline & - Child self-report: FPS-R \\
\hline & - FLACC \\
\hline & Adverse events: none mentioned \\
\hline \multirow[t]{3}{*}{ Notes } & Study dates: April to December 2009 \\
\hline & Funding: none stated \\
\hline & Conflicts of interest: none declared \\
\hline
\end{tabular}

\section{Risk of bias}

Bias Authors' judgement Support for judgement

Random sequence genera- Low risk tion (selection bias)

Quote: "randomization procedure managed by an independent statistician...using a computer program" (p. 79) 
Minute 2012 (Continued)

$\begin{array}{ll}\begin{array}{l}\text { Allocation concealment } \\ \text { (selection bias) }\end{array} & \text { Low risk } \\ \end{array}$
(selection bias)

High risk

Study participants and personnel were not blinded

Blinding of participants and personnel (performance bias)

All outcomes

$\begin{array}{lll}\text { Blinding of outcome as- } & \text { High risk } & \text { No blinding of outcome assessment } \\ \text { sessment (detection bias) } & & \end{array}$

(

All outcomes

Incomplete outcome data Low risk
(attrition bias)

All outcomes

Selective reporting (re- Unclear risk Insufficient information to permit judgment of 'low' or 'high' risk
porting bias)

Other bias

High risk

Multiple potential sources of bias related to study design (e.g. application of other interventions between groups)

Mutlu 2015a

\section{Study characteristics}

Methods RCT. 3 arms.

\section{Participants}

Number of children: 44 control, 44 treatment (balloon inflation)

Sex of children: $48 \mathrm{M}, 40 \mathrm{~F}$

Age range of children: 9 - 12 years

Mean age range of children: $10.39 \pm 1.08$ years (treatment balloon inflation), $10.36 \pm 1.12$ years (control)

Needle procedure: venipuncture

Diagnosis of child: none reported

Inclusion criteria: 9 - 12 years, presented at the blood testing room

Exclusion criteria: taken analgesic drugs within 24 hours prior to the blood sampling procedure, had fever, mental or neurological disorders, a medical history of fainting, chronic diseases that necessitated frequent blood sampling procedures, previously undergone surgery

Setting: blood testing room of pediatric department of large research hospital in Instanbul, Turkey

Interventions

1. Balloon Inflation: Before the procedure, children were asked to choose a balloon of the color of their choice and inflate it. The balloon was then deflated. During the procedure, the child inflated the balloon again.

2. Cough Trick: [k1] Before the procedure, children were told that they would be asked to cough while their blood was being taken. As a preliminary exercise, the children were asked before the procedure to take a deep breath and then cough actively. During the procedure, the child was asked to cough.

3. Control: The usual procedure of the blood testing room was followed. Parents were allowed to accompany their children but no pain reducing intervention of any kind was applied. 
Mutlu 2015a (Continued)

\begin{tabular}{|c|c|}
\hline Outcomes & $\begin{array}{l}\text { Pain measure: } \\
\text { - Child self-report: FPS-R } \\
\text { Adverse events: none mentioned }\end{array}$ \\
\hline \multirow[t]{3}{*}{ Notes } & $\begin{array}{l}\text { We did not include the cough trick group in this review, } \\
\text { psychological mechanism. }\end{array}$ \\
\hline & Study dates: April to July 2011 \\
\hline & Funding: Research Fund of Istanbul University, Turkey \\
\hline
\end{tabular}

\section{Risk of bias}

\begin{tabular}{|c|c|c|}
\hline Bias & Authors' judgement & Support for judgement \\
\hline $\begin{array}{l}\text { Random sequence genera- } \\
\text { tion (selection bias) }\end{array}$ & Low risk & "using a computer program" p.179 \\
\hline $\begin{array}{l}\text { Allocation concealment } \\
\text { (selection bias) }\end{array}$ & Unclear risk & Insufficient information to permit judgment of 'low' or 'high' risk. \\
\hline $\begin{array}{l}\text { Blinding of participants } \\
\text { and personnel (perfor- } \\
\text { mance bias) } \\
\text { All outcomes }\end{array}$ & High risk & Study participants and personnel were not blinded \\
\hline $\begin{array}{l}\text { Blinding of outcome as- } \\
\text { sessment (detection bias) } \\
\text { All outcomes }\end{array}$ & High risk & No blinding of outcome assessment. \\
\hline $\begin{array}{l}\text { Incomplete outcome data } \\
\text { (attrition bias) } \\
\text { All outcomes }\end{array}$ & High risk & Reasons for missing data likely to be related to true outcome. \\
\hline $\begin{array}{l}\text { Selective reporting (re- } \\
\text { porting bias) }\end{array}$ & Unclear risk & Insufficient information to permit judgment of 'low' or 'high' risk \\
\hline Other bias & Low risk & Appears to be free of other bias that would affect outcomes. \\
\hline
\end{tabular}

\section{Nguyen 2010}

\section{Study characteristics}

\begin{tabular}{ll}
\hline Methods & RCT. 2 arms. \\
\hline Participants & Number of children: 20 control, 20 treatment \\
& Sex of children: $25 \mathrm{M}, 15 \mathrm{~F}$ \\
& Age range of children: $7-12$ years \\
& Mean age of children: $8.8 \pm 1.59$ years (intervention); $9.4 \pm 1.93$ years (control) \\
& Needle procedure: LP
\end{tabular}


Nguyen 2010 (Continued)

\section{Diagnosis: leukemia}

Inclusion criteria: 7 - 12 year olds, with leukemia, due to undergo a LP

Exclusion criteria: significant hearing or visual impairment, cognitive disorder

Setting: hospital oncology ward at NHP, Hanoi, Vietnam

Interventions

1. Music distraction: Children listened to music using earphones beginning 10 minutes prior to the procedure.

2. Control: Children wore earphones without music beginning 10 minutes prior to the procedure.

\begin{tabular}{ll}
\hline Outcomes & Pain measure: \\
- Child self-report: NRS 0 - 100 (during procedure) \\
Distress measure: \\
- Spielberger State-Trait Anxiety Inventory (STAI-Short Form, range 6 - 24) (post-procedure) \\
Physiological measure: \\
- Heart rate \\
- Blood pressure (systolic and diastolic) \\
- Oxygen saturation \\
Adverse events: none mentioned \\
Study dates: November 2007 to July 2008. \\
Funding: none stated \\
Conflicts of interest: none declared
\end{tabular}

\section{Risk of bias}

\begin{tabular}{|c|c|c|}
\hline Bias & Authors' judgement & Support for judgement \\
\hline $\begin{array}{l}\text { Random sequence genera- } \\
\text { tion (selection bias) }\end{array}$ & Unclear risk & $\begin{array}{l}\text { Randomized - no further details. Insufficient information to permit judgment } \\
\text { of 'low' or 'high' risk }\end{array}$ \\
\hline $\begin{array}{l}\text { Allocation concealment } \\
\text { (selection bias) }\end{array}$ & Unclear risk & $\begin{array}{l}\text { Unclear if all appropriate safeguards taken with assignment envelopes (i.e. se- } \\
\text { quentially-numbered or sealed) }\end{array}$ \\
\hline $\begin{array}{l}\text { Blinding of participants } \\
\text { and personnel (perfor- } \\
\text { mance bias) } \\
\text { All outcomes }\end{array}$ & High risk & Participants were not blinded \\
\hline $\begin{array}{l}\text { Blinding of outcome as- } \\
\text { sessment (detection bias) } \\
\text { All outcomes }\end{array}$ & High risk & No blinding of self-report outcome assessment \\
\hline $\begin{array}{l}\text { Incomplete outcome data } \\
\text { (attrition bias) } \\
\text { All outcomes }\end{array}$ & Low risk & No missing data \\
\hline $\begin{array}{l}\text { Selective reporting (re- } \\
\text { porting bias) }\end{array}$ & Unclear risk & Insufficient information to permit judgment of 'low' or 'high' risk \\
\hline
\end{tabular}


Nguyen 2010 (Continued)
Other bias
High risk
Potential source of bias related to measurement of outcomes

Nilsson 2015

\section{Study characteristics}

\begin{tabular}{ll}
\hline Methods & RCT (randomized cross-over trial). 2 arms. \\
\hline Participants & Number of children: 20 control first, 17 treatment first \\
Sex of children: 0 M, $37 \mathrm{~F}$ & Age range of children: 11 - 12 years \\
& Mean age range of children: not reported \\
& Needle procedure: vaccination \\
& Diagnosis of child: none reported \\
Inclusion criteria: 11 - 12 years, receiving 3 HPV vaccinations \\
Exclusion criteria: none given \\
Setting: three schools in western Sweden \\
$\begin{array}{l}\text { 1. Relaxation and guided imagery: Nurses provided relaxation and guided imagery during the proce- } \\
\text { dure. Children were encouraged to progressively relax their muscles and think about something posi- } \\
\text { tive. The nurse encouraged them to engage in the fantasy by asking detailed questions about it. } \\
\text { 2. Standard care: Standard care was performed according to regulations. The nurses were instructed to } \\
\text { talk as they normally do during vaccinations without any systematic relaxation or other non-pharma- } \\
\text { cological or pharmacological intervention. }\end{array}$ \\
\hline Interventions
\end{tabular}

Outcomes

Pain measure:

- Child self-report: Color Analogue Scale (CAS)

Distress measure:

- Child self-report: verbal rating scale for stress (0 - 10)

Physiological measure:

- Salivary cortisol (nmol/L)

Adverse events: none mentioned

Notes Outcomes included from time 1 only (before the cross-over to other condition)

Study dates: September 2012 to September 2013.

Funding: grants from the Ebba Danelius Foundation, Swedish Association of Paediatric Nurses, the Gertrud Östlinder Foundation and the Jerring Foundation.

Conflicts of interest: none declared

\section{Risk of bias}

\section{Bias}

Authors' judgement Support for judgement

Psychological interventions for needle-related procedural pain and distress in children and adolescents (Review) 
Nilsson 2015 (Continued)

Random sequence genera- Low risk Quote: "using a computer program (randomizer.org)" (p. 726) tion (selection bias)

Allocation concealment $\quad$ Unclear risk Insufficient information to permit judgment of 'low' or 'high' risk
(selection bias)

(selection bias)

Blinding of participants High risk Study participants and personnel were not blinded

and personnel (perfor-

mance bias)

All outcomes

\begin{tabular}{|c|}
\hline Blinding of outcome as- \\
\hline
\end{tabular}

sessment (detection bias)

All outcomes

Incomplete outcome data Low risk Some missing data but likely not related to outcomes of interest
(attrition bias)

All outcomes

\begin{tabular}{lll}
\hline $\begin{array}{l}\text { Selective reporting (re- } \\
\text { porting bias) }\end{array}$ & Unclear risk & Insufficient information to permit judgment of 'low' or 'high' risk \\
\hline Other bias & Low risk & Appears to be free of other bias that would affect outcomes \\
\hline
\end{tabular}

Noguchi 2006

\section{Study characteristics}

\begin{tabular}{ll}
\hline Methods & RCT. 3 arms. \\
\hline Participants & Number of children: 20 control, 42 treatment \\
Sex of children: $37 \mathrm{M}, 25 \mathrm{~F}$ \\
Age range of children: 4 - 6 years \\
Mean age of children: $4.55 \pm .65$ years \\
Needle procedure: immunization \\
Diagnosis: pediatric outpatients \\
Inclusion criteria: 4 - 6 years old, would be receiving 1 or more injections, were able to comprehend \\
English well enough to understand and complete the focus of the attention task \\
Exclusion criteria: none reported \\
Setting: 3 medical clinics in the USA
\end{tabular}

Interventions $\quad$ Musical story distraction: Children listened to a recording of a children's story that was sung with instrumental accompaniment using headphones. Visual aids depicting story events and characters were presented to children. An experimenter was present to redirect the child if needed.

2. Spoken story distraction:Children listened to a spoken recording of the same children's story using headphones. Visual aids depicting story events and characters were presented to children. An experimenter was present to redirect the child if needed.

3. Standard care control: No intervention 
Noguchi 2006 (Continued)
Outcomes
Pain measure:
- Child self-report: FPS
- Experimenter report: FPS
Distress measure:
- Behavioral: OSBD
Adverse events: none mentioned

The distraction conditions included reassurance which has been shown in other studies to be dis-
tress-promoting.
Study dates: study dates not reported
Funding: none stated
Conflicts of interest: none declared

\section{Risk of bias}

\begin{tabular}{lll}
\hline Bias & Authors' judgement & Support for judgement \\
\hline $\begin{array}{l}\text { Random sequence genera- } \\
\text { tion (selection bias) }\end{array}$ & Low risk & $\begin{array}{l}\text { Quote:"randomly assigned...based on a randomly-generated sequence of } \\
\text { numbers" (p. 19 Par 1) }\end{array}$ \\
\hline $\begin{array}{l}\text { Allocation concealment } \\
\text { (selection bias) }\end{array}$ & Unclear risk & Insufficient information to permit judgment of 'low' or 'high' risk \\
\hline $\begin{array}{l}\text { Blinding of participants } \\
\text { and personnel (perfor- } \\
\text { mance bias) } \\
\text { All outcomes }\end{array}$ & High risk & Study participants and personnel were not blinded \\
\hline $\begin{array}{l}\text { Blinding of outcome as- } \\
\text { sessment (detection bias) } \\
\text { All outcomes }\end{array}$ & High risk & No blinding of outcome assessment \\
\hline $\begin{array}{l}\text { Incomplete outcome data } \\
\text { (attrition bias) } \\
\text { All outcomes }\end{array}$ & Low risk & No missing data \\
\hline $\begin{array}{l}\text { Selective reporting (re- } \\
\text { porting bias) }\end{array}$ & Unclear risk & Insufficient information to permit judgment of 'low' or 'high' risk \\
\hline \begin{tabular}{l} 
Other bias \\
\hline
\end{tabular} & High risk & Multiple potential sources of bias related to study design and other problems \\
\hline
\end{tabular}

\section{Oliveira 2017}

\section{Study characteristics}

Methods $\quad$ RCT (randomized cross-over trial). 2 arms.

Participants Number of children: 18 control, 22 treatment

Sex of children: $16 \mathrm{M}, 24 \mathrm{~F}$ 
Oliveira 2017 (Continued)

Age range of children: 6 - 12 years

Mean age of children: $8.72 \pm 1.80$ years

Needle procedure: venepuncture or arterial puncture

Diagnosis: onco-hematology (42.5\%), endocrinology (15\%), pulmonology (15\%), nephrology (10\%), rheumatology (7.5\%), gastroenterology (2.5\%), cardiology (2.5\%), and immunology $(2.5 \%)$

Inclusion criteria: children aged 6 - 12 years, sufficient language skills to communicate, in a hospital setting with different diagnoses, prescribed venipuncture or arterial puncture based on clinical demand, hospitalized for at least 1 day and had a time interval of not more than 7 days between the puncture procedures

Exclusion criteria: children with neurological impairments or communication problems and children under sedation

Setting: pediatric inpatient units in hospital in Brazil

1. Audiovisual distraction: Children watched short films on a portable DVD player before and throughout the procedure. A researcher directed the child's attention to the video by making comments about the scenes and characters. The parents of the children were present during the intervention, but they were instructed not to interfere with the procedure.

2. Usual care: Procedure conducted as in routine hospital care. At the time of the study, no non-pharmacological or pharmacological protocols were adopted by the hospital in routine puncture procedures.

\begin{tabular}{ll}
\hline Outcomes & Pain measure: \\
- Child self-report: VAS \\
- Child self-report: FPS-R \\
Adverse events: none mentioned \\
\hline Wotes \\
We included only outcomes from Time 1, prior to the cross-over. \\
Funding: none stated \\
Conflicts of interest: none declared
\end{tabular}

\section{Risk of bias}

\begin{tabular}{lll}
\hline Bias & Authors' judgement & Support for judgement \\
\hline $\begin{array}{l}\text { Random sequence genera- } \\
\text { tion (selection bias) }\end{array}$ & Low risk & Quote: "randomizer.org" (p. 179) \\
\hline $\begin{array}{l}\text { Allocation concealment } \\
\text { (selection bias) }\end{array}$ & Unclear risk & Insufficient information to permit judgment of 'low' or 'high' risk. \\
\hline $\begin{array}{l}\text { Blinding of participants } \\
\begin{array}{l}\text { and personnel (perfor- } \\
\text { mance bias) }\end{array}\end{array}$ & High risk & Participants were not blinded \\
All outcomes & & \\
\hline
\end{tabular}

\begin{tabular}{lll}
\hline Blinding of outcome as- & High risk & No blinding of outcome assessment \\
sessment (detection bias) & \\
All outcomes &
\end{tabular}


Oliveira 2017 (Continued)

Incomplete outcome data Low risk No missing data
(attrition bias)

All outcomes

Selective reporting (re- Unclear risk Insufficient information to permit judgment of 'low' or 'high' risk porting bias)

Other bias Low risk Appears to be free of other bias that would affect outcomes.

Pourmovahed 2013

\section{Study characteristics}

\begin{tabular}{|c|c|}
\hline Methods & RCT. 2 arms. \\
\hline \multirow[t]{9}{*}{ Participants } & Number of children: 50 control, 50 treatment \\
\hline & Sex of children: $58 \mathrm{M}, 42 \mathrm{~F}$ \\
\hline & Age range of children: 6 - 15 years \\
\hline & Mean age range of children: $9.45 \pm 2.80$ years \\
\hline & Needle procedure: LP \\
\hline & Diagnosis of child: leukemia \\
\hline & $\begin{array}{l}\text { Inclusion criteria: } 6 \text { - } 15 \text { years, coming to oncology ward suffering from leukemia and hospitalized in the } \\
\text { pediatric ward, alertness, verbal, subjective, visual and hearing ability, absence of pain and physiologi- } \\
\text { cal needs (thirst, need for excretion) before injection }\end{array}$ \\
\hline & Exclusion criteria: patients who received a second injection, had respiratory difficulties \\
\hline & Setting: pediatric ward at Shahid Sadoughi University of Medical Sciences, Yazd, Iran \\
\hline \multirow[t]{2}{*}{ Interventions } & $\begin{array}{l}\text { 1. Hey-Hu regular breathing: The Hey-Hu technique was demonstrated to the children before injection. } \\
\text { In this method, the child takes a deep breath, exhales while whispering hey, then inhales deeply again } \\
\text { and exhales whispering hu. This was practiced with the child before the procedure and was then per- } \\
\text { formed } 1 \text { minute before until the end of the procedure. }\end{array}$ \\
\hline & 2. Control: No specific description was mentioned in the study. \\
\hline
\end{tabular}

Outcomes Pain measure:

- Child self-report: Wong Baker FACES pain scale

Adverse events: 3 children discontinued intervention due to respiratory difficulties.

\begin{tabular}{ll}
\hline Notes & Registered in Iranian Registry of Clinical Trials (Code IRCT2012102311230N1 \\
Study dates: 2011 \\
Funding: none stated \\
Conflicts of interest: none declared
\end{tabular}

\section{Risk of bias}

Bias Authors' judgement Support for judgement

Psychological interventions for needle-related procedural pain and distress in children and adolescents (Review) 
Pourmovahed 2013 (Continued)

\begin{tabular}{ll}
$\begin{array}{l}\text { Random sequence genera- } \\
\text { tion (selection bias) }\end{array}$ & Quote: "sampling method was random (using random allocation software)" ( $p$. \\
\hline
\end{tabular}

Allocation concealment $\quad$ Unclear risk Insufficient information to permit judgment of 'low' or 'high' risk
(selection bias)

Blinding of participants $\quad$ High risk
and personnel (perfor-
mance bias)

\begin{tabular}{|c|c|c|}
\hline $\begin{array}{l}\text { Blinding of outcome as- } \\
\text { sessment (detection bias) } \\
\text { All outcomes }\end{array}$ & High risk & No blinding of outcome assessment \\
\hline $\begin{array}{l}\text { Incomplete outcome data } \\
\text { (attrition bias) } \\
\text { All outcomes }\end{array}$ & Low risk & $\begin{array}{l}\text { Missing data balanced across groups and unlikely to be related to true out- } \\
\text { come }\end{array}$ \\
\hline $\begin{array}{l}\text { Selective reporting (re- } \\
\text { porting bias) }\end{array}$ & Unclear risk & Insufficient information to permit judgment of 'low' or 'high' risk \\
\hline Other bias & Low risk & Appears to be free of other bias that would affect outcomes \\
\hline
\end{tabular}

\section{Press 2003}

\section{Study characteristics}

\begin{tabular}{|c|c|}
\hline Methods & RCT. 2 arms. \\
\hline \multirow[t]{9}{*}{ Participants } & Number of children: 46 control, 48 treatment \\
\hline & Sex of children: 57 M, $37 \mathrm{~F}$ \\
\hline & Age range of children: 6 - 16 years \\
\hline & Mean age of children: $11.5 \pm 2.5$ years (intervention); $9.9 \pm 2.3$ years (control) \\
\hline & Needle procedure: venepuncture \\
\hline & Diagnosis: none reported \\
\hline & $\begin{array}{l}\text { Inclusion criteria: } 6 \text { - } 16 \text { years old, undergoing venepuncture, conscious, Hebrew -speaking, no hearing } \\
\text { problems }\end{array}$ \\
\hline & Exclusion criteria: none reported \\
\hline & Setting: pediatric emergency department of the Saroka University Medical Centre, Israel \\
\hline \multirow[t]{2}{*}{ Interventions } & $\begin{array}{l}\text { 1. Active distraction: Children listened to music using headphones and were asked a question about } \\
\text { the song's content. }\end{array}$ \\
\hline & 2. Standard care control: Nurses provided usual care. \\
\hline \multirow[t]{3}{*}{ Outcomes } & Pain measures: \\
\hline & - Child self-report: $10 \mathrm{~cm}$ VAS combined with a Faces Pain Scale \\
\hline & - Parent report: $10 \mathrm{~cm}$ VAS combined with a Faces Pain Scale \\
\hline
\end{tabular}


Press 2003 (Continued)

- Nurse report: $10 \mathrm{~cm}$ VAS combined with a Faces Pain Scale

Adverse events: none mentioned

Study dates: study dates not reported
Funding: none stated
Conflicts of interest: none declared

\section{Risk of bias}

\begin{tabular}{lll}
\hline Bias & Authors' judgement & Support for judgement \\
\hline $\begin{array}{l}\text { Random sequence genera- } \\
\text { tion (selection bias) }\end{array}$ & Unclear risk & $\begin{array}{l}\text { Randomized - no further details. Insufficient information to permit judgment } \\
\text { of 'low' or 'high' risk }\end{array}$ \\
\hline $\begin{array}{l}\text { Allocation concealment } \\
\text { (selection bias) }\end{array}$ & Unclear risk & Insufficient information to permit judgment of 'low' or 'high' risk \\
\hline $\begin{array}{l}\text { Blinding of participants } \\
\text { and personnel (perfor- } \\
\text { mance bias) } \\
\text { All outcomes }\end{array}$ & High risk & Study participants and personnel were not blinded \\
\hline
\end{tabular}

Blinding of outcome assessment (detection bias)

High risk No blinding of outcome assessment

All outcomes

Incomplete outcome data Low risk No missing data

(attrition bias)

All outcomes

\begin{tabular}{lll}
\hline $\begin{array}{l}\text { Selective reporting (re- } \\
\text { porting bias) }\end{array}$ & Unclear risk & Insufficient information to permit judgment of 'low' or 'high' risk \\
\hline Other bias & High risk & $\begin{array}{l}\text { Had a potential source of bias related to the specific study design (e.g. modi- } \\
\text { fied pain measure) }\end{array}$ \\
\hline
\end{tabular}

Ramírez-Carrasco 2017

\section{Study characteristics}

\begin{tabular}{ll}
\hline Methods & RCT. 2 arms. \\
\hline Participants & Number of children: 20 control, 20 treatment \\
& Sex of children: $16 \mathrm{M}, 24 \mathrm{~F}$ \\
& Age range of children: 5 - 9 years \\
& Mean age range of children: $90 \pm 17.15$ months \\
& Needle procedure: dental anesthetic \\
& Diagnosis of child: healthy children
\end{tabular}


Ramírez-Carrasco 2017 (Continued)

Inclusion criteria: participants must have never received dental care, seeking attention at the Pediatric Dentistry Clinic a t the Autonomous University of San Luis Potosi for the first time and their dental treatment had to include a local anesthetic

Exclusion criteria: none stated

Setting: pediatric dentistry clinic a t the Autonomous University of San Luis Potosi, Mexico

Interventions
hypnosis intervention included a standard 3-minute progressive muscle relaxation induction followed
by a 5-minute deepening procedure aimed at increasing the person's focus, absorption, and concentra-
tion. In the intervention phase the hypnotic suggestions were aimed at modifying their perception of
pain. Participants were asked to visualize a safe and special garden with a fountain in the middle. They
were told the fountain water would make their mouth numb and relaxed, so they would feel complete-
ly comfortable and relaxed while the dentist "made their tooth feel better". Standard conventional be-
havior management techniques were also used.
2. Control: Children were asked to wear headphones to block out the sound of the dental drill. Stan-
dard conventional behavior management techniques were used.
Pain measure:
- Behavioural: FLACC
Physiological measure:
- Heart rate
Skin conductance
Adverse events: None mentioned
Study dates: study dates not reported
Funding: none stated
Conflicts of interest: none declared
Notes

\section{Risk of bias}

\begin{tabular}{|c|c|c|}
\hline Bias & Authors' judgement & Support for judgement \\
\hline $\begin{array}{l}\text { Random sequence genera- } \\
\text { tion (selection bias) }\end{array}$ & Unclear risk & $\begin{array}{l}\text { Randomized - no further details. Insufficient information to permit judgment } \\
\text { of 'low' or 'high' risk }\end{array}$ \\
\hline $\begin{array}{l}\text { Allocation concealment } \\
\text { (selection bias) }\end{array}$ & Unclear risk & Insufficient information to permit judgment of 'low' or 'high' risk \\
\hline $\begin{array}{l}\text { Blinding of participants } \\
\text { and personnel (perfor- } \\
\text { mance bias) } \\
\text { All outcomes }\end{array}$ & High risk & Study participants and personnel were not blinded \\
\hline $\begin{array}{l}\text { Blinding of outcome as- } \\
\text { sessment (detection bias) } \\
\text { All outcomes }\end{array}$ & Low risk & Quote: "evaluators blind to the patients' group membership" (p. 2) \\
\hline $\begin{array}{l}\text { Incomplete outcome data } \\
\text { (attrition bias) } \\
\text { All outcomes }\end{array}$ & Low risk & No missing data \\
\hline
\end{tabular}


Ramírez-Carrasco 2017 (Continued)
Selective reporting (re-
High risk
Outcomes insufficiently reported for inclusion in meta-analysis porting bias)

Other bias

Unclear risk

Insufficient information to permit judgment of 'low' or 'high' risk

Rimon 2016

\section{Study characteristics}

\begin{tabular}{|c|c|}
\hline Methods & RCT. 2 arms. \\
\hline \multirow[t]{9}{*}{ Participants } & Number of children: 24 control, 29 treatment \\
\hline & Sex of children: 21 M, $32 \mathrm{~F}$ \\
\hline & Age range of children: 2 - 15 years \\
\hline & Mean age range of children: $6.9 \pm 3.4$ years (control); $5.6 \pm 2.8$ years (treatment) \\
\hline & Needle procedure: blood draw or IV access \\
\hline & Diagnosis of child: none reported \\
\hline & Inclusion criteria: accompanied by a parent \\
\hline & $\begin{array}{l}\text { Exclusion criteria: if they needed urgent IV cannulation, had developmental disabilities, were critically } \\
\text { ill or needed IV cannulation for the treatment of a severe bacterial infection, or if they had received glu- } \\
\text { cocorticoids during the preceding } 6 \text { weeks }\end{array}$ \\
\hline & Setting: pediatric emergency department in Israel \\
\hline \multirow[t]{2}{*}{ Interventions } & $\begin{array}{l}\text { 1. Medical clown: Children spent } 15 \text { minutes with the medical clown before the procedure, followed by } \\
\text { blood collection in the presence of the medical clown. The medical clown used CBT, including distrac- } \\
\text { tion through humour (magic tricks, puppets, jokes) and imagery (imagining a pleasant object). }\end{array}$ \\
\hline & $\begin{array}{l}\text { 2. No medical clown: Parents were not given any instructions in how to help their child, nor did emer- } \\
\text { gency department nurses use any guided imagery or distraction techniques, even though many were } \\
\text { knowledgeable about distraction techniques. }\end{array}$ \\
\hline \multirow[t]{6}{*}{ Outcomes } & Pain measure: \\
\hline & - Child self-report (4 - 7 year olds): FPS-R \\
\hline & - Child self-report (7+ years): ViAS (100 mm VAS) \\
\hline & Physiological measure: \\
\hline & - Serum cortisol plasma levels \\
\hline & Adverse events: none mentioned \\
\hline \multirow[t]{3}{*}{ Notes } & Study dates: 1-year period ending in September 2015. \\
\hline & Funding: The Magi Foundation and The Adelis Foundation \\
\hline & Conflicts of interest: none declared \\
\hline \multicolumn{2}{|l|}{ Risk of bias } \\
\hline Bias & Authors' judgement Support for judgement \\
\hline
\end{tabular}

Psychological interventions for needle-related procedural pain and distress in children and adolescents (Review) 
Rimon 2016 (Continued)

$\begin{array}{ll}\begin{array}{l}\text { Random sequence genera- } \\ \text { tion (selection bias) }\end{array} & \text { Low risk } \\ \end{array}$

\begin{tabular}{|c|c|c|}
\hline $\begin{array}{l}\text { Allocation concealment } \\
\text { (selection bias) }\end{array}$ & Unclear risk & $\begin{array}{l}\text { Unclear if all appropriate safeguards taken with assignment envelopes (i.e. } \\
\text { opaque) }\end{array}$ \\
\hline
\end{tabular}

Blinding of participants High risk Study participants and personnel were not blinded
and personnel (perfor-
mance bias)
All outcomes

\begin{tabular}{lll}
\hline $\begin{array}{l}\text { Blinding of outcome as- } \\
\text { sessment (detection bias) } \\
\text { All outcomes }\end{array}$ & High risk & No blinding of outcome assessment \\
\hline $\begin{array}{l}\text { Incomplete outcome data } \\
\text { (attrition bias) } \\
\text { All outcomes }\end{array}$ & Low risk & Missing data minor and deemed unlikely to influence study outcomes \\
\hline $\begin{array}{l}\text { Selective reporting (re- } \\
\text { porting bias) }\end{array}$ & Unclear risk & Unclear reporting of pain outcomes for 2 - 3-year-olds. \\
\hline Other bias & Low risk & Appears to be free of other bias that would affect outcomes \\
\hline
\end{tabular}

\section{Sahiner 2016}

\section{Study characteristics}

\begin{tabular}{|c|c|}
\hline Methods & RCT. 4 arms. \\
\hline \multirow[t]{9}{*}{ Participants } & Number of children: 30 control, 30 per treatment group (90) \\
\hline & Sex of children: $63 \mathrm{M}, 57 \mathrm{~F}$ \\
\hline & Age range of children: 6 - 12 years \\
\hline & Mean age range of children: $9.1 \pm 1.6$ years \\
\hline & Needle procedure: venipuncture \\
\hline & Diagnosis of child: none reported \\
\hline & Inclusion criteria: 6 - 12 years, requested blood tests \\
\hline & Exclusion criteria: none given \\
\hline & Setting: Phlebotomy Unit of the Karaman Maternity and Children Hospital in Turkey \\
\hline \multirow[t]{3}{*}{ Interventions } & $\begin{array}{l}\text { 1. Distraction cards: Children received visual cards covered with pictures and shapes just before the } \\
\text { procedure. The child carefully examined the cards and then the researcher asked questions about the } \\
\text { cards (e.g. Can you see the comet?) until the procedure was complete. }\end{array}$ \\
\hline & $\begin{array}{l}\text { 2.Listening to cartoon music: Music from } 15 \text { cartoons watched by children aged } 6 \text { to } 12 \text { years was } \\
\text { played and the child was asked to identify which cartoon the music belonged to. A new song was } \\
\text { played when the child recognized the music until the procedure was complete. }\end{array}$ \\
\hline & $\begin{array}{l}\text { 3. Balloon Inflation: Children were given a balloon of their color choice. They were asked to inflate the } \\
\text { balloon before the procedure and keep on inflating until the procedure was complete. Children were } \\
\text { given the balloons to keep. }\end{array}$ \\
\hline
\end{tabular}


Sahiner 2016 (Continued)

4. Control: The routine blood-taking procedure was followed.

$\begin{array}{ll}\text { Outcomes } & \text { Pain measure: } \\ \text { - Child self-report: Wong Baker FACES scale } \\ \text { - Parent report of child pain: Wong Baker FACES scale } \\ \text { - Researcher report of child pain: Wong Baker FACES scale } \\ \text { Distress measure: } \\ \text { - Parent report of child anxiety: CFS } \\ \text { - Researcher report of child anxiety: CFS } \\ \text { Adverse events: none mentioned } \\ \text { Study dates: study dates not reported } \\ \text { Funding: none stated } \\ \text { Conflicts of interest: none declared }\end{array}$

Risk of bias

\begin{tabular}{|c|c|c|}
\hline Bias & Authors' judgement & Support for judgement \\
\hline $\begin{array}{l}\text { Random sequence genera- } \\
\text { tion (selection bias) }\end{array}$ & Low risk & Quote: "computer generated table of random numbers" (p. 4) \\
\hline $\begin{array}{l}\text { Allocation concealment } \\
\text { (selection bias) }\end{array}$ & Unclear risk & Insufficient information to permit judgment of 'low' or 'high' risk. \\
\hline $\begin{array}{l}\text { Blinding of participants } \\
\text { and personnel (perfor- } \\
\text { mance bias) } \\
\text { All outcomes }\end{array}$ & High risk & Study participants and personnel were not blinded \\
\hline $\begin{array}{l}\text { Blinding of outcome as- } \\
\text { sessment (detection bias) } \\
\text { All outcomes }\end{array}$ & High risk & No blinding of outcome assessment. \\
\hline $\begin{array}{l}\text { Incomplete outcome data } \\
\text { (attrition bias) } \\
\text { All outcomes }\end{array}$ & Low risk & No missing data \\
\hline $\begin{array}{l}\text { Selective reporting (re- } \\
\text { porting bias) }\end{array}$ & Low risk & Objectives clearly stated and fully reported \\
\hline Other bias & Low risk & Appears to be free of other bias that would affect outcomes \\
\hline
\end{tabular}

Sander Wint 2002

\section{Study characteristics}

Methods RCT. 2 arms.

Participants

Number of children: 13 control, 17 treatment 
Sander Wint 2002 (Continued)

Sex of children: $16 \mathrm{M}, 14 \mathrm{~F}$

Age range of children: 10 - 19 years

Mean age of children: not reported (median $=13.6$ years)

Needle procedure: LP

Diagnosis: acute lymphoblastic leukemia (ALL), or lymphoma

Inclusion criteria: 10 - 19 years old, being treated for cancer, receiving LPs as part of therapy and undergoing at least a second LP, able to understand and communicate in English, able to hear and see

Exclusion criteria: none reported

Setting: clinic treatment room at pediatric teaching hospital in the South West, USA

$\begin{array}{ll}\text { Interventions } & \begin{array}{l}\text { 1.Virtual reality distraction: In addition to standard care, adolescents wore virtual reality glasses that } \\ \text { provided 3D viewing and music in stereo sound. Nurses explained the purpose of the virtual reality } \\ \text { glasses and the need for adolescents to focus their attention on what they were hearing and seeing. }\end{array} \\ \text { 2. Standard care control: Adolescents received standard nursing care including conscious sedation, } \\ \text { topical anesthetic, explanation of the procedure, and parental presence. }\end{array}$

\section{Risk of bias}

\begin{tabular}{lll}
\hline Bias & Authors' judgement & Support for judgement \\
\hline $\begin{array}{l}\text { Random sequence genera- } \\
\text { tion (selection bias) }\end{array}$ & Unclear risk & $\begin{array}{l}\text { Randomized - no further details. Insufficient information to permit judgment } \\
\text { of 'low' or 'high' risk }\end{array}$ \\
\hline $\begin{array}{l}\text { Allocation concealment } \\
\text { (selection bias) }\end{array}$ & Unclear risk & Insufficient information to permit judgment of 'low' or 'high' risk \\
\hline $\begin{array}{l}\text { Blinding of participants } \\
\text { and personnel (perfor- } \\
\text { mance bias) } \\
\text { All outcomes }\end{array}$ & High risk & Study participants and personnel were not blinded \\
\hline
\end{tabular}

Blinding of outcome as- High risk No blinding of self-report outcome assessment
sessment (detection bias)

All outcomes

\begin{tabular}{lll}
\hline $\begin{array}{l}\text { Incomplete outcome data } \\
\text { (attrition bias) } \\
\text { All outcomes }\end{array}$ & Low risk & No missing data \\
\hline $\begin{array}{l}\text { Selective reporting (re- } \\
\text { porting bias) }\end{array}$ & High risk & One or more outcomes of interest are reported incompletely
\end{tabular}


Sander Wint 2002 (Continued)
Other bias
High risk
Multiple potential sources of bias related to study design and other problems
(e.g., small and unequal sample size)

Sinha 2006

\section{Study characteristics}

\begin{tabular}{ll}
\hline Methods & RCT. 2 arms. \\
\hline Participants & Number of children: 120 control, 120 treatment \\
Sex of children: $120 \mathrm{M}, 120 \mathrm{~F}$ \\
Age range of children: 6 - 18 years \\
Mean age of children: $10.73 \pm 3.5$ years (intervention); $10.81 \pm 3.9$ years (control) \\
Needle procedure: sutures for laceration repair \\
Diagnosis: uncomplicated laceration repair involving only the skin and subcutaneous tissue, <5 cm in \\
length \\
Inclusion criteria: 6 - 18 years old, visiting ED for laceration repair between noon and midnight \\
Exclusion criteria: children presenting with multiple lacerations greater than or equal to 1 complex lac- \\
eration, or a laceration with other injuries \\
Setting: hospital emergency department in a 253 -bed tertiary care children's hospital serving a popula- \\
tion of 2.5 million in a 17 -county service region in the United States
\end{tabular}

Interventions

1.Distraction: Children were given a choice of distracters including music, video games, or cartoon video. For children who did not show interest in any of these, a child life specialist read a book or blew bubbles during the procedure. Procedure was explained to the child.

2. Standard care control: Procedure was explained to the child.

Pain measure:
- Child self-report: 7-point FPS
Anxiety/Distress measure:
- Child self-report: State scale of State Trait Anxiety Inventory for Children (STAIC)
- Caregiver/parent report: 100 mm VAS
Adverse events: none mentioned
SDs were not reported in the paper and we calculated them from available data. The STAIC outcome
was only used with children 10 years and older.
Study dates: October 2003 to August 2004
Funding: Ken Graff Young Investigator Grant award by the Section on Emergency Medicine, American
Academy of Pediatrics
Conflicts of interest: none declared

Risk of bias 
Sinha 2006 (Continued)

\section{Bias Authors' judgement Support for judgement}

Random sequence genera- Unclear risk tion (selection bias)

Randomly assigned by a patient allocation scheme implementing a stratified block design to ensure equal gender. Insufficient information to permit judgment of 'low' or 'high' risk

\begin{tabular}{lll}
\hline $\begin{array}{l}\text { Allocation concealment } \\
\text { (selection bias) }\end{array}$ & Unclear risk & $\begin{array}{l}\text { Unclear if all appropriate safeguards taken with assignment envelopes } \\
\text { (i.e. opaque) }\end{array}$ \\
\hline $\begin{array}{l}\text { Blinding of participants } \\
\text { and personnel (perfor- } \\
\text { mance bias) }\end{array}$ & High risk & Participants were not blinded \\
All outcomes & & \\
\hline
\end{tabular}

\begin{tabular}{|c|c|c|}
\hline $\begin{array}{l}\text { Blinding of outcome as- } \\
\text { sessment (detection bias) } \\
\text { All outcomes }\end{array}$ & High risk & No blinding of self-report and parent-report outcome assessment \\
\hline $\begin{array}{l}\text { Incomplete outcome data } \\
\text { (attrition bias) } \\
\text { All outcomes }\end{array}$ & Low risk & Reported missing data did not impact outcomes \\
\hline $\begin{array}{l}\text { Selective reporting (re- } \\
\text { porting bias) }\end{array}$ & Low risk & Insufficient information to permit judgment of 'low' or 'high' risk \\
\hline Other bias & High risk & $\begin{array}{l}\text { Multiple potential sources of bias related to study design and other problems } \\
\text { (e.g. "heightened awareness of distraction techniques amongst ED personnel" } \\
\text { p. 1167) }\end{array}$ \\
\hline
\end{tabular}

\section{Tak 2006}

\section{Study characteristics}

\begin{tabular}{ll}
\hline Methods & RCT. 6 arms. \\
\hline Participants & Number of children: 20 control, 20 treatment \\
Sex of children: $25 \mathrm{M}, 15 \mathrm{~F}$ \\
Age range of children: 3 - 12 years \\
Mean age of children: $6.6 \pm 2.9$ years (intervention); $6.6 \pm 2.7$ years (control) \\
Needle procedure: venepuncture \\
Diagnosis: none reported \\
Inclusion criteria: Dutch children receiving a venepuncture \\
Exclusion criteria: children of non-Dutch parentage \\
Setting: outpatient centre of the St Antonius Ziekenhuis in Nieuwegein (the Netherlands) \\
Definitions for the following condition components are provided below. \\
1. Placebo, distraction, information \\
2. EMLA, distraction, information \\
3. Placebo, information
\end{tabular}


Tak 2006 (Continued)

4. EMLA, information

5. Information

6. Non-treatment control

Distraction: During the venepuncture, a funny 6-minute fragment of a video cartoon (Walk Disney's 'Beauty and the Beast') was shown. Sound could be heard through a headphone.

Procedural Information: All children except those in the control groups received information on the venepuncture by means of a photo book. The supervising research assistant asked the child to read the book with his/her parent(s) while in the waiting room. The 24 photos, each accompanied by a short and simple text, showed step-by-step what was to come from entrance to departure from the hospital. A boy 8 years old acted as the model.

EMLA: EMLA cream was applied by the laboratory personnel on duty who did not know whether the cream was EMLA or a placebo cream. These were not necessarily the same persons as those who did the pricking.

Placebo: A placebo cream was applied by the laboratory personnel on duty who did not know whether the cream was EMLA or a placebo cream. These were not necessarily the same persons as those who did the pricking.

*Because EMLA requires 1 hour to produce its effect, the children in the4 'cream conditions' passed that time in the waiting room in the presence of their parent(s).

Non-treatment control: no treatment provided

Pain measure:
- Child self-report: Oucher scale (for children < 6 years)
- Child self-report: VAS (for children $>6$ years)
Distress measure:
- Behavioral: Groningen Distress Scale (GDS)
Adverse events: none mentioned

Notes

We used a total $\mathrm{N}$ of 94 for this study (instead of 136) because we only included 4 of 6 conditions (i.e. placebo, distraction, information versus placebo, information and information versus non-treatment control). Although GDS ratings were calculated at 3 time points in this study (child entering the room, just before venepuncture, and during venepuncture), we only used the 'during venepuncture' scores in the analyses for this review.

Study dates: September 1993 to February 1995

Funding: none stated

Conflicts of interest: none declared

\section{Risk of bias}

\begin{tabular}{lll}
\hline Bias & Authors' judgement & Support for judgement \\
\hline $\begin{array}{l}\text { Random sequence genera- } \\
\text { tion (selection bias) }\end{array}$ & Unclear risk & $\begin{array}{l}\text { Randomized - no further details. Insufficient information to permit judgment } \\
\text { of 'low' or 'high' risk }\end{array}$ \\
\hline $\begin{array}{l}\text { Allocation concealment } \\
\text { (selection bias) }\end{array}$ & Unclear risk & Insufficient information to permit judgment of 'low' or 'high' risk \\
\hline $\begin{array}{l}\text { Blinding of participants } \\
\begin{array}{l}\text { and personnel (perfor- } \\
\text { mance bias) }\end{array}\end{array}$ & High risk & Participants and personnel were not blinded \\
\hline
\end{tabular}


Tak 2006 (Continued)

All outcomes

Blinding of outcome as-
sessment (detection bias) $\quad$ High risk No blinding of outcome assessment

sessment (detection bias)

All outcomes

Incomplete outcome data Unclear risk No reasons for missing data provided
(attrition bias)

All outcomes

Selective reporting (re- Unclear risk $\quad$ Insufficient information to permit judgment of 'low' or 'high' risk
porting bias)

porting bias)

\begin{tabular}{ll}
\hline Other bias $\quad$ Unclear risk $\quad$ Insufficient information to assess whether an important risk of bias exists \\
\hline
\end{tabular}

Tyc 1997

\section{Study characteristics}

\begin{tabular}{|c|c|}
\hline Methods & RCT. 2 arms. \\
\hline \multirow[t]{9}{*}{ Participants } & Number of children: 28 treatment, 27 control \\
\hline & Sex of children: $50.9 \% \mathrm{M}, 49.1 \% \mathrm{~F}$ \\
\hline & Age range of children: 6.3 - 18.6 years \\
\hline & Mean age range of children: 12.5 years \\
\hline & Needle procedure: IV insertion prior to MRI \\
\hline & $\begin{array}{l}\text { Diagnosis of child: CNS cancer ( } 27 \% \text { medulloblastoma, } 24 \% \text { CNS glioma, } 49 \% \text { variety of malignant CNS } \\
\text { neoplasms) }\end{array}$ \\
\hline & $\begin{array}{l}\text { Inclusion criteria: } 6 \text { - } 18 \text { years, English-speaking, scheduled to receive an MRI procedure of the brain or } \\
\text { spine, received at least } 1 \text { previous MRI procedure at hospital within the last } 12 \text { months, in remission or } \\
\text { had stable disease, or both }\end{array}$ \\
\hline & $\begin{array}{l}\text { Exclusion: children who had relapsed or had evidence of progressive disease or had severe cognitive } \\
\text { deficits, or both }\end{array}$ \\
\hline & Setting: St Jude’s Children's Hospital, Tennessee, United States \\
\hline \multirow[t]{2}{*}{ Interventions } & $\begin{array}{l}\text { 1. CBT: Children received the CBT } 1 \text { to } 2 \text { hours prior to the procedure. The intervention consisted of } \\
\text { filmed modeling (a 15-minute film depicted the steps involved in preparing for the MRI), breathing ex- } \\
\text { ercises (both passive and active exercises), emotive imagery/distraction (focus on emotive or pleas- } \\
\text { ant mental images), behavioral rehearsal (involved practice for starting an IV and lying still inside the } \\
\text { MRI), and positive incentive (showing the child a small trophy and saying he/she could win the trophy } \\
\text { by "doing the best they could do"). }\end{array}$ \\
\hline & $\begin{array}{l}\text { 2. Standard care control (SCC): Children received the standard preparation for the MRI exam at this in- } \\
\text { stitution. Prior to their procedure, they had the opportunity to discuss details about the MRI procedure } \\
\text { with the technologist and view the magnet. }\end{array}$ \\
\hline \multirow[t]{4}{*}{ Outcomes } & Distress measure: \\
\hline & $\begin{array}{l}\text { - Child self-report of anxiety: State-Trait Anxiety Inventory for Children (STAI-C) Child self-report of IV } \\
\text { distress: } 10 \text {-point scale (post-procedure) }\end{array}$ \\
\hline & - Parent report of child IV distress: 10-point scale (post-procedure) \\
\hline & - Staff report of child IV distress: 10-point scale \\
\hline
\end{tabular}

Psychological interventions for needle-related procedural pain and distress in children and adolescents (Review) 
Tyc 1997 (Continued)

- Behavioral: MRI Behavior Checklist

Adverse events: none mentioned

Notes

Parent and staff IV distress ratings were pooled together to create one overall 'observer-reported distress' outcome. Only outcomes related to the IV (not the MRI) were used in the analyses for this review. The STAI-C scores were used in this study to assess background variables, therefore they were not included in the analyses for this review.

Study dates: study dates not reported

Funding: American Lebanese Syrian Associated Charities (ALSAC) and the National Cancer Institute, Cancer Center Support (CORE) Grants CA 21765 and CA 23099

Conflicts of interest: none declared

\section{Risk of bias}

\begin{tabular}{|c|c|c|}
\hline Bias & Authors' judgement & Support for judgement \\
\hline $\begin{array}{l}\text { Random sequence genera- } \\
\text { tion (selection bias) }\end{array}$ & Unclear risk & $\begin{array}{l}\text { Randomized - no further details. Insufficient information to permit judgment } \\
\text { of 'low' or 'high' risk }\end{array}$ \\
\hline $\begin{array}{l}\text { Allocation concealment } \\
\text { (selection bias) }\end{array}$ & Unclear risk & Insufficient information to permit judgment of 'low' or 'high' risk \\
\hline $\begin{array}{l}\text { Blinding of participants } \\
\text { and personnel (perfor- } \\
\text { mance bias) } \\
\text { All outcomes }\end{array}$ & High risk & Study participants were not blinded \\
\hline $\begin{array}{l}\text { Blinding of outcome as- } \\
\text { sessment (detection bias) } \\
\text { All outcomes }\end{array}$ & High risk & No blinding of outcome assessment \\
\hline $\begin{array}{l}\text { Incomplete outcome data } \\
\text { (attrition bias) } \\
\text { All outcomes }\end{array}$ & Low risk & No missing data \\
\hline $\begin{array}{l}\text { Selective reporting (re- } \\
\text { porting bias) }\end{array}$ & Unclear risk & Insufficient information to permit judgment of 'low' or 'high' risk \\
\hline Other bias & High risk & Multiple potential sources of bias related to study design and other problems \\
\hline
\end{tabular}

Vessey 1994

\section{Study characteristics}

\begin{tabular}{ll}
\hline Methods & RCT. 2 arms. \\
\hline Participants & Number of children: 50 control, 50 treatment \\
& Sex of children: $62 \mathrm{M}, 38 \mathrm{~F}$ \\
& Age range of children: $3.6-12.11$ years \\
& Mean age of children: 7 years 4 months \pm 3.3 months
\end{tabular}


Vessey 1994 (Continued)

Needle procedure: routine blood draw

Diagnosis: none

Inclusion criteria: must have had 2 or fewer blood draws in the 6 months preceding the procedure, free of chronic conditions, fluent in English

Exclusion criteria: none given

Setting: ambulatory care clinic of a children's hospital in the South Centre USA

Interventions

1. Distraction: Children were distracted using the Illusion Kaleidoscope. They were encouraged to concentrate on what they were seeing.

2. Standard care control: Children received standard procedure preparation.

Pain measure:
- Child self-report: Wong-Baker FACES Pain Rating Scale
- Behavioral: CHEOP scale
Adverse events: none mentioned
The authors found that age was a significant covariate, whereby younger children reported perceiv-
ing greater intensities of pain and demonstrated more active observable behavioral distress to the
venepuncture than the older children. They provided adjusted means (but not adjusted SDs). Since the
adjusted means were only slightly different from the original means, we used the original means and
SDs for the analyses in this review.
Study dates: study dates not reported
Funding: University of Arkansas for Medical Sciences, College of Nursing, Intramural Grants Program,
and the U.S. Public Health Service, Division of Nursing, Advanced Nursing Education Award, Grant
\#D23-NU-00948-02
Conflicts of interest: none declared

\section{Risk of bias}

\begin{tabular}{lll}
\hline Bias & Authors' judgement & Support for judgement \\
\hline $\begin{array}{l}\text { Random sequence genera- } \\
\text { tion (selection bias) }\end{array}$ & Low risk & $\begin{array}{l}\text { Quote: "subjects were randomly assigned...using a random number table" (p. } \\
370 \text { Par 10) }\end{array}$ \\
\hline $\begin{array}{l}\text { Allocation concealment } \\
\text { (selection bias) }\end{array}$ & High risk & Use of an open random allocation schedule (e.g. random-number table) \\
\hline $\begin{array}{l}\text { Blinding of participants } \\
\begin{array}{l}\text { and personnel (perfor- } \\
\text { mance bias) } \\
\text { All outcomes }\end{array}\end{array}$ & High risk & Participants and personnel were not blinded \\
\hline
\end{tabular}

Blinding of outcome as- High risk No blinding of self-report outcome assessment

sessment (detection bias)

All outcomes

Incomplete outcome data Low risk No missing data
(attrition bias)
All outcomes


Vessey 1994 (Continued)

Selective reporting (re- Unclear risk Insufficient information to permit judgment of 'low' or 'high' risk porting bias)

Other bias

Unclear risk

Insufficient information to assess whether an important risk of bias exists

Vosoghi 2010

\section{Study characteristics}

\begin{tabular}{|c|c|}
\hline Methods & RCT. 2 arms. \\
\hline \multirow[t]{9}{*}{ Participants } & Number of children: 36 treatment, 36 control \\
\hline & Sex of children: 37 M, $35 \mathrm{~F}$ \\
\hline & Age range of children: $3-6$ years old \\
\hline & Mean age range of children: not reported \\
\hline & Needle procedure: IV insertion \\
\hline & Diagnosis of child: infectious diseases (57), internal medicine diseases (15) \\
\hline & $\begin{array}{l}\text { Inclusion criteria: } 3 \text { - } 6 \text { years, orientation to time, place and people, ability to make verbal communica- } \\
\text { tion }\end{array}$ \\
\hline & $\begin{array}{l}\text { Exclusion: pain, seizure, or any life-threatening condition, administration of pain killers, insertion of }>1 \\
\text { catheter, time of attempting to insert the catheter }>60 \text { seconds }\end{array}$ \\
\hline & Setting: emergency department of a children's hospital in Iran \\
\hline \multirow[t]{2}{*}{ Interventions } & $\begin{array}{l}\text { 1. Distraction: } 2 \text { minutes before the IV insertion, distraction was done using a bubble maker (i.e. a train } \\
\text { that whistles and makes bubbles while moving) and was continued until the end of the procedure. }\end{array}$ \\
\hline & 2. Control: Same overall study procedure for all participants. No distraction was administered. \\
\hline \multirow[t]{6}{*}{ Outcomes } & Pain measure: \\
\hline & - Child self-report: OUCHER \\
\hline & Physiological measure: \\
\hline & - Heart rate \\
\hline & - Oxygen saturation \\
\hline & Adverse events: none mentioned \\
\hline \multirow[t]{4}{*}{ Notes } & $\begin{array}{l}\text { This was an article in Farsi and we had a translator help us with data extraction. For study exclusion cri- } \\
\text { teria, the authors did not explain what they meant by 'pain' but presumably this was pain not explicitly } \\
\text { due to the needle procedure. In addition, although means and SDs for the OUCHER were not reported } \\
\text { in the paper, we obtained them through a contact with the study authors. }\end{array}$ \\
\hline & Study dates: study dates not reported \\
\hline & Funding: none stated \\
\hline & Conflicts of interest: none declared \\
\hline
\end{tabular}

\section{Risk of bias}

Psychological interventions for needle-related procedural pain and distress in children and adolescents (Review) 
Vosoghi 2010 (Continued)

\begin{tabular}{lll} 
Bias & Authors' judgement & Support for judgement \\
\hline $\begin{array}{l}\text { Random sequence genera- } \\
\text { tion (selection bias) }\end{array}$ & Unclear risk & $\begin{array}{l}\text { Randomized - no further details. Insufficient information to permit judgment } \\
\text { of 'low' or 'high' risk }\end{array}$ \\
\hline $\begin{array}{l}\text { Allocation concealment } \\
\text { (selection bias) }\end{array}$ & Unclear risk & Insufficient information to permit judgment of 'low' or 'high' risk \\
\hline $\begin{array}{l}\text { Blinding of participants } \\
\begin{array}{l}\text { and personnel (perfor- } \\
\text { mance bias) }\end{array}\end{array}$ & High risk & No mention of blinding but nature of psychological intervention precludes this \\
All outcomes &
\end{tabular}

\begin{tabular}{|c|c|c|}
\hline $\begin{array}{l}\text { Blinding of outcome as- } \\
\text { sessment (detection bias) }\end{array}$ & High risk & No blinding of outcome assessment \\
\hline
\end{tabular}

All outcomes

Incomplete outcome data Unclear risk Insufficient reporting of exclusions to permit judgment of 'low' or 'high' risk
(attrition bias)

(attrition bias)

All outcomes

\begin{tabular}{lll}
\hline $\begin{array}{l}\text { Selective reporting (re- } \\
\text { porting bias) }\end{array}$ & High risk & $\begin{array}{l}\text { One or more outcomes of interest are reported incompletely to include in } \\
\text { meta-analyses }\end{array}$
\end{tabular}

Other bias Unclear risk Insufficient information to assess whether an important risk of bias exists

Wang 2008

\section{Study characteristics}

\begin{tabular}{ll}
\hline Methods & RCT. 3 arms. \\
\hline Participants & Number of children: 100 control, 100 treatment \\
Sex of children: $98 \mathrm{M}, 102 \mathrm{~F}$ \\
Age range of children: 8 - 9 years \\
Mean age of children: not reported \\
Needle procedure: venepuncture \\
Diagnosis: pneumonia, asthma, encephalitis, allergic purpura \\
Inclusion criteria: 8 - 9 years old, requiring venepuncture for a period of IV treatment in the pediatric \\
department \\
Exclusion criteria: history of puncture during the past 3 months, treatment with anxiolytic or narcot- \\
ic analgesics medication 72 hours prior to the venepuncture, presence of insufficient mental develop- \\
ment, alteration of mental status and cognitive impairment, visual and auditory deficits \\
Setting: hospital pediatric department in China
\end{tabular}

Interventions

. Audiovisual distraction: Children watched cartoon videos during the procedure. They were given a choice of 10 appropriate cartoon videos. 
Wang 2008 (Continued)

2. Psychological interventions: Participants received conventional psychological interventions in a fixed scheme delivered by a research nurse (e.g. comfort provided, procedure explained, therapeutic touch, guided imagery, and encouragement) with no audiovisual distraction.

3. Control condition: Children received no intervention.

\begin{tabular}{ll}
\hline Outcomes & Pain measure: \\
& - Child self-report: $10 \mathrm{~cm}$ VAS \\
& Adverse events: none mentioned \\
\hline Notes & Study dates: study dates not reported \\
& Funding: none stated. \\
& Conflicts of interest: none declared
\end{tabular}

\section{Risk of bias}

\begin{tabular}{|c|c|c|}
\hline Bias & Authors' judgement & Support for judgement \\
\hline $\begin{array}{l}\text { Random sequence genera- } \\
\text { tion (selection bias) }\end{array}$ & Low risk & $\begin{array}{l}\text { Quote:"randomly assigned...according to random numbers...generated for } \\
\text { Research Randomizer" (p. } 580 \text { Par 6) }\end{array}$ \\
\hline $\begin{array}{l}\text { Allocation concealment } \\
\text { (selection bias) }\end{array}$ & Unclear risk & $\begin{array}{l}\text { Unclear if all appropriate safeguards taken with assignment envelopes (i.e. } \\
\text { opaque) }\end{array}$ \\
\hline $\begin{array}{l}\text { Blinding of participants } \\
\text { and personnel (perfor- } \\
\text { mance bias) } \\
\text { All outcomes }\end{array}$ & High risk & Study participants and personnel were not blinded \\
\hline $\begin{array}{l}\text { Blinding of outcome as- } \\
\text { sessment (detection bias) } \\
\text { All outcomes }\end{array}$ & High risk & No blinding of self-report outcome assessment \\
\hline $\begin{array}{l}\text { Incomplete outcome data } \\
\text { (attrition bias) } \\
\text { All outcomes }\end{array}$ & Low risk & No missing data \\
\hline $\begin{array}{l}\text { Selective reporting (re- } \\
\text { porting bias) }\end{array}$ & Unclear risk & Insufficient information to permit judgment of 'low' or 'high' risk \\
\hline Other bias & High risk & $\begin{array}{l}\text { Had a potential source of bias related to significantly different to length of pro- } \\
\text { cedure time (p.581) }\end{array}$ \\
\hline
\end{tabular}

Windich-Biermeier 2007

\section{Study characteristics}

\begin{tabular}{ll}
\hline Methods & RCT. 2 arms. \\
\hline Participants & Number of children: 28 control, 22 treatment \\
& Sex of children: $27 \mathrm{M}, 23 \mathrm{~F}$ \\
& Age range of children: 5 - 18 years
\end{tabular}


Windich-Biermeier 2007 (Continued)

Mean age of children: $10.5 \pm 3.8$ years

Needle procedure: venous port access or venepuncture

Diagnosis: cancer

Inclusion criteria: 5 - 18 years old, able to understand and speak English, able to hear and see, had a diagnosis of leukemia, lymphoma, a solid tumor, histiocytosis, were receiving chemotherapy, had a physician order for a port access/venepuncture, had a least 1 previous access/venepuncture

Exclusion criteria: septic, dehydrated, vomiting, sedated, medically unstable, diagnosed with mental illness, or scheduled for another procedure following port access/venepuncture

Setting: hospital pediatric medical centre in the southwestern United States

Interventions

1. Parent coaching and child distraction: In addition to standard care, children chose 1 distracter (book, bubbles, music, Gameboy, or virtual reality glasses). Parents were instructed to actively coach the child throughout the procedure to use the distracter.

2. Standard care control: Included an explanation of the procedure, use of topical anesthetic, and parental presence during the procedure.
Pain measure:

- Child self-report: CAS

Distress measures:

- Child self-report: GFS

- Parent report: GFS

- Nurse report: GFS

- Behavioral: OSBD

Adverse events: none mentioned
Data for parent-reported fear, nurse-reported fear, and OBSD broken down by group (intervention versus control) were not reported, and therefore could not be included in the analyses for this review. Also, although the authors label the intervention as "distraction", they describe it as involving distraction with parent coaching. We therefore classified it in the 'Parent Coaching + Child Distraction' intervention category for this review. Lastly, the intervention and control groups differed in terms of various variables (e.g. type of topical analgesic used, parental presence, number of cannulation attempts); however, there were no statistically significant differences between the groups on any of these variables.

Study dates: study dates not reported

Funding: American Holistic Nurses' Association, Children's Medical Center Dallas Foundation, and Children's Medical Center Dallas Woman's Auxiliary

Conflicts of interest: none declared.

\section{Risk of bias}

\begin{tabular}{lll}
\hline Bias & Authors' judgement & Support for judgement \\
\hline $\begin{array}{l}\text { Random sequence genera- } \\
\text { tion (selection bias) }\end{array}$ & Low risk & $\begin{array}{l}\text { Quote: "randomly assigned using an SPSS pseudo-random number genera- } \\
\text { tor" (p. 9) }\end{array}$ \\
\hline $\begin{array}{l}\text { Allocation concealment } \\
\text { (selection bias) }\end{array}$ & Unclear risk & Insufficient information to permit judgment of 'low' or 'high' risk \\
\hline
\end{tabular}


Windich-Biermeier 2007 (Continued)
Blinding of participants
High risk
Study participants and personnel were not blinded and personnel (perfor- mance bias)
All outcomes

\begin{tabular}{|c|c|c|}
\hline $\begin{array}{l}\text { Blinding of outcome as- } \\
\text { sessment (detection bias) } \\
\text { All outcomes }\end{array}$ & High risk & No blinding of self-report outcome assessment \\
\hline $\begin{array}{l}\text { Incomplete outcome data } \\
\text { (attrition bias) } \\
\text { All outcomes }\end{array}$ & Low risk & No missing data \\
\hline $\begin{array}{l}\text { Selective reporting (re- } \\
\text { porting bias) }\end{array}$ & High risk & One or more outcomes of interest are reported incompletely \\
\hline Other bias & Unclear risk & Insufficient information to assess whether an important risk of bias exists \\
\hline
\end{tabular}

Yinger 2016

\section{Study characteristics}

\begin{tabular}{|c|c|}
\hline Methods & RCT. 2 arms. \\
\hline \multirow[t]{9}{*}{ Participants } & Number of children: 29 control, 29 treatment \\
\hline & Sex of children: $27 \mathrm{M}, 31 \mathrm{~F}$ \\
\hline & Age range of children: 4 - 6 years \\
\hline & Mean age of children: $56.6 \pm 6.7$ months \\
\hline & Needle procedure: immunizations \\
\hline & Diagnosis: none reported \\
\hline & $\begin{array}{l}\text { Inclusion criteria: } 48 \text { - } 72 \text { months of age, accompanied by at least } 1 \text { English-speaking parent or legal } \\
\text { guardian, and scheduled to receive at least } 1 \text { immunization by injection during their doctor visit }\end{array}$ \\
\hline & Exclusion criteria: none reported \\
\hline & $\begin{array}{l}\text { Setting: } 3 \text { healthcare sites in the southeastern USA ( } 2 \text { family medicine clinics; } 1 \text { hospital-affiliated pedi- } \\
\text { atric practice) }\end{array}$ \\
\hline \multirow[t]{2}{*}{ Interventions } & $\begin{array}{l}\text { 1. Music therapy: The music therapy intervention included different songs and CBTs within each phase } \\
\text { of the medical procedure, including the preparatory phase (introductory song to teach deep breathing } \\
\text { and information provision), during the procedure (coaching and active engagement in music as behav- } \\
\text { ioral distraction, in addition to engaging children in non-procedural talk about the music as a form of } \\
\text { cognitive distraction), and recovery phase (presented a new instrument and additional songs to pro- } \\
\text { vide distraction). After the child had recovered and no longer displayed distress behaviors, the clini- } \\
\text { cian-researcher presented a good-bye song to aid with completion of the procedure. }\end{array}$ \\
\hline & $\begin{array}{l}\text { 2. Standard care: The clinician-researcher remained in the room to hold and monitor the video camera, } \\
\text { but did not interact with the child, child's parents, or nurse(s). }\end{array}$ \\
\hline Outcomes & Pain measure: \\
\hline
\end{tabular}


Yinger 2016 (Continued)

Distress measure:

- Parent-report: Researcher created tool (7-point Likert Scale)

- Behavioural: distress behaviors from Child-Adult Medical Procedure Interaction Scale-Revised (CAMPIS-R)

Adverse events: none mentioned

Study: study dates not reported
Funding: none stated
Conflicts of interest: none declared

\section{Risk of bias}

\begin{tabular}{|c|c|c|}
\hline Bias & Authors' judgement & Support for judgement \\
\hline $\begin{array}{l}\text { Random sequence genera- } \\
\text { tion (selection bias) }\end{array}$ & Low risk & Quote: "web-based randomization program" (p. 348) \\
\hline $\begin{array}{l}\text { Allocation concealment } \\
\text { (selection bias) }\end{array}$ & High risk & Quote: "full allocation concealment was not possible" (p. 348) \\
\hline $\begin{array}{l}\text { Blinding of participants } \\
\text { and personnel (perfor- } \\
\text { mance bias) } \\
\text { All outcomes }\end{array}$ & High risk & Study participants and personnel were not blinded \\
\hline $\begin{array}{l}\text { Blinding of outcome as- } \\
\text { sessment (detection bias) } \\
\text { All outcomes }\end{array}$ & High risk & No blinding of outcome assessment \\
\hline $\begin{array}{l}\text { Incomplete outcome data } \\
\text { (attrition bias) } \\
\text { All outcomes }\end{array}$ & Low risk & Missing data balanced across groups \\
\hline $\begin{array}{l}\text { Selective reporting (re- } \\
\text { porting bias) }\end{array}$ & Low risk & Primary and secondary outcomes identified and fully reported \\
\hline Other bias & Low risk & Appears to be free of other bias that would affect outcomes \\
\hline
\end{tabular}

Zieger 2013

\section{Study characteristics}

\begin{tabular}{ll}
\hline Methods & RCT. 2 arms. \\
\hline Participants & Number of children: 60 control, 60 treatment \\
& Sex of children: $60 \mathrm{M}, 60 \mathrm{~F}$ \\
& Age range of children: $6-12$ years \\
& Mean age range of children: $8.4 \pm 2.4$ years (treatment), $8.7 \pm 2.1$ years (control) \\
& Needle procedure: venipuncture
\end{tabular}


Inclusion criteria: 6 - 12 years, indication for a blood withdrawal, presence during the study of at least 1 parent with sufficient knowledge of German language

Exclusion criteria: none given

Setting: general pediatric and coagulation outpatient clinics in Germany

Interventions

1. Picture book: Children received a picture book before the procedure that showed a realistic representation of the blood withdrawal procedure performed on an 8-year-old boy. The decision for the use of local anesthesia was left to the attending physician.

2. Standard procedure: Children did not receive an object intervention or a systematic distraction. Instead, children had a waiting period. The decision for use of local anesthesia was left to the attending physician.

\begin{tabular}{ll}
\hline Outcomes & Pain measures: \\
- Child self-report: FPS-R \\
Adverse events: none mentioned \\
\hline Notes & Study dates: study dates not reported \\
& Funding: CSL Behring \\
& Conflicts of interest: none declared \\
\hline
\end{tabular}

\section{Risk of bias}

\begin{tabular}{|c|c|c|}
\hline Bias & Authors' judgement & Support for judgement \\
\hline $\begin{array}{l}\text { Random sequence genera- } \\
\text { tion (selection bias) }\end{array}$ & Unclear risk & $\begin{array}{l}\text { Block randomized - no further details. Insufficient information to permit judg- } \\
\text { ment of 'low' or 'high' risk. }\end{array}$ \\
\hline $\begin{array}{l}\text { Allocation concealment } \\
\text { (selection bias) }\end{array}$ & Unclear risk & Insufficient information to permit judgment of 'low' or 'high' risk. \\
\hline $\begin{array}{l}\text { Blinding of participants } \\
\text { and personnel (perfor- } \\
\text { mance bias) } \\
\text { All outcomes }\end{array}$ & High risk & Study participants and personnel were not blinded \\
\hline $\begin{array}{l}\text { Blinding of outcome as- } \\
\text { sessment (detection bias) } \\
\text { All outcomes }\end{array}$ & High risk & No blinding of outcome assessment \\
\hline $\begin{array}{l}\text { Incomplete outcome data } \\
\text { (attrition bias) } \\
\text { All outcomes }\end{array}$ & Low risk & No missing data \\
\hline $\begin{array}{l}\text { Selective reporting (re- } \\
\text { porting bias) }\end{array}$ & Low risk & Objectives clearly stated and reported fully \\
\hline Other bias & High risk & $\begin{array}{l}\text { Potential source of bias related to inconsistent use and duration of topical } \\
\text { anesthetic }\end{array}$ \\
\hline
\end{tabular}


APPT: adolescent pediatric pain tool; BMA: bone marrow aspiration; CAMPIS-R: child-adult medical procedure inventory scale-revised; CAPS: children's anxiety and pain scale; CAS: color analogue scale; CFCS: child facial coding system; CFS: children's fear scale; CHEOPS: Children's Hospital East Ontario pain scale; CNS: central nervous system; DPTP: diphtheria, pertussis, tetanus and poliomyelitis; EMLA: eutectic mixture of local anesthetics; FLACC: face, legs, activity, crying, consolability; FPS: faces pain scale; GDS: Groningen distress scale; GFS: glasses fear scale; IV: intravenous; LP: lumbar puncture; MOPS: modified objective pain score; MRI: magnetic resonance imaging; MTPPPS: modified toddler-preschool post-operative pain scale; mYAPS: modified Yale pre-operative anxiety scale; NRS: numerical rating scale; OSBD: observational scale of behavioral distress; PBCL: procedural behavioral checklist; PBRS: procedural behavioral rating scale; PPQR: perception of procedures questionnaire-revised; STAI-C: state trait anxiety inventory for children; VAS: visual analogue scale

Characteristics of excluded studies [ordered by study ID]

\begin{tabular}{|c|c|}
\hline Study & Reason for exclusion \\
\hline Agarwal 2008 & Older than included age range/adult sample \\
\hline Agarwal 2017 & Reported assignment not truly random \\
\hline Alavi 2005 & Cross-over design with data not available pre-cross-over \\
\hline Alderfer 2010 & Inappropriate outcome measures/outcomes not related to pain or anxiety \\
\hline Alhani 2010 & $\begin{array}{l}\text { Not a randomized controlled trial/reported assignment not truly random/quasi-randomized as- } \\
\text { signment }\end{array}$ \\
\hline Anghelescu 2013 & Intervention not primarily psychological \\
\hline Anson 2010 & Older than included age range/adult sample \\
\hline Arts 1994 & $\begin{array}{l}\text { Met inclusion criteria but missing data necessary for pooling such as means, standard deviations, } \\
\text { and/or cell sizes }\end{array}$ \\
\hline Ashkenzai 2006 & $\begin{array}{l}\text { Not a randomized controlled trial/reported assignment not truly random/quasi-randomized as- } \\
\text { signment }\end{array}$ \\
\hline Atkinson 2009 & $\begin{array}{l}\text { Not a randomized controlled trial/reported assignment not truly random/quasi-randomized as- } \\
\text { signment }\end{array}$ \\
\hline Bagnasco 2012 & $\begin{array}{l}\text { Not a randomized controlled trial/reported assignment not truly random/quasi-randomized as- } \\
\text { signment }\end{array}$ \\
\hline Baxter 2011 & $\begin{array}{l}\text { Inappropriate intervention/cannot isolate effects of psychological components from multicompo- } \\
\text { nent intervention }\end{array}$ \\
\hline Ben-Pazi 2017 & Reported assignment not truly random, quasi-randomized assignment \\
\hline Bengston 2002 & $\begin{array}{l}\text { Met inclusion criteria but missing data necessary for pooling such as means, standard deviations, } \\
\text { and/or cell sizes }\end{array}$ \\
\hline Benjamin 2016 & $\begin{array}{l}\text { Inappropriate intervention/cannot isolate effects of psychological components from multicompo- } \\
\text { nent intervention }\end{array}$ \\
\hline Berberich 2009 & Only 1 group received an adjunct pharmacological intervention \\
\hline Berge 2017 & Inclusion of children with known needle phobias \\
\hline Boivin 2008 & $\begin{array}{l}\text { Not a randomized controlled trial/reported assignment not truly random/quasi-randomized as- } \\
\text { signment }\end{array}$ \\
\hline
\end{tabular}




\begin{tabular}{|c|c|}
\hline Study & Reason for exclusion \\
\hline Bowen 1999 & Failed randomization \\
\hline Broome 1998 & No control/comparison group or inappropriate control group \\
\hline Bruck 1995 & Inappropriate outcome measures/outcomes not related to pain or anxiety \\
\hline Bufalini 2009 & Use of general anesthesia/conscious sedation prior to needle procedure \\
\hline Bufalini 2012 & Conference presentation abstract/not a published RCT \\
\hline Carlson 2000 & $\begin{array}{l}\text { Met inclusion criteria but missing data necessary for pooling such as means, standard deviations, } \\
\text { and/or cell sizes }\end{array}$ \\
\hline Chan 2013 & Inappropriate outcome measures or outcomes not related to pain or anxiety \\
\hline Chen 2000b & $\begin{array}{l}\text { Met inclusion criteria but missing data necessary for pooling such as means, standard deviations, } \\
\text { and/or cell sizes }\end{array}$ \\
\hline Chow 2017 & No needle procedure \\
\hline Christiano 1996 & $\begin{array}{l}\text { Not a randomized controlled trial/reported assignment not truly random/quasi-randomized as- } \\
\text { signment }\end{array}$ \\
\hline Cline 2006 & $\begin{array}{l}\text { Not a randomized controlled trial/reported assignment not truly random/quasi-randomized as- } \\
\text { signment }\end{array}$ \\
\hline Cohen 1997 & $\begin{array}{l}\text { Not a randomized controlled trial/reported assignment not truly random/quasi-randomized as- } \\
\text { signment }\end{array}$ \\
\hline Cohen 1999 & $\begin{array}{l}\text { Not a randomized controlled trial/reported assignment not truly random/quasi-randomized as- } \\
\text { signment }\end{array}$ \\
\hline Cohen 2002 & $\begin{array}{l}\text { Not a randomized controlled trial/reported assignment not truly random/quasi-randomized as- } \\
\text { signment }\end{array}$ \\
\hline Cohen 2010 & $\begin{array}{l}\text { Not a randomized controlled trial/reported assignment not truly random/quasi-randomized as- } \\
\text { signment }\end{array}$ \\
\hline Cramer-Berness 2005 & Younger than included age range/infant sample \\
\hline Crowley 2011 & $\begin{array}{l}\text { Not a randomized controlled trial/reported assignment not truly random/quasi-randomized as- } \\
\text { signment }\end{array}$ \\
\hline Cumino 2017 & No needle procedure \\
\hline Dahlquist 2002 & $\begin{array}{l}\text { Met inclusion criteria but missing data necessary for pooling such as means, standard deviations, } \\
\text { and/or cell sizes }\end{array}$ \\
\hline Dahlquist 2005 & Secondary data analysis/original study not included in review \\
\hline Davit 2011 & $\begin{array}{l}\text { Not a randomized controlled trial/reported assignment not truly random/quasi-randomized as- } \\
\text { signment }\end{array}$ \\
\hline Demir 2012 & Intervention not primarily psychological \\
\hline Drahota 2008 & Older than included age range/adult sample \\
\hline
\end{tabular}




\begin{tabular}{|c|c|}
\hline Study & Reason for exclusion \\
\hline Dufresne 2010 & $\begin{array}{l}\text { Not a randomized controlled trial/reported assignment not truly random/quasi-randomized as- } \\
\text { signment }\end{array}$ \\
\hline El-Sharkawi 2012 & Cross-over design with data not available pre-cross-over \\
\hline Fancourt 2016 & Conference presentation abstract \\
\hline Fassler 1985 & $\begin{array}{l}\text { Met inclusion criteria but missing data necessary for pooling such as means, standard deviations, } \\
\text { and/or cell sizes }\end{array}$ \\
\hline Felluga 2016 & Fewer than 5 participants per condition \\
\hline Firoozi 2014 & Conference presentation abstract or not a published RCT \\
\hline Forsner 2014 & Not a randomized controlled trial \\
\hline Franck 2014 & Could not isolate effects of psychological components from multicomponent intervention \\
\hline Franzoi 2016 & No needle procedure \\
\hline French 1994 & $\begin{array}{l}\text { Not a randomized controlled trial/reported assignment not truly random/quasi-randomized as- } \\
\text { signment }\end{array}$ \\
\hline Garret-Bernardin 2017 & Intervention not primarily psychological \\
\hline Gilbert 1982 & $\begin{array}{l}\text { Met inclusion criteria but missing data necessary for pooling such as means, standard deviations, } \\
\text { and/or cell sizes }\end{array}$ \\
\hline Goymour 2000 & $\begin{array}{l}\text { Met inclusion criteria but missing data necessary for pooling such as means, standard deviations, } \\
\text { and/or cell sizes }\end{array}$ \\
\hline Hartling 2013 & Missing data necessary for pooling, such as means, SDs, and cell sizes \\
\hline Hatava 2000 & Surgical procedure \\
\hline Hawkins 1998 & No control/comparison group or inappropriate control group \\
\hline Heckler-Medina 2006 & $\begin{array}{l}\text { Not a randomized controlled trial/reported assignment not truly random/quasi-randomized as- } \\
\text { signment }\end{array}$ \\
\hline Hedén 2009 & $\begin{array}{l}\text { Not a randomized controlled trial/reported assignment not truly random/quasi-randomized as- } \\
\text { signment }\end{array}$ \\
\hline Hillgrove-Stuart 2013 & Younger than included age range \\
\hline Hoffman 2011 & $\begin{array}{l}\text { Not a randomized controlled trial/reported assignment not truly random/quasi-randomized as- } \\
\text { signment }\end{array}$ \\
\hline Howe 2011 & $\begin{array}{l}\text { Not a randomized controlled trial/reported assignment not truly random/quasi-randomized as- } \\
\text { signment }\end{array}$ \\
\hline Hudson 2015 & Older than included age range or adult sample \\
\hline Inal 2010 & $\begin{array}{l}\text { Met inclusion criteria but missing data necessary for pooling such as means, standard deviations, } \\
\text { and/or cell sizes }\end{array}$ \\
\hline
\end{tabular}




\begin{tabular}{|c|c|}
\hline Study & Reason for exclusion \\
\hline Isong 2014 & No needle procedure \\
\hline Jacobson 2006 & Older than included age range/adult sample \\
\hline Jay 1987 & $\begin{array}{l}\text { Met inclusion criteria but missing data necessary for pooling such as means, standard deviations, } \\
\text { and/or cell sizes }\end{array}$ \\
\hline Jay 1990 & Inappropriate outcome measures/outcomes not related to pain or anxiety \\
\hline Jay 1991 & $\begin{array}{l}\text { Inappropriate intervention/cannot isolate effects of psychological components from multicompo- } \\
\text { nent intervention }\end{array}$ \\
\hline Jay 1995 & No control/comparison group or inappropriate control group \\
\hline Jibb 2017 & Mixed causes of pain and not available for needle procedure only \\
\hline Jimeno 2014 & $\begin{array}{l}\text { Not a randomized controlled trial, reported assignment not truly random, quasi-randomized as- } \\
\text { signment, randomization failed }\end{array}$ \\
\hline Kain 2006 & Use of general anesthesia/conscious sedation prior to needle procedure \\
\hline Kammerbauer 2011 & $\begin{array}{l}\text { Not a randomized controlled trial/reported assignment not truly random/quasi-randomized as- } \\
\text { signment }\end{array}$ \\
\hline Kazak 1996 & Means or standard deviations, or both, not available \\
\hline Kazak 1998 & $\begin{array}{l}\text { Met inclusion criteria but missing data necessary for pooling such as means, standard deviations, } \\
\text { and/or cell sizes }\end{array}$ \\
\hline Kearl 2015 & Not a randomized controlled trial \\
\hline Kettwich 2007 & No needle procedure \\
\hline Klingman 1985 & $\begin{array}{l}\text { Met inclusion criteria but missing data necessary for pooling such as means, standard deviations, } \\
\text { and/or cell sizes }\end{array}$ \\
\hline Klorman 1980 & Surgical procedure \\
\hline Kolk 2000 & No control/comparison group or inappropriate control group \\
\hline Krauss 1996 & Non-published dissertation study \\
\hline Kuttner 1988 & $\begin{array}{l}\text { Met inclusion criteria but missing data necessary for pooling such as means, standard deviations, } \\
\text { and/or cell sizes }\end{array}$ \\
\hline Kwekkeboom 2003 & Older than included age range/adult sample \\
\hline Lawes 2008 & $\begin{array}{l}\text { Not a randomized controlled trial/reported assignment not truly random/quasi-randomized as- } \\
\text { signment }\end{array}$ \\
\hline Lee 2013 & $\begin{array}{l}\text { Inappropriate intervention or could not isolate effects of psychological components from multi- } \\
\text { component intervention }\end{array}$ \\
\hline Lessi 2011 & $\begin{array}{l}\text { Not a randomized controlled trial/reported assignment not truly random/quasi-randomized as- } \\
\text { signment }\end{array}$ \\
\hline
\end{tabular}




\begin{tabular}{|c|c|}
\hline Study & Reason for exclusion \\
\hline Liossi 2007 & $\begin{array}{l}\text { Not a randomized controlled trial/reported assignment not truly random/quasi-randomized as- } \\
\text { signment }\end{array}$ \\
\hline Lustman 1983 & Surgical procedure \\
\hline MacLaren 2005 & $\begin{array}{l}\text { Not a randomized controlled trial/reported assignment not truly random/quasi-randomized as- } \\
\text { signment }\end{array}$ \\
\hline MacLaren 2007 & $\begin{array}{l}\text { Not a randomized controlled trial/reported assignment not truly random/quasi-randomized as- } \\
\text { signment }\end{array}$ \\
\hline Malone 1996 & $\begin{array}{l}\text { Met inclusion criteria but missing data necessary for pooling such as means, standard deviations, } \\
\text { and/or cell sizes }\end{array}$ \\
\hline Manimala 2000 & $\begin{array}{l}\text { Not a randomized controlled trial/reported assignment not truly random/quasi-randomized as- } \\
\text { signment }\end{array}$ \\
\hline Manne 1990 & $\begin{array}{l}\text { Not a randomized controlled trial/reported assignment not truly random/quasi-randomized as- } \\
\text { signment }\end{array}$ \\
\hline Manne 1994 & $\begin{array}{l}\text { Not a randomized controlled trial/reported assignment not truly random/quasi-randomized as- } \\
\text { signment }\end{array}$ \\
\hline Marec-Bérard 2009 & Intervention not primarily psychological \\
\hline Marechal 2017 & No needle procedure \\
\hline McCarthy 1998 & Failed randomization \\
\hline McCarthy 2014 & Reported assignment not truly random \\
\hline Mclnally 2005 & $\begin{array}{l}\text { Not a randomized controlled trial/reported assignment not truly random/quasi-randomized as- } \\
\text { signment }\end{array}$ \\
\hline McWhorter 2014 & Older than included age range or adult sample \\
\hline Megel 1998 & $\begin{array}{l}\text { Met inclusion criteria but missing data necessary for pooling such as means, standard deviations, } \\
\text { and/or cell sizes }\end{array}$ \\
\hline Melamed 1974 & Surgical procedure \\
\hline Moadad 2016 & $\begin{array}{l}\text { Inappropriate intervention/cannot isolate effects of psychological components from multicompo- } \\
\text { nent intervention }\end{array}$ \\
\hline Mohan 2015 & Mixed procedures and data not available for needle procedure only \\
\hline Mutlu 2015b & "Cough trick" group excluded as intervention not primarily psychological \\
\hline Myrvik 2009 & Non-published dissertation study \\
\hline Nilsson 2009 & $\begin{array}{l}\text { Not a randomized controlled trial/reported assignment not truly random/quasi-randomized as- } \\
\text { signment }\end{array}$ \\
\hline O'Laughlin 1995 & $\begin{array}{l}\text { Met inclusion criteria but missing data necessary for pooling such as means, standard deviations, } \\
\text { and/or cell sizes }\end{array}$ \\
\hline
\end{tabular}




\begin{tabular}{|c|c|}
\hline Study & Reason for exclusion \\
\hline Oberoi 2016 & Inappropriate outcome measures or outcomes not related to pain or anxiety \\
\hline Olsen 1991 & $\begin{array}{l}\text { Not a randomized controlled trial/reported assignment not truly random/quasi-randomized as- } \\
\text { signment }\end{array}$ \\
\hline Ozdemir 2012 & Younger than included age range/infant sample \\
\hline Park 2008 & Intervention not primarily psychological \\
\hline Pederson 1996 & Fewer than 5 participants per condition \\
\hline Peretz 1999 & $\begin{array}{l}\text { Met inclusion criteria but missing data necessary for pooling such as means, standard deviations, } \\
\text { and/or cell sizes }\end{array}$ \\
\hline Posner 1998 & Non-published dissertation study \\
\hline Powers 1993 & $\begin{array}{l}\text { Not a randomized controlled trial/reported assignment not truly random/quasi-randomized as- } \\
\text { signment }\end{array}$ \\
\hline Quan 2016 & No needle procedure \\
\hline Rajan 2017 & Use of sedation \\
\hline Ramponi 2009 & $\begin{array}{l}\text { Not a randomized controlled trial/reported assignment not truly random/quasi-randomized as- } \\
\text { signment }\end{array}$ \\
\hline Reeb 1997 & $\begin{array}{l}\text { Met inclusion criteria but missing data necessary for pooling such as means, standard deviations, } \\
\text { and/or cell sizes }\end{array}$ \\
\hline Rogovik 2007 & $\begin{array}{l}\text { Not a randomized controlled trial/reported assignment not truly random/quasi-randomized as- } \\
\text { signment }\end{array}$ \\
\hline Russell 2012 & Failed randomization \\
\hline Salih 2010 & Older than included age range/adult sample \\
\hline Santos 2000 & $\begin{array}{l}\text { Met inclusion criteria but missing data necessary for pooling such as means, standard deviations, } \\
\text { and/or cell sizes }\end{array}$ \\
\hline Schechter 2010b & $\begin{array}{l}\text { Not a randomized controlled trial/reported assignment not truly random/quasi-randomized as- } \\
\text { signment }\end{array}$ \\
\hline Schneider 2011 & Older than included age range/adult sample \\
\hline Schreiber 2016 & $\begin{array}{l}\text { Inappropriate intervention/cannot isolate effects of psychological components from multicompo- } \\
\text { nent intervention }\end{array}$ \\
\hline Schur 1986 & $\begin{array}{l}\text { Not a randomized controlled trial/reported assignment not truly random/quasi-randomized as- } \\
\text { signment }\end{array}$ \\
\hline Seiden 2014 & No needle procedure \\
\hline Shabanloei 2010 & Older than included age range/adult sample \\
\hline Shahabi 2007 & Cross-over design with data not available pre-cross-over \\
\hline
\end{tabular}




\begin{tabular}{|c|c|}
\hline Study & Reason for exclusion \\
\hline Shanmugam 2016 & Data not available for eligible age range \\
\hline Shemesh 2017 & Intervention not primarily psychological \\
\hline Shimizu 2005 & Older than included age range/adult sample \\
\hline Sikorova 2011 & $\begin{array}{l}\text { Not a randomized controlled trial/reported assignment not truly random/quasi-randomized as- } \\
\text { signment }\end{array}$ \\
\hline Singh 2016 & $\begin{array}{l}\text { Not a randomized controlled trial, reported assignment not truly random, quasi-randomized as- } \\
\text { signment, randomization failed }\end{array}$ \\
\hline Skinner 2015 & Conference presentation abstract \\
\hline Slack 2009 & Older than included age range/adult sample \\
\hline Slifer 2009 & No control/comparison group or inappropriate control group \\
\hline Slifer 2011 & $\begin{array}{l}\text { Not a randomized controlled trial/reported assignment not truly random/quasi-randomized as- } \\
\text { signment }\end{array}$ \\
\hline Smith 1989 & No control/comparison group or inappropriate control group \\
\hline Smith 1996 & No control/comparison group or inappropriate control group \\
\hline Sparks 2001 & $\begin{array}{l}\text { Not a randomized controlled trial/reported assignment not truly random/quasi-randomized as- } \\
\text { signment }\end{array}$ \\
\hline Stefano 2005 & $\begin{array}{l}\text { Not a randomized controlled trial/reported assignment not truly random/quasi-randomized as- } \\
\text { signment }\end{array}$ \\
\hline Stevenson 2005 & $\begin{array}{l}\text { Inappropriate intervention/cannot isolate effects of psychological components from multicompo- } \\
\text { nent intervention }\end{array}$ \\
\hline Suresh 2015 & No needle procedure \\
\hline Sury 2010 & $\begin{array}{l}\text { Not a randomized controlled trial/reported assignment not truly random/quasi-randomized as- } \\
\text { signment }\end{array}$ \\
\hline Thurgate 2005 & $\begin{array}{l}\text { Not a randomized controlled trial/reported assignment not truly random/quasi-randomized as- } \\
\text { signment }\end{array}$ \\
\hline Tokunaga 2017 & Older than included age range or adult sample \\
\hline Tyson 2014 & Mixed procedures and data not available for needle procedure only \\
\hline Tüfekci 2009 & $\begin{array}{l}\text { Not a randomized controlled trial/reported assignment not truly random/quasi-randomized as- } \\
\text { signment }\end{array}$ \\
\hline Ujaoney 2013 & Intervention not primarily psychological \\
\hline Vernon 1974 & $\begin{array}{l}\text { Met inclusion criteria but missing data necessary for pooling such as means, standard deviations, } \\
\text { and/or cell sizes }\end{array}$ \\
\hline Vika 2009 & Older than included age range/adult sample \\
\hline
\end{tabular}




\begin{tabular}{|c|c|}
\hline Study & Reason for exclusion \\
\hline Vohra 2011 & $\begin{array}{l}\text { Not a randomized controlled trial/reported assignment not truly random/quasi-randomized as- } \\
\text { signment }\end{array}$ \\
\hline Wall 1989 & No control/comparison group or inappropriate control group \\
\hline Wallace 2010 & Intervention not primarily psychological \\
\hline Weber 2010 & No needle procedure \\
\hline Weinstein 2003 & No needle procedure \\
\hline Winborn 1989 & Surgical procedure \\
\hline Wood 2002 & $\begin{array}{l}\text { Not a randomized controlled trial/reported assignment not truly random/quasi-randomized as- } \\
\text { signment }\end{array}$ \\
\hline Yoo 2011 & $\begin{array}{l}\text { Not a randomized controlled trial/reported assignment not truly random/quasi-randomized as- } \\
\text { signment }\end{array}$ \\
\hline Young 1988 & $\begin{array}{l}\text { Met inclusion criteria but missing data necessary for pooling such as means, standard deviations, } \\
\text { and/or cell sizes }\end{array}$ \\
\hline Zabin 1982 & Non-published dissertation study \\
\hline Zahr 1998 & $\begin{array}{l}\text { Not a randomized controlled trial/reported assignment not truly random/quasi-randomized as- } \\
\text { signment }\end{array}$ \\
\hline Zeltzer 1982 & $\begin{array}{l}\text { Met inclusion criteria but missing data necessary for pooling such as means, standard deviations, } \\
\text { and/or cell sizes }\end{array}$ \\
\hline
\end{tabular}

\section{DATA AND ANALYSES}

\section{Comparison 1. Distraction}

\begin{tabular}{|c|c|c|c|c|}
\hline Outcome or subgroup title & No. of studies & $\begin{array}{l}\text { No. of partici- } \\
\text { pants }\end{array}$ & Statistical method & Effect size \\
\hline 1.1 Self-reported pain & 30 & 2802 & $\begin{array}{l}\text { Std. Mean Difference (IV, Random, } \\
95 \% \mathrm{CI} \text { ) }\end{array}$ & $-0.56[-0.78,-0.33]$ \\
\hline 1.2 Self-reported distress & 4 & 426 & $\begin{array}{l}\text { Std. Mean Difference (IV, Random, } \\
95 \% \mathrm{CI} \text { ) }\end{array}$ & $-0.82[-1.45,-0.18]$ \\
\hline 1.3 Observer-reported pain & 11 & 1512 & $\begin{array}{l}\text { Std. Mean Difference (IV, Random, } \\
95 \% \mathrm{CI} \text { ) }\end{array}$ & $-0.62[-1.00,-0.23]$ \\
\hline $\begin{array}{l}1.4 \text { Observer-reported dis- } \\
\text { tress }\end{array}$ & 5 & 1067 & $\begin{array}{l}\text { Std. Mean Difference (IV, Random, } \\
95 \% \mathrm{CI} \text { ) }\end{array}$ & $-0.72[-1.41,-0.03]$ \\
\hline $\begin{array}{l}1.5 \text { Behavioral measures- } \\
\text { Pain }\end{array}$ & 4 & 309 & $\begin{array}{l}\text { Std. Mean Difference (IV, Random, } \\
95 \% \mathrm{CI} \text { ) }\end{array}$ & $-0.33[-0.69,0.03]$ \\
\hline
\end{tabular}




\begin{tabular}{lllll}
\hline Outcome or subgroup title & No. of studies & $\begin{array}{l}\text { No. of partici- } \\
\text { pants }\end{array}$ & Statistical method & Effect size \\
\hline $\begin{array}{l}\text { 1.6 Behavioral measures- Dis- } \\
\text { tress }\end{array}$ & 7 & 500 & $\begin{array}{l}\text { Std. Mean Difference (IV, Random, } \\
95 \% \text { Cl) }\end{array}$ & $-0.44[-0.84,-0.04]$ \\
\hline $\begin{array}{l}1.7 \text { Physiological measure - } \\
\text { heart rate }\end{array}$ & 3 & 252 & $\begin{array}{l}\text { Std. Mean Difference (IV, Random, } \\
95 \% \text { Cl) }\end{array}$ & $-0.64[-0.89,-0.38]$ \\
\hline $\begin{array}{l}1.8 \text { Physiological measure - } \\
\text { oxygen saturation }\end{array}$ & 2 & 112 & $\begin{array}{l}\text { Std. Mean Difference (IV, Random, } \\
95 \% \text { Cl) }\end{array}$ & 0.60 [0.22, 0.98] \\
\hline
\end{tabular}

\section{Analysis 1.1. Comparison 1: Distraction, Outcome 1: Self-reported pain}

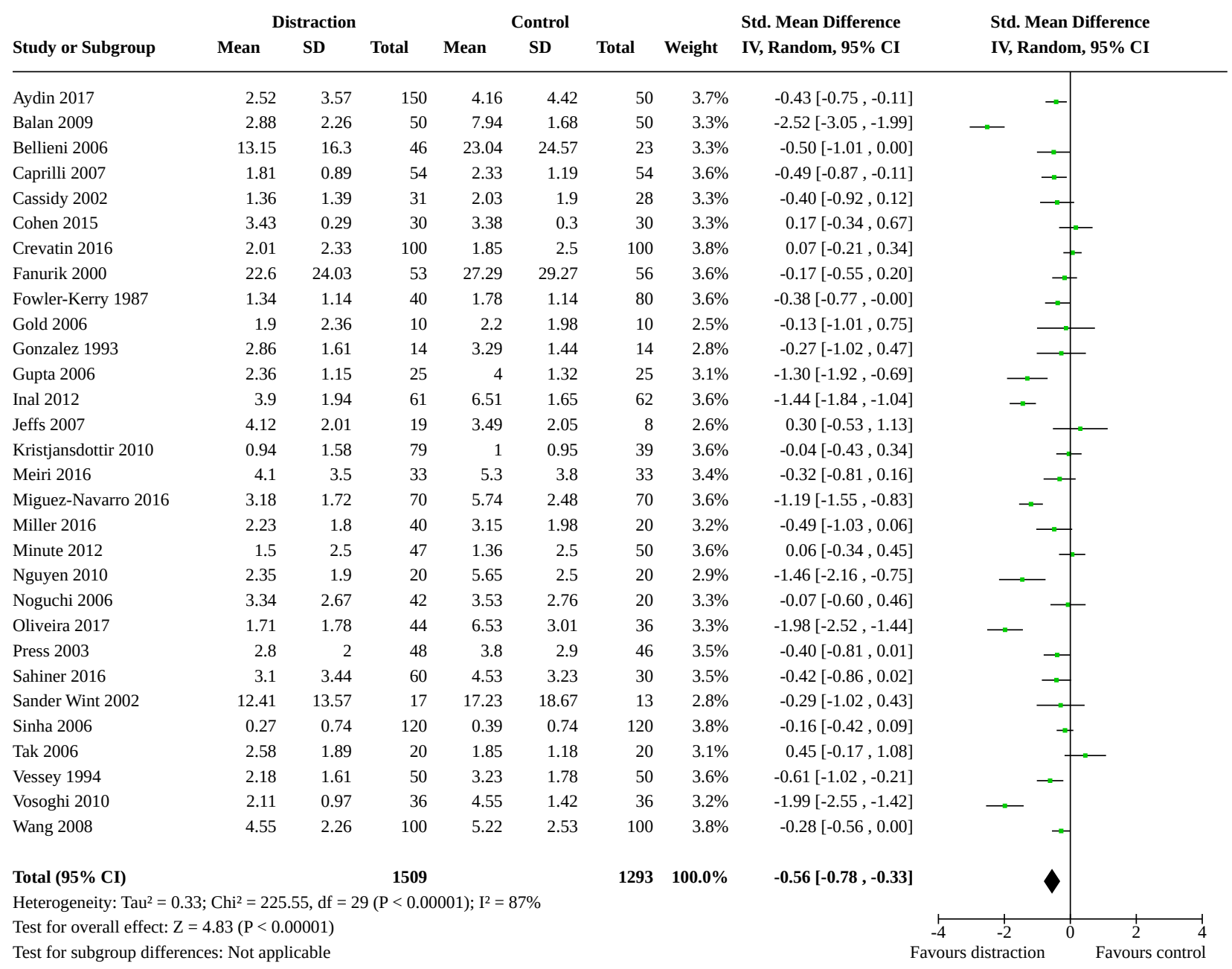


Analysis 1.2. Comparison 1: Distraction, Outcome 2: Self-reported distress

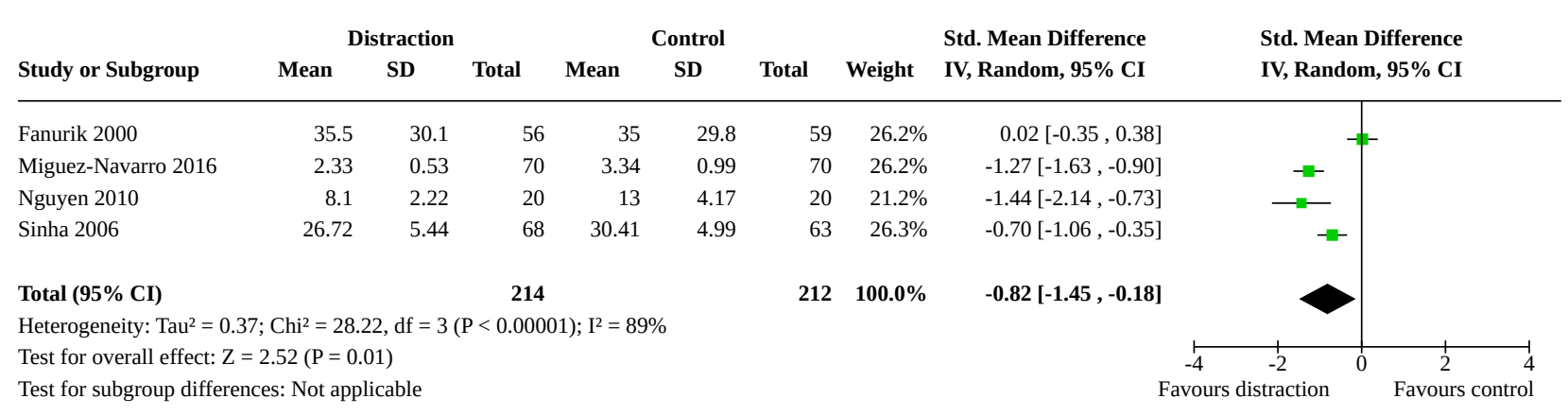

Analysis 1.3. Comparison 1: Distraction, Outcome 3: Observer-reported pain

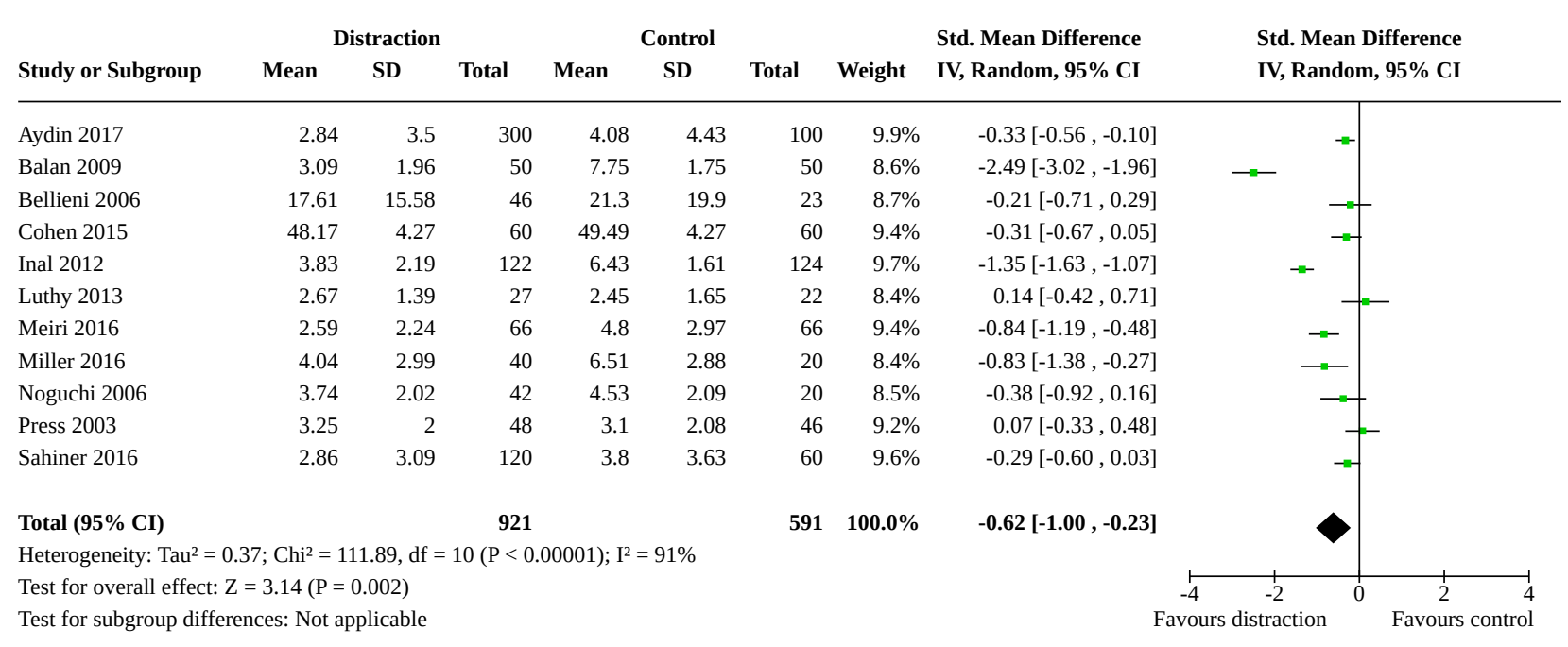

Analysis 1.4. Comparison 1: Distraction, Outcome 4: Observer-reported distress

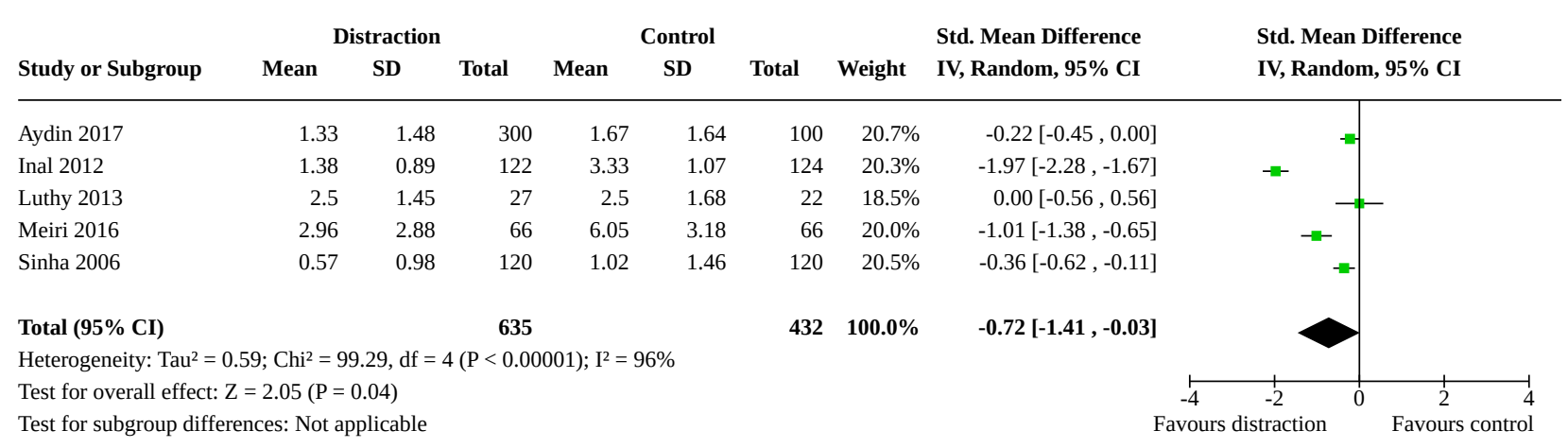


Analysis 1.5. Comparison 1: Distraction, Outcome 5: Behavioral measures- Pain

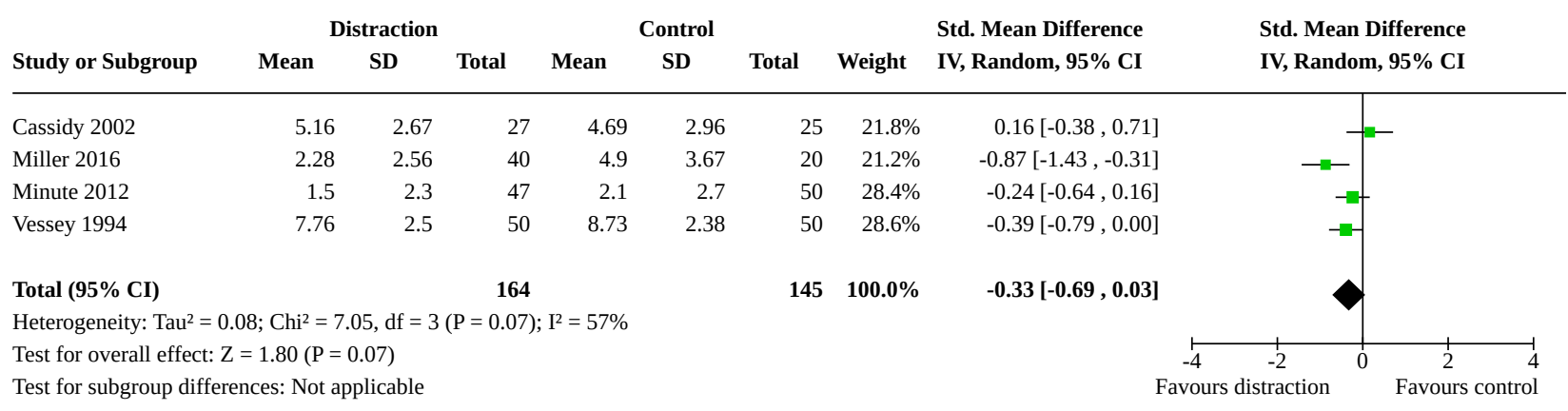

Analysis 1.6. Comparison 1: Distraction, Outcome 6: Behavioral measures- Distress

\begin{tabular}{|c|c|c|c|c|c|c|c|c|c|}
\hline \multirow[b]{2}{*}{ Study or Subgroup } & \multicolumn{3}{|c|}{ Distraction } & \multicolumn{3}{|c|}{ Control } & \multicolumn{2}{|r|}{ Std. Mean Difference } & Std. Mean Difference \\
\hline & Mean & SD & Total & Mean & SD & Total & Weight & IV, Random, 95\% CI & IV, Random, 95\% CI \\
\hline
\end{tabular}

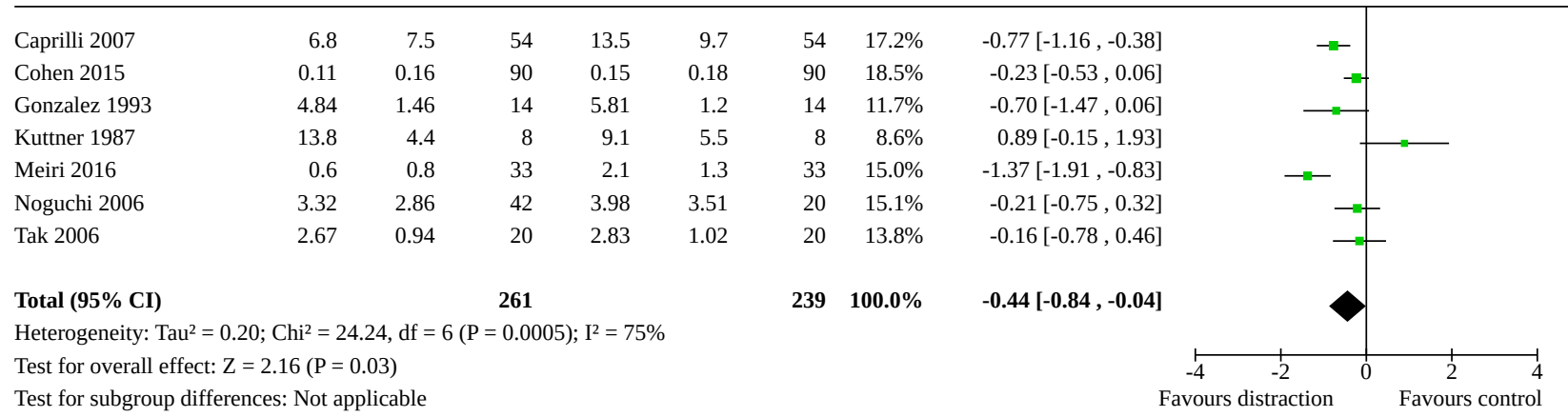

\section{Analysis 1.7. Comparison 1: Distraction, Outcome 7: Physiological measure - heart rate}

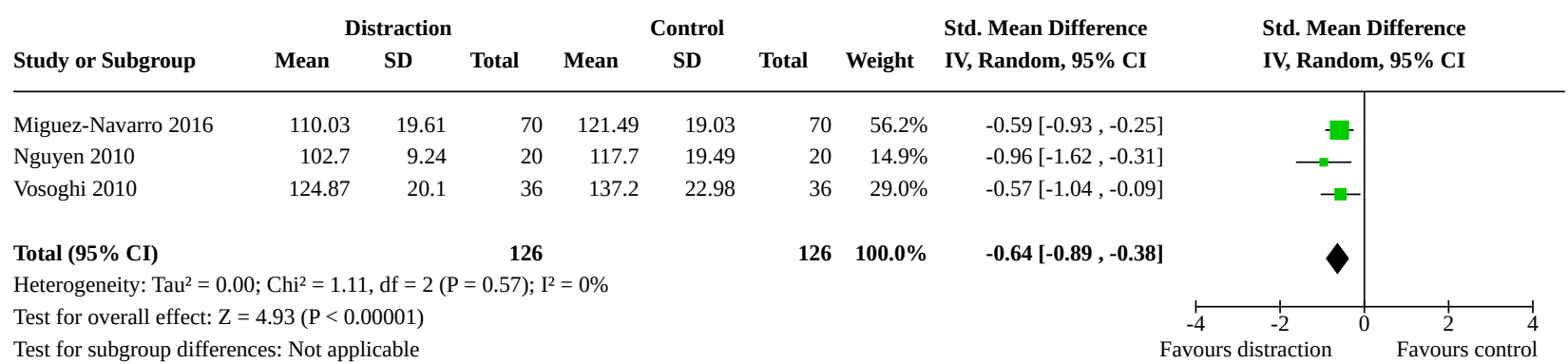

Analysis 1.8. Comparison 1: Distraction, Outcome 8: Physiological measure - oxygen saturation

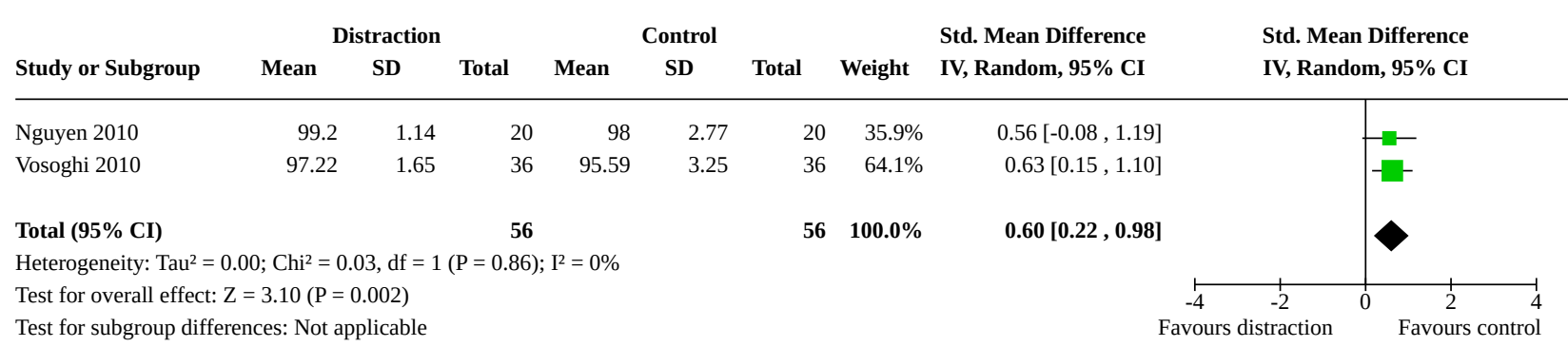


Comparison 2. CBT-combined

\begin{tabular}{|c|c|c|c|c|}
\hline Outcome or subgroup title & No. of studies & $\begin{array}{l}\text { No. of partici- } \\
\text { pants }\end{array}$ & Statistical method & Effect size \\
\hline 2.1 Self-reported pain & 14 & 1359 & $\begin{array}{l}\text { Std. Mean Difference (IV, Random, } \\
95 \% \mathrm{Cl} \text { ) }\end{array}$ & $-0.27[-0.58,0.03]$ \\
\hline 2.2 Self-reported distress & 6 & 234 & $\begin{array}{l}\text { Std. Mean Difference (IV, Random, } \\
95 \% \mathrm{CI})\end{array}$ & $-0.26[-0.56,0.04]$ \\
\hline 2.3 Observer-reported pain & 4 & 385 & $\begin{array}{l}\text { Std. Mean Difference (IV, Random, } \\
95 \% \mathrm{Cl} \text { ) }\end{array}$ & $-0.52[-0.73,-0.30]$ \\
\hline $\begin{array}{l}2.4 \text { Observer-reported dis- } \\
\text { tress }\end{array}$ & 6 & 765 & $\begin{array}{l}\text { Std. Mean Difference (IV, Random, } \\
95 \% \mathrm{CI} \text { ) }\end{array}$ & $0.08[-0.34,0.50]$ \\
\hline $\begin{array}{l}2.5 \text { Behavioral measures- } \\
\text { Pain }\end{array}$ & 2 & 95 & $\begin{array}{l}\text { Std. Mean Difference (IV, Random, } \\
95 \% \mathrm{CI} \text { ) }\end{array}$ & $-0.65[-2.36,1.06]$ \\
\hline $\begin{array}{l}\text { 2.6 Behavioral measures- } \\
\text { Distress }\end{array}$ & 11 & 1105 & $\begin{array}{l}\text { Std. Mean Difference (IV, Random, } \\
95 \% \mathrm{CI} \text { ) }\end{array}$ & $-0.40[-0.67,-0.14]$ \\
\hline $\begin{array}{l}\text { 2.7 Physiological measure - } \\
\text { Cortisol }\end{array}$ & 3 & 310 & $\begin{array}{l}\text { Std. Mean Difference (IV, Random, } \\
95 \% \mathrm{CI})\end{array}$ & $-1.16[-3.37,1.06]$ \\
\hline
\end{tabular}

\section{Analysis 2.1. Comparison 2: CBT-combined, Outcome 1: Self-reported pain}

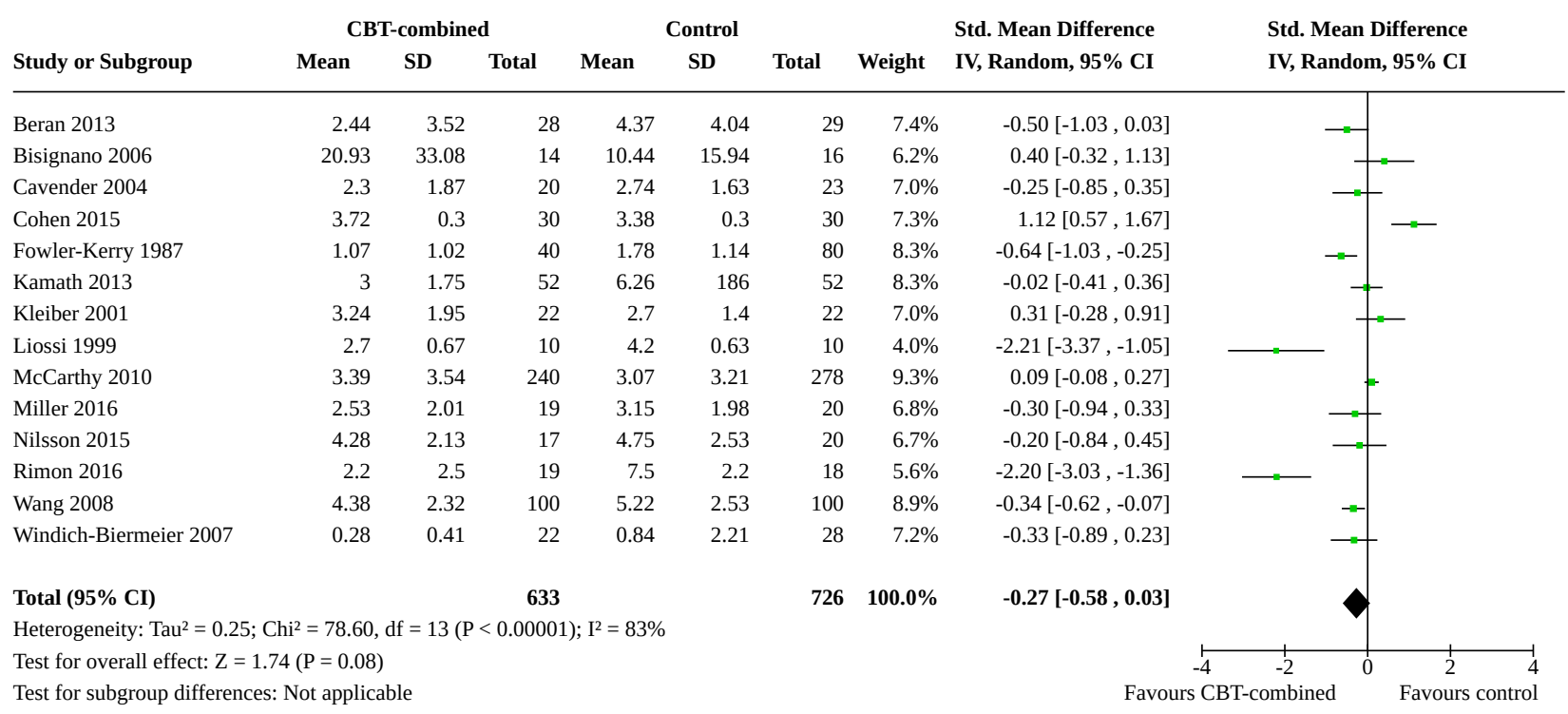


Analysis 2.2. Comparison 2: CBT-combined, Outcome 2: Self-reported distress

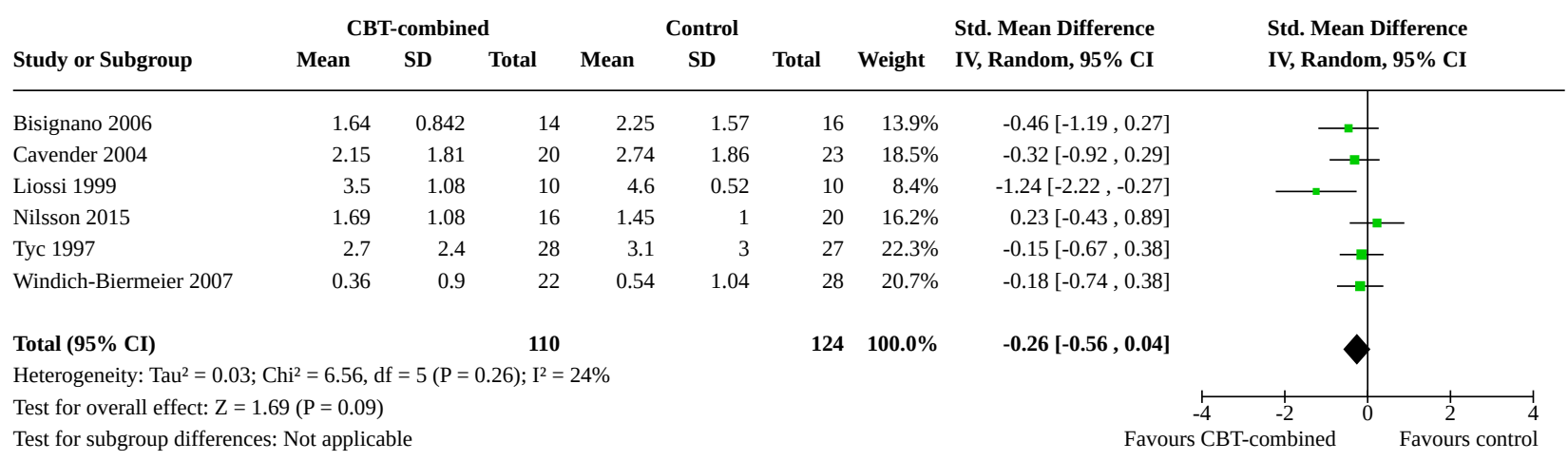

Analysis 2.3. Comparison 2: CBT-combined, Outcome 3: Observer-reported pain

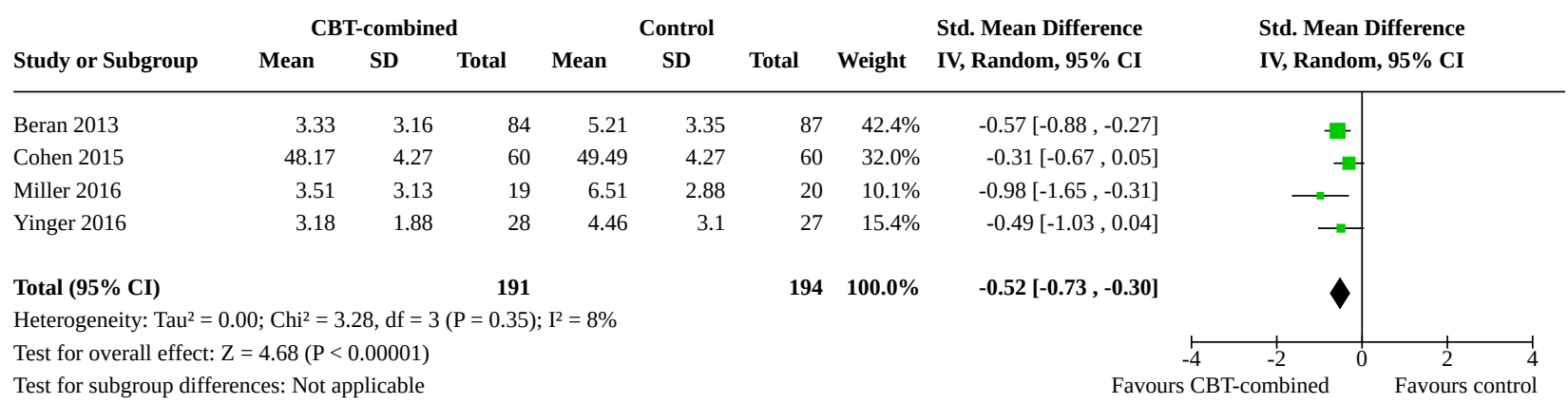

Analysis 2.4. Comparison 2: CBT-combined, Outcome 4: Observer-reported distress

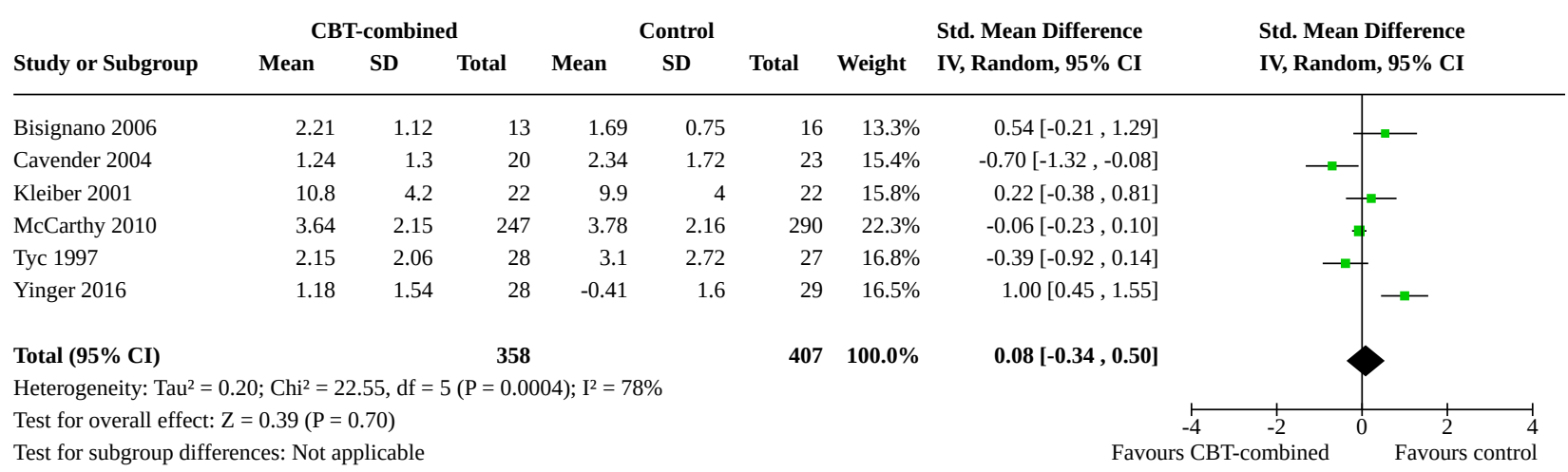


Analysis 2.5. Comparison 2: CBT-combined, Outcome 5: Behavioral measures- Pain

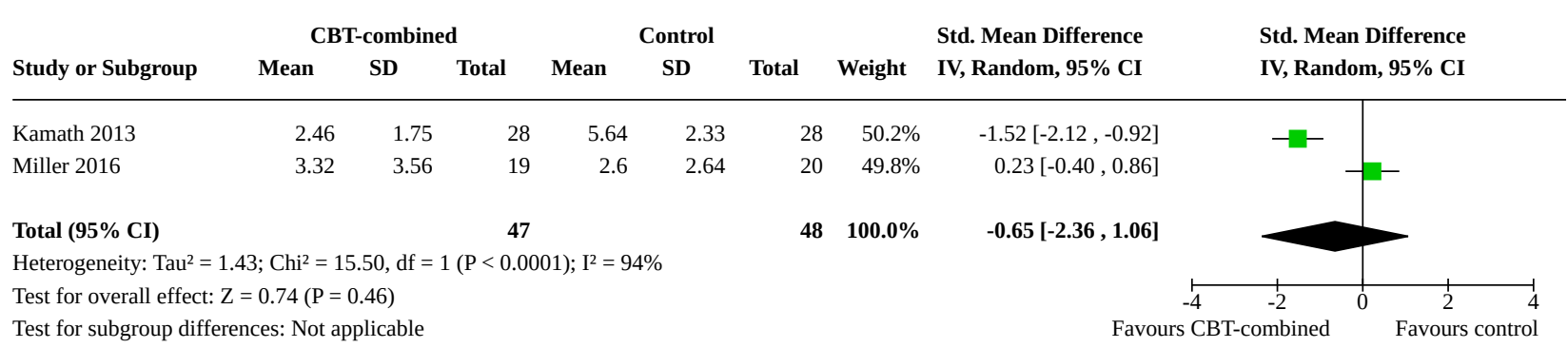

Analysis 2.6. Comparison 2: CBT-combined, Outcome 6: Behavioral measures- Distress

\begin{tabular}{lcccccccc} 
& \multicolumn{3}{c}{ CBT-combined } & \multicolumn{3}{c}{ Control } & & \multicolumn{2}{c}{ Std. Mean Difference } & Std. Mean Difference \\
Study or Subgroup & Mean & SD $\quad$ Total & Mean & SD & Total & Weight & IV, Random, 95\% CI & IV, Random, 95\% CI
\end{tabular}

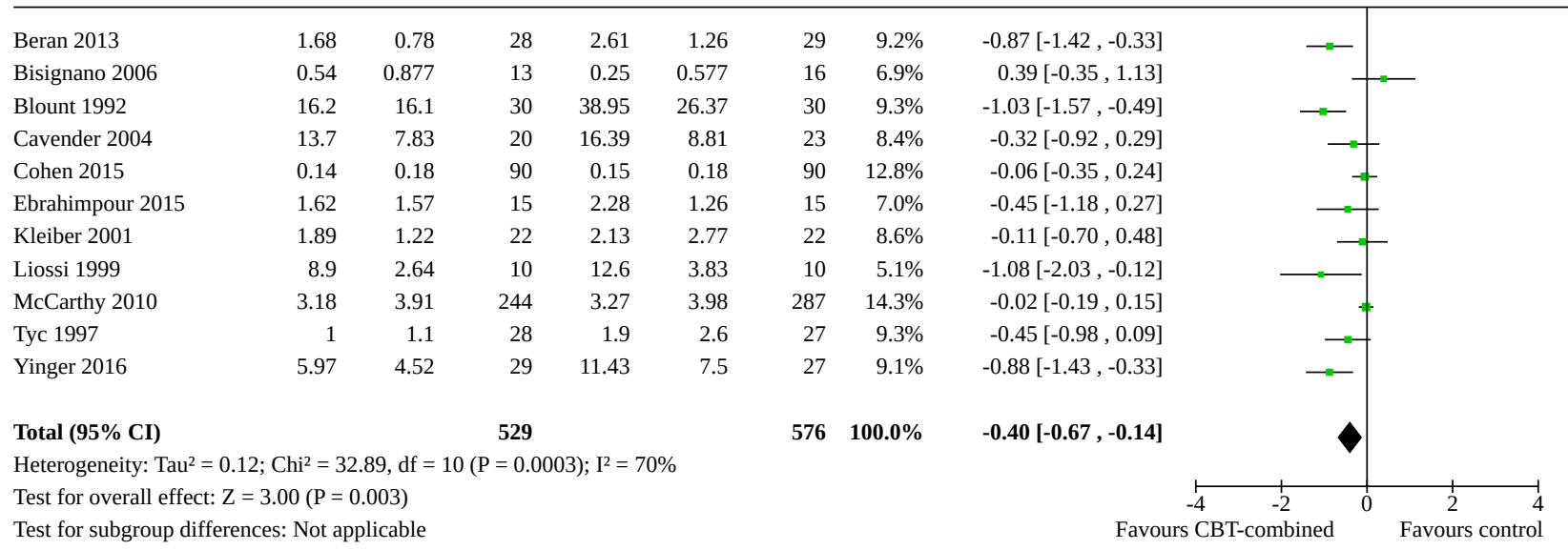

\section{Analysis 2.7. Comparison 2: CBT-combined, Outcome 7: Physiological measure - Cortisol}

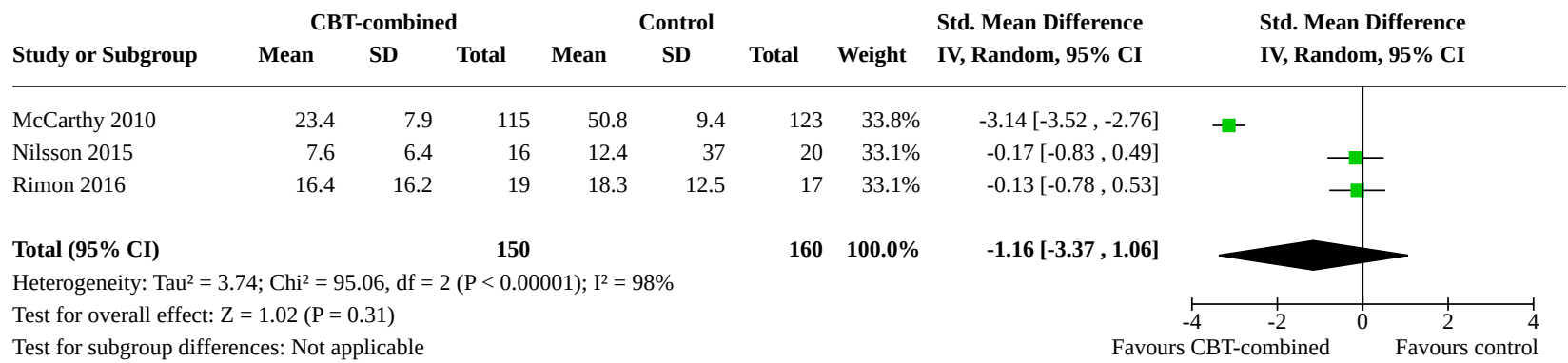

\section{Comparison 3. Hypnosis}

\begin{tabular}{lllll}
\hline Outcome or subgroup title & No. of studies & $\begin{array}{l}\text { No. of partici- } \\
\text { pants }\end{array}$ & Statistical method & Effect size \\
\hline 3.1 Self-reported pain & 5 & 176 & $\begin{array}{l}\text { Std. Mean Difference (IV, Random, } \\
95 \% \text { CI) }\end{array}$ & $-1.40[-2.32,-0.48]$ \\
\hline
\end{tabular}




\begin{tabular}{lllll}
\hline Outcome or subgroup title & No. of studies & $\begin{array}{l}\text { No. of partici- } \\
\text { pants }\end{array}$ & Statistical method & Effect size \\
\hline 3.2 Self-reported distress & 5 & 176 & $\begin{array}{l}\text { Std. Mean Difference (IV, Random, } \\
95 \% \text { Cl) }\end{array}$ & $-2.53[-3.93,-1.12]$ \\
\hline $\begin{array}{l}\text { 3.3 Behavioral measures- } \\
\text { Pain }\end{array}$ & 2 & 69 & $\begin{array}{l}\text { Std. Mean Difference (IV, Random, } \\
95 \% \text { Cl) }\end{array}$ & $-0.38[-1.57,0.81]$ \\
\hline $\begin{array}{l}\text { 3.4 Behavioral measures- } \\
\text { Distress }\end{array}$ & 6 & 193 & $\begin{array}{l}\text { Std. Mean Difference (IV, Random, } \\
95 \% \text { Cl) }\end{array}$ & $-1.15[-1.76,-0.53]$ \\
\hline
\end{tabular}

\section{Analysis 3.1. Comparison 3: Hypnosis, Outcome 1: Self-reported pain}

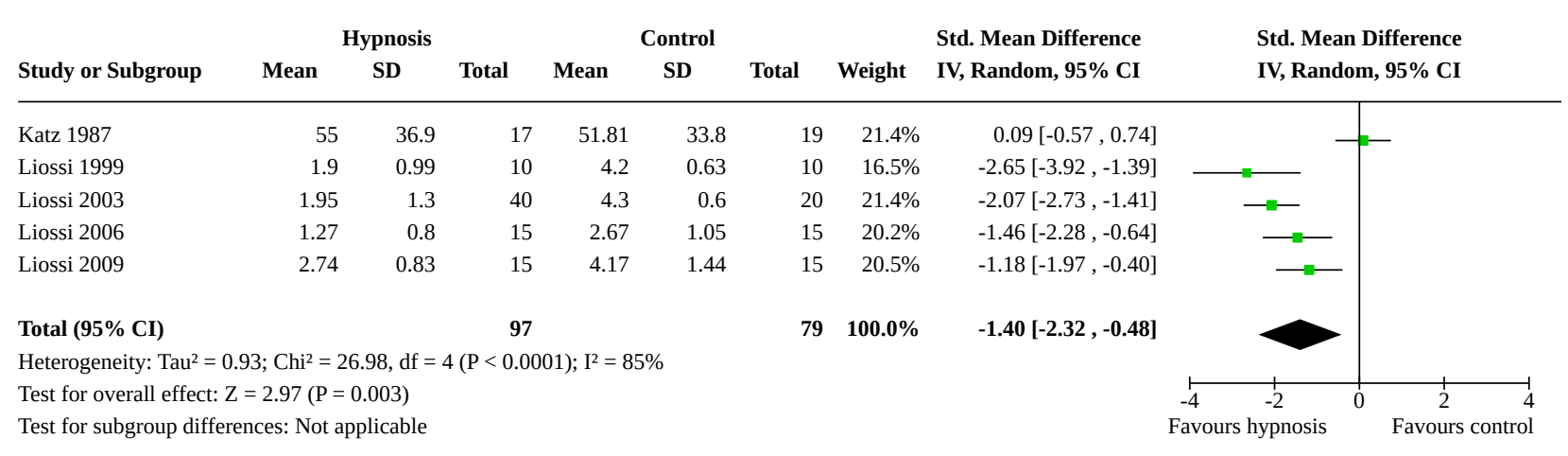

\section{Analysis 3.2. Comparison 3: Hypnosis, Outcome 2: Self-reported distress}

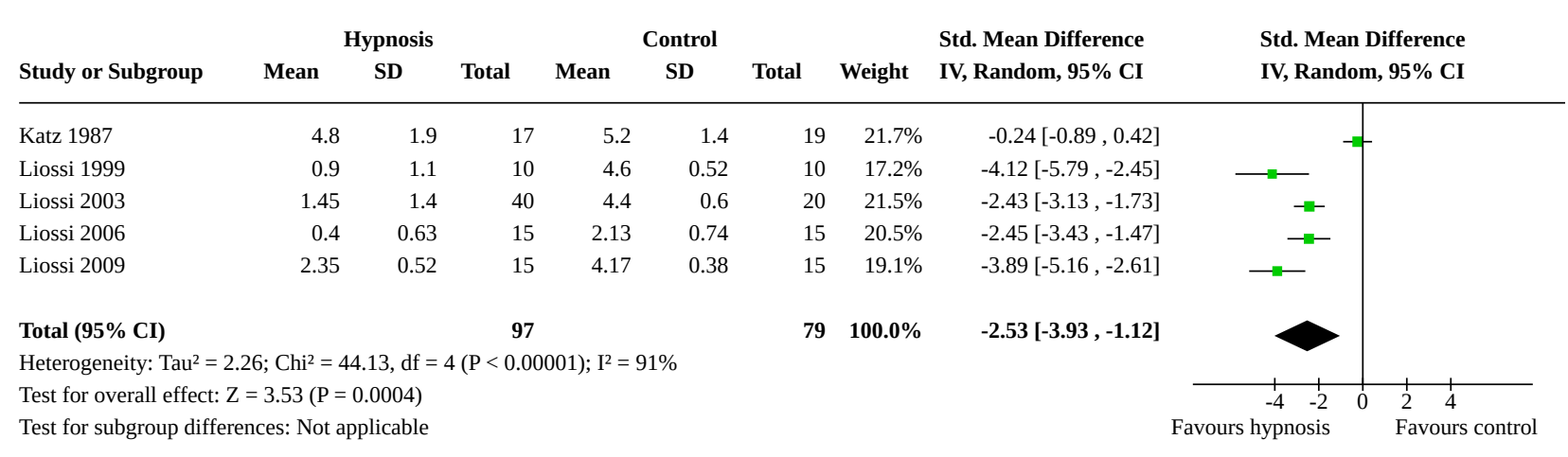

\section{Analysis 3.3. Comparison 3: Hypnosis, Outcome 3: Behavioral measures- Pain}

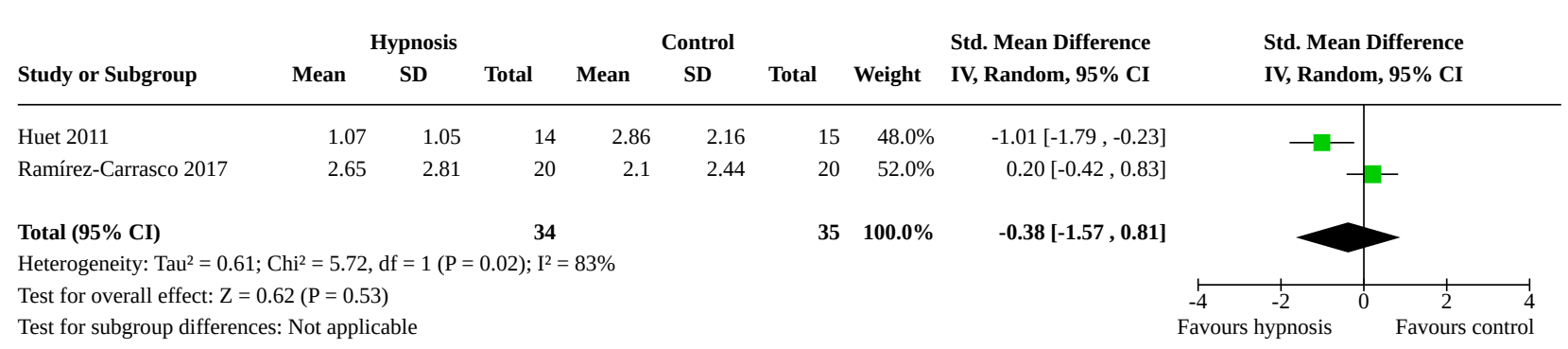


Analysis 3.4. Comparison 3: Hypnosis, Outcome 4: Behavioral measures- Distress

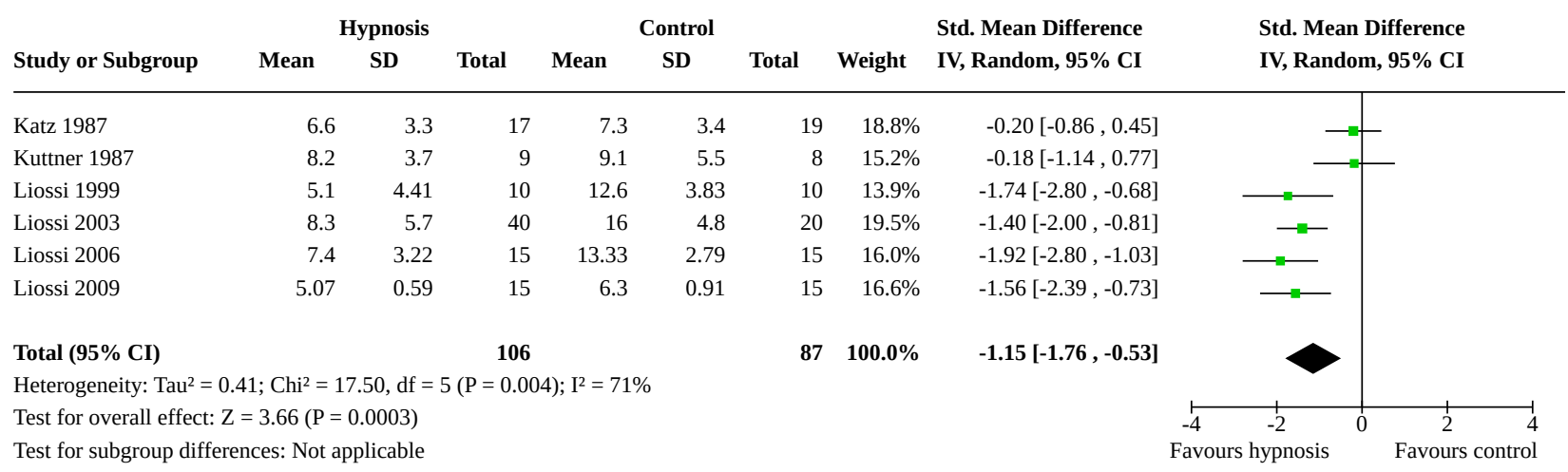

Comparison 4. Preparation/Information

\begin{tabular}{lllll}
\hline Outcome or subgroup title & No. of studies & $\begin{array}{l}\text { No. of partici- } \\
\text { pants }\end{array}$ & Statistical method & Effect size \\
\hline 4.1 Self-reported pain & 4 & 313 & $\begin{array}{l}\text { Std. Mean Difference (IV, Random, } \\
95 \% \text { CI) }\end{array}$ & $-0.18[-0.60,0.23]$ \\
\hline 4.2 Observer-reported pain & 3 & 259 & $\begin{array}{l}\text { Std. Mean Difference (IV, Random, } \\
95 \% \text { CI) }\end{array}$ & $-0.40[-0.98,0.18]$ \\
\hline
\end{tabular}

Analysis 4.1. Comparison 4: Preparation/Information, Outcome 1: Self-reported pain

\begin{tabular}{|c|c|c|c|c|c|c|c|c|c|c|}
\hline \multirow[b]{2}{*}{ Study or Subgroup } & \multicolumn{3}{|c|}{ Preparation/Information } & \multicolumn{3}{|c|}{ Control } & \multirow[b]{2}{*}{ Weight } & \multirow{2}{*}{$\begin{array}{l}\text { Std. Mean Difference } \\
\text { IV, Random, } 95 \% \text { CI }\end{array}$} & \multirow{2}{*}{\multicolumn{2}{|c|}{$\begin{array}{l}\text { Std. Mean Difference } \\
\text { IV, Random, } 95 \% \text { CI }\end{array}$}} \\
\hline & Mean & SD & Total & Mean & SD & Total & & & & \\
\hline Harrison 1991 & 2 & 1.73 & 50 & 3.06 & 1.22 & 50 & $27.6 \%$ & $-0.70[-1.11,-0.30]$ & - & \\
\hline Miller 2016 & 3.11 & 1.86 & 19 & 3.15 & 1.98 & 20 & $20.2 \%$ & $-0.02[-0.65,0.61]$ & - & \\
\hline Tak 2006 & 2.82 & 1.76 & 26 & 2.3 & 1.66 & 28 & $23.0 \%$ & $0.30[-0.24,0.84]$ & - & \\
\hline Zieger 2013 & 2.1 & 2.8 & 60 & 2.6 & 2.7 & 60 & $29.2 \%$ & $-0.18[-0.54,0.18]$ & & \\
\hline Total $(95 \%$ CI) & & & 155 & & & 158 & $100.0 \%$ & $-0.18[-0.60,0.23]$ & & \\
\hline \multicolumn{11}{|c|}{ Heterogeneity: $\mathrm{Tau}^{2}=0.12 ; \mathrm{Chi}^{2}=9.49, \mathrm{df}=3(\mathrm{P}=0.02) ; \mathrm{I}^{2}=68 \%$} \\
\hline \multirow{2}{*}{\multicolumn{5}{|c|}{$\begin{array}{l}\text { Test for overall effect: } \mathrm{Z}=0.86(\mathrm{P}=0.39) \\
\text { Test for subgroup differences: Not applicable }\end{array}$}} & & & & -4 & -2 & 4 \\
\hline & & & & & & & & Favours pre & tion/info & \\
\hline
\end{tabular}


Analysis 4.2. Comparison 4: Preparation/Information, Outcome 2: Observer-reported pain

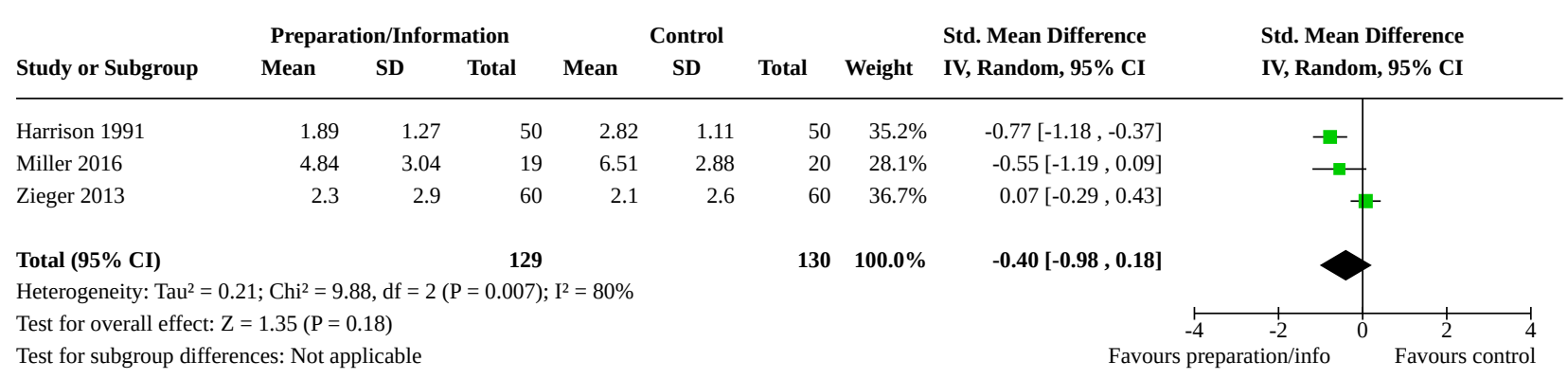

Comparison 5. Breathing

\begin{tabular}{lllll}
\hline Outcome or subgroup title & No. of studies & $\begin{array}{l}\text { No. of partici- } \\
\text { pants }\end{array}$ & Statistical method & Effect size \\
\hline 5.1 Self-reported pain & 4 & 298 & $\begin{array}{l}\text { Std. Mean Difference (IV, Random, } \\
95 \% \mathrm{CI})\end{array}$ & -1.04 [-1.86, -0.22] \\
\hline
\end{tabular}

Analysis 5.1. Comparison 5: Breathing, Outcome 1: Self-reported pain

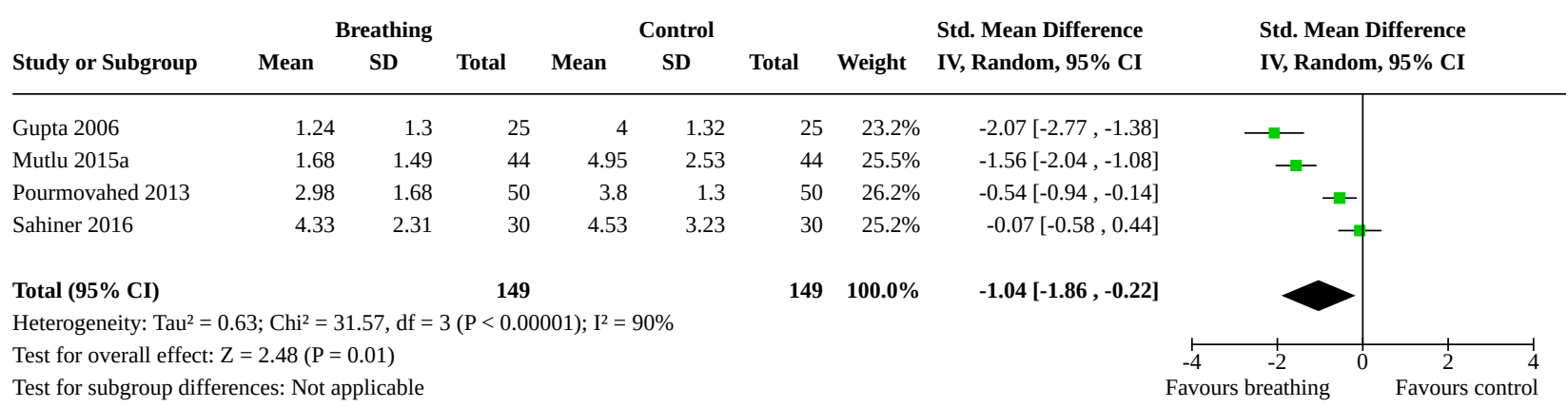

\section{Comparison 6. Suggestion}

\begin{tabular}{lllll}
\hline Outcome or subgroup title & No. of studies & $\begin{array}{l}\text { No. of partici- } \\
\text { pants }\end{array}$ & Statistical method & Effect size \\
\hline 6.1 Self-reported pain & 3 & 218 & $\begin{array}{l}\text { Std. Mean Difference (IV, Random, } \\
95 \% \mathrm{Cl})\end{array}$ & $-0.13[-0.40,0.15]$ \\
\hline
\end{tabular}




\section{Analysis 6.1. Comparison 6: Suggestion, Outcome 1: Self-reported pain}

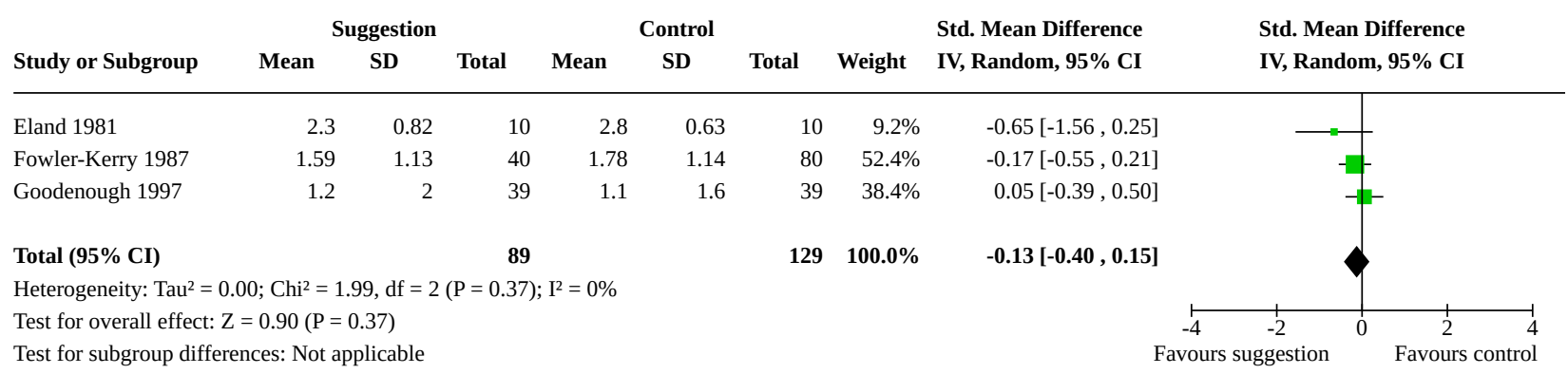

\section{ADDITIONAL TABLES}

Table 1. Definitions of medical procedures

\begin{tabular}{ll}
\hline Procedure & Definition \\
\hline $\begin{array}{l}\text { Accessing a portacath (also } \\
\text { known as a port) }\end{array}$ & $\begin{array}{l}\text { Insertion of a needle into an implanted access device (portacath) which facilitates the drawing of } \\
\text { blood and intravenous (or intra-arterial) injections by not having to locate and insert a cannula into } \\
\text { a new vessel. Some ports are connected for intrathecal, intraperitoneal or intracavitary injections. }\end{array}$
\end{tabular}

Arterial blood gas $(\mathrm{ABG}) \quad$ A test which analyses arterial blood for oxygen, carbon dioxide and bicarbonate content in addition to blood $\mathrm{pH}$. Used to test the effectiveness of respiration.

Arterial line (also known as in- Insertion of a catheter into an artery.

tra-arterial catheter)

Arterial puncture A hole, wound, or perforation of an artery made by puncturing.

Bone marrow aspiration (BMA) The bone marrow is the tissue that manufactures the blood cells and is in the hollow part of most bones. This test is done by suctioning some of the bone marrow for examination.

Bone marrow biopsy (BMB) The removal and examination of tissue, cells, or fluids from the bone marrow of a living body; usually performed at the same time as a BMA.

Central line (also known as central venous catheter)

Insertion of a catheter into the large vein above the heart, usually the subclavian vein, through which access to the blood stream can be made. This allows drugs and blood products to be given and blood samples withdrawn.

Finger prick/pin Obtaining blood by puncturing the tip of the finger.

Immunization (also known as immunization)

Protection against a particular disease or treatment of an organism by protecting against certain pathogen attacks; the introduction of microorganisms that have previously been treated to make them harmless.

\begin{tabular}{ll}
\hline Injection & The act of forcing a liquid into tissue, the vascular tree, or an organ. \\
\hline Intramuscular injection & Injection administered by entering a muscle. \\
\hline IV/catheter insertion & $\begin{array}{l}\text { A narrow short, flexible, synthetic (usually plastic) tube known as a catheter, that is inserted ap- } \\
\text { proximately one inch into a vein to provide temporary intravenous access for the administration of } \\
\text { fluid, medication, or nutrients. }\end{array}$
\end{tabular}

Lumbar punctures (LP) (also known as spinal tap)
The withdrawal of cerebrospinal fluid or the injection of anesthesia by puncturing the subarachnoid space located in the lumbar region of the spinal cord. 
Table 1. Definitions of medical procedures (Continued)

\begin{tabular}{ll} 
Paracentesis & $\begin{array}{l}\text { A surgical puncture of a bodily cavity (e.g. abdomen) with a trocar, aspirator, or other instrument } \\
\text { usually to draw off an abnormal effusion for diagnostic or therapeutic purposes. }\end{array}$ \\
\hline Subcutaneous injection & Injection administered under the skin. \\
\hline $\begin{array}{l}\text { Suture (also known as lacera- } \\
\text { tion repair) }\end{array}$ & A stitch made with a strand or fiber used to sew parts of the living body. \\
\hline $\begin{array}{l}\text { Thoracocentesis (also called } \\
\text { thoracentesis) }\end{array}$ & Aspiration of fluid from the chest. \\
\hline $\begin{array}{l}\text { Venepuncture (also known as } \\
\text { venipuncture) }\end{array}$ & $\begin{array}{l}\text { The surgical puncture of a vein typically for withdrawing blood or administering intravenous med- } \\
\text { ication. }\end{array}$
\end{tabular}

Table 2. Means and standard deviations for outcomes from single trials

\begin{tabular}{|c|c|c|c|c|c|c|}
\hline Interven- & Outcome & Study & Treatment & & Cor & \\
\hline & & & $\mathbf{N}$ & Mean (SD) & $\mathbf{N}$ & Mean (SD \\
\hline \multirow[t]{3}{*}{ Distraction } & $\begin{array}{l}\text { Physiological measure - Respiratory } \\
\text { rate }\end{array}$ & Nguyen 2010 & 20 & $25.1(3.6)$ & 20 & $28.5(3.86)$ \\
\hline & Physiological measure - Systolic BP & Nguyen 2010 & 20 & $97.1(8.57)$ & 20 & $105.6(15.97)$ \\
\hline & Physiological measure - Diastolic BP & Nguyen 2010 & 20 & $65.2(6.83)$ & 20 & $69.8(11.67)$ \\
\hline \multirow[t]{3}{*}{ Hypnosis } & Observer-reported distress & Katz 1987 & 17 & $3(0.9)$ & 19 & $3.3(0.6)$ \\
\hline & $\begin{array}{l}\text { Physiological measure - Skin conduc- } \\
\text { tance }\end{array}$ & $\begin{array}{l}\text { Ramírez-Car- } \\
\text { rasco } 2017\end{array}$ & 20 & $10.61(6.42)$ & 20 & $8.74(4.63)$ \\
\hline & Physiological measure - Heart rate & $\begin{array}{l}\text { Ramírez-Car- } \\
\text { rasco } 2017\end{array}$ & 20 & $93.57(12.33)$ & 20 & $99.3(18.56)$ \\
\hline \multirow{4}{*}{$\begin{array}{l}\text { Prepara- } \\
\text { tion/Infor- } \\
\text { mation }\end{array}$} & Observer-reported distress & $\begin{array}{l}\text { Harrison } \\
1991\end{array}$ & 50 & $2.43(1.62)$ & 50 & $3.17(1.3)$ \\
\hline & Behavioural measure - Pain & Miller 2016 & 19 & $3.21(3.46)$ & 20 & $4.90(3.67)$ \\
\hline & Behavioural measure - Distress & Tak 2006 & 26 & $2.64(1.1)$ & 28 & $2.37(1.12)$ \\
\hline & Physiological measure - Pulse rate & $\begin{array}{l}\text { Harrison } \\
1991\end{array}$ & 50 & $84.6(8.6)$ & 50 & $88.6(8.3)$ \\
\hline \multirow[t]{2}{*}{ Breathing } & Observer-reported pain & Sahiner 2016 & 60 & $2.56(3.24)$ & 60 & $3.80(2.93)$ \\
\hline & Observer-reported distress & Sahiner 2016 & 60 & $0.59(1.03)$ & 60 & $1.25(1.41)$ \\
\hline Suggestion & Self-reported distress & $\begin{array}{l}\text { Goodenough } \\
1997\end{array}$ & 39 & $0.7(1.1)$ & 39 & $1.1(1.3)$ \\
\hline
\end{tabular}


Table 2. Means and standard deviations for outcomes from single trials (Continued)

\begin{tabular}{|c|c|c|c|c|c|c|}
\hline & Observer-reported pain & $\begin{array}{l}\text { Goodenough } \\
1997\end{array}$ & 39 & $0.9(1.6)$ & 39 & $1.7(2.3)$ \\
\hline & Observer-reported distress & Eland 1981 & 10 & $1.8(0.71)$ & 10 & $1.8(0.79)$ \\
\hline \multirow[t]{8}{*}{$\begin{array}{l}\text { Memory } \\
\text { Alteration }\end{array}$} & $\begin{array}{l}\text { Self-reported pain } \\
\text { (during procedure change score) }\end{array}$ & Chen 1999 & 15 & $-0.06(3.9)$ & 9 & $-0.02(3.2)$ \\
\hline & $\begin{array}{l}\text { Observer-reported pain } \\
\text { (during procedure change score) }\end{array}$ & Chen 1999 & 20 & 04. (3.1) & 22 & $-0.1(1.8)$ \\
\hline & $\begin{array}{l}\text { Observer-reported distress } \\
\text { (during procedure change score) }\end{array}$ & Chen 1999 & 25 & $-0.2(2.6)$ & 25 & $-0.5(1.9)$ \\
\hline & $\begin{array}{l}\text { Behavioural measure - Distress } \\
\text { (during procedure change score) }\end{array}$ & Chen 1999 & 25 & $-0.62(3.7)$ & 25 & $-0.48(2.0)$ \\
\hline & $\begin{array}{l}\text { Physiological measure - Heart rate } \\
\text { (during procedure change score) }\end{array}$ & Chen 1999 & 24 & $0.1(26.9)$ & 20 & $-4.9(21.8)$ \\
\hline & $\begin{array}{l}\text { Physiological measure - Cortisol } \\
\text { (during procedure change score) }\end{array}$ & Chen 1999 & 22 & $0.01(0.18)$ & 22 & $0.01(0.2)$ \\
\hline & $\begin{array}{l}\text { Physiological measure - Systolic BP } \\
\text { (during procedure change score) }\end{array}$ & Chen 1999 & 23 & $-0.5(11.8)$ & 19 & $-5.4(7.9)$ \\
\hline & $\begin{array}{l}\text { Physiological measure - Diastolic BP } \\
\text { (during procedure change score) }\end{array}$ & Chen 1999 & 23 & $-4.1(10.9)$ & 19 & $2.9(10.2)$ \\
\hline
\end{tabular}

\section{AP PEN DICES}

\section{Appendix 1. MEDLINE search strategy}

1 Needles/

2 (needle or inject $\left.^{\star}\right) \cdot \mathrm{mp}$.

3 (immuni* or vaccin ${ }^{\star}$ or finger prick ${ }^{\star}$ or heel prick $\left.{ }^{\star}\right) \cdot m p$.

4 (lumbar puncture* or spinal tap*).mp.

5 (bone marrow adj (aspiration or biops $\left.\left.{ }^{\star}\right)\right) . m p$.

6 (intravenous or intra-venous or venepuncture* or venous cannulation*).mp.

7 (catheter adj5 insert*).mp.

8 (central line adj5 insert $\left.{ }^{\star}\right) \cdot \mathrm{mp}$.

9 (local adj (analges ${ }^{\star}$ or anaesthe* or anesthe $\left.\left.e^{\star}\right)\right) . \mathrm{mp}$.

10 (arterial adj (puncture or line $\left.\left.{ }^{\star}\right)\right) \cdot \mathrm{mp}$. 
11 (artery adj5 puncture).mp

12 (thoracocentesis or paracentesis).mp.

131 or 2 or 3 or 4 or 5 or 6 or 7 or 8 or 9 or 10 or 11 or 12

14 Pain/

15 ((needle ${ }^{\star}$ or immuni ${ }^{\star}$ or vaccin ${ }^{\star}$ or inject* or procedure $^{\star}$ or intervention $\left.{ }^{\star}\right)$ adj5 (pain ${ }^{\star}$ or distress or discomfort or fear $^{\star}$ or fright $^{\star}$ or anxious or anxiet $\left.\left.{ }^{\star}\right)\right) \cdot \mathrm{mp}$.

1614 or 15

17 (rehears $^{\star}$ or coping or verbal ${ }^{\star}$ encourage or positiv $^{\star}$ reinforce ${ }^{\star}$ or reward ${ }^{\star}$ or token ${ }^{\star}$ or self talk or selftalk ${ }^{\star}$ or stop signal ${ }^{\star}$ or structured attention).mp.

18 ((cognitive* or behaviour $^{\star}$ or behavior $\left.{ }^{\star}\right)$ adj5 (intervention* or therap* or distract $\left.\left.^{\star}\right)\right)$.mp.

19 (((audiovisual or audio visual or visual $\left.{ }^{\star}\right)$ and distract $\left.^{\star}\right)$ or movie or television $^{\star}$ or tv or game or toy $^{\star}$ or virtual reality or tactile* stimulat*).mp.

20 ((multisensory or multi-sensory) adj stimulation).mp.

21 Therapeutic Touch/

22 Relaxation/

23 Breathing Exercises/

24 Laughter Therapy/

25 exp Psychotherapy/

26 (desensiti $^{\star}$ or relax ${ }^{\star}$ or therapeutic touch ${ }^{\star}$ or breathing exercise* or hypnosis or hypnoti* or hypnotherapy or image* or psychotherap*).mp.

27 (autogenic training or auto suggestion $\left.{ }^{\star}\right) \cdot \mathrm{mp}$.

28 ((colour or color $^{\star}$ or music $^{\star}$ or play) and (therap* or distract $\left.\left.^{\star}\right)\right) \cdot \mathrm{mp}$.

2917 or 18 or 19 or 20 or 21 or 22 or 23 or 24 or 25 or 26 or 27 or 28

$30 \exp$ Child/

31 exp Infant/

32 exp Adolescent/

33 (child $^{\star}$ or infant $^{\star}$ or adolescent ${ }^{\star}$ or adolescence).mp.

3430 or 31 or 32 or 33

3513 and 16 and 29 and 34

36 randomized controlled trial.pt.

37 controlled clinical trial.pt.

38 randomized.ab.

39 placebo.ab.

40 drug therapy.fs.

41 randomly.ab.

42 trial.ab.

43 or $/ 36-42$

Psychological interventions for needle-related procedural pain and distress in children and adolescents (Review) 
44 exp animals/ not humans.sh.

4543 not 44

4635 and 45

$47\left(201303^{\star}\right.$ or $201304^{\star}$ or $201305^{\star}$ or $201306^{\star}$ or $201307^{\star}$ or $201308^{\star}$ or $201309^{\star}$ or $201310^{\star}$ or $201311^{\star}$ or $201312^{\star}$ or $2014^{\star}$ or $2015^{\star}$ or $\left.2016^{\star}\right)$.ed.

4846 and 47

\section{Appendix 2. PsycINFO search strategy}

1 (needle ${ }^{\star}$ or inject $\left.{ }^{\star}\right) . \mathrm{mp}$.

2 (immuni* or vaccin ${ }^{\star}$ or finger prick ${ }^{\star}$ or heel prick $\left.{ }^{\star}\right) \cdot m p$.

3 (lumbar puncture* or spinal tap*).mp.

4 (bone marrow adj (aspiration or biops $\left.{ }^{\star}\right)$ ).mp.

5 (intravenous or intra-venous or venepuncture* or venous cannulation $\left.^{\star}\right) . \mathrm{mp}$.

6 (catheter adj5 insert*).mp.

7 (central line adj5 insert $\left.{ }^{\star}\right) \cdot \mathrm{mp}$.

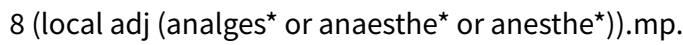

9 (arterial adj (puncture or line*)).mp.

10 (artery adj5 puncture).mp.

11 (thoracocentesis or paracentesis).mp.

12 Pain/

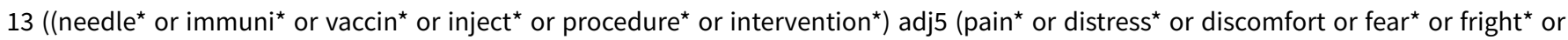
anxious or anxiet $\left.\left.{ }^{\star}\right)\right) \cdot \mathrm{mp}$.

\section{2 or 13}

15 (rehears $^{\star}$ or coping or verbal ${ }^{\star}$ encourage ${ }^{\star}$ or positiv ${ }^{\star}$ reinforce ${ }^{\star}$ or reward ${ }^{\star}$ or token* or self talk or selftalk ${ }^{\star}$ or stop signal ${ }^{\star}$ or structured attention).mp.

16 ((cognitive* or behaviour ${ }^{\star}$ or behavior $\left.{ }^{\star}\right)$ adj5 (intervention* or therap $^{\star}$ or distract $\left.\left.^{\star}\right)\right) . \mathrm{mp}$.

17 (((audiovisual or audio visual or visual $\left.{ }^{\star}\right)$ and distract $\left.^{\star}\right)$ or movie* or television ${ }^{\star}$ or tv or game* or toy* or virtual reality or tactile* stimulat*).mp.

18 ((multisensory or multi-sensory) adj stimulation).mp.

19 exp relaxation therapy/

20 Relaxation/

21 exp Psychotherapy/

22 (desensiti $^{\star}$ or relax ${ }^{\star}$ or therapeutic touch* ${ }^{\star}$ or breathing exercise* or hypnosis or hypnoti* or hypnotherapy or image ${ }^{\star}$ or psychotherap*).mp.

23 (autogenic training or auto suggestion $\left.{ }^{\star}\right) . \mathrm{mp}$.

24 (( colour $^{\star}$ or color ${ }^{\star}$ or music ${ }^{\star}$ or play) and (therap ${ }^{\star}$ or distract $\left.\left.{ }^{\star}\right)\right) . m p$.

25 (child $^{\star}$ or infant $^{\star}$ or adolescent ${ }^{\star}$ or adolescence).mp.

26 or $/ 1-11$

Psychological interventions for needle-related procedural pain and distress in children and adolescents (Review) 
27 or $/ 15-24$

2814 and 26 and 27 and 25

29 clinical trials/

30 (randomis* or randomiz ${ }^{\star}$.tw.

31 (random\$ adj3 (allocat\$ or assign\$)).tw.

32 ((clinic\$ or control\$) adj trial\$).tw.

33 ((singl\$ or doubl\$ or trebl\$ or tripl\$) adj3 (blind\$ or mask\$)).tw.

34 (crossover\$ or "cross over\$").tw.

35 random sampling/

36 Experiment Controls/

37 Placebo/

38 placebo\$.tw.

39 exp program evaluation/

40 treatment effectiveness evaluation/

41 ((effectiveness or evaluat\$) adj3 (stud\$ or research\$)).tw.

42 or/29-41

4328 and 42

44 limit 43 to $y r=" 2013$-Current"

\section{Appendix 3. CENTRAL search strategy}

\#1 MeSH descriptor: [Needles] this term only

$\# 2$ needle $^{\star}$ or inject*

\#3 immuni* or vaccin* or (finger next prick ${ }^{\star}$ ) or (heel next prick ${ }^{\star}$ )

\#4 (lumbar next puncture ${ }^{\star}$ ) or (spinal next tap*)

\#5 bone next marrow next (aspiration or biops ${ }^{\star}$ )

\#6 intravenous or intra-venous or venepuncture* or (venous next cannulation ${ }^{\star}$ )

\#7 catheter near insert*

\#8 (central next line) near insert*

\#9 local next (analges ${ }^{\star}$ or anaesthe* or anesthe ${ }^{\star}$ )

\#10 arterial next (puncture or line ${ }^{\star}$ )

\#11 artery near puncture

\#12 thoracocentesis or paracentesis

$\# 13$ (\#1 or \#2 or \#3 or \#4 or \#5 or \#6 or \#7 or \#8 or \#9 or \#10 or \#11 or \#12)

\#14 MeSH descriptor: [Pain] this term only

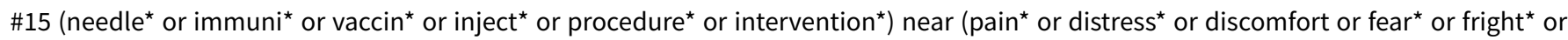
anxious or anxiet ${ }^{\star}$ ) 
\#16 (\#14 or \#15)

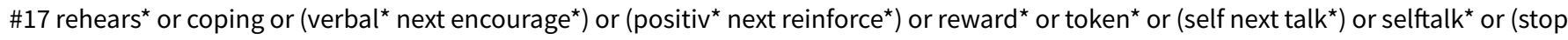
next signal* ${ }^{\star}$ or (structured next attention)

\#18 (cognitive or behaviour $^{\star}$ or behavior ${ }^{\star}$ ) near (intervention* or therap ${ }^{\star}$ or distract $^{\star}$ )

\#19 (((audiovisual or (audio next visual) or visual $\left.{ }^{\star}\right)$ and distract $\left.{ }^{\star}\right)$ or movie* or television ${ }^{\star}$ or tv or game or toy $^{\star}$ or (virtual next reality) or (tactile next stimulat $\left.{ }^{\star}\right)$ )

\#20 (multisensory or multi-sensory) next stimulation

\#21 MeSH descriptor: [Therapeutic Touch] this term only

\#22 MeSH descriptor: [Relaxation] this term only

\#23 MeSH descriptor: [Breathing Exercises] this term only

\#24 MeSH descriptor: [Laughter Therapy] this term only

\#25 MeSH descriptor: [Psychotherapy] explode all trees

\#26 desensiti* or relax* or (therapeutic next touch ${ }^{\star}$ ) or (breathing next exercise*) or hypnosis or hypnoti* or hypnotherapy or image* or psychotherap*

\#27 (autogenic next training) or (auto next suggestion*)

\#28 (colour ${ }^{\star}$ or color $^{\star}$ or music ${ }^{\star}$ or play) and (therap* or distract $^{\star}$ )

\#29 (\#17 or \#18 or \#19 or \#20 or \#21 or \#22 or \#23 or \#24 or \#25 or \#26 or \#27 or \#28)

\#30 MeSH descriptor: [Child] explode all trees

\#31 MeSH descriptor: [Infant] explode all trees

\#32 MeSH descriptor: [Adolescent] explode all trees

\#33 child* or infant* ${ }^{\star}$ r adolescent* or adolescence

\#34 (\#30 or \#31 or \#32 or \#33)

\#35 (\#13 and \#16 and \#29 and \#34) from 2013 to 2016

\section{Appendix 4. Embase search strategy}

1 Needles/

2 (needle* $^{\star}$ or inject $\left.{ }^{\star}\right) \cdot \mathrm{mp}$.

3 (immuni* or vaccin ${ }^{\star}$ or finger prick ${ }^{\star}$ or heel prick $\left.{ }^{\star}\right) \cdot m p$.

4 (lumbar puncture ${ }^{\star}$ or spinal tap $\left.{ }^{\star}\right) \cdot \mathrm{mp}$.

5 (bone marrow adj (aspiration or biops $\left.\left.s^{\star}\right)\right) \cdot \mathrm{mp}$.

6 (intravenous or intra-venous or venepuncture* or venous cannulation $\left.{ }^{\star}\right)$.mp.

7 (catheter adj5 insert*).mp.

8 (central line adj5 insert $\left.{ }^{\star}\right) \cdot \mathrm{mp}$.

9 (local adj (analges ${ }^{\star}$ or anaesthe $e^{\star}$ or anesthe $\left.\left.e^{\star}\right)\right) . m p$.

10 (arterial adj (puncture or line*)).mp.

11 (artery adj5 puncture).mp.

12 (thoracocentesis or paracentesis).mp. 
131 or 2 or 3 or 4 or 5 or 6 or 7 or 8 or 9 or 10 or 11 or 12

14 Pain/

15 ((needle* or immuni $^{\star}$ or vaccin ${ }^{\star}$ or inject ${ }^{\star}$ or procedure* or intervention ${ }^{\star}$ ) adj5 (pain* or distress ${ }^{\star}$ or discomfort or fear ${ }^{\star}$ or fright ${ }^{\star}$ or anxious or anxiet $\left.\left.{ }^{\star}\right)\right) \cdot \mathrm{mp}$.

1614 or 15

17 (rehears $^{\star}$ or coping or verbal ${ }^{\star}$ encourage* or positiv* reinforce $^{\star}$ or reward ${ }^{\star}$ or token* or self talk or selftalk ${ }^{\star}$ or stop signal ${ }^{\star}$ or structured attention).mp.

18 ((cognitive* or behaviour $^{\star}$ or behavior $\left.{ }^{\star}\right)$ adj5 (intervention* or therap ${ }^{\star}$ or distract $\left.\left.^{\star}\right)\right) . \mathrm{mp}$.

19 (((audiovisual or audio visual or visual $\left.{ }^{\star}\right)$ and distract $\left.^{\star}\right)$ or movie $^{\star}$ or television ${ }^{\star}$ or tv or game ${ }^{\star}$ or toy* or virtual reality or tactile stimulat*).mp.

20 ((multisensory or multi-sensory) adj stimulation).mp.

21 Hypnosis/

22 Breathing Exercises/

23 exp Psychotherapy/

24 (desensiti $^{\star}$ or relax ${ }^{\star}$ or therapeutic touch* or breathing exercise* or hypnosis or hypnoti* or hypnotherapy or image* or psychotherap*).mp.

25 (autogenic training or auto suggestion*).mp.

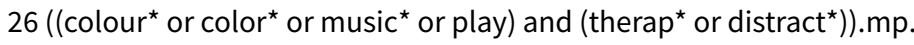

2717 or 18 or 19 or 20 or 21 or 22 or 23 or 24 or 25 or 26

$28 \exp$ Child/

29 exp Infant/

30 exp Adolescent/

31 (child $^{\star}$ or infant ${ }^{\star}$ or adolescent* ${ }^{\star}$ r adolescence).mp.

3228 or 29 or 30 or 31

3313 and 16 and 27 and 32

34 random $\$ . t w$.

35 factorial\$.tw.

36 crossover\$.tw.

37 cross over\$.tw.

38 cross-over\$.tw.

39 placebo $\$ . t w$.

40 (doubl\$ adj blind\$).tw.

41 (singl\$ adj blind\$).tw.

42 assign\$.tw.

43 allocat\$.tw.

44 volunteer\$.tw.

45 Crossover Procedure/

Psychological interventions for needle-related procedural pain and distress in children and adolescents (Review) 
46 double-blind procedure.tw.

47 Randomized Controlled Trial/

48 Single Blind Procedure/

49 or/34-48 (1763514)

50 (animal/ or nonhuman/) not human/

5149 not 50

5233 and 51

$53\left(201303^{\star}\right.$ or $201304^{\star}$ or $201305^{\star}$ or $201306^{\star}$ or $201307^{\star}$ or $201308^{\star}$ or $201309^{\star}$ or $201310^{\star}$ or $201311^{\star}$ or $201312^{\star}$ or $2014^{\star}$ or $2015^{\star}$ or $\left.2016^{\star}\right) \cdot d d$.

5452 and 53

\title{
Appendix 5. Web of Science (ISI Web of Knowledge)
}

\author{
\# 18 \#17 AND \#12
}

Databases=SCI-EXPANDED, SSCI, CPCI-S, CPCI-SSH,

\# 17 \#16 AND \#13

Databases=SCI-EXPANDED, SSCl, CPCI-S, CPCI-SSH, BKCl-

\section{\# 16 \#15 OR \#14}

Databases $=\mathrm{SCl}$-EXPANDED, SSCl, CPCI-S, CPCI-SSH,

\# 15 Topic=((audio visual ${ }^{\star}$ OR audiovisual* OR touch* OR humor OR humour OR laugh* OR psychotherapy OR desensit*) OR (hypnotherap* OR coach ${ }^{\star}$ OR inform ${ }^{\star}$ OR thought-stop* OR thought stop* OR thought ${ }^{\star}$ ) OR (coping* OR cope OR memor OR train $\left.^{\star}\right)$ )

Databases=SCI-EXPANDED, SSCI, CPCI-S, CPCI-SSH,

\# 14 Topic=((intervention* OR cognitive* OR cbt OR behavio* OR distract* OR music $\left.{ }^{\star}\right)$ OR (virtual reality OR rehears ${ }^{\star}$ OR coping ${ }^{\star}$ OR reinforce* OR hypnosis OR hypnot* ${ }^{\star}$ OR (reward* OR self-talk OR self talk OR relax ${ }^{\star}$ OR breath* OR suggest* OR image $\left.{ }^{\star}\right)$ )

Databases=SCI-EXPANDED, SSCI, CPCI-S, CPCI-SSH,

\# 13 Topic=((child* OR youth* OR teen* OR adolescen* OR infant*)) AND Topic=((pain* OR hurt* OR anxiety OR anxious OR distress OR discomfort ${ }^{\star}$ OR fear $\left.\left.{ }^{\star}\right)\right)$ AND Topic $=\left(\left(\right.\right.$ needle ${ }^{\star}$ OR inject* OR procedure* OR vaccin ${ }^{\star}$ OR lumbar puncture* OR bone marrow OR spinal tap OR intravenous OR venepuncture ${ }^{\star}$ OR venipuncture* OR catheter ${ }^{\star}$ OR puncture* OR thoracentes ${ }^{\star}$ OR paracentes ${ }^{\star}$ OR central line $\left.{ }^{\star}\right)$ )

Databases=SCI-EXPANDED, SSCI, CPCI-S, CPCI-SSH,

\# 12 \#11 OR \#8 OR \#7 OR \#6 OR \#5 OR \#2 OR \#1

Databases=SCI-EXPANDED, SSCI, CPCI-S, CPCI-SSH,

\# 11 \#10 AND \#9

Databases=SCI-EXPANDED, SSCI, CPCI-S, CPCI-SSH,

\# 10 TS=random* OR TI=random*

Databases $=\mathrm{SCl}$-EXPANDED, SSCl, CPCI-S, CPCI-SSH,

\# 9 TS=(allocate ${ }^{\star}$ OR assign^) OR TI=(allocate* OR assign $\left.{ }^{\star}\right)$

Databases=SCI-EXPANDED, SSCl, CPCI-S, CPCI-SSH,

\# 8 TS=crossover ${ }^{\star}$ OR TI=crossover ${ }^{*}$

Databases=SCI-EXPANDED, SSCI, CPCI-S, CPCI-SSH, 
\# 7 TS $=\left(\right.$ mask $^{\star}$ OR blind $\left.{ }^{\star}\right)$ OR TI=(mask* OR blind $\left.{ }^{\star}\right)$

Databases=SCI-EXPANDED, SSCI, CPCI-S, CPCI-SSH,

\# 6 TS=(singl* OR Doubl ${ }^{\star}$ OR Tripl* OR Trebl $\left.{ }^{\star}\right)$ OR TI=(singl* OR Doubl* OR Tripl* OR Trebl*)

Databases=SCI-EXPANDED, SSCI, CPCI-S, CPCI-SSH,

\# 5 \#4 AND \#3

Databases=SCI-EXPANDED, SSCI, CPCI-S, CPCI-SSH,

\# 4 TS=trial* OR TI=trial*

Databases $=\mathrm{SCl}$-EXPANDED, SSCl, $\mathrm{CPCI}-\mathrm{S}, \mathrm{CPCl}-\mathrm{SSH}$,

\# $3 \mathrm{TI}=\mathrm{clin}^{\star} \mathrm{OR} \mathrm{TS}=\mathrm{clin}^{*}$

Databases=SCI-EXPANDED, SSCI, CPCI-S, CPCI-SSH,

\# $2 \mathrm{TI}=$ randomi $^{\star}$ OR TS=randomi ${ }^{\star}$

Databases=SCI-EXPANDED, SSCl, CPCI-S, CPCI-SSH,

\# 1 TS=Randomized clinical trial ${ }^{\star}$ OR TI=Randomized clinical trial ${ }^{\star}$

Databases=SCI-EXPANDED, SSCI, CPCI-S, CPCI-SSH,

\section{Appendix 6. CINAHL search strategy}

\section{S17 S7 AND S16}

\section{S16 S8 OR S9 OR S10 OR S11 OR S12 OR S13 OR S14 OR S15}

S15 (allocat* random*)

S14 (MH "Quantitative Studies")

S13 (MH "Placebos")

S12 placebo*

S11 (random* allocat*)

S10 (MH "Random Assignment")

S9 (Randomi?ed control $^{\star}$ trial $^{\star}$ ) Limiters - Published Date from: 20090101-20130231

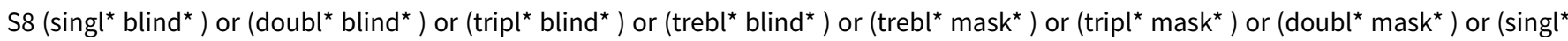
mask* $^{*}$

S7 (AB ( intervention* OR cognitive* OR CBT OR behavio* OR distract* OR music* OR TV* OR DVD* OR virtual reality OR rehears* OR coping OR reinforcement* OR reward* OR self-talk OR self talk OR audiovisual OR audio visual OR movie* OR therapeutic touch OR relax* OR

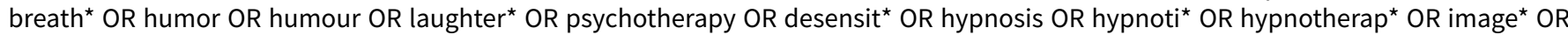
prepar* OR suggest* OR coach* OR inform* OR thought-stop* OR though stop* OR coping OR cope OR memor* OR train* or muscle* OR model $^{\star}$ or rehears $\left.{ }^{\star}\right)$ ) and (S3 and S4 and S5 and S6)

S6 AB intervention* OR cognitive* OR CBT OR behavio* OR distract* OR music* OR TV* OR DVD* OR virtual reality OR rehears ${ }^{\star}$ OR coping OR reinforcement* OR reward* OR self-talk OR self talk OR audiovisual OR audio visual OR movie* OR therapeutic touch OR relax* OR breath* OR humor OR humour OR laughter* OR psychotherapy OR desensit* OR hypnosis OR hypnoti* OR hypnotherap* OR image* OR prepar ${ }^{\star}$ OR suggest* OR coach* OR inform* OR thought-stop* OR though stop* OR coping OR cope OR memor* OR train* or muscle* OR model* or rehears*

S5 AB pain* OR hurt* OR anxiety OR anxious OR distress* OR discomfort* OR fear*

S4 AB child* OR youth* or teen* or adolescen* OR infant* 
S3 AB needle* OR inject* OR vaccin* OR lumbar puncture* OR bone marrow OR spinal tap OR intravenous OR venepuncture* OR venipuncture ${ }^{\star}$ OR catheter ${ }^{\star}$ OR puncture ${ }^{\star}$ OR thoracentes ${ }^{\star}$ OR paracentes ${ }^{\star}$ OR central line*

$S 2 A B$ needle and $A B$ pain and $A B$ children

S1 needle and pain and children

WHAT'S NEW

\begin{tabular}{lll}
\hline Date & Event & Description \\
\hline 14 October 2020 & Review declared as stable & See Published notes. \\
\hline
\end{tabular}

\section{H I S T O R Y}

Protocol first published: Issue 1, 2005

Review first published: Issue 4, 2006

\begin{tabular}{lll}
\hline Date & Event & Description \\
\hline 13 September 2017 & New search has been performed & $\begin{array}{l}\text { We have updated this review to include the results of a new } \\
\text { search conducted in September 2017. }\end{array}$ \\
\hline 5 September 2017 & $\begin{array}{l}\text { New citation required and conclusions } \\
\text { have changed }\end{array}$ & $\begin{array}{l}\text { Since the last version of this review (published in 2013), 20 new } \\
\text { relevant RCTs including 2156 participants have provided addi- } \\
\text { tional information to change some of the review conclusions. }\end{array}$
\end{tabular}

This second update differs from the first update of the review by: (1) assessing the quality of the body of evidence using GRADE; and (2) amending psychological intervention categories to more closely reflect presumed mechanisms of treatment effect.

\begin{tabular}{ll}
\hline 2 September 2013 & $\begin{array}{l}\text { New citation required and conclusions } \\
\text { have changed }\end{array}$
\end{tabular}
have changed
New search has been performed
Since the last version of this review (published in 2006), new relevant studies have provided additional information to change the conclusions.

Review updated. This update differed from the original review by limiting the included studies to true RCTs published in academic journals (i.e. excluded quasi-randomized trials and dissertation studies). As such we excluded seven studies from the 28 included in the original review and added an additional 18 studies from this review update, for a total of 39 RCTs included in the update.

\begin{tabular}{lll}
\hline 24 September 2010 & Amended & Contact details updated. \\
\hline 13 May 2009 & Amended & Contact details updated. \\
\hline 2 July 2008 & Amended & Converted to new review format. \\
\hline
\end{tabular}

\section{CONTRIBUTIONS OF AUTHORS}

- KA Birnie contributed to coordinating the review, data collection for the review, screening search results, organizing retrieval of papers, screening retrieved papers, appraising quality of papers, extracting data from papers, writing to authors of papers for additional information, data management for the review, entering data into RevMan, analysis of data, interpretation of data, providing methodological perspective, providing clinical perspective, and writing the review. 
- M Noel contributed to data collection for the review, screening search results, screening retrieved papers, appraising quality of papers, extracting data from papers, interpretation of data, providing methodological perspective, providing clinical perspective, and writing the review.

- CT Chambers contributed to conceiving and designing the review, designing search strategies, interpretation of data, providing a methodological perspective, providing a clinical perspective, writing the review (or protocol), providing general advice on the review, and performing previous work that was the foundation of the current review.

- LS Uman contributed to conceiving and designing the review, designing search strategies, providing a methodological perspective, providing a clinical perspective, writing previous reviews and protocol, providing general advice on the review, and performing previous work that was the foundation of the current review.

- JA Parker contributed to data management for the review, interpretation of data, providing a methodological perspective, providing general advice on the review.

\section{DECLARATIONS OF INTEREST}

- KA Birnie: none known. Dr. Birnie is a registered psychologist and works with children, adolescents, adults, and their families with pain and other acute and chronic illness.

- M Noel: none known. Dr. Noel is a registered psychologist and works with children and adolescents with acute and chronic illness, and their families.

- CT Chambers: none known. Dr. Chambers is a registered psychologist and works with children and their families with pain and other acute and chronic illness.

- LS Uman: none known. Dr. Uman is a registered psychologist who works with youth and their families to address complex pain, other health-related issues, and a variety of mental health concerns.

- JA Parker: none known.

\section{SOURCES OF SUPPORT}

\section{Internal sources}

- No sources of support supplied

\section{External sources}

- For Original Review (Uman et al., 2006) - CGS-M Award from the National Science and Engineering Research Council (NSERC) awarded to LS Uman (2004 to 2005), Canada

- For Original Review (Uman et al., 2006) - Graduate Award from the Nova Scotia Health Research Foundation (NSHRF) awarded to LS Uman (2005 to 2006), Canada

- For Original Review (Uman et al., 2006) - Pain in Child Health (PICH) top-up funding awarded to LS Uman (2004 to 2006), Canada

- For Original Review and First Review Update (Uman et al., 2006; 2013) - Dalhousie Cochrane Group funding awarded to LS Uman, Canada

- For Original Review and First Review Update (Uman et al., 2006; 2013) - Canada Research Chairs (CRCs) awarded to C Chambers and P McGrath, Canada

- For Second Review Update - Fellowship from the Canadian Institutes of Health Research awarded to KA Birnie (2016 to 2019 ), Canada

\section{DIFFERENCES BETWEEN PROTOCOLANDREVIEW}

Age range expanded from three to 18 to two to 19 years from the protocol (Uman 2005) to the original review (Uman 2006).

The original review (Uman 2006) also differed from the protocol (Uman 2005) by excluding funnel plots as a debated method for assessing publication bias.

The first review update (Uman 2013) differed from the original review (Uman 2006) by excluding non-randomized trials and excluding nonpublished trials (for example, dissertations).

The first review update also replaced our original measure of study quality (Jadad 1996) with the recommended Cochrane 'Risk of bias' tool. This second review update (2018) reflects contemporary requirements for Cochrane Reviews since the development of the original review protocol, such as the inclusion of GRADE and Summary of Findings tables. This second update (2018) differs from the first update of the review (Uman 2013) by amending psychological intervention categories to more closely reflect presumed mechanisms of treatment effect. We have also updated the text in the introduction. There are no other new differences from the protocol to this second review update.

\section{NOTES}

In August 2020 we did not identify any potentially relevant studies likely to change the conclusions. Therefore, this review has now been stabilised following discussion with the authors and editors. The review will be reassessed for updating in two years. If appropriate, we will update the review before this date if new evidence likely to change the conclusions is published, or if standards change substantially which necessitate major revisions. 


\section{N D EX TERMS}

\section{Medical Subject Headings (MeSH)}

Anxiety [ ${ }^{\star}$ prevention \& control] [psychology]; Central Venous Catheters [adverse effects]; Cognitive Behavioral Therapy [ ${ }^{\star}$ methods]; Hypnosis; Immunization; *Needles; Pain, Procedural [* prevention \& control] [ ${ }^{\star}$ psychology]; Phlebotomy [psychology]; Punctures [*psychology]; Randomized Controlled Trials as Topic; Self Report

\section{MeSH check words}

Adolescent; Adult; Child; Child, Preschool; Humans 